\title{
THE INFANCY OF ANIMALS
}

IX P PYCRAFT,AIS, F.ZS. 
7 thon

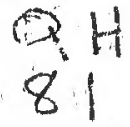

pq9

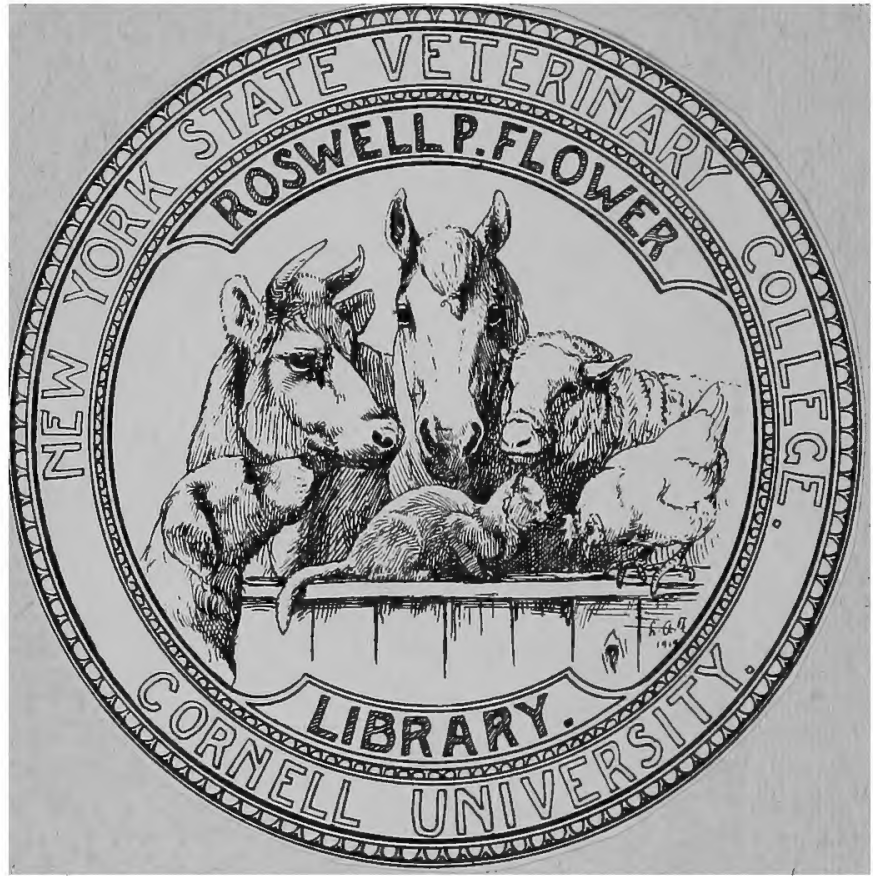




\section{QH 81.P99 Cornell University Library}

The infancy of animals,

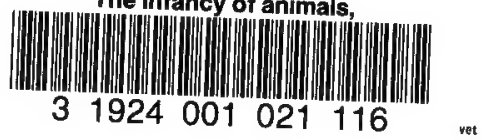




\section{Cornell University Library}

The original of this book is in the Cornell University Library.

There are no known copyright restrictions in the United States on the use of the text.

http://www.archive.org/details/cu31924001021116 


\section{POPULAR POCKET NATURE BOOKS}

In small volumes ( $7 \frac{1}{2}$ in. $\times 5$ in.), richly gilt, rounded corners, ss. net.

\section{BIRDS OF THE COUNTRYSIDE}

By FRANK FINN, F.Z.S.

With $\mathrm{I} 2$ coloured plates, 118 illustrations from photographs printed on art paper, and numerous outline drawings.

\section{EGGS AND NESTS OF BRITISH BIRDS}

By FRANK FINN, F.Z.S.

With 20 coloured plates and many other illustrations, both coloured and uncoloured, of all the British Birds'-Eggs, reproduced frome actual specimens.

\section{PETS AND HOW TO KEEP THEM}

By FRANK FINN, F.Z.S.

With I07 illustrations, mostly from photographs, and including I 2 coloured plates on art paper.

\section{WILD FRUITS OF THE COUNTRYSIDE}

By F. EDWARD HULME, F.L.S., F.S.A., etc.

With 36 coloured plates by the Author, and 25 illustrations from photographs on art paper.

\section{OUR BRITISH TREES AND HOW TO KNOW THEM}

By FRANCIS GEORGE HEATH.

With 250 illustrations. 


\title{
NEW VOLUMES OF POPULAR POCKET NATURE BOOKS
}

In small volumes ( $7 \frac{1}{2}$ in. $\times 5$ in. ), richly gilt, rounded corners, $5 \mathrm{~s}$. net.

\section{Astronomy}

\author{
By G. F. CHAMBERS, F.R.A.S.
}

With 8 coloured plates, and over 200 other illustrations.

This book is scientifically correct in every particular, and is written in a popular style which anyone can understand. Although small in size, it is packed with all necessary information for the amateur astronomer and is illustrated profusely with coloured plates and other illustrations.

\section{Toadstools and Mushrooms of the Countryside}

\author{
By EDWARD STEP, F.L.S.
}

Author of "Wayside and Woodland Blossoms," "Wayside and Woodland Trees," etc.

With 8 coloured plates, and 128 other illustrations from photographs on art paper.

The author, whose popular botanical works are well known to many thousands of readers, has been engaged for over ten years in securing the Nature photographs from which a selection has been made to illustrate this book. With these, in combination with the clear descriptions in absolutely plain, non-technical language, the country rambler with this book in his pocket will be for the first time enabled to identify the mushrooms and toadstools of woodland, field, and wayside.

\section{British Fresh-Water Fishes}

\section{By SIR HERBERT MAXWELL, Bart.}

With 24 beautiful coloured plates.

This small edition of Sir Herbert Maxwell's delightful book on "FreshWater Fishes," with its numerous coloured plates, is a book that will receive the welcome of every fisherman and naturalist. 
tbutcbinson's

Hature

Library

THE INFANCY OF ANIMALS 
UNIFORM WITH "THE INFANCY OF ANIMALS." 68. net each.

\section{MESSMATES :}

\section{A Book of Strange Companionships}

By EDWARD STEP, F.L.S.

Author of "The Romance of Wild Flowers," "Shell Life," etc.

With 55 illustrations from photographs on art paper.

A popular account of the remarkable partnerships habitually set up between animals totally unrelated, and even between animals and plants. These associations, to which Science applies the terms Commensalism and Symbiosis, are quite different from Parasitism, with which many of them were formerly confused, as they are based on the principles of mutual aid and advantage; whilst Parasitism implies advantage to one side and loss to the other. The stories told are of absorbing interest, and the author has told them for the general reader, avoiding all technicalities. The book will be fully illustrated by photographs and drawings.

\section{THE COURTSHIP OF ANIMALS}

By W. P. PYCRAFT, A.L.S., F.Z.S.

With numerous illustrations on art paper.

The aim of this book is to bring together what will surely prove to be a most astounding collection of facts in regard to the Courtship of Animals of all kinds, from Apes to Ants. It will describe the sanguinary conflicts which obtain when mates are only won by battle, as in the case of deer and sea-lions, and other beasts; and the no less bloody, and often fatal battles fought by birds whose legs and wings are armed by fearsome spurs for this purpose. But quite as interesting will be the survey of the methods which more properly fulfil the meaning of courtship-strange dances, love fights and musical rivalry, and the display of gorgeous vestments such as are furnished by the birds. 



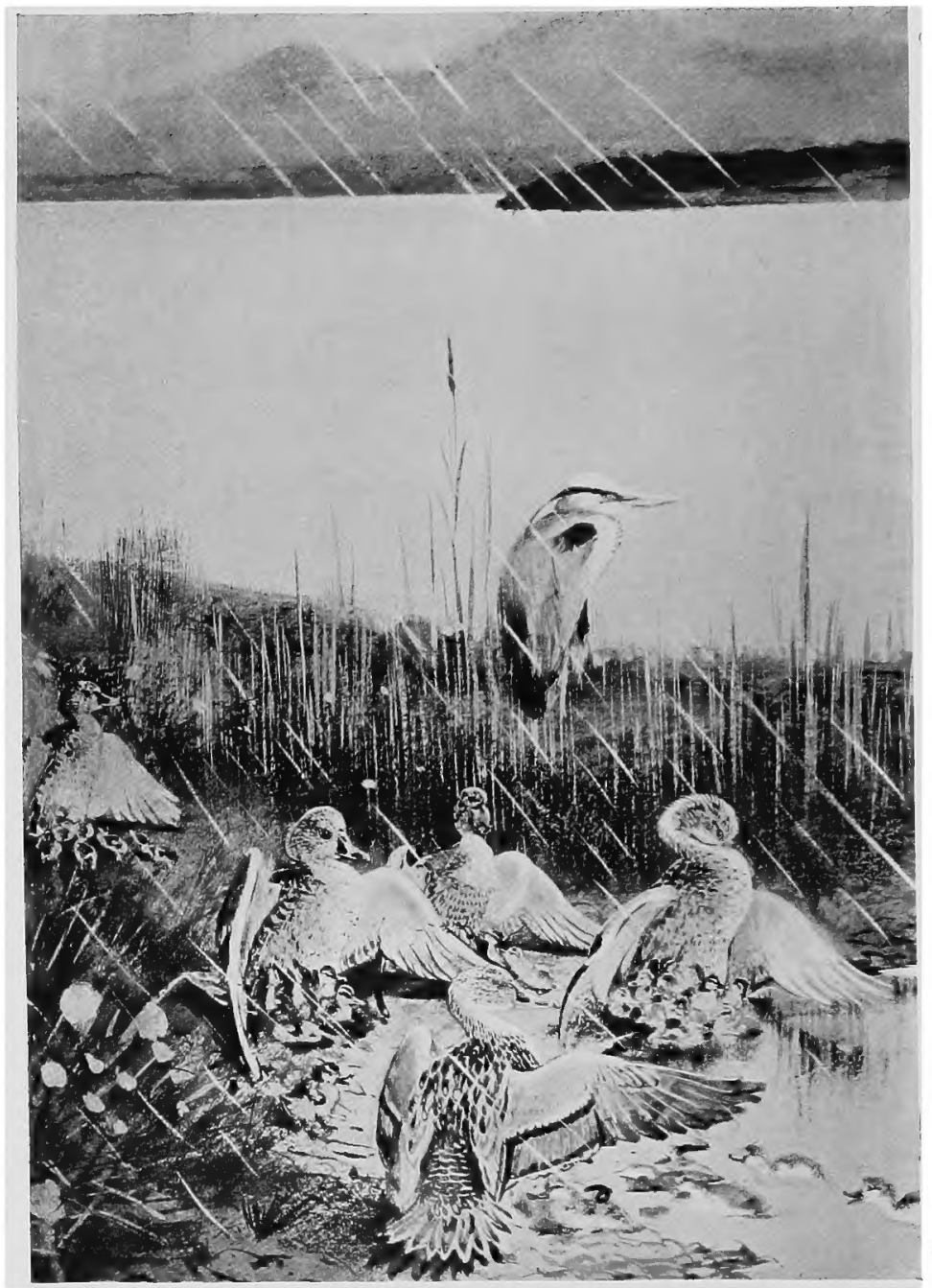

YOUNG MALLARD SHIELDED FROM THE RAIN BENEATH THEIR MOTHERS' WINGS.

From "Surface-Feeding Ducks," ly termission of the auther, Mr.J.G. Mllats, and the pullishers, Messis. Longmans, Green \& Co. 


\title{
THE \\ INFANCY OF ANIMALS
}

\author{
BY \\ W. P. PYCRAFT \\ ZOOLOGICAL DEPARTMENT OF THE BRITISH MUSEUM ; \\ FELLOW OF THE ZOOLOGICAL SOCIETY OF LONDON; \\ ASSOCIATE OF THE LINNEAN SOCIETY ; MEMBER \\ OF THE ROYAL ANTHROPOLOGICAL IN- \\ STITUTE; MEMBER OF THE BRITISH \\ ORNITHOLOGISTS' UNION ; HON. \\ MEMBER OF THE AMERICAN \\ ORNITHOLOGISTS' UNION; \\ ETC., ETC.
}

With 64 Plates on art paper

and numerous Illustrations in the text

SECOND EDITION

LONDON

HUTCHINSON \& CO.

PATERNOSTER ROW 
QH

81

pqq

No. 5726

F

1) 6 
I DEDICATE THIS VOLUME

TO

MY WIFE

WHOSE INTEREST IN THIS THEME

HAS STIMULATED MY OWN 



\section{P R E F A C E}

WhILE most people find young animals "interesting," few perhaps realise how much more so they become when we ask the Why and the Wherefore of their several peculiarities of form and colour, and of the degrees of activity which they display on their entry into the world.

The purpose of this book is to stimulate a wider interest in this theme, which contains food for thought not only for the Evolutionist, but also for the students of Sociology and of child-life in particular, and for that large and growing body who work under the banner of "Nature Study."

In the space of a single small volume it was impossible to do more than make a selection from the vast array of animals whose young clamoured, so to speak, for attention; and it was often difficult to decide which of a dozen claimants best served my purpose. I trust that my critics will bear my difficulty in mind when tempted to take me to task for my sins of omission.

But for the aid of the artist, and the photographer, my task would have been yet harder. And in this matter of illustrations I desire particularly to thank my friends Miss Helen Wilson, Mr. J. G. Millais, Mr. Rowland Ward, and Mr. A. H. Bishop, for their most kindly help. I have also to acknowledge the courtesy of Messrs. Longmans 
Green \& Co., as publishers of Mr. J. G. Millais" "Surface Feeding Ducks," for permission to reproduce the illustration which forms the frontispiece to the present volume. Even more am I indebted, as these pages will prove, to Miss E. L. Turner, whose name as an ornithologist and bird-photographer is now so well known among students of out-door bird-life. Further, I would add my thanks to Prof. Arthur Thomson, Mr. A. Landesborough Thomson and Dr. Soutar for their help in reading through the proofs for me, and for the kindly criticism rendered during this irksome task so cheerfully undertaken. Finally, I have to thank Mr. Roger Ingpen for the immense amount of trouble he took for me in regard to the illustrations, and in the task of seeing these pages through the press.

W. P. Pycraft. 


\section{CONTENTS}

CHAPTER I

INTRODUCTION

RAGE

CHAPTER JJ

Early DaYs and Early Ways • • • • 5

CHAPTER III

Colours and Coloration . . . 26

CHAPTER IV

Milestones of Evolution

CHAPTER V

Young Birds in The Nursery . • . $\quad$ - 54

CHAPTER' VI

Coloration

\section{CHAPTER VII}

Young Birds and the Records of the Past . II4

\section{CHAPTER VIII}

Reptiles and their Progeny • • . 156 
CHAPTER IX

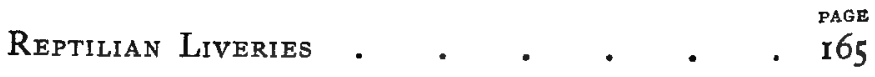

CHAPTER $\mathrm{X}$

Reptiles in the Making • • • • . 176

\section{CHAPTER XI}

Concerning Tadpoles . . . . . I80

CHAPTER XII

The Infancy of Fishes • • . • . 207

CHAPTER XIII

The Infancy of Crabs and Caterpillars • 236

CHAPTER XIV

Puzzles and Paradoxes . . . . $\quad 258$

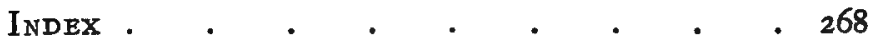




\section{L L US TRATIONS}

\section{LIST OF PLATES}

Young Mallard shielded from the Rain beneath their

Mothers' Wings • . . . . F Fontispiece BACING PAGE

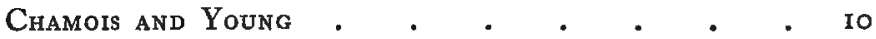
Black-striped Wallaby and Young-Koala and Young I2 American Woolly Opossum and Young-Indian Wild

Sow and Young • Noctule Bat and Young-Cobego and Young • . I6 A Young African Elephant and a Zebra Foal a 22 Zorilla and Young-Pacas or Spotted Cavies . 26 Young American Tapir-Adult American Tapir • $\quad 28$ Young Malayan Tapir-Adult Malayan Tapir . . 30 Young Axis or Indian Spotted Deer . . . 32 Lioness and Cub showing Spots . . . . . 34 Young Himalayan Musk-degr-Harnessed Antelope • 38 Teeth of the Duck-billed Platypus • • • . 44 White-tailed Gnu and Calf . . . . . . 46 Antlers of Red-Deer . . . . . . . . $44^{8}$ Newly-born Indian Elephant . . . . . 50 Mammoths . . . . . . . . . . 50 An Infant supporting its OWN WeIght-AN INFANT showing Hairy Cotering-An Infant sitting • • 52 xi 
Chimpanzet . $\quad$ - $\quad$ - $\quad$ - $\quad$ - 52

Greentinch and Young-Bunting and Young • $\quad 54$ Young Willow-wrens-Young Pigeon • • $\quad 56$

Water-rail removing her Egg-Bearded Tit and Young 58 Tree-pipit removing F seces from Nest . • • $\quad 72$

Pelican freding Young-Flamingoes feeding each other 78 Cormorant feeding Young . . . . . . 80 Emperor Penguin brooding its Young. • . 96 Stone Curlew, brooding, distressed by Heat-Young

Black-caps distressed by Heat • . . . 92 Nestling Cassowary-Nestling Emu • • • $\quad .98$ Young Cereopsis Goose-Young Ostrich-Young Razor-

BILL • . . . . . . . . 100

Snipe Chicks-Young Snipe on the Back of the Mother 104 Young Kingfishers . . . . . . . . . 106

Nestling Common Tern-Nestling Ringed Plover . 108

Nestling Bearded Tit, and Gouldian Finch, showing

Mouth Ornaments . • . . . . 112

Nestling Short-eared Owls-Nestling Great Crested

Grebes . . . . . . . . . . II4

Young Hawfinches-Young Sparrow-hawks . . . II6

Young Stone Curlews-Young Partridges . • 124

Tall of Archamopteryy-Tail of Tawny Eagle . . 136

The Palatal Bones of Birds . . . . . I40

Young Barn-OwL-Young Tawny OWL • • . 152

Wing of the Cassowary . . . . . . . I54

Young Turtegs . . . . . . . . . . I6o

Young Caimans emerging from the Egg-Blue-tongued

Lizard and Young . $\quad . \quad$. . . . 170

Skeleton of the Green Turtle-Skeleton of the Litathery

Turtle - • • • • • • • • I 176

Stages in the Development of the Frog. . . I82 


\section{ILLUSTRATIONS}

xiii

The Paradox Frog and its Tadpole . . . . Igo

Stages in the Development of the Dog-fish, and of

Gymnarchus . . . . . . . 208

EgGs of Fishes . . . . . . . . . 212

Bow-fin and Nest-Butterfish and Eggs • . . 216

Young Bitterling lying in the Gilits of a Mussel-

Young Skate in Oviduct $\quad$ • $\quad$. $\quad$. $\quad$. 222

Young Stalk-tye and Young Ribbon-fish • • 224

Young Fish sheltering under Jeliy-fish • • $\quad 224$

Young ANGLER-FISH . . . . . . . . . 226

YoUng SWORD-FISH . . . . . . . 226

Young and Adult Snake-fish, and Young and Adult

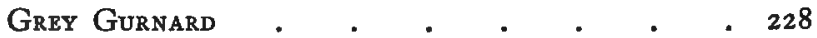

Early Stages in the Life-history of the Plaice - . 230

Transformations of the Eel . . . . . 232

Young CRÀbs . . . . . . . . . 236

Cast-off Shells of a Crab • . . . . $\quad .238$

Larva of Spiny Lobster-Larva of Barnacle-Larva of

Sergestes-Larva of Prawn . . . . . . 240

Stages in the Life-history of the Atlas Moth Cater-

pillar-Caterpillar of the Tiger-moth-of the

Lobster-moth-of the "Feathered Thorn Moth, showing Stick-Like Attitude-of Essex Emerald

Moth, with Leaves attached to Bodx-Dwelling-

Cases of Weater-moths-of Hammock Moth, made

of ExCREMENT . . . . . . . 242

Four Stages in the Life-history of the Puss Moth . 244

Caterpillar Colonies . . . . . . . . 250

INCIDENTS IN THE Life-Histories OF SOME Butterflies AND

Moths . . . . . . . . . 252

The Birth of the Dragon-ply . . . . . 258 


\section{TEXT FIGURES}

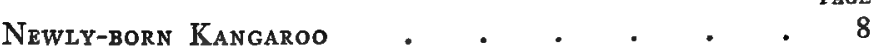

Ring-tailed Lemur and Young . . . . . . 18

Horns of Fossil Deer . . . . . . . 50

Wing of Hoatzin and Young Game-bird (Gallus) - izo

Skeletan of Wings of Fimbryo and Newly-hatched

Bird, and of Leg of a Young Bird . . . I32

Skeleton of Wing of a Young Rhea . . . . I35

Beaks of Nestling Birds compared with those of the

Adults. . . . . . . . . I43

Beak of an Adult and Nestling Cormorant, showing the Closure of the Nostrils . . . . 147

Stages in the Development of a Newt • • I86, 187

The Funnel-mouthed Tadpole (Megalophrys Montana) 189

Nest of Phyllomedusa sauvagit . . . . . . 194

Midwife Toad . . . . . . . . 195

GoELdI's FroG . . . . . . . . 195

POUCHED FROG . . . . . . . . . 196

Surinam Toad • • • . . . . . . 198

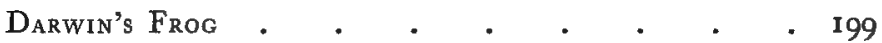

Ichthyophis, the Snake-like Amphibian . . . 203

LARVF, OF ICHTHYOPHIS . . . . . . . 205

Young Mollusca. . . . . . . . . 260

Young Spider Spinning Gossamer $\quad$ • $\quad$ • 262

A Lesson in Degeneration . • . . • . 266 


\section{THE INFANCY OF ANIMALS}

\section{CHAPTER I}

I N T RODUCTION

Tночgн the number of books on Natural History is legion, one may search their pages in vain for any systematic attempt to depict the earlier stages in the life-histories of the creatures described therein. Even in works designed for the use of the specialist one meets with the same neglect. This is the more strange because such stages afford us a key to much that mystifies when studying the later, adult, phases of life.

It is true that many learned treatises have been written on the early, embryonic stages of development from man himself downwards, but little has been done in regard to the later "post-embryonic" stages, which so many creatures have to pass through before they arrive at the age of discretion, or, as we say, become adult. While few of us have the time, or the requisite knowledge or technical skill, to pursue the intricate mazes of embryology, most of us can contrive to learn something at first hand on the varied stages which animals of different kinds must pass through in the juvenile period of their life-history. Whatever group of animals we survey in this regard, we shall find new themes for contemplation, new aspects of 
life, which will afford us a better grip of problems which at present elude us.

That the period of infancy through which the human species must pass is longer than that of any other creature is a fact so obvious as to pass unnoticed by most of us; yet even in the human race it varies considerably in length, more than is generally realised. Why is this? Why, indeed, should Nature have devised this callow stage? These are questions more readily asked than answered; for no sooner do we begin to frame replies than we find ourselves at a loss. Our responses suddenly break off, either because our stock of information is exhausted, or because of the nebulous condition of such facts as we possess, and our inability to find expression for them in common speech. There are animals, as we shall see, which while they may die of old age, and great-great-grandparents into the bargain, yet never assume the bodily form proper to their adult stages of life! There are others whose adult life is limited to a few hours : and some which, on the other hand, have no period of infancy at all.

This childhood of animals, as it has well been called, presents us with a bewildering diversity of aspects, and to avoid the danger of spoiling the conception of animal infancy which we wish to conjure up, it will be necessary to confine our survey to the more obvious and more important incidents.

It has been said that every animal, in the course of its life-history, climbs its own family tree. Time has shown, however, that while this is true in a general way, it must not be taken too literally, for we now know that many of the characters displayed by young animals have been developed to meet the conditions of existence peculiar to that phase of life in which they appear. The " egg-tooth" 
of the embryo chick is not an ancestral character, but an instrument developed for the purpose of cutting a way out of the shell-it is a tin-opener, in short, and disappears soon after hatching. But the ancestral bird Archoeopteryx, we know, had a long lizard-like tail, formed of a number of short cylinders of bone, arranged chain-wise, each bearing a pair of tail quills. In the adult bird to-day we find the tail quills arranged fan-wise, on either side of a short bony blade, an absolutely different plan. But if we examine the tail of an embryo bird, we shall find this blade is made up of a number of separate pieces corresponding with that in the row of bones in the ancestral bird. Thus we find that, in course of ages, the tail has undergone a process of "telescoping," the separate cylinders of bone growing shorter and shorter, so that the tail feathers have been brought closer and closer together till the tail of the modern bird has come into being.

Similarly, we know that the whalebone whales of today are descended from tooth-bearing ancestors, for we find in the jaws of the embryo, vestiges of teeth which never cut the gum. And we might multiply instances of this kind indefinitely from the records of the embryologist. But we are concerned here with post-embryonic life : and here we shall also find characters which on the one hand are reminiscent of past conditions of existence, and on the other characters which either belong to, or are peculiar to, the infantile stages or are foreshadowings of what is to be.

Nowhere is this conflict between the present and the past more fascinatingly presenter than in the study of the coloration of young animals, and on this theme we shall have much to say in these pages. But apart from these purely physical considerations there are yet other 
aspects to be considered, such as the relation which exists between parent and offspring, for while some young animals are jealously guarded by one, at any rate, of their parents, others are orphaned before they are born, or are pitched into the world, so to speak, to live or die as fate may decree.

The higher we get in the scale of creatures, the longer the period of infancy, and the more the care displayed by the parents for their young. All the mammals, without exception, nurse their offspring, for a longer or shorter period. Among the birds we find parasitic species, like the cuckoos, which thrust the parental duties upon other species: and some, like the megapodes, which leave the incubation of their eggs to natural agencies such as the heat generated by decaying vegetation, or that derived from hot springs. The reptiles show little or no parental care; but, strangely enough, the frogs and toads and their kind, and many fishes, furnish us with cases of remarkable solicitude, or apparent solicitude, for their offspring. Since the insects stand still lower in the scale, it is the more strange that we should find among them some of the most wonderful devices for assuring the welfare of the young to be met with in the animal kingdom-devices which almost baffle analysis, since, having regard to what obtains among the higher groups, these tiny creatures seem to be endowed with an intelligence and a solicitude for the welfare of their offspring which are not exceeded even by man himself. Yet we cannot interpret their behaviour in such terms. But this is an aspect which belongs to psychology, and is outside the aims of these pages. 


\section{CHAPTER II}

\section{EARLY DAYS AND EARLY WAYS}

THE playfulness of kittens, the gambols of lambs, and the helplessness of newly-born puppies have become proverbial. But this playfulness, or its absence, is fraught with a deeper meaning than most of us suspect, for these early pulsations of life are most intimately bound up with behaviour in the past and behaviour in the future. For their right interpretation a host of facts have to be taken into account that at first sight would seem to have no possible connection therewith, and often no meaning at all; and this much will have become manifest, we trust, long before the end of this chapter is reached.

Naturally, one would suppose, this study of young animals would begin at the moment of their birth, this being as it were a common point of departure. As a matter of fact, however, this is by no means true. On the contrary, birth occurs at very different stages of development, the particular period or stage thereof being determined by various factors, as we hope to show.

To get a proper grip of all that is here concerned one must remember that the mammal-from man himself downwards-is developed from an egg, just as are the fish, the frog, the reptile, and the bird; nay, more, even some mammals are produced from eggs which in appearance look very like those of a reptile. It is common 
knowledge that the bird is hatched from an egg, after a more or less prolonged period of brooding on the part of one or both of the parents: while in the reptiles and the more lowly vertebrates no brooding is necessary-though, as we shall show, the eggs are often jealously guarded and tended.

Now the birds and the mammals are both descendants of the more lowly reptiles; but have developed along very different lines. But, great as their transformation has been, each retains more or fewer records in their structure affording indubitable proof of the source of their being. Among the higher mammals, however, these proofs of parentage have in the course of ages grown more and more illegible, and but for the clues presented in the more lowly types these evidences of past happenings might well escape discovery altogether. Happily for' us, however, in certain lowly creatures, to wit the Australian duck-billed platypus, or ornithorhynchus, and the spiny ant-eater, or echidna, evidences of this reptilian ancestry are writ large in their bony framework; and hence, long since, it became apparent that the lord of creation himself is not merely a blood-relation of the ape, but is the last term of a series of evolutionary changes which began with the beginnings of the despised and cold-blooded reptiles!

The full force, however, of this conviction was not realised until a few years ago, when, in 1884 , the amazing discovery was made that these same lowly mammals presented a still more significantly reptilian feature in that their young were hatched from eggs! The hallmark of the mammal, however, was readily apparent, for it was at once established that the young were nourished by milk secreted by the mother. Very well. We have just remarked that the condition of the young at birth 
affords a by no means common standard of measurement. There is a by no means sharp division between the embryonic and post-embryonic stages of development: nor do the post-embryonic stages of development even in closely related animals follow similar lines.

The platypus and the echidna afford illustrations of these facts. In the former the egg when laid is deposited in a nest in a burrow, and brooded, bird-wise; in the echidna the egg as soon as laid is thrust by the parent's beak-like muzzle into a pouch on the belly answering to that of the kangaroo. Here it is carried until the young hatches, when the shell is thrown out and the young settles down to grow. The platypus has no pouch.

The marsupials-among which the kangaroos are familiar forms-represent a grade higher in the evolutionary scale. Here the young are born. That is to say the egg, as in the case of all the rest of the mammals, no longer becomes enclosed within a shell containing a store of food material for the nourishment of the growing embryo, but instead becomes attached to the wall of the uterus or womb, and draws its nourishment from the maternal tissues. Sooner or later the development of the embryo runs its appointed course and birth takes place. Now in the kangaroo this occurs when the young is but ill formed, minute, blind, naked, and helpless. It is then transferred by the parent, by means of her lips, to her pouch, there to slowly acquire consciousness and activity. But mark the difference between this sojourn in the maternal pouch in the case of the kangaroo and the echidna. In the latter the nourishing milk appears as an exudation from the skin, and is lapped up by the young : the same applies in the case of the platypus. But in the kangaroo this wasteful and primitive arrange- 
ment is superseded by the much more effective fashion of conveying the milk to the mouth by means of a teat. That is to say, a concentration of the milk-secreting area of the skin has taken place. But the young kangaroo is,

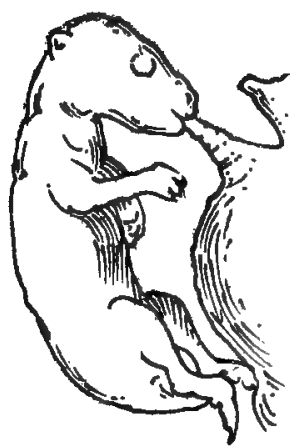

NEWLY-BORN KANGAROO ATTACHED TO THE TEAT OF THE PARENT. so to speak, prematurely born, and has to be attached to the teat by the parent; and when once this feat has been accomplished it retains it within its mouth unceasingly, till development has far advanced, and the milk is periodically squirted down its throat by the muscular action of the parent. This is probably an involuntary action determined by the stimulus set up when the milk glands become surcharged.

But the bald statement of these facts leaves untouched a whole series of inexplicable happenings, though they are by common consent regarded as explained by the blessed word "instinct." It is this mysterious impulse which directs the mother, untaught, how to dispose of the barely tangible scrap of life which she has produced, and this same impulse which causes the young to open its mouth to grasp the teat. Between these patent facts and the obscure, nebulous, directing force behind them-the "instincts" -there is an intimacy of relationship which means life or death to the race. Instinct and its twin brother Intelligence are the guardian angels of life: subtle, intangible, all-pervading, protean.

Among the mammals, it is to be remarked, it is the rule that the young should enter the world in a helpless con- 
dition, and, as a rule, before the eyelids have opened, and while the body is yet naked, or but scantily clothed. Yet there are degrees of helplessness, and of nakedness, which is as much as to say that the period of birth is hastened or retarded in accordance with the needs of the environment. The rabbit and the hare furnish a very good illustration of these differences, and the conditions which apparently govern them. In the rabbit the young are prematurely born, so to speak, before the eyelids have opened, or the hair has thrust its way through the skin. The birth of the young hare, on the other hand, is retarded until a further stage of development has been reached, so that it is ushered into the world with open eyes, and a thick coat of fur. But mark the different conditions which obtain in the two cases. The young rabbit is born in a warm and sheltered burrow, the young hare above ground. The rabbit, for some considerable time, is shielded from enemies; the hare, on the other hand, knows no such security, and its retarded birth has therefore hastened the time when it will be able to escape danger by flight. For the moment, the maternal care in distributing her litter over a fairly wide area, and the likeness in coloration between the young and their surroundings, have to suffice; and as a matter of fact they suffice very well, or hares would be less plentiful.

That there are considerable differences in the birth periods of the marsupials and the rodents, for instance, there can be no question. In other words the birth period is, as we have already remarked, not a common standard of measurement: what are post-natal stages of development in the one case are pre-natal in the other. And this fact will become the more apparent if comparison is made between the young of several dissimilat 
types. The fawn, the kid, the calf, the foal, the kitten, the puppy, and the young kangaroo are all so many witnesses of this fact.

These most important differences are seldom realised. Indeed we commonly ignore the early stages of development in young mammals altogether, as is shown by the fact that we have special names only for such species as have a commercial value, or otherwise force themselves on our attention. Not else are young mammals labelled, so to speak, by special names, and this because they do not manifest themselves till the period of infancy is past.

The young, then, of the ungulates-that is to say of the "hoofed" animals-deer, oxen, antelopes, sheep and goats, swine, horses, rhinoceroses, camels, and so on, and of the types wherewith we have contrasted themafford a striking illustration of the impossibility of drawing a hard-and-fast line between pre- and post-natal characters. The eyes of the young rabbit do not open till some days after birth, and similarly the appearance of its fur is a post-natal event. The "leveret" remains within the womb till both these events have been accomplished. The young of the ungulates, similarly, are not born until their development is, relatively, far advanced. In the matter of length of leg indeed they lack little of their final measure; and they are no less advanced in other ways.

The reason for these exceptional features is not far to seek. The ungulates are vegetarians, living for the most part in herds, and hence, to obtain a sufficiency of food, they can have no permanent abiding-place, no fixed quarters. Further, they have become the prey of hosts of carnivorous enemies, hosts which else had never come into being. That is to say, the development of the 


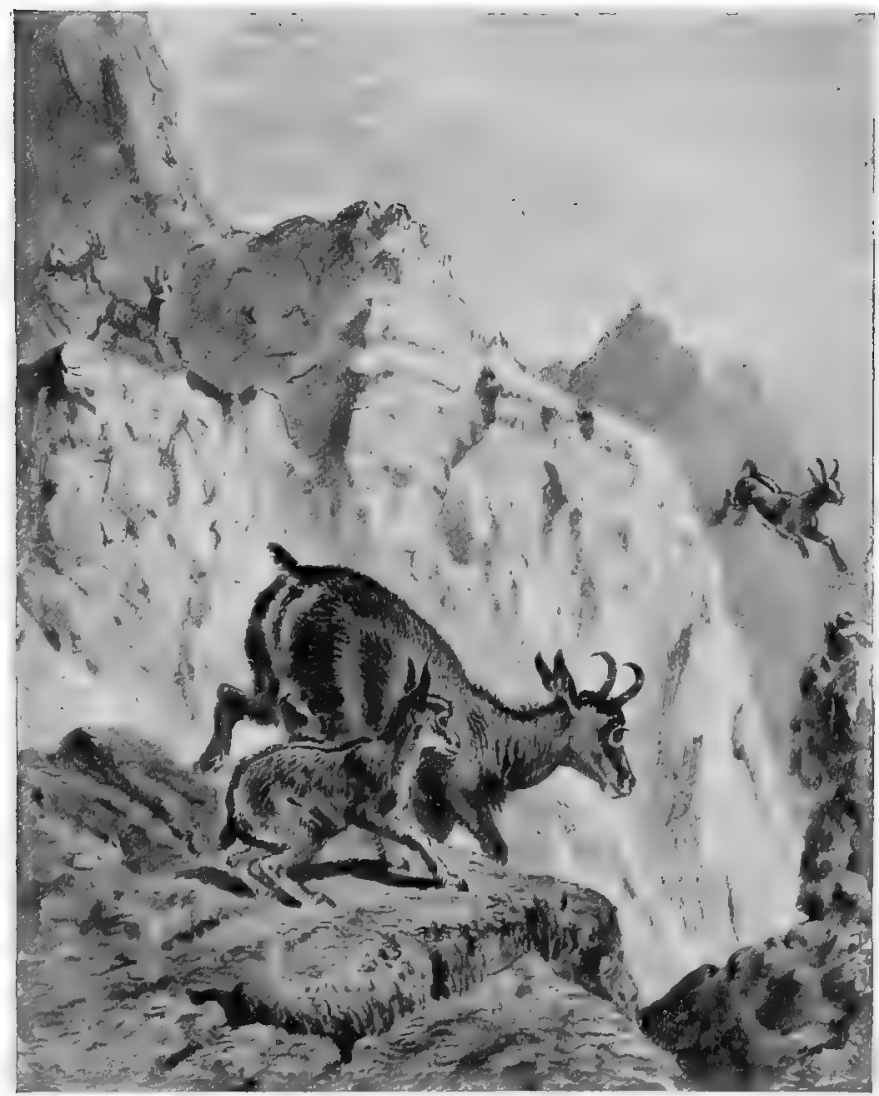

Atter Wolt.

\section{CHAMOIS AND YOUNG.}

The amazing agility and surefootedness of the Chamois is the outcome of a vigorous selection commencing from a few hours after birth and sustained through life. Only the "fittest" survive.

Io] 

larger carnivores has largely depended on the existence of the ungulates. But be that as it may, the carnivores are there, constantly harassing their more or less defenceless prey. And so it has come about that, partly because the ungulates must of necessity be nomads, and partly because at times the whole herd must take to its heels and run, their young must either be portable, or able to run with the rest. The latter expedient has naturally proved to be the more advantageous.

But even here we meet with exceptions to the rule. Thus with the deer, which are typically forest-haunting animals, and therefore less nomadic, the young are helpless for some days after birth, but they can be, and are, hidden away in thickets. A comparison between a fawn and a foal will bring home this fact at once. There is a vast contrast in their relative size and degree of activity.

But let us examine this matter of the care of the young a little more closely, starting first of all with such as are borne day and night by the female, till they can fend for themselves, or approach that stage of independence. Curiously enough, this custom is met with among one of the lowliest of living mammals-the spiny ant-eater, or echidna, which carries a pair of eggs in a pouch answering to that of the kangaroo. In this particular case, however, we do not certainly know how long after hatching the offspring are kept in the pouch. The marsupials afford numerous and diverse instances of pouch-borne young. The kangaroos, wallabies, and rat-kangaroos always carry their young in the pouch until they are of considerable size, and quite able to take care of themselves. But one young is born at a time, and the pouch forms a most capacious pocket. Occasionally, however, it is said that a second young one is born before the first has 
been turned adrift. But this is doubtful, for it is hard to see how so helpless a scrap of life as a newly-born kangaroo could avoid being swept from its teat and crushed at the bottom of the pouch by its now lively brother. In the case of the larger species of kangaroo the young one, or "joey" as it is called by the settlers, attains the size of a hare, or even larger, before it finally leaves its living cradle.

There can be no doubt but that such a pouchful must at all times be a considerable burden, and it would appear that for some considerable time before the youngster finally outgrows his cradle he is made to run with his parent during a great part of the day. If danger threatens, however, the mother quickly transfers her offspring to her pouch and makes off. If she is pursued, and feels in danger of being overtaken, without hesitation she will eject the youngster and leave him to his fate in order to save her own life.

Here, it may be remarked in passing, we seem to see the maternal instinct in the making. On the first alarm her immediate action is one of anxiety for her helpless offspring. But the steady, demoralising influence of fear sooner or later begets an overmastering desire to secure her own safety, to effect which she sacrifices even this her most precious possession to the pursuing Fates.

The Cuscuses of the Austro-Malayan region, and the Phalangers of Australia are all arboreal creatures, and carry their young in pouches. Occasionally twins are produced, but as a rule the nursery has but one occupant. In the case of the flying-phalangers of Australia--small mammals which do not fly but take flying leaps from the topmost boughs of some high tree to the lower branches of a neighbouring tree, supported on folds of skin stretched 


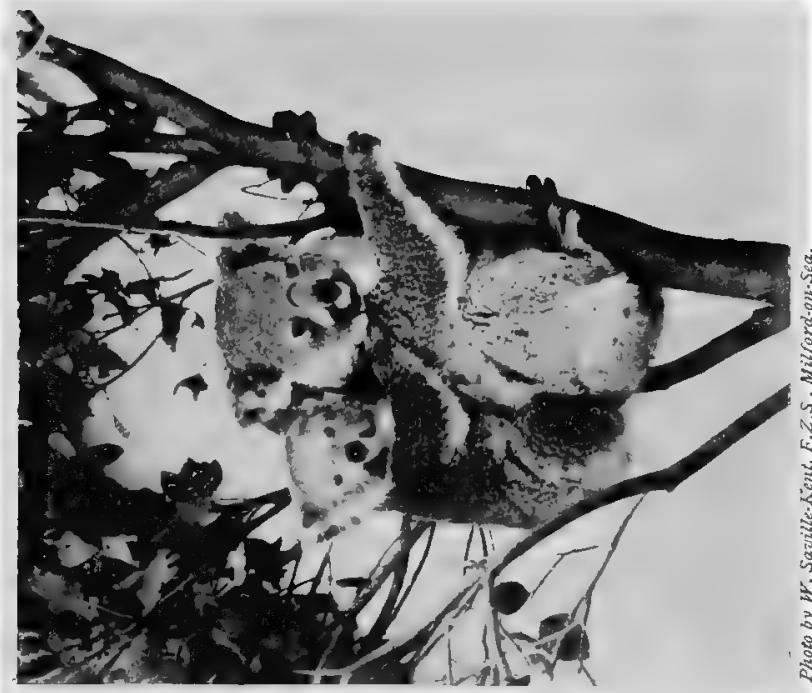

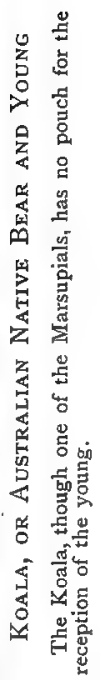
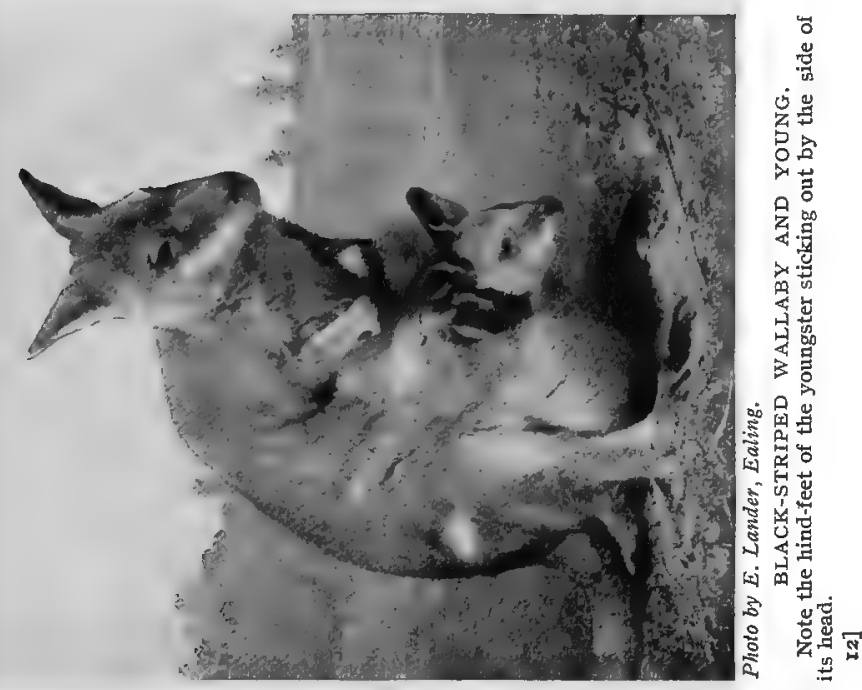

between the outspread limbs and the body-room is found for four; while in the case of the Bandicoots (Perameles) and the Dasyures (Dasyurus) as many as six, at any rate for a time, are crowded into the pouch, which opens towards the tail, instead of headwards as in kangaroos. In the Australian pouched mice (Pbascogale) litters of as many as ten may be produced; and here, strangely enough, there is no pouch for their reception, this extremely useful receptacle having degenerated to a mere fold of skin on the abdomen. The young, in consequence, are compelled to maintain their hold upon their mother by clinging to the fur of her belly, aided, no doubt, by their hold upon her teats. Since the mother is a creature no larger than a mouse, the burden of ten youngsters attached in this way must be a very appreciable one, and probably they are soon transferred to some snug and safe retreat where they can be suckled at intervals.

Yet other marsupials, however, for some mysterious reason, have suppressed their pouches. The Australian Koala, or "native bear" (Phascolarctos koala), is one of these. The young koala, however, seems to be no whit less well off than the young kangaroo snugly curled up in a deep pocket, for it contrives to maintain a firm and lasting grip of its mother's fur, which is long and woolly. Similarly, of the American Opossums, which are also marsupials, some species have lost this family badge, others have retained it. Thus the best-known member of this group, the "common opossum" (Didelphys marsupialis), has a large pouch capable of accommodating all the members of her numerous family with ease-though it is clear they cannot long be carried after this fashion. On the other hand two species of South American opossums (Didelphys crassicaudata, and the 
smaller $D$. dorsigera) have lost their pouches, and carry their young, after the method invented by the koala, on their backs.

But while the koala has but one young one to cater for at a time, these American species have each to accommodate a litter. Happily they have developed long prehensile tails; and the young swiftly acquire ability to put theirs to very good purpose, twining them round the mother's tail, which for this purpose is arched over the back; thus anchored, and with a firm grip of her fur, they can travel everywhere. But when we recall the fact that both the koala and these opossums are tree-dwellers, it gives one furiously to think why the koala should be tailless and the opossums should have developed tails of such an exceptional character. Further, it seems hopeless to ask, Why, among these opossums, should some have retained the pouch while others have lost it ?

So far as the evidence goes the conditions of existence are alike in all. May we assume that the loss is due to an "inherent" tendency to suppress the pouch, a tendency which might have proved fatal to the well-being of the species, which would have vanished without leaving a trace of the cause of disappearance, but happily the organism responded by changing the fashion of nursing ?

In many respects the history of young bats is even more remarkable than that of the young marsupials, inasmuch as they are borne about by their mothers on their aerial journeys in quest of daily bread. If all accounts be true, some of these living flying machines carry not only more than one passenger, but contrive to do this even when the burden exceeds the weight of their own bodies.

Thus Mr. Hudson, in his entertaining volume "The Naturalist in La Plata," tells us that "while taking bats 


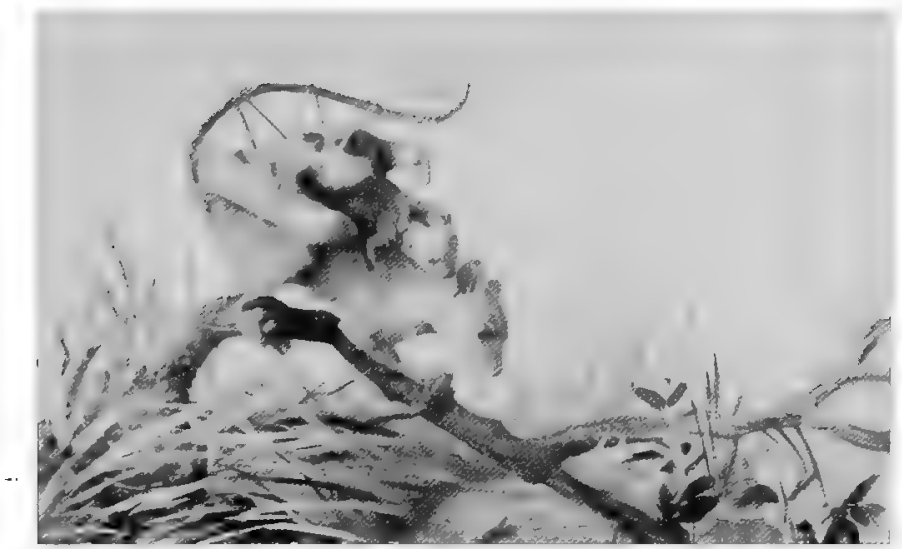

Photo by Saville-Kent.

AMERICAN WOOLLY OPOSSUM.

Only in the opossums are the young carried after this fashion.

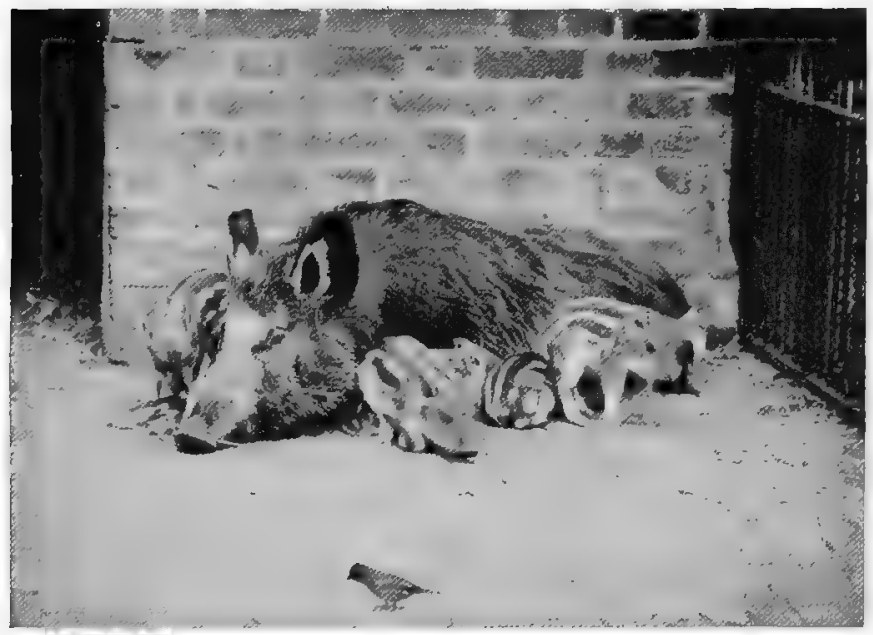

Photo by W. P. Dando, F.Z.S.

INDIAN WILD SOW AND LITTER.

Young pigs, though at first helpless, are soon able to run. Their striped coloration is a survival of an earlier, adult livery.

I4] 

one day in December, I captured a female of our common Buenos Ayrean species (Molossus bonariensis) with her young attached to her, so large that it seemed incredible she should be able to fly and take insects with such a weight to drag her down. The young were about a third less in size than the mother, so that she had to carry a weight greatly exceeding that of her own body. They were fastened to her breast and belly, one on each side, as when first born; and possibly the young bat does not change its position, or move, like the young developed opossum, to other parts of the body, until mature enough to begin an independent life. On forcibly separating them from their parent, I found they were not yet able to fly, but when set free fluttered feebly to the ground. This bat certainly appeared more burdened with its young than any animal I had ever observed."

In the days when Mr. Hudson was writing, the fact that two young were produced at a birth was regarded as a somewhat unusual event-possibly as rare as is the case of human twins. Later, however, it was found that not only is the production of twins by certain species no unusual occurrence, but that in a North American species no less than four young are born at a time; and the presence on the mother of two pairs of nipples shows that this is the normal size of the family. Now, hitherto it has been taken for granted that young bats remain attached to their parents from the moment of their birth till they attain strength enough to fly. Hence no little astonishment has been felt at the prowess of species which could not only fly burdened with a family heavier than the parental body, but could perform the swift and complex aerial evolutions necessary for the capture of their agile prey, when so loaded. 
Somehow or another, people seem to be convinced that natural history in our own islands is an unprofitable study, yielding no discoveries of any scientific worth. On the other hand, the distant tropics, or indeed any land remote from the British Islands, may be regarded as a sure and certain happy hunting ground for zoological surprises of all sorts. These impressions, I say, are common, but they are very far indeed from being well founded. This very theme of young bats and their upbringing proves this; for during the last few years our native bats have been most patiently and laboriously studied by Major Barrett Hamilton and others, and they have brought to light some extremely interesting facts, bearing directly on this very theme.

For example, it has been found, in regard to the largest and handsomest of our native bats, the Noctule (Nyctalus noctula), that the young at the moment of birth is dropped into a pocket formed by the interfemoral membrane, that is to say by the skin stretched between the hindlegs, and enclosing the tail as a central supporting rod. Naked and blind, it is then carefully licked clean by the mother and transferred to the membrane of her wing; there the umbilical cord is gnawed off, and the placenta eaten. She then cleans herself, and presently gives her precious charge its first drink of milk. About a fortnight elapses before the eyes open, and the fur appears. Blind and naked though they are on entering the world, these young yet display a wonderful amount of activity. For in another case, within a few moments after birth the youngster worked its way under its mother's shoulder and so round on to her back, where it clung, head downwards, by means of its powerful hind-toes, and quite exposed. 

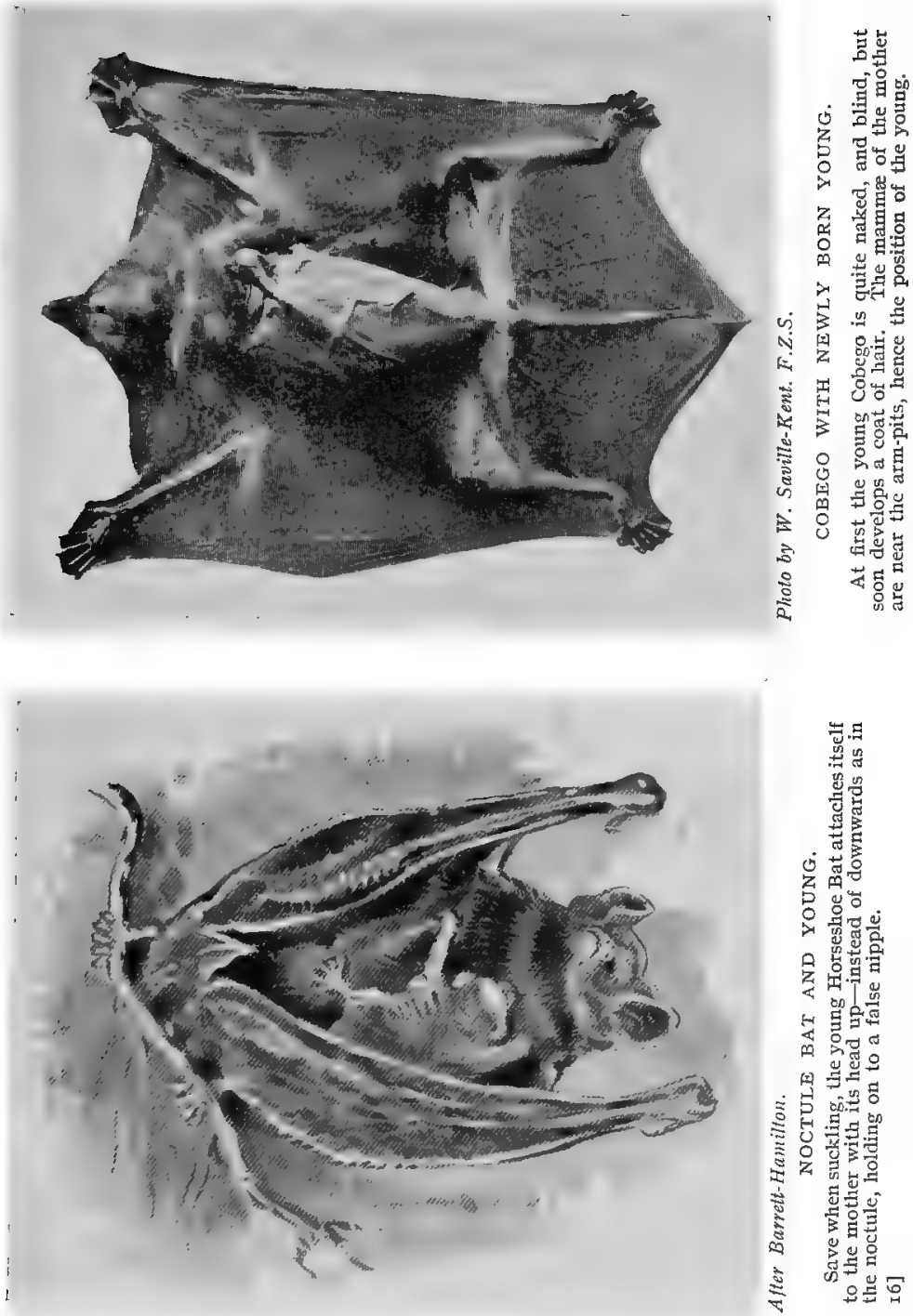

Now in the case of the noctule bat it seems that while the young one is constantly carried during the first few days of its life, even by the tenth day it is sometimes left at home clinging to the walls of the tree trunk, or other retreat chosen by the parent. At any rate a case is on record where a colony of females were disturbed and left their den hurriedly; on this being examined, a youngster of about ten days old was found clinging to its walls. Yet in another case where a similar colony was disturbed it was noticed that when most of the mothers flew. away they bore half-grown young with them clinging to their sides, and causing, apparently, no inconvenience whatever. During these journeys in mid-air the young maintain their hold by clinging to the nipple, and grasping hold of the mother's fur with their hind-feet.

From these facts, then, and others which could be quoted, it seems that too much has been made of the carrying power of bats; that towards the later stages of development-and young bats seem to be suckled for about two months-the young, especially when two or more are concerned, are left at home while the mother forages for food, or on occasions when a hurried exit becomes necessary to escape danger. In the case of the Lesser Horseshoe Bat, it has been shown that the mothers will indeed, if frightened, thus temporarily abandon their offspring. The male parent, it is to be noted, bears no part in nursing.

Before we leave this fascinating theme of young bats space must be found wherein to mention certain curious facts regarding our Greater Horse-shoe Bat (Rbinolophus ferrum-equinum). In this species, singularly enough, the females have two pairs of nipples: one holding the normal place on the chest, the other in the groin. Now the first pair are milk-yielding, but the second are known 
as "false nipples," and this because they yield no milk, but serve solely as points of attachment for the young one, to one or other of which, in short, it holds by means of its teeth, while the hind-feet grip the fur on the sides of the body. When the young

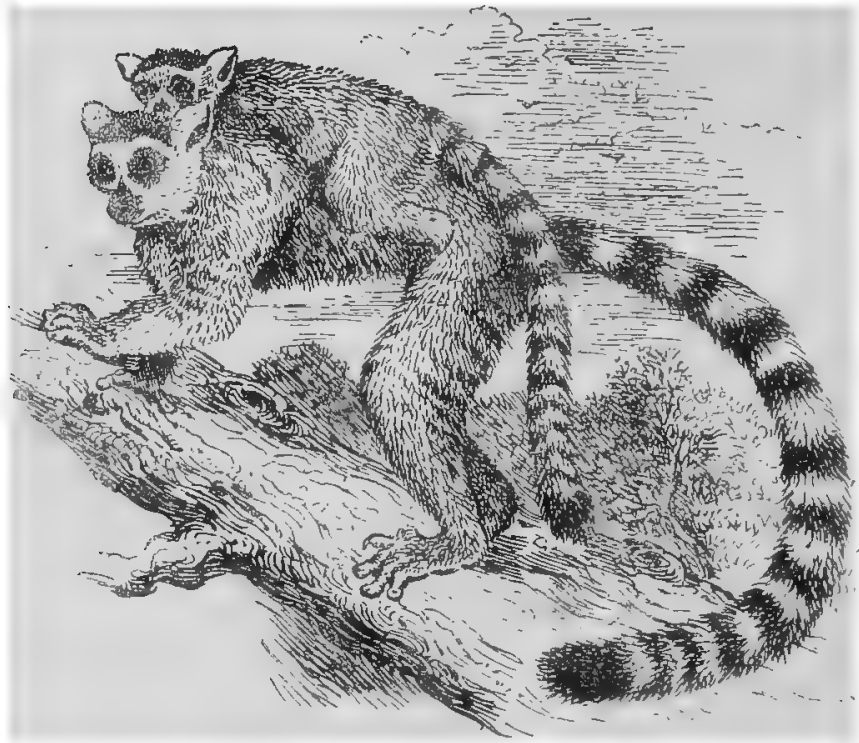

RING-TAILED LEMUR, AND YOUNG.

- In some species the young one coils itself around the mother.

one desires to feed he shifts his position and takes hold of the breast nipple. But when at rest, as the mother hangs head downwards, the youngster, holding on to the false nipple, has his head uppermost-a position assumed by the young of no other bat. No less curious is the case of the extraordinary naked bat (Cbiromeles torquata) of the Malay countries. This creature is perfectly hairless, and consequently, to afford security for the young 
one, a nursery has been developed around the nipples, recalling the pouch of the marsupials. Herein the young one is snugly tucked away during the mother's aerial excursions.

From what obtains among the bats one might naturally suppose that the so-called Flying-squirrels-which by the way do not fly, but glide in a downward direction through the air, supported by folds of skin stretched between the limbs and body-would similarly carry their young: the more so because of the difficulty one might imagine they would find in returning to any particular tree which might be selected as a nursery. But as a matter of fact they do not, but build nests to serve as nurseries. Those fantastic-looking creatures, the flying lemurs, or Cobegos (Galeopithecus), however, have adopted the plan followed by the bats, and carry their single young one attached to the under side of the body, as may be seen in our illustration. Dr. Alfred Russel Wallace describes how he shot a female cobego to the breast of which was attached a small, blind, naked young one; but neither he nor any other naturalist seems to have discovered how long this condition of helplessness endures.

It is a curious fact that in all the cases so far mentioned, when the young are carried, this burden is undertaken by the female alone: among the mammals, indeed, the male rarely takes any part in the work of tending the offspring.

The only other mammals which habitually carry their offspring are the members of the order Primates, which includes man, the apes and monkeys, and the lemurs. Among savage peoples, at any rate, the male never, so far as is known, bears any share in the transport of his children. Human babies, however, unlike those of their 
more lowly relations, are unable to hold on of themselves, but must be carried in the arms of one or other of the parents, or in a sling of some kind. Among the apes and monkeys they are carried by the mother either at her breast or on her back, the young one gripping her fur with hands and feet. Some of the lemurs have adopted a plan of their own; the young one attaching itself transversely across its mother's abdomen, its head resting against one flank, its hind-quarters against the other, holding on by gripping her fur with hands and feet, and, as an additional anchor, curling its long tail round her loins. Others adopt the more normal plan as shown in our illustration.

In the matter of the number of young produced at a birth we are confronted with some puzzling facts. It is generally held that this number is regulated, or determined, by the incidence of the mortality due to the ravages of predatory animals, disease, or accident, so that species in which the average duration of life is short must produce a large number of young and at a rapid rate.

The Rodents, as a group, are exceedingly prolific. Young mice may themselves become parents within six weeks of their birth; and by the end of the year may contemplate their descendants to the sixth or seventh generation -a formidable host when we remember that ten may be produced at a birth. And mice, it is to be remembered, form no inconsiderable portion of the diet of hosts of carnivorous birds and beasts.

On the other hand, the antelopes, for example, produce but one young at a birth, annually; and in spite of the fact that they are constantly harassed by large carnivora like lions and hunting-dogs, and have to contend with prolonged periods of drought. Certain species, like the 
spring-buck-before the invasion of their haunts by white men and railways-maintained huge numbers, roaming the veldt in hundreds of thousands. It is difficult to appraise the relative values of these two contrasts because we have no accurate knowledge of the average duration of life in either the case of the mouse or the antelope.

The horse and the ox again produce but one at a birth, the pigs as many as fifteen; but though the horse may attain to forty years of age and the pig to twenty-five, during the reproductive period the pig produces more young than the horse-from which we must assume that at some phase of their life wild pigs must be called upon to stand a heavy death-rate. In the case of the horse, at a generous estimate not more than fifteen young are produced by any one pair ; in the case of a pig not less than 180 , for the sow becomes sexually mature at about nine months old. She will continue bearing, say, till twelve years, producing from eight to fifteen or even more at a birth. At least this is true of the domesticated races of pigs, which may produce two litters a year. But in the case of the wild pig we may put the number of young produced at one hundred with a fair show of accuracy.

The lion, one might suppose, would produce fewer young than the zebra or antelope, on which it preys, though the reverse is actually the case. There seems, however, good evidence to show that there is a very considerable infantile mortality among these great carnivores; though so far no one has been able to detect its form-whether from some disease like distemper, or from the action of selection in weeding out those who bungle at killing.

Surprise has been expressed that lions and other African 
carnivores, for example, are not only not more numerous than they are, but that they did not, long since, increase more rapidly than the animals they preyed upon, and so extinguish both themselves and their victims ages ago. And support is lent to such a view by the undoubted fact that in colder climates an abnormal increase in the food supply is accompanied by an abnormally increased fertility of the animals affected thereby. Thus "lemming years"-or seasons when this interesting and remarkable rodent is unusually abundant-are marked by an increase in the numbers of all the predatory birds and beasts which prey upon them: the lemmings themselves owing their increase to more favourable conditions -warmer weather, more abundant food. This increase of predatory species is not merely the gathering of a crowd to the feast: it is an actual increase in number by a rise in the birth-rate, both the number produced at a birth and the number of families produced during the year being materially increased.

Such phenomena, however, are rather peculiar to rorthern latitudes, where we may imagine the maximum potentiality of reproduction only occasionally finds an opening. In hot countries there is no such check on reproduction, and the adjustment between the eaters and the eaten has long since struck a balance.

Whatever be the factors controlling the number of young produced at a birth, it is certain that we find a wide range in the period of infancy, which is associated with the time necessary to attain maturity, which in turn is related to the bulk of the body. Young mice can scarcely be said to have any childhood, for, as we have already remarked, they may themselves be parents within six weeks of their birth. The elephant does not 


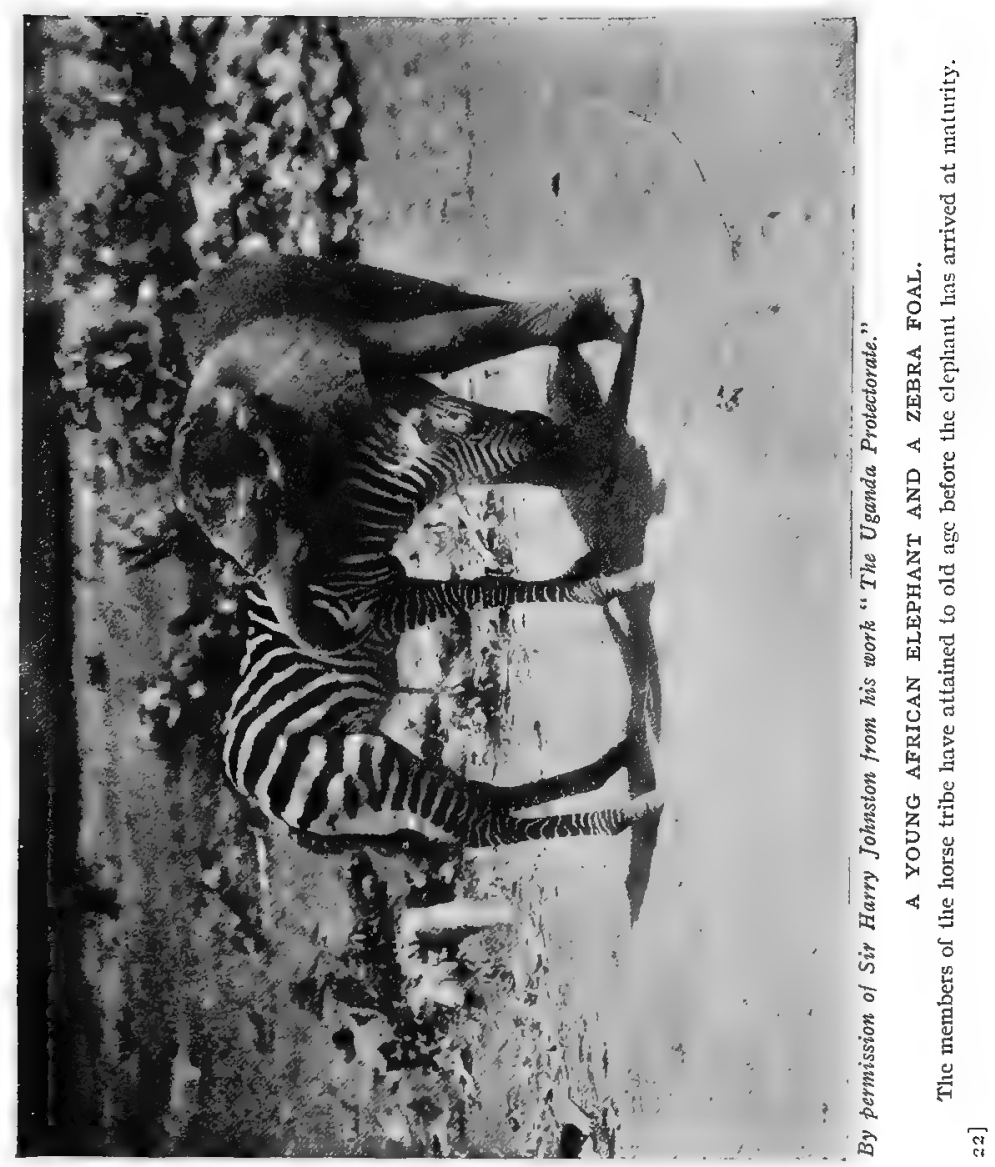



attain maturity until five-and-twenty, or according to others. between thirty and forty years of age, and consequently its period of infancy is a prolonged one: we may assume a similar prolonged infancy in the case of the whales. And this because, as we have just indicated, the greater an animal's bulk the longer the time necessary to attain maturity-that is to say to attain to the reproductive period.

This latter phase must similarly be prolonged, partly because of the parental care necessary for the well-being and survival of the young, and partly because each pair of individuals must produce sufficient offspring to ensure the continuance of the race, for of the number born only a fraction can attain maturity.

The elephant affords us an instructive illustration of this rule. It certainly cannot begin the duties of reproduction, which Nature forces upon every living thing, until from twenty-five to thirty years of age; and the period of gestation is nearly two years, consequently it must continue fruitful for at least fifty or sixty years, and some authorities place this estimate still higher. The pig may attain the age of twenty-five years, the horse of forty, or even more. But we cannot take into account the maximum age of the individual; all that counts from our present point of view is the period which extends from birth to the end of the reproductive period, which is considerably less than the maximum life period.

How vital to the race is this matter of reproduction may be gathered from the fact that sexual maturity is attained before physical maturity: even in the human race this is the case; and this fact is commonly lost sight of in estimating the severity of the struggle for existence. It evidently stands in direct relation to another fact no 
less important in this connection : to wit, that a longer time is required by a large animal than a small one to attain maturity, and consequently the reproductive period must be proportionately extended to ensure that a sufficient number of individuals shall survive to reproduce in their turn. It does not follow, however, that small animals are of necessity short-lived, for the pike and the carp are said to live a hundred years, a sea-anemone fifty years, a cray-fish twenty years.

But we are concerned now solely with the duration of life in the mammals and the bearing thereof on the prenascent period. Whenever this covers any appreciable length of time, from many days to many months, the young display features peculiar to this time. It must be remembered that they are developing mentally as well as physically. During this stage, then, they undergo a more or less extensive education to fit them for the strenuous life before them. Not the least important part of this education is the requirement of rapid co-ordination of movement; and especially of those movements on the accurate performance of which life itself may, even in the near future, depend.

A part of this education appears to be spontaneous, or instinctive-as for example the gambollings of lambs, and the play of kittens and puppies. At any rate, in these things they seem to receive no direct instruction from the parents : they do not, in other words, play by imitating the actions of their elders. The nature of this play is, as we have just remarked, the mirror image of some of the most critical moments of the life before them. The gambollings of the lamb are unconscious anticipations of a race for life with wolves; the play of the kitten reproduces all the movements which will be necessary for 
the capture of its prey. Dogs, it will be noticed, differ from cats in that their play is more often a rehearsal, not of the tribal habits of procuring food, but of personal contests, of duels to the death.

But the finishing touches to this education do certainly seem to be imparted by direct instruction from the parents. Cats certainly train their young in the art of mouse-killing; young lions are as certainly trained to slaughter, accompanying their parents in the search for food till long after they are full grown, and receiving therefrom constant instruction in all the arts of seeking cover, the final spring, and the methods of dispatching the victim.

Unfortunately, of this aspect of the life of young animals we know practically nothing: almost all the facts so far collected have reference to domesticated animals; but enough has been seen of wild creatures to show that centuries of domestication have not destroyed their primeval instincts in this direction. 


\section{CHAPTER III}

\section{COLOURS AND COLORATION}

THAT there can be any particular meaning in the coloration of young mammals, that the pattern of the coat of the newly dropped fawn could afford material for more than passing comment, is a possibility that, to some at any rate, may present an air of novelty. Nevertheless a careful survey of all the facts bearing on this theme will reveal a story of quite surprising interest: holding its own proper place in that wonderful mosaic which we call the "life-history," a part of which we have already discussed.

But at the very outset, it must be remarked, the task of translating this story of coloration is one of uncommon difficulty. Yet, in a rough sort of way, we might còvey at any rate a summary thereof, a sort of adumbration of the truth, in the paraphrase "the skins of the fathers are thrust upon the children, even unto the third and fourth generation," and that is why the liveries of young mammals often differ conspicuously in coloration from those of their parents. Indeed, there is good reason for assuming, in the first place, that these infantile mantles present, in their coloration, the hues which tinted their remote forbears; and in the second, that they furnish the still defenceless young with a mantle of invisibility against predatory animals during such time as they must needs be left unguarded by their parents. 


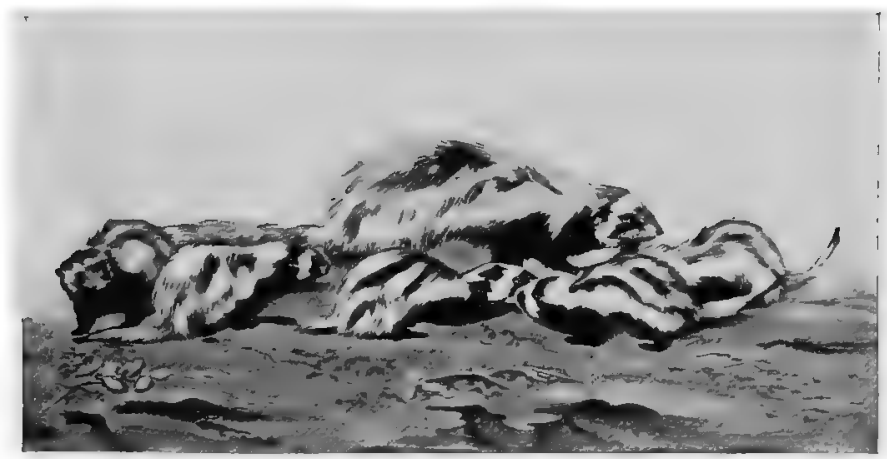

ZORILLA AND YOUNG.

Note that the stripes are more distinct in the young.

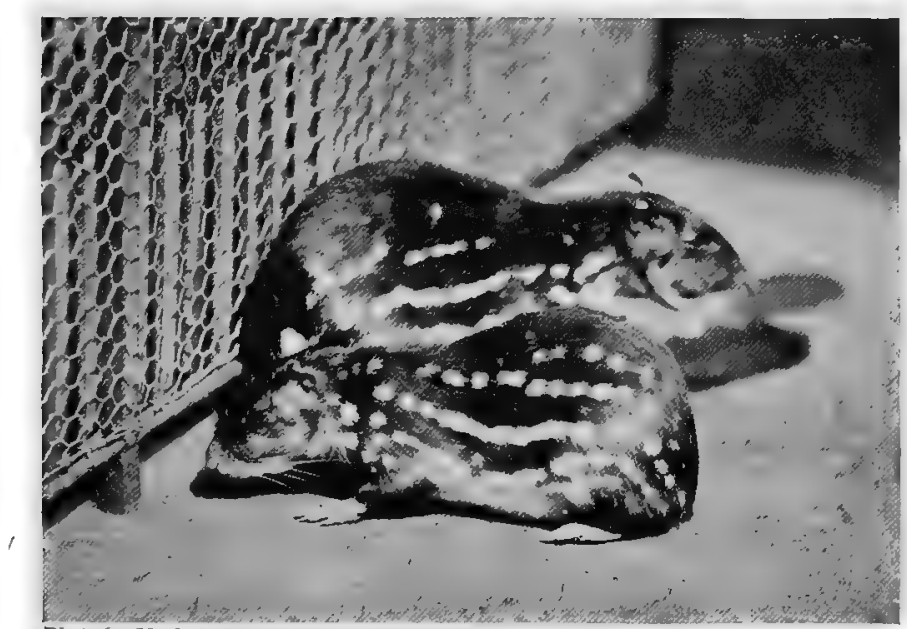

Photo by York \& Son, Notting Hill.

PACAS OR SPOTTED CAVIES.

These animals show how stripes are broken up to form a spotted livery. 

There is certainly nothing to lead us to believe that these peculiarities of pattern are recent developments due to what we may call modern, or existing, factors of selection: that is to say they are not due to the action of selective forces now at work determining the survival of such variations only, in new-born and adolescent individuals, as make for the evolution of this or that particular pattern and coloration. Yet they do represent the action of just these transforming factors on the generations of a remote past, and they have survived till to-day in just so many instances as they have continued to be efficient patterns: and, in so far, they are of course still subject to the sumptuary laws of natural selection, which is concerned now, so to speak, only with maintaining the ancient standard of adaptive perfection.

But what facts are there in support of the foregoing assumptions ? And what interpretation is to be placed on types of coloration which, it may be inferred, do not display this mark of the dead hand, so to speak? Briefly, young mammals may be either: longitudinally striped, transversely striped, spotted, or self-coloured. And while in any of such cases they may reflect the coloration of their parents, very commonly they do not. The most interesting of all these types of coloration, in many respects, is the first named on our list; it is also the least common, so far as mammals are concerned, though it is a somewhat remarkable fact that longitudinal stripes occur in young animals of all kinds. We meet with them among the birds, the reptiles, the amphibia, the fishes, and in the larval stages of many groups of lowlier animals; and in all these cases, as among the mammals, the parents display a totally diverse type of coloration. 
So then we have good reason for assuming that longitudinal striping stands for more than meets the eye at a first glance; and we may safely regard such a style of coloration as one which has survived from a very remote antiquity. On the whole it is now characteristic rather of young than adult animals. Striped adults, be it noted, always produce striped young; but more commonly, among existing mammals, striped young, at any rate longitudinally striped young, are the offspring of "selfcoloured" parents.

Very well. From what we have said it might well have been expected that the marsupials, as representing some of the lowliest of the mammalia, would, almost without exception, have displayed what we may call this primitive, old-style coloration, at any rate when young. Yet, curiously enough, such is not the case : on the contrary, this coloration is met with only in a very few marsupials, and here in both adult and young phases of development. It is found, for example, in the pretty little long-snouted phalanger ( $T$ arsipes rostratus), and the three-striped opossum (Didelpbys americanus) of Brazil, in which a black stripe runs from head to tail along the spine, and one on either side of this. Another opossum has but a single black band running down the back; and one of the smaller kangaroos, or "wallabies" (Petrogale xantbopus), has a single white stripe running along the flank and across the thigh. But this last case really hardly comes within the pale of longitudinal striping from our present point of view, and probably represents a more recently, independently acquired character, comparable to that of the African antelope (p. 3I).

Perhaps nowhere, among living mammals, can this "ancestral-juvenile" longitudinal striping be more per- 


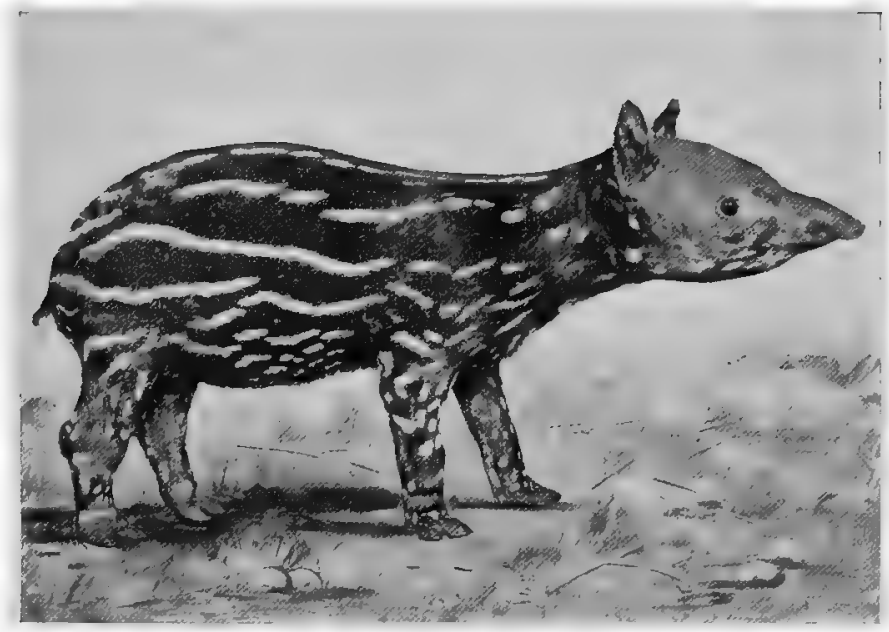

\section{YOUNG AMERICAN TAPIR.}

The stripes are on the way to become broken up into spots.

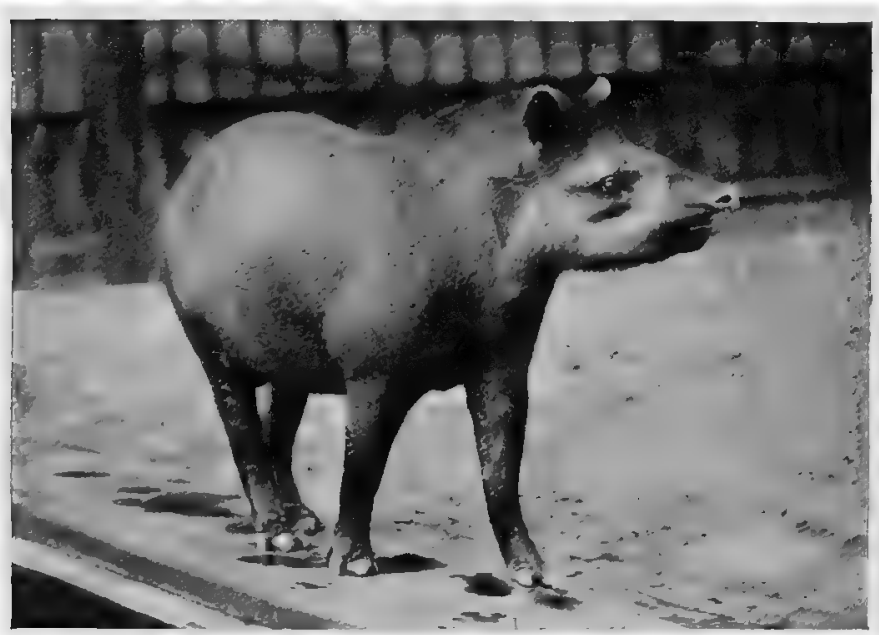

Photo by G. W. Wilson \& Co., Ltd, Aberdecn.

ADULT AMERICAN TAPIR.

The $\mathrm{e}^{-\mathrm{a}}$ adult is self-coloured, strongly contrasting in this respect with the larger Malayan Tapir. 28] 

fectly illustrated than in the case of the wild swine and the tapirs. The wild swine, at any rate those of the genus Sus, and the allied species of Red River hog, when adult are "self-coloured," when young are marked by broad bands of white running from head to tail, on a background of dark brown. In the tapirs the facts are more curious. The young, both of the Malayan and South American species, be it noted, very closely resemble one another, the body being marked by a series of relatively short, creamy-white bars, whose extremities tend to overlap one another, and a number of white spots evidently formed of disintegrated bars. The adults, however, differ conspicuously one from another in this matter of coloration, the American species being self-coloured, the Malayan parti-coloured, the head and fore-quarters and the hind-legs being black, while the rest of the trunk, from the shoulders backwards, is of a dirty white, forming a pattern unique among mammals.

Now let us see what relation this longitudinally striped, or longitudinally striped and spotted coloration bears to the environment in which these young pigs and tapirs live. Some years ago Dr. W. N. Ridley gave us an insight into the daily life of the young Malayan tapir. He found that during the heat of the day it seeks the grateful shade afforded by bushes, in which situation its coat is so exactly like a patch of ground flecked with sunlight that the solidity of the body vanishes, as it were, into thin air. And this because rays of sunlight passing between leaves form numberless spots and shafts of light over the ground; so that, falling on the hide of the resting tapir, as well as all around, it naturally becomes impossible to distinguish the stripes and spots of the resting animal from the similar pattern surrounding it. 
As a proof of the marvellous way in which the young tapir harmonises with its surroundings, Dr. Ridley tells us that one day, at high noon, wishing, for safety's sake, to shut up a captive specimen which had the run of his garden in Singapore, he began to hunt about among the bushes, but absolutely failed, for some moments, to see it at all, even when, as he eventually found, he was looking straight down on it!

But stranger still, for a season the young tapir wears both the adult and juvenile liveries at the same time, the latter becoming more and more ghostly, and finally disappearing, as the former waxes in intensity! There is no other animal known to me which exhibits quite so remarkable a change of coloration as this; the effect is quite uncanny! And according to Dr. Ridley the piebald garb of the adult, after the last of the spots has vanished, is no less a protective dress-though this seems curious. But Dr. Ridley assures us that when lying down during the day it exactly resembles a grey boulder bathed in sunlight; and as it often lives near the rocky streams of the hill-jungles, it is really almost as invisible then as when it was bedecked in stripes and speckles.

We may take it that the garb of the young pig is, then, similarly a protective garment. As much cannot be said, at any rate with as much feeling of certainty, of the grizzled colour of the adult. But then the wild boar, after he has attained maturity, is not an animal that may be, or is likely to be, attacked light-heartedly by any other denizen of the jungle inclined to predatory expeditions.

As we have already remarked, adult mammals with a longitudinally striped livery are comparatively rare; and it is a moot point whether certain of the African 


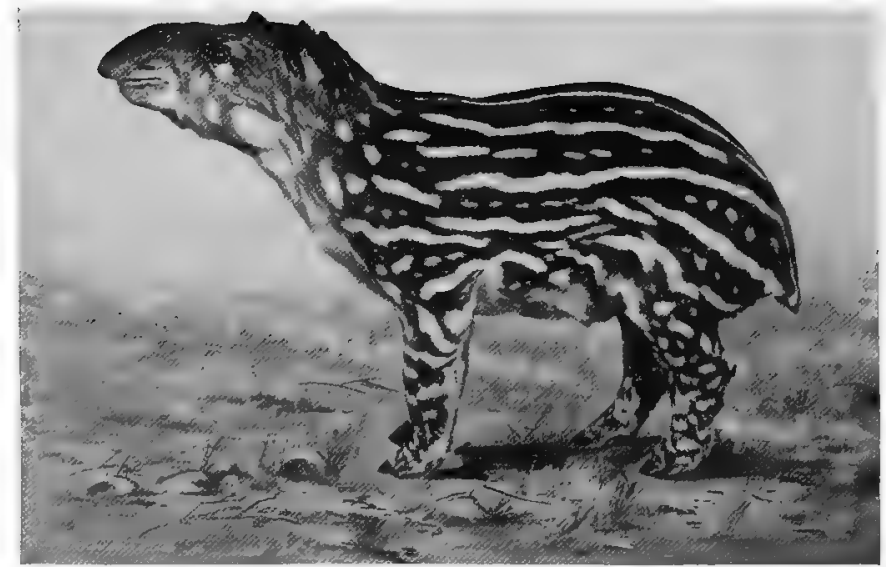

YOUNG MALAYAN TAPIR.

The evolution of a spotted livery has proceeded further than in the Common Tapir.

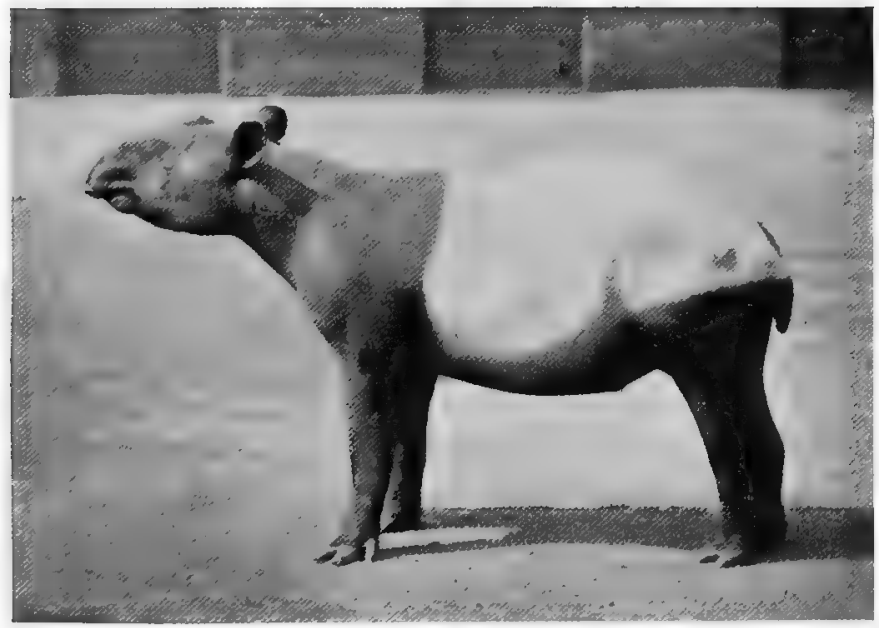

Photo by York \& Son, Notting Hill.

ADULT MALAYAN TAPIR.

The coloration of the Malayan Tapir is unique, and is apparently of a highly protective character, as also, curiously enough, is that of the young.

30] 

antelopes, which are characterised by a broad dark-brown or black bar running along the flank and across the thigh, have not really "acquired" this character independently. That is to say this bar is not the last of a once numerous series such as we have seen to be characteristic of the primitive livery. And the fact that the stripe is less developed in the young bears out this view.

And now let us briefly touch upon that other, and far more common pattern, wherein the stripes run in an exactly opposite direction-that is to say across, instead of along the body. It is a significant fact that numerous mammals present this form of striping. The thylacine, or tasmanian wolf, and the banded ant-eater (Myrmecobius fasciatus) among the marsupials; the zebras and asses, the kudus, elands, gnus, and harnessed antelopes, and a large percentage of the carnivora, of which the tiger may be taken as an example.

Now in the majority of cases of this kind both adults and young are marked alike. So that here, then, we have in existence to-day the same conditions as obtained in regard to the longitudinally striped animals ages ago. It would seem from this as though this particular form of "secant" coloration was a much more efficient form of protection than the now almost superseded longitudinal striping, which, as we have remarked, among the mammals is relatively rare. And, curiously enough, we have a repetition of the lines of evolution already seen in the case of the more primitive striping. That is to say, we find cases where the stripes are well developed in the young, and gradually fade with advancing age, leaving a "self-coloured" coat.

No better illustration of the fact could be found than that furnished by the elands, where the calf is vividly 
striped, the cow not at all. Among certain breeds of ponies, as among the Norwegian and Indian Kathiawar races, more or less markedly striped animals make their appearance with considerable frequency. In a young Norwegian pony curiously zebra-like stripes have been observed on the forehead, and in the Kathiawar ponies stripes commonly occur on the legs in addition to a stripe down the back and across the shoulders. So that in the case of the Eland calf and these ponies we may see the evolution of a new livery-the gradual suppression of the stripes and the formation of a "self-coloured" coat. Sooner or later, it may be ages hence, the young eland will cease to be striped-if the stripes have ceased to serve any useful purpose-and these ponies will have lost the last witness of their sometime zebra-like markings.

Young whose hides are spotted must now come under survey. Among both longitudinally and transversely striped species, it should be remarked, are some in which the stripes on the one hand are white against a dark grey, blackish, or rufous background, as the case may be; and on the other black, or nearly so, set off against a lighter background. And so it is with the spotted types: we have white-spotted deer and black-spotted leopards, for example. Whether these positive and negative types of spots represent liveries of equal antiquity, or are divergent modes of expressing the same theme, are questions which naturally suggest themselves, but the answer thereto has yet to be discovered!

If one might hazard a guess, one would, I think, feel inclined to regard the white-spotted as the more ancient type. However, be that as it may, there seems butylittle room for doubt that spots are less ancient than stripes, if only from the fact that in a large number of cases at 


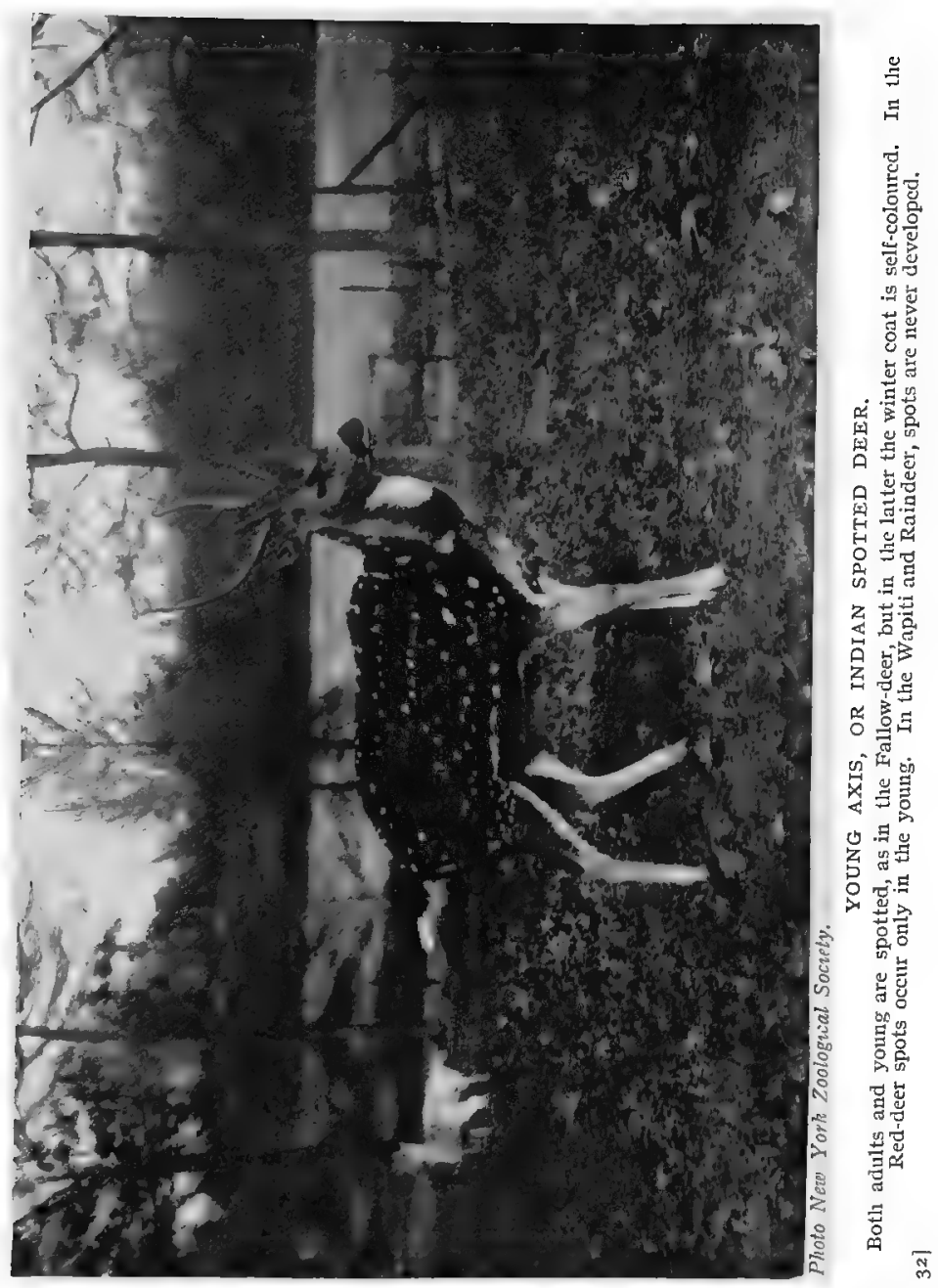



any rate, and possibly in all, they have been formed by the breaking up of stripes; and while in some cases these disintegrated stripes were transverse, in others, and perhaps more frequently, they were longitudinal.

The paca (Cologenys paca), the spotted and striped hyænas, the curious little Indian chevrotain (Tragulus meminna) and the handsome harnessed antelope will serve to show transitional stages in the passage from stripes to spots. But I can call to mind no instances where the adult is spotted and the young are striped. Yet we should expect to find such cases. But we do find a number of instances where the adults are self-coloured and the young are spotted, or display both stripes and spots, that is to say stripes in process of conversion into spots. Young deer of many species show this to perfection. In the young of the hog-deer (Cervus porcinus), axis-deer (C. axis), reddeer (C. elapbus) and fallow-deer (C. dama), for instance, the spots, though sharply defined, are seen to be ranged in longitudinal lines, and these are much more sharply defined in the young than in the adult. In some deer, as in the case of the red-deer and musk-deer, the spots vanish with adolescence, in others, as in the axis-deer, they are retained throughout life. In some cases, however, as in the fallow-deer, the hide of the adult is alternately spotted and self-coloured. And these changes appear to play an important rôle in the animal's well-being.

The fallow-deer, it must be remembered, is a foresthaunting species, and during the summer months ruminates, for choice, in sunny glades, lying amid the undergrowth and bracken, where the play of the sunlight through the foliage scatters spots and shafts of golden light on every side. Thus the spotted hides of the deer blend insensibly with their surroundings, and, so long as they 
remain motionless, so long do they remain invisible. But with the fall of the leaf and the gloomy days of winter the character of the environment changes. Spots no longer serve to conceal, but rather to advertise. Accordingly, with the autumn a self-coloured coat is assumed, which no less perfectly harmonises with the barren ground and the bare stems of dried bracken and other undergrowth. In the axis-deer, also a forest animal, the spotted coat is worn the year round, and this because it is happy in living in regions where the sombre pall of winter is never spread.

Of all the instances of striped and spotted young which as they attain maturity assume a self-coloured garb, perhaps the most striking, because somehow the most unexpected, is that furnished by the case of the lion: for young lion cubs show the most convincing proofs that their forbears wore a livery displaying both spots and stripes-which must be interpreted to mean that at some remote period the lion, like the tiger, wore a coat of stripes. Then the stripes gradually broke up to form spots; and finally, so far as the adults are concerned, even these have disappeared, though they may be traced even in full-grown lions, only vanishing completely when they have become of full age.

These facts are not so surprising as they may seem at first sight, because, except for their different coloration, and that the male lion wears a mane, the lion and the tiger are extraordinarily alike-so much so that only an expert can distinguish the skeletons of the two animals, and even here only by slight differences in the skull. These gradual changes of coloration, which have followed one another in the life-history of the lion, must have arisen in relation to changes in its haunts and habits. 


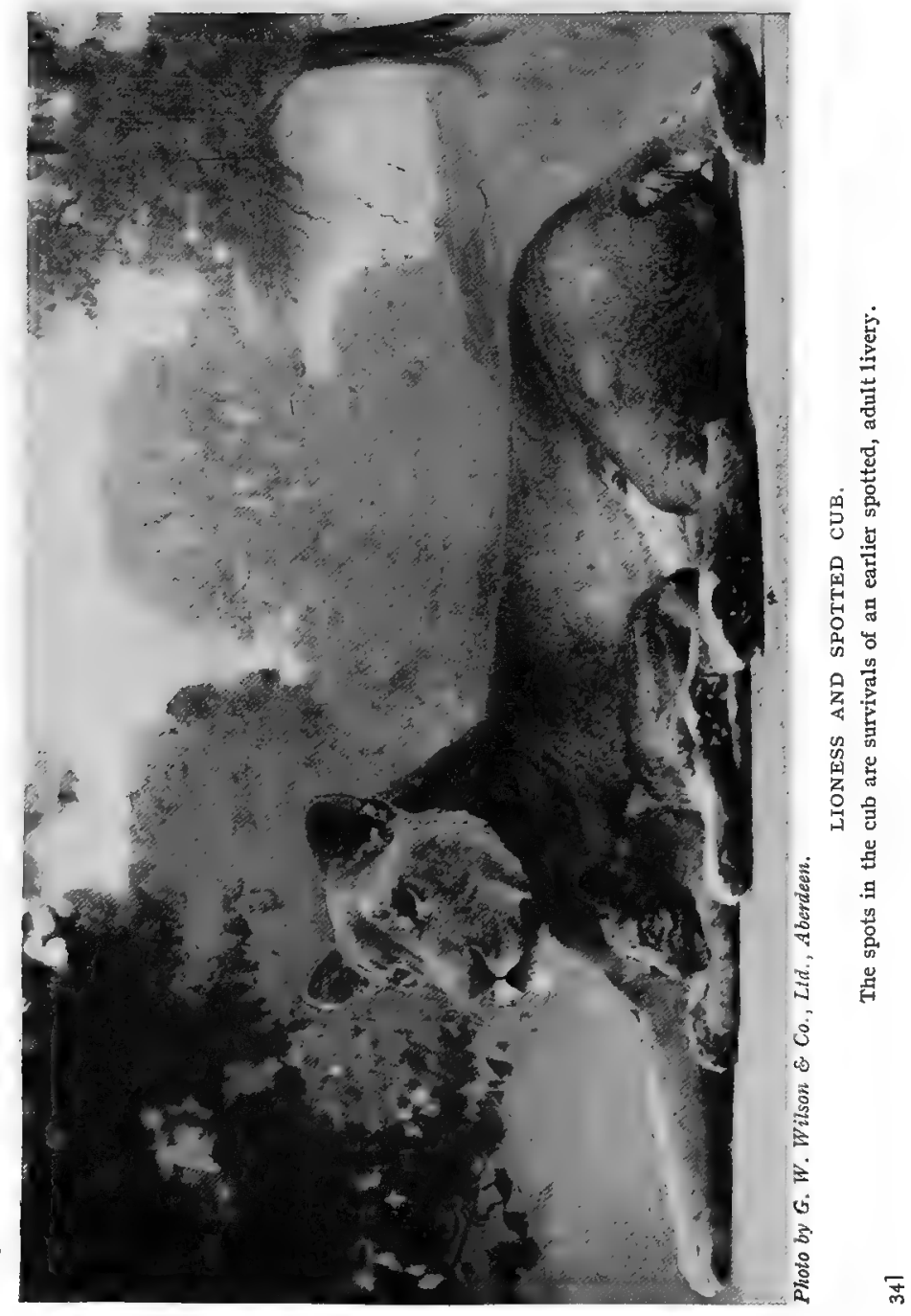



To-day the lion is a dweller in the open, the tiger in dense jungles, where his stripes, harmonising with the tall reed stems, make him invisible, and so the more able to stalk his prey without being seen.

Whether, from the very dawn of their development, the coloration of mammals was relieved by a pattern of some sort, or whether they slowly evolved, first a striped and then a spotted livery, in accordance with the needs of their environment, or not, we cannot say. But it is certain that a considerable number of mammalia at the present day seem to do best with a coat devoid of any distinctive markings at all. The lion affords a striking case in point. But in this species the tell-tale spots survive in the young. In the majority of cases, however, even these have vanished, and from birth to old age the coat is "self-coloured."

In most cases of this kind the young do not differ appreciably, if at all, from their parents. But we find striking exceptions to this rule. Thus, fox cubs are of a uniform smoke-grey colour, contrasting strongly therein with their parents. The young of certain seals, however, present some puzzling features. In the case of the common seal the "pup" is of a uniform yellowish white colour but the adult is spotted; while in the Harp seal (Phoca grcenlandica) the young is white, the adult ornamented by a long bow-shaped belt of dark brown on either side of the body, the ends of the bow meeting over the back to enclose a space. Now, here-and the seals furnish yet other similar cases-the normal conditions are reversed, for where a "self-coloured" stage is contrasted with one displaying a marked pattern, one has come to expect the young to display the pattern, the adult the patternless condition. 


\section{THE INFANCY OF ANIMALS}

If the rule of ancestral liveries holds good here, if the coloration of these young is to be regarded as reminiscent of the liveries of their forbears-and this rule certainly holds good in the majority of animals-then, it would seem, we must regard all the species of seals which have white young to-day as species which have emerged from a white phase of coloration such as is common to both young and adult stages of the polar bear, for example. This of course may actually have been the case : but if so it constitutes a very remarkable phenomenon, inasmuch as pure white liveries are always regarded as having been, so to speak, purged of pigment, and consequently indicating the final term in the evolution of coloration.

The solution of the riddle seems to have been made by Mr. Alex Rogers, the Curator of the Perth Museum, who remarks, "The white colour of the young seal may of course be ascribed to protective resemblance ... and, as a matter of fact, $I$ have seen several men pass quite close to the 'white coat' (young seal) lying on the ice without seeing it." But, he remarks, the only enemy of the young seal .... is the Polar bear, and this he does not regard as numerous enough to have enforced a need for protective coloration. He suggests, then, another interpretation. "The heat of the sun on the ice is intense. The old seals can usually protect themselves from this by a frequent bath; the young, however, do not take to the water during the first twenty-four days. Now when it happens that a pack of old seals and young are trapped on the ice-a frequent occurrence--by what is known as a ' jam,' thus leaving no air-holes for them to reach the water, the old ones become what is termed by sealers, 'burned skins.'

"The skin becomes parched and dry, and strips off in 
flakes if the hand be drawn along the back. The young seals are quite uninjured by the sun, being protected, no doubt, by the white colour of their coat."

In discussing problems of coloration one runs the risk of an unconscious bias towards one aspect only. We are inclined to concentrate attention on the stripes and spots, and their waxing and waning, and so lose sight of their relation to the external world. This is a danger which one must not allow to pass out of mind, for the two aspects are mutually dependent on one another if we are to arrive at a right understanding of the facts under review.

So far as the evidence goes in regard to mammals, it would seem that such species as dwell amid cover afforded by vegetation are striped, or spotted, those which dwell out in the open are "self-coloured." But there are many exceptions to such generalisations, and it must not be forgotten that these patterns-forming as they do a more or less perfect obliterative coloration, causing the solid body to vanish, as it were, into thin air-are effective only when the creatures so marked are at rest. But this is when it is of greatest use.

In many cases, by reason of the bulk of the animal, or the development of efficient weapons of offence, a patterned coat is of no importance as a means of protection, and accordingly gradually disappears. . Yet it maintains its purpose during the early stages of growth before the weapons have developed; and hence, as in the case of the wild swine, the ancestral livery is revived in the young. We may take it that so soon as these patterns fail to serve any useful end-their purpose is to "cut up" the solid appearance of the body, and so 
destroy its contours, hence they are called "secant" patterns-they begin to disintegrate; though the process of their decay may be infinitely slow. But so long as and in so far as they confer benefits, so long and so far will they be retained.

What, then, regulates their persistence? what determines their change in form ? Apparently that sumptuary law which is a part of the machinery of natural selection. If among adults, either by the development of weapons or other means of protection from enemies, or by a change in the environment suppressing enemies, the need for a striped or spotted livery is past, then so surely will that livery begin to degenerate; and this because natural selection no longer rewards, so to speak, those individuals in which this or that livery is best developed: all the members of the race, the defective as well as those which have attained the maximum of perfection in this particular, have an equal chance. It ceases to confer any benefits, and thus in course of ages will gradually fade away.

Since ancestral characters tend to reappear in the young, the pattern now lost in the adult may well be preserved in the young : because any in which it is defective will be killed out. In the case of the stripes in young pigs, for example, as we have already pointed out, these markings persist in the wild species, but they are wanting in the domesticated races, where such a pattern is valueless.

Similarly, the unseen hand of natural selection is no less active in determining changes of pattern-the change from a striped to a spotted livery. So long as stripes, as such, conferred a benefit, so long did they maintain their integrity. Any individual variations tending to disturb the pattern were suppressed.

But this same tendency to vary brings with it advan- 

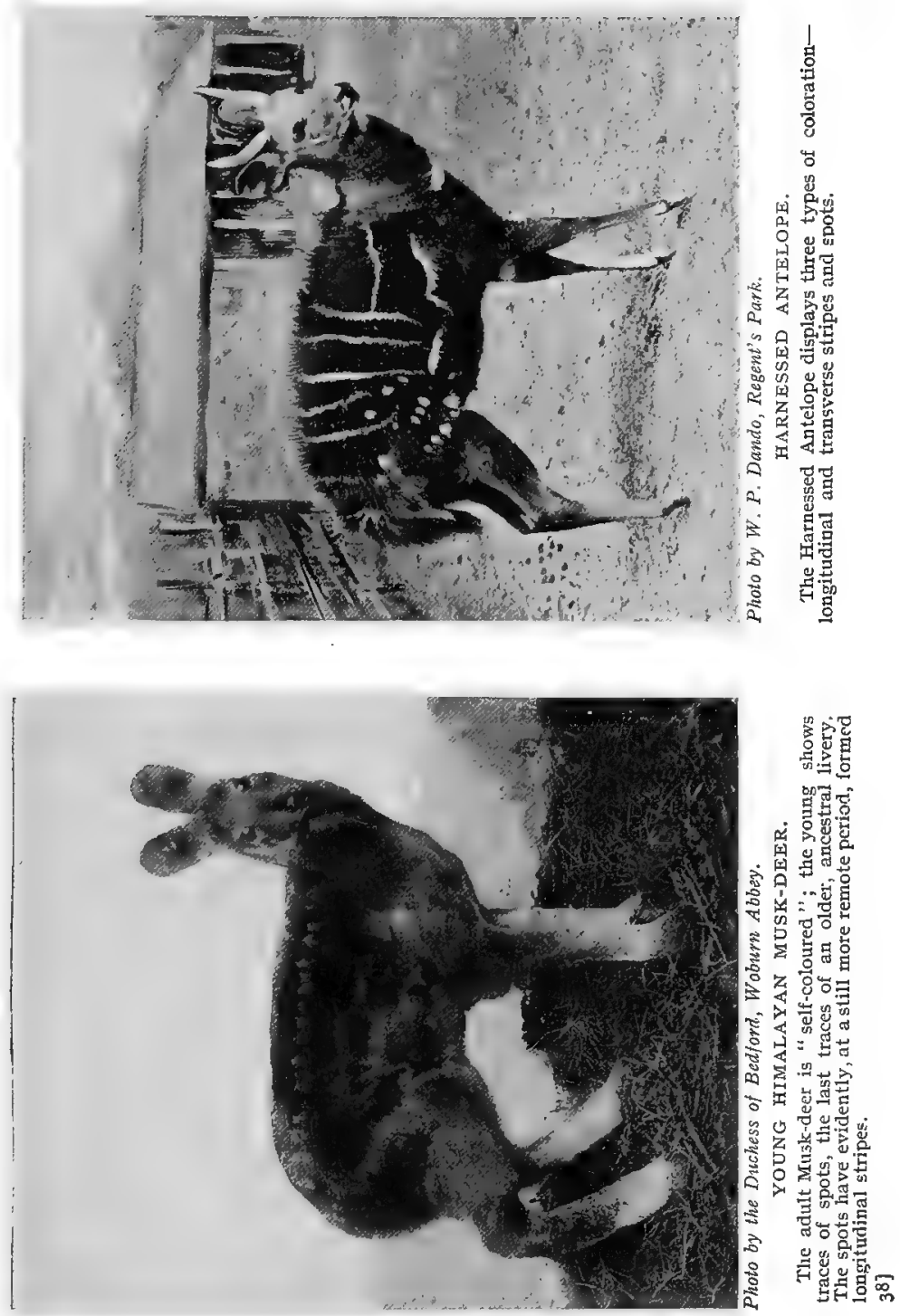

tages. Sooner or later, we may suppose, the tendency to produce spots instead of stripes becomes a valuable one, and $10 !$ in due time the stripes are broken up and spots take their place, as in the case of deer. Some species have both adults and young spotted, the year round; in some the young, and the adults during a part of the year, are spotted : in others, as in red-deer, the young only are spotted. Finally, as in the case of reindeer for instance, the spots have vanished completely from the life-history: though it is quite possible that traces might be found in the embryo just before birth.

The tendency has been for new characters to make their first appearance in the adult male. By the time they have attained something like perfection in him they begin to be transmitted to the female, and in course of time to the offspring, until all three have the same livery. 


\section{CHAPTER IV}

\section{MILESTONES OF EVOLUTION}

Rudyard Kipling, in his "Just So Stories," gave us a whimsical account, among other things, of "How the Elephant got his Trunk!" which does not accord, however, with the evidence furnished by facts gathered at first hand! Such evidence can only be obtained from Nature herself, and much has been laboriously pieced together, during recent years, by a study of fossil remains gathered from various remote quarters of the globe. But there are many other problems about which we are equally curious, and which must be solved in part by a reference to fossil remains, and in part by a study of early stages of growth, which in many cases afford us most surprising results.

Time was, indeed, when it was believed that these early-growth stages, if carefully followed, would reveal all the mysteries of evolution, since, it was supposed, every animal had to climb its own genealogical tree, so to speak. But it was soon found that such hopes were over-sanguine, for records of some of the most important phases have been lost completely, and others blurred; while some of the phenomena have nothing to do with ancestry, but represent what we may call scaffoldingfeaturesiphich have been introduced solely for the benefit of the individual. 
The study of young mammals does, nevertheless, throw a flood of light bearing on their ancestry, and illumines no less the stages in the development of the particular characteristics of this or that group of individuals. In fact, the stages of development are so many signposts along the pathway of evolution.

As we have already pointed out, there is no common, fixed, starting-point at which the study of young mammals, or of any other young animals, begins : we cannot even draw a hard-and-fast line between the embryonic and the post-embryonic life, for some animals are born at relatively much earlier stages of development than others, as we have seen in the cases of the kangaroo and the horse, for instance.

But let us pass from the abstract to the concrete; selecting, by way of a commencement, some facts revealed by a study of the teeth. Mammals differ from all other tooth-bearing animals of to-day in that they never develop more than two sets during their lifetime. The first is known as the milk-dentition, because it is developed towards the end of the suckling period, the second as the permanent set. In this "milk-dentition" the teeth are fewer in number and smaller in size than those of the permanent set; they may even be less complex in structure than the permanent teeth.

It has been supposed that these "milk"-teeth bear no relation to more primitive, adult types of teeth, but have been developed solely as temporary instruments for dealing with solid food until the jaws have attained their full size, and have consequently developed the necessary space for the accommodation of the larger and more numerous adult teeth. But this is only partly true. These milk-teeth do indeed represent the adult type of 
dentition of more remote ancestors. This is shown in the case of the fossil horse Merychippus, where the milk teeth are of the short-crowned type, lacking the "cement" seen in the yet older fossil species Ancbitherium, whereas the teeth of the later, permanent set of Merycbippus show the high-crowned cemented type characteristic of the more specialised members of the family Equidx.

Again, the grinders or cheek-teeth of the milk series of the Wart-hog (Phacocherus) are numerous, as in typical pigs, but in the adult wart-hog all are finally lost save the hindmost molar, which is of huge size, recalling in many respects that of the elephant.

In those extraordinarily coloured creatures the " Ratels" -iron-grey above and black below-the chief grinder or "carnassial" of the milk-set differs conspicuously from that of the adult, and resembles that of the permanent carnassial of the more lowly Galictis. Among the majority of the marsupials only one milk-tooth in each jaw is present, answering to the last of the grinders of the milk series, and this is more complex in character than the tooth which finally replaces it. For a long while it remained a moot point whether this tooth was to be regarded as the precursor of a milk-dentition, or was the last survivor of a set of "milk-teeth" to be finally eliminated. Most authorities inclined to the view that the marsupials retained their milk-teeth throughout life, with the exception of the one replacing tooth, which was regarded as the first member of a dentition answering to the permanent dentition of other groups, including Man himself.

We now know that this view was incorrect; that the tooth in question is the only one of a complete series to come to perfection; for in some of the marsupials rudiments, or more correctly vestiges, of a complete set 
of milk-teeth-cutting-teeth (incisors), eye-teeth (canines), and cheek-teeth or grinders (pre-molars and molars)-are to be found enclosed within the gums, but only one pair ever cuts the gum and attains maturity, and this is the tooth which, in the kangaroos, gave rise to so much debate. Why has this tooth alone of its series survived ? and how is it that all the teeth of the permanent set are precociously developed, replacing or suppressing all the milk-teeth save one-that which answers to the hindmost of the milk-teeth ? This is one of the mysteries to which no clue is yet obtainable, and affords an admirable illustration of the importance of the study of young animals.

Among the seals the milk-teeth are either shed just before birth, or immediately after. But the most curious and the most interesting facts of all which have been gleaned from a study of the teeth in young mammals, and of the light they throw on the problems of evolution, have been furnished by the whale-bone whales. These, as everybody knows, have replaced teeth by an extraordinary development of horny plates known as "whalebone," and it was long supposed that the last vestiges of teeth had vanished ages ago.

Not so, however, for in the jaws of embryos of the Lesser Rorqual or Piked Whale (Balcenoptera acutirostris) and of the Common Rorqual (B. musculus) a complete set of tooth rudiments may be found, which are presently absorbed without cutting the gum. But more than this. It has been found that vestiges of both the milk and the permanent series are present, the latter being the more degenerate. The milk series are, as usual, fewer in number than the permanent set, but they present one extremely interesting feature, in that they are furnished, many of them, with two and three cusps apiece! 
Now in all living whales, where the jaws are armed with teeth during life, these are simple pegs; but in certain fossil whales, which are in other respects also less highly specialised than their modern representatives, the teeth bear three cusps.

Thus, then, the embryonic teeth of these whales recall those of the ancestral zeuglodont. The "whale-bone," then, represents an entirely new structure replacing the teeth : an adaptation to new methods of feeding developed during the struggle for existence. A parallel case is furnished by that quaint-looking relic the Duck-billed Platypus (Ornithorbynchus). This animal was long supposed to be as innocent of teeth as a whale-bone whale, curious horny pads having taken their place.

But a few years ago the astonishing discovery was made that for a time the/jaws of the young platypus are armed with teeth, answering to the grinders, and these too of a peculiar and complicated pattern found in no other mammals. Speedily, however, the skin of the gums around and under the teeth hardens, until it attains a horny consistency, by which time the roots of these teeth have become absorbed and the crowns are in consequence shed. So that the adult Duck-bill grinds its food by means of horny pads, which seem to serve better than the teeth which they replaced.

But young mammals furnish us with many other records, no less fleeting and transitory, of the remote past : records which must be sought for sometimes during embryonic, and sometimes during later stages of development, when they vanish without leaving a trace behind them. To take a case in point. The whales, porpoises and dolphins, as everybody knows, have lost every trace of hair from their bodies, save a few bristles which appear on the lips 


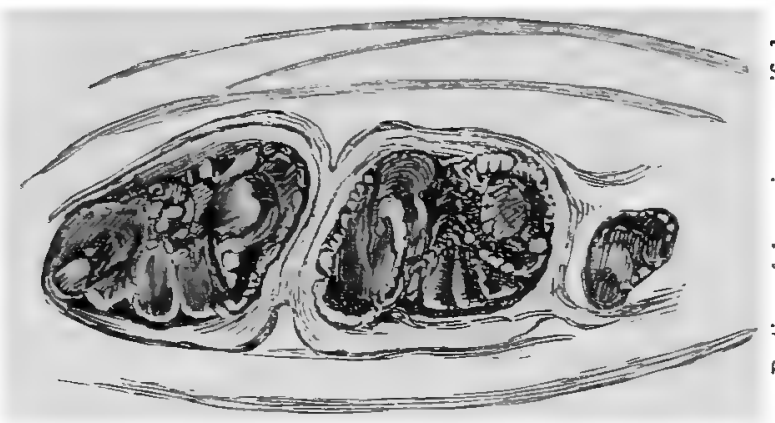

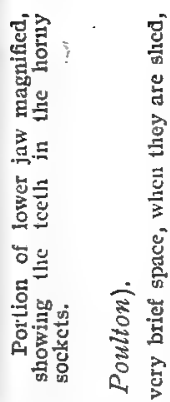

है

$\Xi$
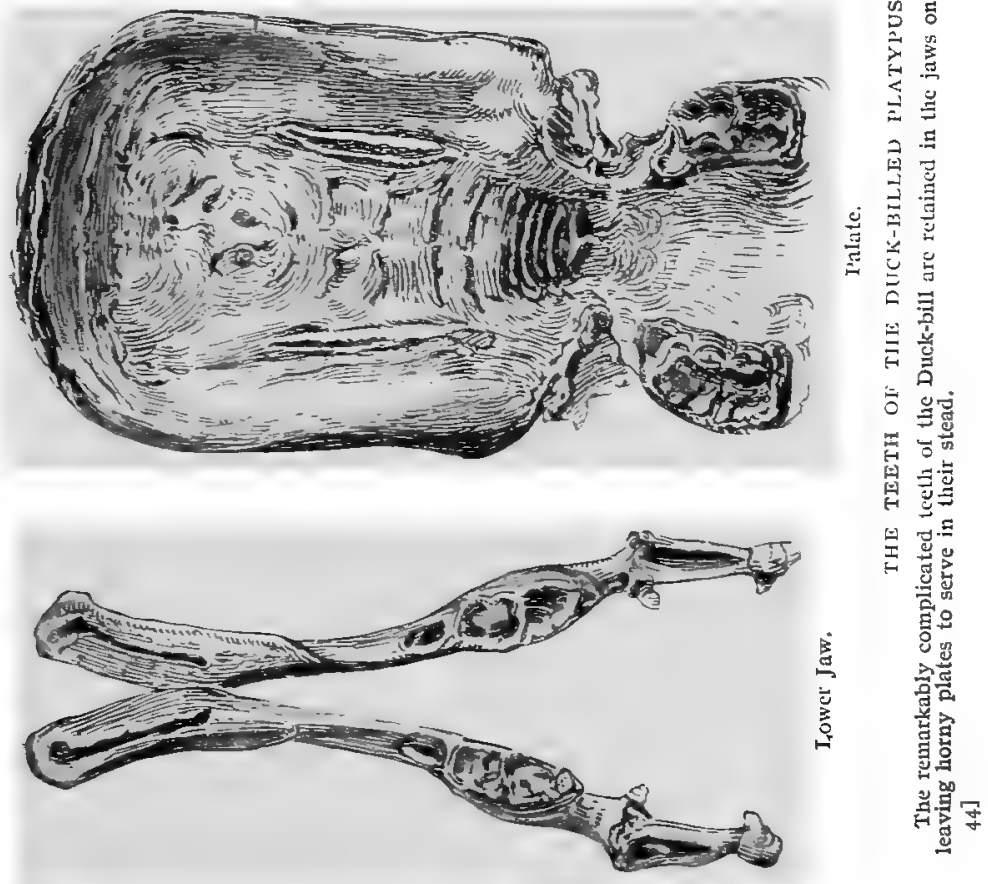



\section{MILESTONES OF EVOLUTION}

of a few species, and the skin has become as smooth as glass, and with a dull polish.

Now we have good reason to believe that their remote ancestors wore armour, concealed, perchance, with a scanty covering of hair. And this because, in the first place, certain fossil species, known as zenglodonts, which were at any rate nearly related to the whale tribe of to-day, certainly had such an armour; and in the second, traces of armour are actually present at any rate occasionally in adults of the common porpoise, where the dorsal fin is studded with bony bosses, and in another (tropical) species, Neomeris, where rows of bony plates are found running all the way down the back, embedded in the skin. These can certainly serve no useful purpose to-day, and must be regarded as remnants, vestiges, of a more perfect armature worn by the generations of long ago.

The correctness of this surmise receives considerable confirmation when we turn to the embryos of these porpoises, for in both the bony remains are relatively much larger than in the adults, in which, it is plain, they are gradually disappearing. We may venture to prophesy that in the course of a few more thousand generations all record of their presence will be lost in the adults, and after a still greater lapse of time in the embryos as well.

The revelations of the dissecting-room seem hardly likely to furnish material that could be of any interest save to the specialist. And in truth the mere record of facts obtained from such a source makes but a useless catalogue. In mentälly turning over its pages we find ourselves asking, "Can these dry bones live?" But after a little while more and more items on the list leap to the eyes, each with a message. Those which more 
especially attract attention are the records of what are known as vestigial structures, the apparently useless remnants of once functional and well-grown organs.

Time was when these structures seemed to defy interpretation: they were the untranslatable hieroglyphics of pre-Darwinian days. But if we read them, as the master taught us, in conjunction with the records of the rocks, we are able to make of these fragments an intelligible, if imperfect, story of evolution. Illustrations of this fact have already been given in the case of the bony nodules in the skin of the porpoise, for example; but still more striking are the facts furnished by a study of horns and antlers.

Horns of ruminants, it must be remembered, first appeared as bony "bosses" on the forehead, and gradually assumed a spike-shaped form. Later the peculiar spiral twists and graceful curves, characteristic of the different types displayed by oxen, antelopes, sheep and goats, were evolved.

To-day, in the individual life of each species, we can actually watch these changes of form from the original pair of spikes-changes which represent the gradual acquirements during enormous periods of time. The nature of such transformations is well displayed in the case of the horns of the gnu, shown in the accompanying photograph. In the calf, it will be noticed, the horns are of the ancestral, upright, or columnar form: in the adult, it will be seen, the bases are enormously thickened, while the horn curves abruptly downwards and then as abruptly upwards.

Unhappily the white-tailed gnu is almost or quite extinct as a wild animal, so that we can now hardly hope to obtain the whole series of gradations in development 


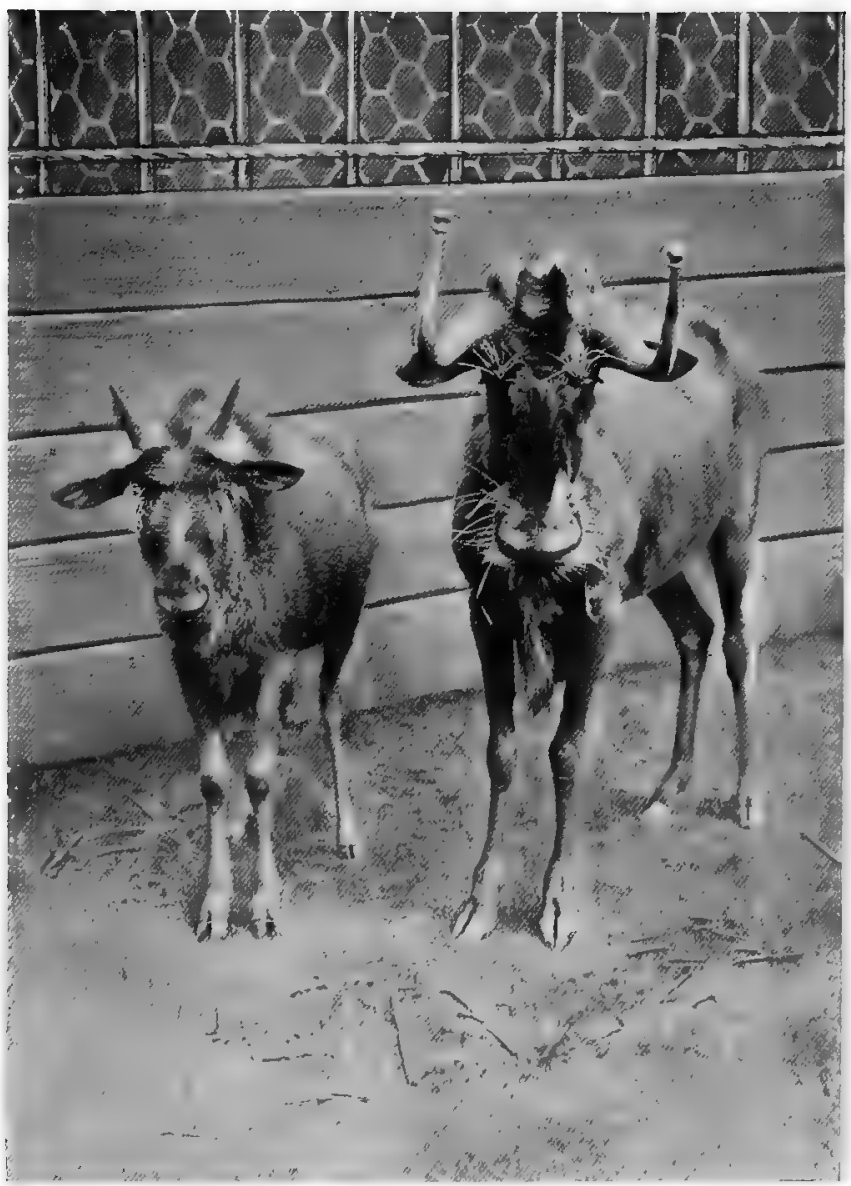

Photo by W. P. Dando, F.Z.S.

\section{WHITE-TAILED GNU AND CALF.}

When they first appear, the horns of the gnu have the form of short blunt spikes, set wide apart. The singular hook-shaped horns of the adult touching at their bases, are very slowly developed, but of the intermediate stages of growth there are no records. 

which take place between the columnar, pointed shafts and the strangely curved adult weapons. These could easily have been obtained in days gone by, when large numbers were slain for food, or "sport." But in those days the importance of these things was undreamed of.

The antlers of deer yield a still more striking illustration of the way in which young mammals, in the course of their development, repeat in broad outlines, anyhow, the history of their race. The antlers of deer, it will be remembered, differ from the horns of oxen and antelopes, for example, in many ways. In the first place they are commonly more or less elaborately branched; in the second they have no horny outer covering or sheath, to serve as a protection against the action of sun and wind and rain. Very well. Now let us take a rapid survey of the apparent course of evolution of these most wonderful weapons.

To begin with, we must regard the stately giraffe and the lordly deer as divergent branches of the same family. Now the giraffes are horn-bearing creatures. But their horns differ conspicuously from those of oxen and their kin, in that they are covered with skin and hair like the rest of the body. But in that strange animal the Okapi, whose discovery created such widespread interest about a dozen years ago, the tips of these horns project through the skin in the form of a pair of polished cusps. It is probable that these cusps are remnants of once larger structures, answering to the antlers of deer, and possibly resembling the antlers of the small Asiatic muntjac deer. Herein we find a pair of long, skincovered horns or "pedicles," answering to those of the giraffe and okapi, surmounted each by a shaft of naked bone forked at the tip: they are the "antlers," and are 
small in proportion to their skin-covered bases, or "pedicles."

But in the majority of deer the antler has increased enormously in size, while the pedicle is commonly reduced to a short column at its very base. The antlers, as everybody knows, present a most wonderful variety in shape, and in the number and form of the "tines" or branches; but whether we contemplate the enormous weapons of the extinct Irish " elk," the huge palmated antlers of the moose, or the singularly beautiful and branching beams of the red-deer or caribou, we must remember that all alike have their origin in a simple, short pillar of bone, and that all alike start to-day from the same point, as we shall presently show.

Before we enter on this aspect of their history, however, let us pause for a moment to contrast the antlers of the deer with the horns of the ox and antelope. These last, it will be remembered, are bony outgrowths of the skull protected by a sheath of horny matter: while in the deer, as we have remarked, they are not thus protected, but are exposed to the action of the weather.

Now, since the permanent retention of such a mass of dead bone seems, for some obscure reason, to be inimical to the well-being of the animal, these antlers are periodically shed and replaced. The work of rebuilding begins in the form of a swollen knob surmounting the pedicle, and covered with a peculiar velvet-like skin. This "knob" is made up of a mass of growing bone-tissue and blood-vessels. Rapidly increasing in size, it presently assumes the form of a pair of knobs : one of these forms the first or "brow" tine, the other grows up to form the main shaft or "beam" of the antler, from which, at their appointed place, the "tines" characteristic of 


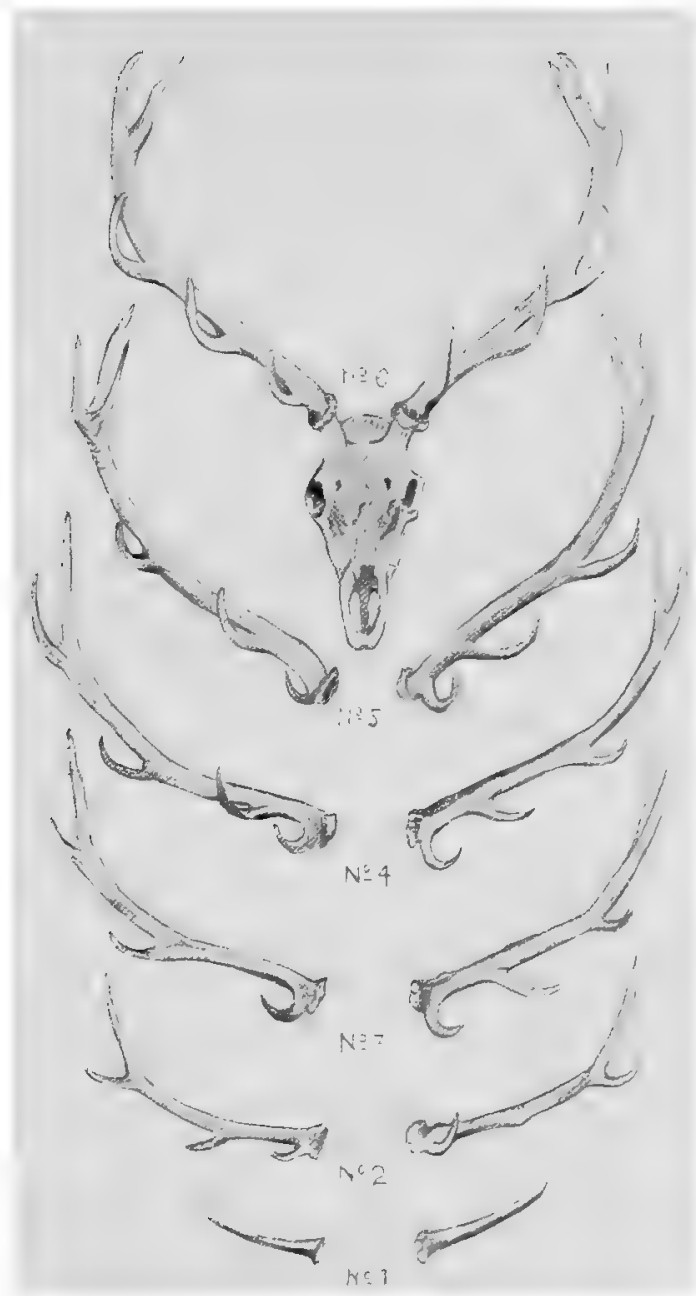

ANTLERS OF RED-DEER (after Millais).

These show the successive stages of development, from the "pricket" stage to the full-grown antler. Stages I and 2 answer to the adult stages of more ptimitive extinct species. $4^{8]}$ 

the species appear, one after the other, until the antler has attained its full size: it is still covered by the velvet skin. Presently, however, the blood supply is cut off by the growth of a ring of bone at the base of the antler; and this is speedily followed by the sloughing away of the "velvet," the remnants of which are removed by the animal itself, which rubs its new-grown weapons against the boughs of a tree until the offending rags have been removed.

In species like the giant wapiti and the red-deer, for example, where the antlers attain a great size and numerous branches, their maximum development is not attained until the animal has reached its prime. Each new pair is larger and more complex than the last. Sooner or later, however, old age overtakes the proud possessor of these splendid ornaments, and the first sign of the process of decay is seen in their decline, after each renewal, both in size and complexity. This gradual increase in the complexity of the antlers which takes place during the lifetime of the individual is, be it noted, a repetition of what has taken place during the history of the race; and this much is established by the records obtained from fossils.

The earliest known deer, which carry us back to the Lower Miocene period, were hornless, like adult females and the fawns of to-day: by the period of the Middle Miocene the males of some species had acquired small antlers forked at the tip. These answer to the second pair of antlers developed by, say, the young red-deer in its second year. We may safely assume that still earlier there were species which, when adult, bore simple, unbranched antlers, or "prickets," like those of the sevenmonths-old fawn of the red-deer. 


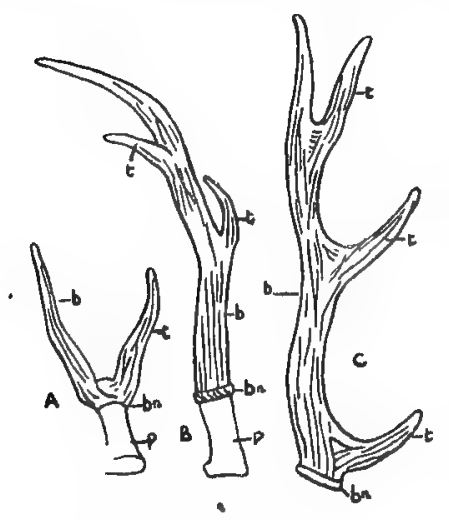

HORNS OF FOSSIL DEER.

A. Dicroseros elegans, Miocene, France.

B. Cervus pentilici, L. Pliocene, Pikermi. Pay-de-Dome. After Smith-Woodward. some, like the Roe-deer, have not advanced beyond the stage attained during the Miocene period, and between this and the magnificent weapons of the red-deer and wapiti we have a wonderful variety in size, form and complexity.

One of the most characteristic features of a mammal is its covering of hair; but in some species this has, in the course of ages, gradually disappeared or become considerably reduced in length and quantity, while in others it has become transformed into spines, or replaced by bony plates, and much of what we know as to these changes we owe to the study of young mammals.

Thus, for example, neither the elephant nor the rhinoceros are conspicuous for their hairiness, yet when quite young both are emphatically hairy. From this fact we infer that this hairiness is reminiscent of a yet more hairy ancestral condition; and the inference is justified by an appeal to the past, for we find that during these earlier 



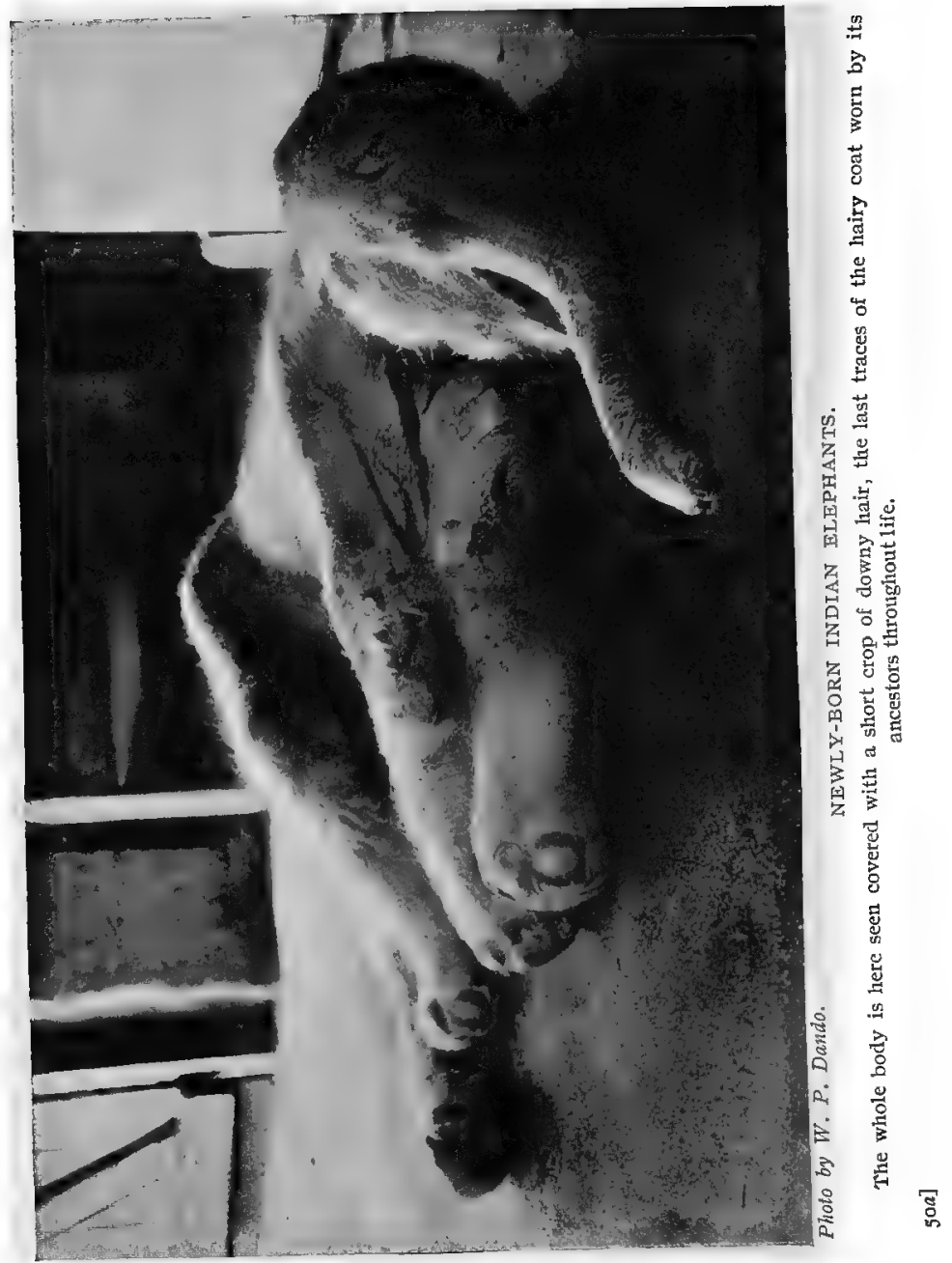




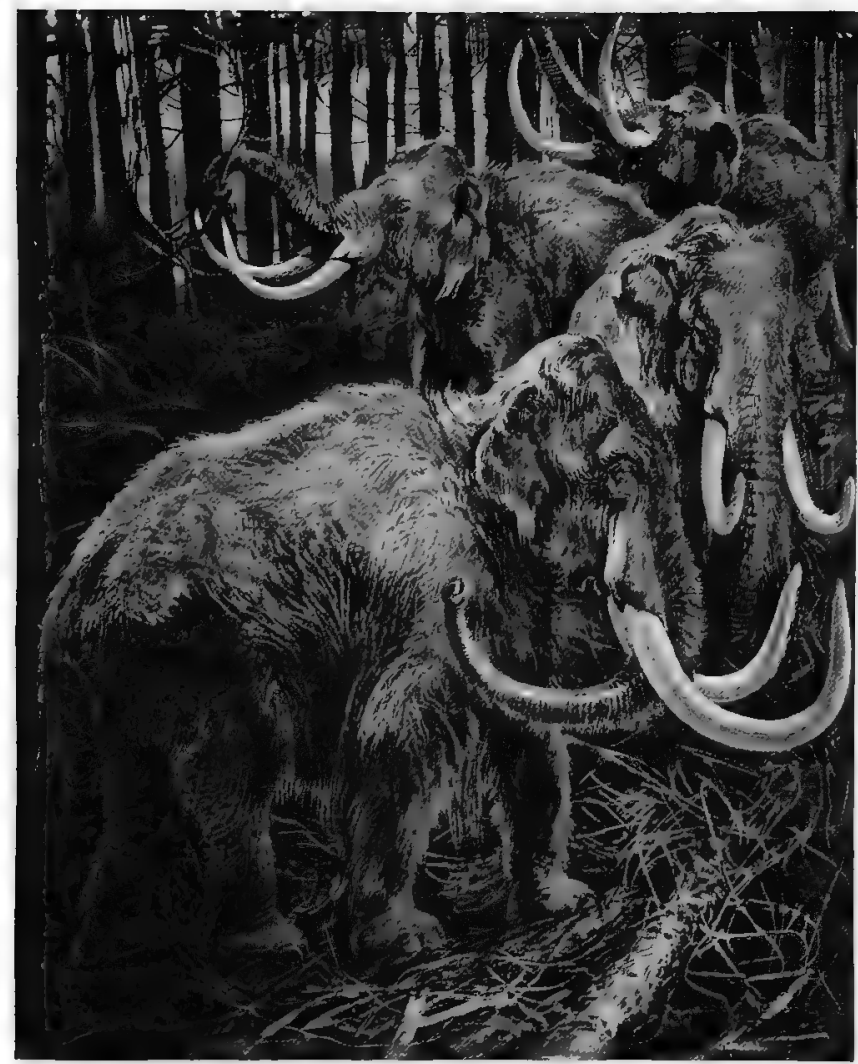

After a drawing by Sir Harry Johnston from "Marvels of the Universe."

\section{MAMMOTHS.}

The Mammoths, and probably other extinct species of Elephants, were covered in long hair. The existing species of elephants pass through a hairy stage when very young. 

days there lived at any rate two species which were clad in long, shaggy coats, and these, too, roamed over what now form the British Islands. The one we know as the Mammoth, the other as the woolly rhinoceros.

From this we may regard it as fairly certain that of the many species of elephants and rhinoceroses which have become extinct all were more or less hairy. In the woolly species the hair had become lengthened, in adaptation to the requirements of a cold climate, or at any rate of a climate characterised by long and severe winters.

The hedgehog, when newly born, is blind and naked; later a hairy coat appears, the hairs on the upper part of the body being white and flattened. These soon develop into the spines characteristic of the adult. Here we get an insight into the origin of the spines, and the repetition of ancestral characters. This history is the more interesting, because in the tenrec of Madagascar, another member of the same great family, the Insectivora, we have a reversal of this process. Young tenrecs have an armature of strong white spines arranged in longitudinal lines along the back, but before the adult stage is attained the spines are shed and succeeded by a crest of long, stiff hairs, from which we may infer that the more remote ancestors of this animal were armed with spines. And this inference is materially strengthened by the fact that in two nearly related species-the half-spined and black-headed tenrecs, these spines are retained throughout life; while in yet another species, the hedgehog tenrec (Ericulus setosus) the spiny armature has increased, covering the whole of the upper surface of the body as in the true hedgehog.

We might add considerably to the number of instances of this kind, but let two more suffice. The "Eared-seals" 
(sea lions and sea bears), or "Fur-seals," as they are variously called, differ from the "Hair-seals," among other things, in having a close velvety under-fur, which forms the "sealskin" of commerce. Now, in one of the "eared-seals" (Otaria fubata), an Australian species, this under-fur is met with in the cub alone. Thus, were the adult alone known, it would form a curious exception to a universal rule; but the young one shows us that this species, as a matter of fact, forms no exception to this rule.

Man himself forms our second illustration. His body is a living museum of relics of an ancient order of things, demonstrating more eloquently than mere words do, his kinship with the unlovely, hairy apes. In the process of that transformation which has given the "paragon of animals" his finely finished body, the loss of this hair has been a most conspicuous feature. Yet just before he makes his entry into the world he is made, for a short space, to don a vesture of hair reminiscent of the old Adam-for a short space his nakedness is masked by a dense covering of fine hairs. But these are hastily removed, so that at birth there is no witness of this lowly origin. Only in these latter days has the spirit of inquiry and the power of divination sprung up amidst us, and thereby we have made the chastening discovery that we are indeed a little lower than the angels.

For the most part the study of this evidence is possible only to those who have by special training acquired the key to interpretation; but there are one or two facts, which, ever since man came into being, have been confronting every adult in the community, though unrealised till recently. These facts concern babies in their earliest infancy. 



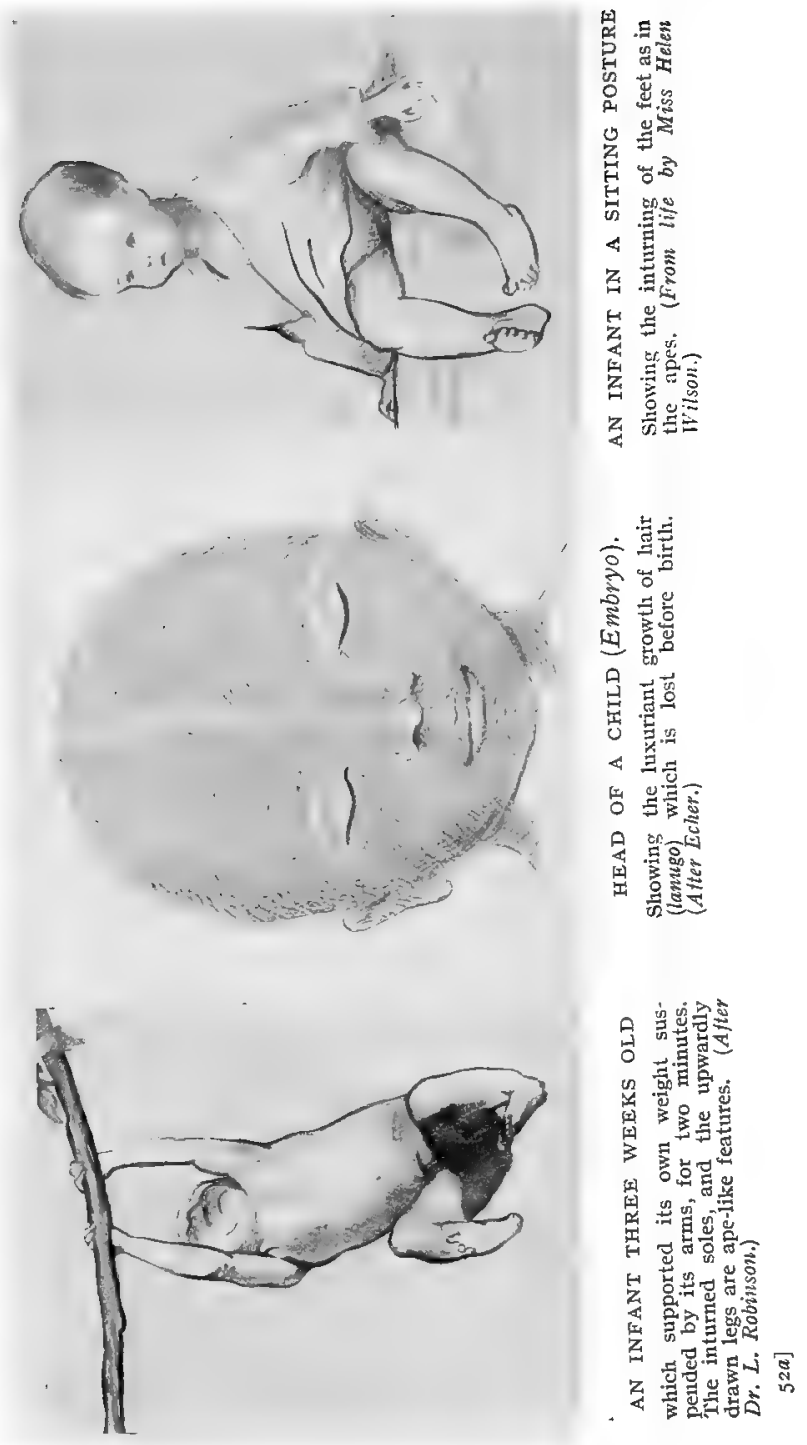




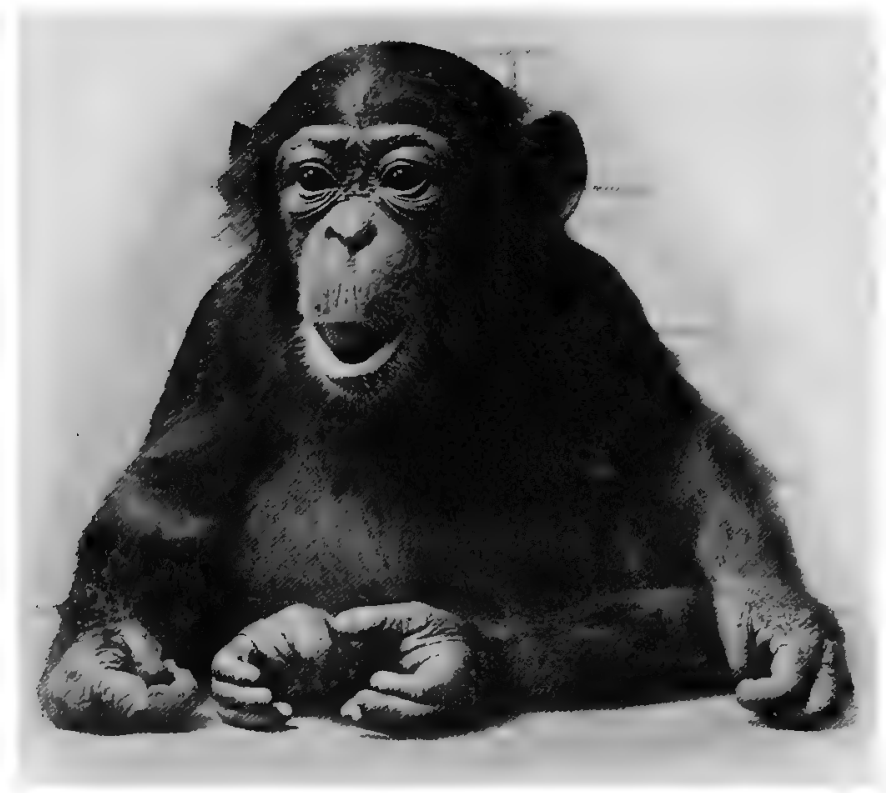

Photo by W. P. Dando.

$$
\text { CHIMPANZEE-“ JIMMY," }
$$

The foot, in the Apes, serves as a hand, as may be seen in the opposable hindtoe, which serves as a thumb. In Man this power of moving the big-toe has been lost, and the foot has lengthened; but in very young children the soles still turn inwards when sitting.

$52 b]$ 

We refer, for instance, to the fact that an infant at three weeks old is quite capable of sustaining the weight of the body when suspended by the arms. That is to say, if the hands be made to grip a rod of suitable size, such an infant will support its own weight for as long as two minutes; and during this time, it is significant to note, the legs are drawn up, the soles of the feet turned inwards, and the toes spread, instinctively seeking for a grasp for the feet, as a young chimpanzee would do.

The unexpected muscular force of an infant's grip is exactly comparable to that displayed by the young of anthropoid apes-gorillas and chimpanzees, for example -which are perforce obliged to cling to the mother's hair as she carries them about amid the tree-tops. The feet and legs of infants display an even greater likeness to those of the apes, whose forbears and ours must be accorded a common ancestry. This likeness lies in the unmistakably incurved shape of the shank of the leg, and the inturned position of the soles of the feet when the body is in a sitting posture.

Further, the feet of infants display a quite remarkable mobility in all directions, as do those of apes; and similarly the great toe in its freedom of lateral movement reminds one forcibly of the opposable hind-toe of the grasping foot of the apes and monkeys.

Later, as the child begins to acquire the art of standing alone, it will be noticed that the toes are always strongly bent towards the ground, making an unconscious effort to obtain a grip of the carpet or whatever else may be under the feet : this again is a survival of an old habit. 


\section{CHAPTER V}

\section{YOUNG BIRDS IN THE NURSERY}

IT not seldom happens that what one is at first inclined to regard as a piece of unnecessary detail in a picture proves, on a little closer examination, to be a source of inspiration giving to the whole canvas a new value. And so many of the details herein set down will, I believe, sooner or later help some one or other of my readers to look with new eyes on the Mystery-play of Life.

For completeness' sake, no doubt, in considering the matter of the case of the young among birds, we should begin with the building of the nursery, and the subsequent labours of brooding the eggs. But we are more especially concerned in these pages with the young which have attained to being, than with those which are only about to be, and hence these initial stages are only referred to when they throw light on what otherwise would be obscure in the later stages.

All things considered, we may say that the parental instincts in birds and beasts are more highly developed than in more lowly creatures. That is to say they display a greater solicitude for the well-being of their offspring than, say, the reptiles, or the fishes, or animals yet lower in the scale. But summaries of this kind must be made with reservations. The factors underlying this apparently higher ethical plane are too subtle for our present discern- 


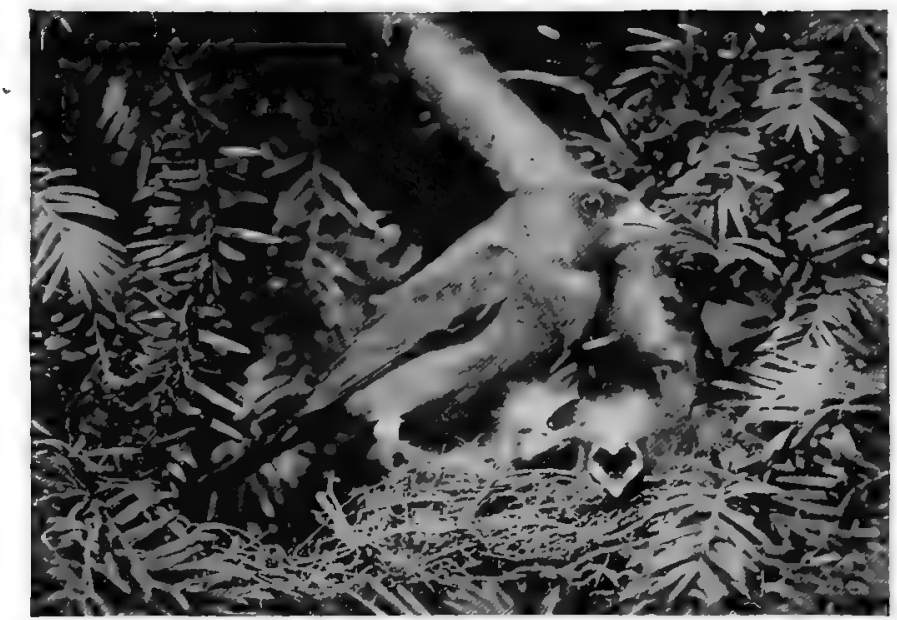

GREENFINCH AND YOUNG.

The adult greenfinch is a seed-eater, but the young are fed on insects, which form a more stimulating diet.

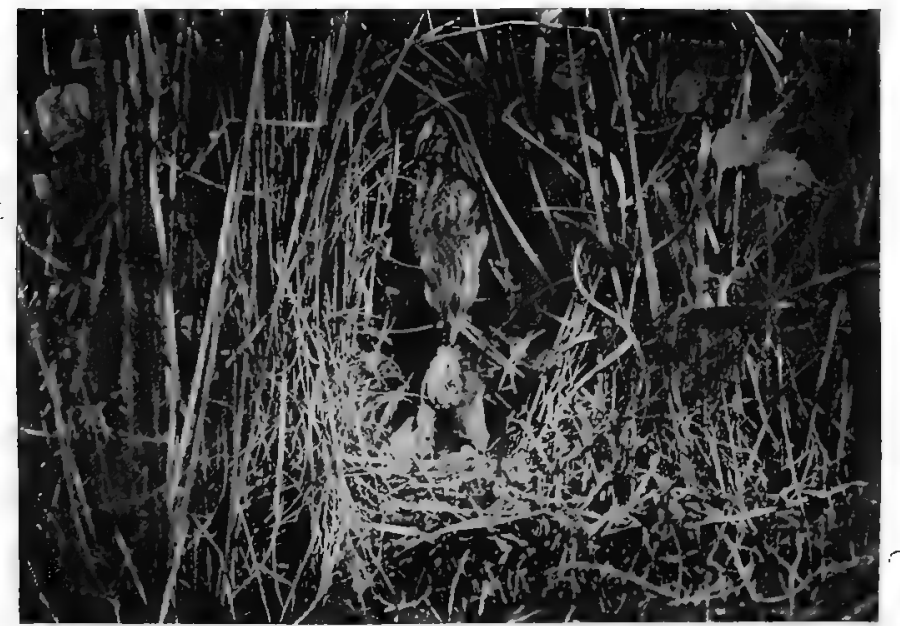

Photos by Mass E. L. Turner

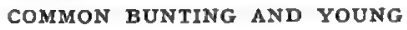

The Buntings, like the Finches, are seed-eaters, but the young are fed at first on regurgitated insects, later on insects in the raw state. 

ment and analysis, and any attempt to penetrate these mysteries must take into consideration the far more helpless condition displayed by the early post-embryonic condition of such young in comparison with those of more lowly types. This helplessness stands, apparently, in direct relation to the increased vitality shown by the adults. Yet it would not be true to say that the "coldblooded" types are more creatures of habit than the warm-blooded; nevertheless this difference of temperament must be our starting-point in picking up the trail we are all so anxious to find.

In considering all organisms, or parts of organisms, our standard of comparison is the distance they have travelled from what must have been their starting-point : in some cases this can be more or less accurately measured, in others we must set up some hypothetical standard. Where the departure from the type is slight we say that the thing measured is "primitive," that is to say, it represents, more or less nearly, the original, ancestral condition; where the departure is considerable, then, in so far, it is "specialised." A dinghey is a more primitive kind of boat than a racing skiff, which is a specialised kind of craft, capable of performing, and designed for performing, limited functions. But the term "primitive" is a relative term. The old wooden three-decker battleship is a "primitive" craft compared with the warship of to-day, but compared with the ancient trireme it is highly specialised.

On the whole, it would be better, probably, if this word "primitive" were used in a more restricted sense, and were commonly replaced by the word "generalised." But whichever word we elect to use, the idea, the mental image we"desire to conjure up, is a state of things more 
nearly approaching the ancestral state of things than is found to commonly prevail among the creatures of which we are at the moment speaking.

Thus, then, in comparing young birds we describe those which are of the precocious type as more primitive, more generalised, than those of the helpless type, and this because activity is the common characteristic of young reptiles, the stock from which the birds have descended. We have reason to believe, as has been shown already in these pages, that the young of the earliest known birds were of the precocious type, and any departure from this in the direction of specialisation is a departure from which return is impossible.

Very well. Let us then begin our survey of the nursery life, so to speak, of young birds by a review of that of the precocious types. Since these enter the world in a condition to pick up food for themselves within an hour or so after birth the parents are saved an enormous amount of labour and fatigue; for the young accompany them on their wanderings, and all feed together. Nevertheless Nature seems to put the welfare of the race above that of the individual, for while the parents escape the strain of foraging for food, with the attendant and almost ceaseless journeyings to and from the nest, things which have to be borne when the young are helpless, they are at the same time in so far relieved of parental responsibility.

And thus it is that we find in many cases the care of the family falls entirely on the shoulders of the female, as, for example, among the polygamous gallinaceous birds, and among the ducks, phalaropes and hemipodes, or entirely on the male, as in the rhea and emu. In either case this is a source of weakness to the family, 

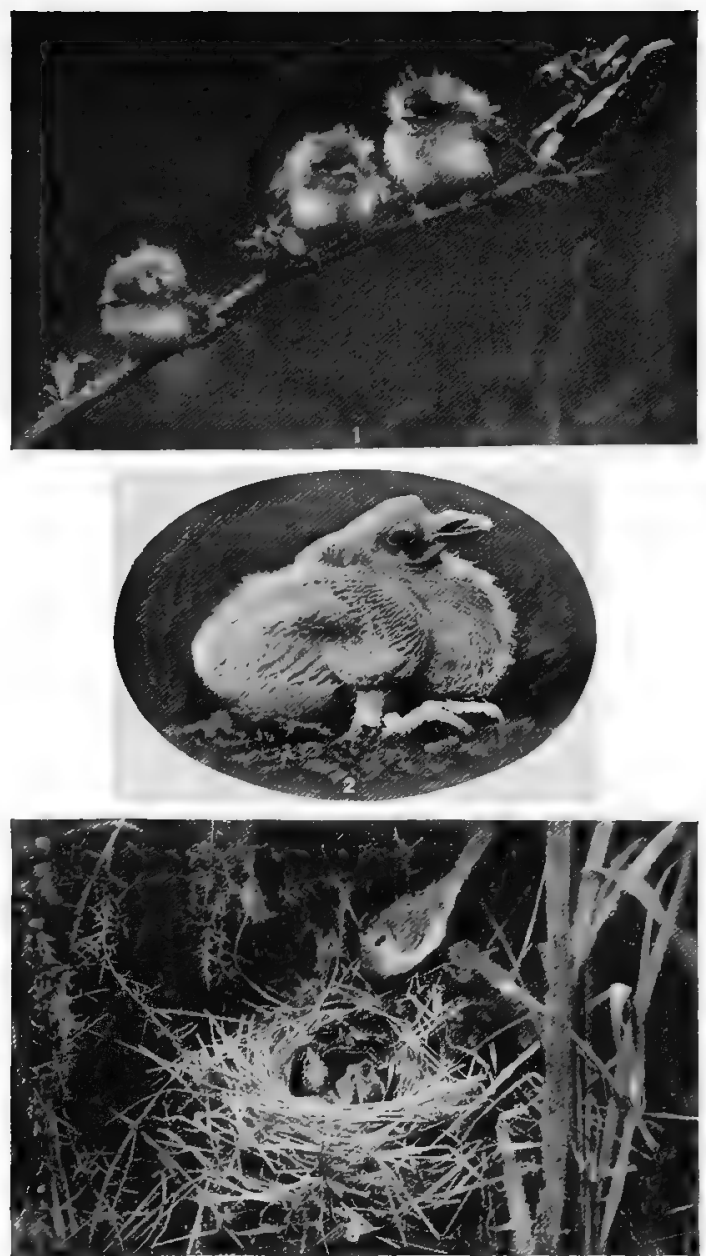

I and 3. YouNG WILLOW-WRENS (Photos by Miss E. L. Turner) 2. YOUNG PIGEON (Photo by C. Reid, Wishaw).

The Pigeon, a near relation of the Plover, is in its nestling stage reduced to the same helpless condition which obtains among the Passeres-e.g. Willow Wren-and for the same reasons. 56] 

increasing the risks to which the young, the source of future families, are exposed. But this, as we shall see, is only one of the disadvantages of active young.

All the same, when neither polygamy nor polyandry obtains-a state of society impossible when the young demand unlimited care, save only when parasitism prevails, as among the cuckoos-the parents of precocious birds are no whit behind species of more restricted liberty in their care for the young. Even where the duties of incubation fall entirely on the female, the male comes forward to bear his share as soon as hatching has taken place. Discovering choice morsels of food, he calls his mate and her chicks to the feast, taking nothing for himself, and when their safety is threatened by birds or beasts of prey, and even by man himself, he displays not seldom a high degree of courage.

In their defence, in the case of the ptarmigan, for example, both parents display extreme anxiety. The female, if flushed with her young and they do not follow at once-for they rapidly develop considerable powers of flight-flies straight away for about two hundred yards, then suddenly she shoots up into the air some twenty or thirty feet, at the same time calling loudly " $A c k$, ack, ack," apparently to distract the attention of the disturber of the peace, a stratagem described by Mr. J. G. Millais. Meanwhile the cock flies round in wide circles, finally alighting on the top of some prominent projecting rock, where he may further distract attention. Even the hill-fox is said to be attacked if the young are endangered, and doubtless many of the bolder spirits pay the penalty of their daring with their lives. Man himself will be buffeted should he approach too near the young before they are capable of flight. 
The common partridge is no less conspicuous for courage in defence of its offspring. Records have been made of partridges attacking foes so formidable as foxes, dogs, stoats, and weasels. On occasion, instead of open battle one or both parents will feign lameness, and thereby endeavour to lure the enemy from the neighbourhood of the nestlings, which, by admonitions, soon scatter widely, and if the alarm-notes of the parents continue will then lie close, concealed by the likeness of their coloration to their surroundings. Usually, when foraging for food, the male runs ahead, and stands for a few moments surveying everything. If all is well, he goes on, uttering a low "zut-zut," while the female, crouching low, follows with the brood, seeking seeds and insects at every step. To what lengths some birds will go in the defence of their young is well illustrated by the case of a wild duck (Anas boscas), which came under the notice of Sir Ralph PayneGallway. A farm-boy, so the story runs, fell in with a brood of ducklings and drove them before him to Lord Cavan's lodge, the mother following after, and keeping close the whole way. He drove them into the yard, and into a shed, but even here the undaunted mother followed, and in spite of the presence of dogs and people!

More striking still is the chain of events witnessed during the summer of 1909 by Miss E. L. Turner, whose reputation as an ornithologist removes any doubt as to possible errors of interpretation. On the occasion in question she was endeavouring to secure photographs of the final stages of incubation of a pair of water-rails. The story opens when the female returned to the nest, and, "seizing one of the already chipped eggs (chipped by the eggtooth of the enclosed embryo, preparatory to its escape), 


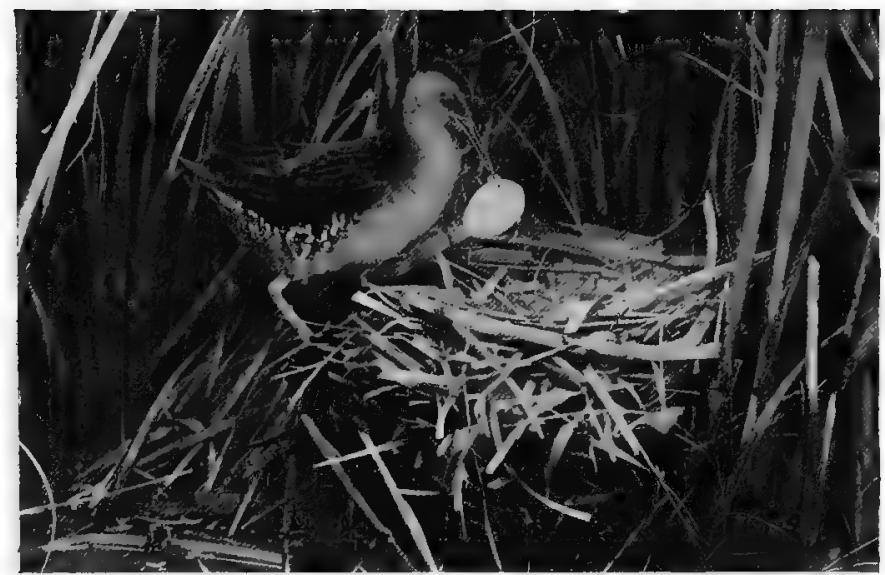

A WATER RAIL REMOVING HER EGGS AND YOUNG

(from a nest whose safety she imagined was threatened).

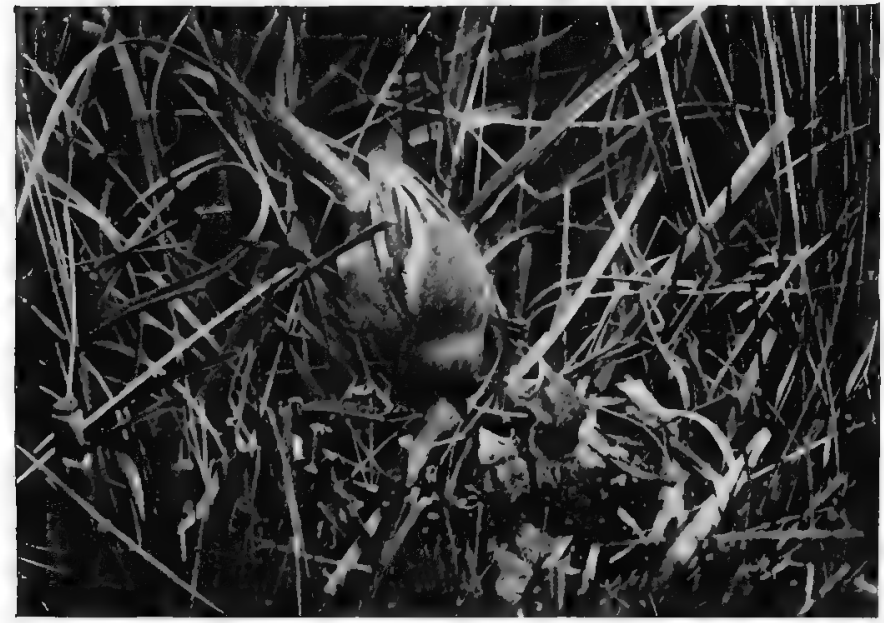

Photas by Muss E. L. Turner.

BEARDED TIT AND YOUNG.

The Bearded Tit is one of the most remarkable of all our native bircls: the young have most curiously ornamented mouths. $\left.5^{8}\right]$ 

she enlarged the hole ... and then contentedly settled down, purring and jerking her tail all the time." After an hour's vigil, waiting for the next step, the bird was aroused by the approach of a keeper, and bolted. Miss Turner then sent the keeper to examine the eggs and report progress. Two of the young were out, and he removed the broken shells. "Then the excitement began. The female returned, stood on tiptoe, peeped into the nest, and quick as thought seized a youngster by the neck and carried him off. So rapid was the manœuvre that I had barely time to secure my picture. . . . No sooner had I changed my plate than she was back again, and this time seized the second unfortunate and bedraggled-looking chick by the head, and whisked him off. She then returned for the third, not yet out of the shell, and seizing him by the shoulder removed him, shell and all, and the fourth also in like manner. There remained only one addled egg, but though this formed a very difficult task, after several unsuccessful efforts she succeeded in getting a firm grasp of it and disappeared. ... After this the bird returned twice and just peeped into the nest, and, thus apparently satisfied as to its emptiness, we saw her no more."

Evidently the stimulus to this most extraordinary conduct was the removal of the empty shells, this mysterious and uncanny disappearance arousing the direst alarm for the safety of her brood. Nestlings, as we have already remarked, on hearing the alarm-note of the parents, will flee, or hide, according to their wont. But in some cases, if taken up in the hand they will even feign death. Birds so unlike as young Norfolk plovers and young ospreys will do this: hanging limp, with eyes closed, allowing themselves to be turned about without giving 
the slightest signs of life, recalling the behaviour of the adult corn-crake.

The instant response to the alarm-note is unquestionably instinctive, as is shown by the astonishing fact that immediately before hatching, that is to say while still imprisoned within the shell, and before they have seen the light of day, the young birds will call vigorously, uttering a plainly audible "cheep, cheep, cheep." If the parents give the alarm-note at this time they secure absolute silence.

Not the least remarkable of these instances of the behaviour of young birds under the influence of fear is the case of the nestling of the Egyptian plover (Pluvianus egyptianus), which buries itself, or is buried by the parent -it is not clear which--an inch or two under the sand till the danger is overpassed. But in this connection, it is to be noted, the eggs are also buried, and this not as a measure of precaution, but as the normal method of disposal. That this is so is shown by the fact, first demonstrated by Mr. A. L. Butler, the Game-warden of the Sudan, that the area over and around the eggs is kept constantly wet by the parent, water being brought from a neighbouring pool or stream, and regurgitated upon the sand over the eggs. The success of this peculiar method of lessening, and even abolishing, the danger of detecting the eggs may well have begun in an accident, but it has now become an invariable practice, so that the first act of the young bird's life on wriggling out of the shell is to push its way up out of the grave, so to speak.

The act of burying seems to have become the instinctive, the natural response in the adult to the stimulus of fear, in regard to both its eggs and young. But it is more than probable that this same instinctive response is as perfect in the nestling at the moment of hatching as it 
will be a year hence when, as an adult, it will deposit its eggs in the sand after the custom of its ancestors for unnumbered generations. There can be no question of "imitation," or of precept, here.

Most of what we know of this strange habit we owe to Mr. Butler, and to him we look for the solution of the vexed question-Does the young bury itself at the alarmnote of the parent, or is it buried? And how is the burying done? Is the work of excavation carried out by the feet, or is the sand shovelled away by the beak ? Lizards which bury themselves in the sand do so by sideto-side wriggling movements of the body, but this could hardly be the method of the nestling bird.

Great as has been the vigilance shown by Mr. Butler, he has not yet succeeded in surprising the bird so as to wrest from it these secrets: he has only been able to draw inferences from its behaviour, and to search in the region marked down as the probable area containing the hidden treasure. Quite recently he got a step further when he succeeded in detecting the fact that the eggs were periodically watered and the method of watering; presently, no doubt, he will witness the burying of the eggs at any rate, which must often be repeated, since they are uncovered and incubated at night.

The conduct which we have just reviewed, of adults and nestlings in moments of great danger, is undoubtedly instinctive, and we may take it that such instinctive responses are kept alive for the benefit of the race by the elimination of all nestlings where they tend to fall below the safety limit. That selection has played some such part is seen from the fact that the fear of man is not included in the list of responses necessary to salvation in regions where birds have never encountered man. 
A further point in the matter of this behaviour is the difference displayed under the same stimulus under different conditions. The adult, when its personal safety alone is concerned, seeks refuge when threatened rather in its protective coloration than in flight, continuing the behaviour which served it in such good stead during its early days of existence, when fear was a new thing-outside experience. But with the advent of the young, personal safety occupies a secondary place, and the behaviour is changed, every effort being made in the interest of the offspring to draw attention to itself.

Among many species the female alone, and in some the male alone, takes charge of the young. And this does not obtain, as is generally supposed, only among polygamous and polyandrous species. The Californian quail affords a case in point. In this species the male takes sole charge of the family when they attain the age of three weeks, when the female begins the labours of rearing a second brood!

A remarkable fact in regard to the nestlings of the peacock pheasant came to light some years ago in the Gardens of the Zoological Society of London, when a brood of young peacock pheasants (Polyplectron chinquis) were being brought up by a bantam hen. These chicks would keep following close on her heels, so that they were often kicked by her as she scraped away the earth in her endeavours to provide them with delicate morsels in the shape of seeds or insects. The explanation of this strange conduct came a year later, when another brood was reared by the natural mother. Then it was found that the chicks always ran close behind her, under the shelter of her great fan-shaped tail, and only ran forward when she called them to pick up food. 
Precocious nestlings of water-birds are often borne about on the backs of their parents, as in the case of young swans and grebes, for example. In the case of the little grebe, or dabchick (Tacbybapteo fuviatilis), the young remain for many hours daily in the nest, perched on the back of the mother, and covered by her wings. During this time they are fed assiduously by the male, who has been seen to take as many as forty journeys with food in the space of a little less than an hour. Later, as the young gather strength, they are fed on the water, the portion of each, consisting either of vegetable matter, aquatic insects, or small fish, being dropped in the water and picked up by the youngsters. If suddenly alarmed when in the nest with her young ones, the dabchick takes at once to the water, her chicks following. If they are unable to keep up, she halts for a moment till they reach her, when raising her wings they creep under, and pressing them to her sides she then bears them off.

Far more remarkable is the case of the woodcock, which, when breeding at a distance from its feeding-ground, as it often does, carries its young to and fro to feed with it. That this is undoubtedly the case few will now deny, though for years the matter gave rise to the most heated controversy. This transportation becomes necessary when the nest is placed on high ground remote from small streams and swampy areas, where food for these highly specialised birds is alone procurable. When such is the case the parents carry the young down at dusk and back again at dawn. So far as can be made out, the precious burden is borne between the feet-though some who have written on this theme hold that they are pressed between the thighs, and further guarded against a fall by means of the long beak, which is placed underneath; 
so that the young ride, as it were, on a witch's broom. The fact of this periodic transportation was long since placed on record by that excellent naturalist St. John, in his delightful "Highland Sports"; and Dr. F. D. Godman, an ornithologist of wide experience, has described the same habit to me in the case of woodcocks nesting in the Azores.

It has been said that the duck known as the goldeneye, which nests in the hollow trunks of trees at a distance of from twelve to twenty feet from the ground, carries her young down, when they are ready to leave the nursery, by pressing them against her neck with the beak. This may be so, but it is certain that the wild duck, for instance -which will occasionally select the boughs of a tree, even as much as twenty feet from the ground, as a site for a nursery-adopts a very different method. Within an hour or so of hatching her offspring must be brought to the ground, and this descent has more than once been witnessed by careful observers: and in each case, by dint of loud quackings and much persuasion, she induced them, one by one, to launch themselves into space, and in no case did any suffer the slightest injury.

Among the Auk tribe, which breed invariably on ledges of precipitous cliffs, the young, though of the precocious type, have gone some way towards the nidicolous condition. They remain on the dizzy heights of the nursery till the wings have grown sufficiently large to serve at least as parachutes, when they are tempted down to the sea by the parents. This descent is undoubtedly a perilous one. The only creditable witness thereof that I know of is my friend Dr. Günther, who is an old and experienced observer. He tells me that the fledgling, displaying unmistakable signs of fear, is tempted to launch itself into 
space, and the force of the descent is then broken by the parents alternately placing themselves beneath the falling youngster to retard its pace, else death from concussion would result on contact with the glittering sea three hundred feet or so below. But occasionally, it woutd seem, persuasion is in vain. One of the exasperated parents then seizes the timid one by the back of the neck and flies down with it.

One is often asked, How do young birds learn to fly? There is no period of "learning": flight is a mode of motion which will not permit of experiments. When a youngster first launches itself into the air it must fly or die. In species where rapid evolutions in mid-air are necessary, as in the case of raptorial birds pursuing an agile prey, which must be overtaken and struck with the feet, a considerable amount of practice is necessary, and there is good evidence that instruction is also given by the parents. But of this more presently. It seems certain that before the first momentous plunge is undertaken the muscles of flight, and their nice adjustments of movement necessary to ensure efficiency, are practised by the nestling in periodical outbursts of wing-flapping at the edge of the nest.

Mr. H. B. Macpherson is one of the few men who have witnessed such practice, and his account thereof he has embodied in his book "The Home Life of the Eagle," one of the most fascinating studies in bird life ever written. He kept a nestling golden eagle under observation, in its native wilds, for five long months-long because during much of the time he was subjected to real hardship from exposure to cold, wind and rain, 3,000 feet up a mountain side. But this by the way. Not until this nestling was two months old did he begin this practice. Then, several 
times a day he would stand erect, with his legs well apart, and flap his wings vigorously and continuously for some seconds, and this exercise was repeated daily for nearly two months. Then, one morning, the mother came swirling down from the blue bearing the hind-quarters of a young rabbit for his breakfast. Settling on the far side of the great nest she flapped her wings repeatedly, as if giving him a flying lesson.

"The eaglet," he says, "now ravenous, seemed to grasp her meaning, and for the first time I saw him on the wing. For one brief second he flew clumsily towards her, then lit on his feet again at her side...." Then came the end of this most wonderful vigil. "For a week or more a heaving mist hung around the eagle's home, but at last there came a night when the white veil was swept from the hills by a wild gale from the north. At midnight the moon peered through a rift in the clouds, and, hoping for the best, I started again for the eyrie at daybreak. Like a red ball of fire the sun leaped up in the east, and the tops of the distant mountains gleamed in its rays, clad thinly in a white garb of mist. The nest was empty when $I$ arrived, and for a moment I feared that the young eagle had gone. A brief search, however, discovered him on the edge of the cliff close to my hiding-place, and the young eagle, now suspicious of any sound, flapped back slowly into the nest. A red dawn spells rain, and sure enough, before an hour had passed the sky became darkened and a steady downpour began once more.

"The hours passed slowly, and the eaglet stood beneath the ledge which had sheltered him from so many storms throughout the summer months. At length he stepped forward to the edge of the cliff and gazed intently upwards, at the same time uttering the low cheeping note with 
which he had always greeted his parents' return. It was a little harsher, though a trifle louder, than the cry with which, as a babe in white down, he had hailed their coming, and the small voice proceeding from so large a bird seemed now somewhat incongruous. Then suddenly a dark form rushed up the corrie, and his mother swung past on silent wings. She circled round and round, as though annoyed at finding him still in the nest, then settled on the rocks beyond and tried to tempt him from his fastness. But the eaglet was unwilling to obey, for his hunger had been appeased, and still the rain pattered down pitilessly outside the eyrie. She rose once more into the air and flew towards him, almost buffeting him with her wings as she swooped past the nest. Again and again she hovered round, and then a wild weird cry ran echoing round down the glen. For the first time I had heard the yelp of the adult eagle, the voice of the Queen of Birds calling to her young. Thrice was the note repeated, then again silence reigned for awhile. The eaglet cheeped continuously till, as though seized by. some irresistible impulse, he flapped to the very edge of the abyss and turned his head from side to side listening to her call. And now he, too, changed his cry, his voice seemed to break, and the adult yelp, though in a lower and feebler key, burst from his throat. The eagles called to each other, yelp answered yelp as they held strange converse in this wild mountain solitude. The young eagle gazed around him as though taking a last farewell of his birthplace, spread out his giant wings, and vanished for ever from my sight among the ledges below."

The Swallow tribe afford us another instance where the capture of food demands great agility on the wing, and this is to be acquired only by practice and precept. 
The nestling swallow, when it takes its first plunge into mid-air, is able to fly; but the capture of food on the wing is another matter, requiring co-ordination of movement and trained perception of what is good to eat. As a consequence, we find that for a day or two young swallows simply practise flight, and are fed by their parents while at rest. The next step comes when they are fed while on the wing, taking their food from the parent's beak as they hover on trembling pinions. Yet a little while and the food is dropped as the parent passes, and the young are made to catch it as it falls. Soon after this they acquire skill enough to capture food for themselves, and the parents begin their preparation for another brood.

What flight is to the eagle diving is to the nestlings of the auk tribe, grebes, and divers ; that is to say, success is a matter of life or death to them. In acquiring the art there can be no doubt but that the young are instructed by their parents. The adult razor-bill has been seen to take her nestling by the neck and dive with it, many times in succession; and as these excursions seem to be anything but pleasant at first, the young one often dives for a moment to dodge its zealous parent, thus effecting the end to be attained. Young grebes are certainly given lessons in diving, and also in catching fish.

During a few weeks spent on one of the Norfolk Broads I had many opportunities of witnessing this. The work of initiation into the art and mysteries of fishing does not seem to be begun until the young are well grown, but still in their striped, downy plumage. During the early days of life they are zealously tended by both parents. But at the time when my observations commenced the male had evidently assigned his position and responsibilities to his mate, for she alone accompanied the young, 
which were rarely more than two in number. As she reappeared after a long dive with a silvery fish in her mouth she would give a loud, harsh call to her offspring, often at considerable distance, the young and their parent having often travelled in opposite directions during the time occupied by the dive. They at once made towards her, uttering a rapid, whistling call, like pee-a, pee-a, pee-a. In their haste, if one were behind them, one could see that they were swimming higher out of the water than is the case with the adult. And this because, the stroke of the foot being lateral, rather than downwards, at each backward thrust there appeared a little semicircular splash of water, simultaneously, one on either side.

As they reached her the most vociferous apparently got the fish; which was at once popped into his mouth. Sometimes, however, the procedure differed: instead of making a continuous approach, she would traverse the distance between them by a series of short dives, appearing and disappearing all the while with the fish in her mouth; and thereby it would seem she was striving to impress on them the association of diving with food. When she at last reached them the fish would be dropped upon the water for the young to pick up themselves. If it retained enough vitality to swim feebly away, she would catch it again and lay it before them till one or other succeeded in seizing it. Immediately after she would dive, and commonly the young would at once follow her; but their submergence was but momentary, increasing as the birds grew larger. There seemed to be no compulsory diving, as appears to be the case in the razor-bill, for example.

When the food has simply to be picked up off the ground, as with seeds or insects, young birds have little to learn in the matter of securing food. The act of picking up is 
instinctive; but some discrimination and experience are doubtless necessary in the choice of food. In certain rare cases the method of feeding to be adopted by the early nestling and in later life differs completely.

In the case of the flamingo, for example, as has been pointed out by a distinguished American ornithologist, Mr. Frank M. Chapman, the very young birds are fed by the parents on a species of "clam broth," a regurgitated soup of semi-digested molluscs. As the birds gain strength, and leave the nest, they pick up food for themselves in the normal bird fashion, and, be it noted, with a beak of normal fashion. But the adult flamingo has evolved a beak of a unique description. Herein the lower jaw is deep, and has a contour recalling that of the whale-bone whales. The upper jaw forms a lid to this, flattened, and bent across its middle at a right angle. In feeding, $\mathrm{Mr}$. Chapman tells us, the movements of the beak are reversed : the upper jaw being moved with great rapidity upon the lower. This curious mechanism has come into being to enable the bird to take advantage of a source of food supply unavailable to its neighbours; thereby avoiding competition in the feeding area-since a larger population can be supported in any given area when that population has different requirements in the matter of food.

In the case of the flamingo, from the time the bird is about three weeks old till it dies of old age, this food appears to consist, in the Bahamas at any rate, entirely of a small shell-fish (Cerithium), one of the univalve molluscs ; and these are obtained after a peculiar fashion. The head is plunged underneath, and held in such a way that the crown looks towards the ground, as if the bird were standing on its head. Meanwhile quantities of sand and mud are taken into the mouth and rapidly sifted; the 
movement of the upper jaw forcing out little jets of water bearing sand and mud, and leaving the shell-fish behind. The work of selection is done partly by means of the large fleshy tongue, and partly by strainers, such as fringe the mouth of many species of ducks, and form the whalebone of whales. These shell-fish, in places, seem to lie half-buried in mud, and in such cases they are released by a curious treading movement of the feet.

Now it would seem that the changed manner of feeding, displayed by the nestling just referred to, is instinctive, for captive nestlings kept by Mr. Chapman would " dance" the rice on which they were fed from the bottom of their feeding dish in order that they might the more easily secure it. It is by no means certain, by the way, that shell-fish form the sole diet of this bird throughout the whole of its range-which is world-wide; and we suspect that vegetable matter and small crustacea will be found to comprise no small part in most cases.

Young birds of prey receive instruction first in the art of breaking up their food, and later in its capture. Mr. Macpherson, in his study of the life-history of the golden eagle, has revealed more to us, on this head, in the matter of birds of prey, than any other writer. At first his young eagle was fed on the livers of hares, rabbits, and grouse : later flesh was added; these morsels he always took from his mother's beak. But soon she began to disembowel her prey in his presence, and eating the entrails herself, would then present the carcase in such a way that he was able to pick out the liver and other tit-bits himself. Thus began his first lessons in feeding himself. On a later occasion the mother returned to the nest and found him calling for food with a rabbit's leg still beside him. Apparently thinking him unreasonable, and annoyed at 
his importunity, she tore the leg apart, ate half, and flew away with the remainder! A day or two afterwards this youngster was found with the whole carcase of a young rabbit which had just been left for him. He soon began his meal, and now, tearing the hind-legs apart as he had seen his mother do a day or so ago, he speedily swallowed the whole, bones and all.

For some time after young eagles and hawks are able to fly they are dependent on their parents for food; but under their instruction, and with practice, they at last begin to achieve success in hunting for themselves. So soon as the parents are satisfied that this period of independence has arrived, their attitude of unceasing solicitude suddenly changes to one of open hostility. As on a foe they turn on the children they have so long and faithfully nurtured and drive them forth from the neighbourhood for ever.

This change of front at first strikes one with astonishment. But a little reflection will show that therein lies the safety not only of the family, but of the race. If all the offspring reared remained in the neighbourhood, an area that will support one pair of eagles will not as easily support two, and the competition for food would become more and more severe with each succeeding generation, till sooner or later many would die from starvation. This explains why we never see more than one pair of eagles or one pair of ravens in any particular locality favoured by these birds: and what is true of these rapacious birds is true no less of other birds, though the fact is less obvious. Yet another advantage, to the race is secured by this at first sight unnatural conduct; and this is the prevention of inbreeding.

While it is a matter of common knowledge that birds 


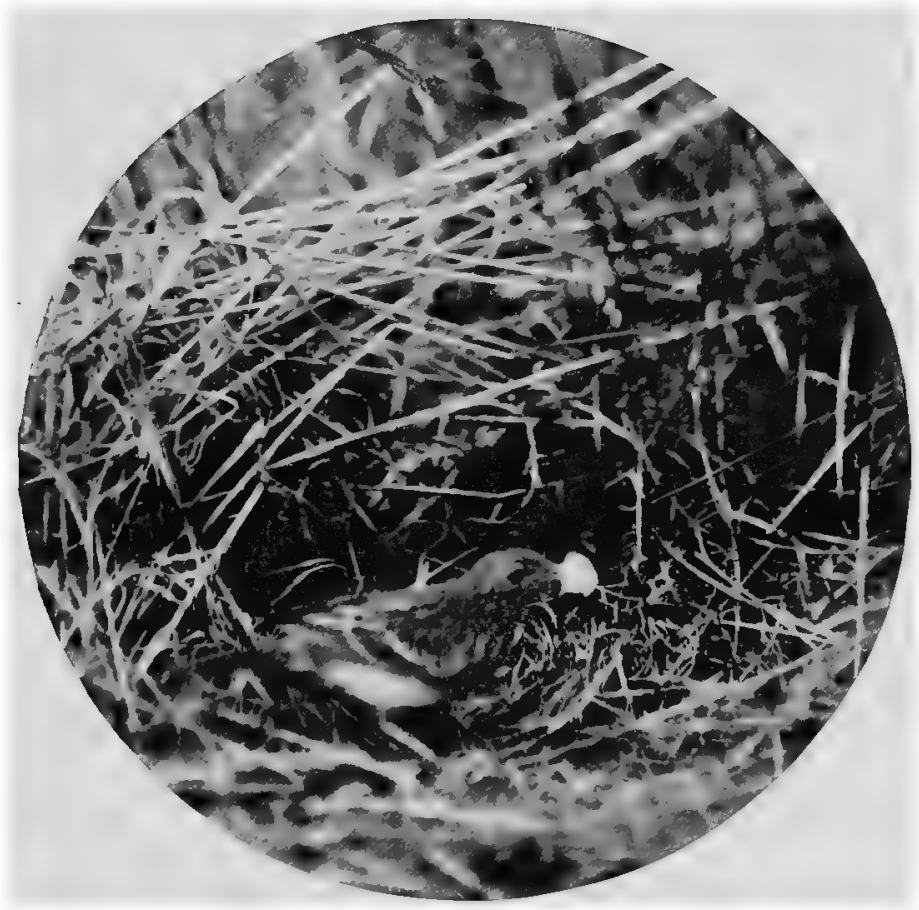

TREE PIPIT REMOVING FACES FROM NEST.

In the "Perching" birds the fæcal matter of the young is enclosed within a delicate skin, enabling the mother to remove it from the nest, and thus keep it in a sanitary condition.

72] 

display a marvellous solicitude for the welfare of their young, and instances of this have already been given in these pages, there are one or two acts of peculiar interest and significance which must find a place here, even though it is true they concern the attitude of the parents to their young, rather than the behaviour of the young themselves, which forms the theme of these pages.

The first of these acts concerns the sanitation of the nest, and in this the nestlings themselves play a very important, though unconscious part, at least in the case of nestlings of the helpless type-for example, among the Passerine birds, such as, for instance, thrushes, finches, warblers, and so on. In how far it applies to others, equally helpless, which belong to that other great, nonPasserine, but nearly related congeries of types, represented by, say, the woodpeckers, swifts, and so on, we do not know, and this because ornithologists, so far, have been more keen on taking eggs and killing adults than on observing their habits. The exceptions to this rule are happily numerous, and to them we owe the little that we know on this subject already.

The sanitary measures in question concern the removal of excrement from the nest. And the unconscious part played by the nestlings, just referred to, consists in the fact that in their case the excrement is surrounded by a white jelly-like mass enclosed within a delicate, film-like envelope or pellicle. No one has yet analysed the composition of this protective covering, nor has any one yet explained how or whence it is formed. Possibly it is secreted by the walls of the cloaca, but we cannot resist a suspicion that it may be formed within a curious pouch known as the Bursa Fabricii, and forming a capacious chamber above the cloaca, and opening into it. So far 
this chamber is of unknown function, but it is significant in this connection that it gradually disappears at the end of the nestling period, hardly a trace remaining in the adult. But whatever its origin, this envelope most effectually serves its purpose: the whole mass may be lifted up in the fingers without soiling them.

The parent birds are most particular in hunting for these capsules of fæcal matter at the bottom of the nest whenever they come to feed the young; and Mr. H. Eliot Howard, in his wonderful book on the "British Warblers," tells us that among these birds at any rate, it is the custom of one or other of the parents, in the absence of the expected matter, to tap the anus of the young bird just fed as a reminder, so to speak, of a duty to be performed. As soon as the capsule is found, it is seized by the beak, borne away from the nest and dropped, but at a safe distance, so as not to reveal the presence of the nursery to possible enemies. In many cases, however, as among the thrushes for instance, this bolus is commonly swallowed, and this not by accident, but by intent. As the young grow and gather strength, however, they relieve the parents of this work of sanitation by raising the tail over the edge of the nest and then expelling the frces.

In a number of species, however, no such facal investments are formed, and, as a consequence, in a short time the area around the actual nest becomes indescribably filthy, as for example in the case of the hoopoe and the kingfisher. But even when the fæces are not protected a certain amount of sanitation is observed : as for example in the case of the golden eagle, which periodically removes the castings of its offspring-the bones, fur and feathers, matted into a ball or "pellet," and thrown out by the mouth-bones and other broken remains of feasts, and 
soiled pieces of heather of which the nest is commonly largely composed. One wonders how much of this apparent recognition of the necessity for cleanliness is "instinctive," and how much is due to, at least a vague realisation of the dangers of dirt. In the case of the eagle, it is significant to note, these efforts to maintain cleanliness cease some time before the fledgeling is able to leave the nest, so that by the time it is vacated it has become exceedingly foul.

Precocious nestlings, as we have already remarked, are for the most part able to feed themselves, under parental guidance as to the suitability of the food. The young hoatzin furnishes an exception to the rule, but in this case it is due to the peculiar environment: the food not being furnished by the tree amid which the nest is placed. The grebes afford another exception, for here the food is furnished by small fish, necessitating a combination of activities in their capture impossible to young birds.

But with nidicolous birds the case is far otherwise. These, apparently without exception, feed their young at first, at any rate, on regurgitated food, in some cases after it has undergone a more or less extensive process of predigestion, sometimes only softened and mixed with saliva. The young of the common sparrow and greenfinch, for instance, are fed at first on regurgitated food, then on insects in what we may call the raw state, and finally on seeds of various kinds.

When the young are fed on insects, the labour entailed on the parents is enormous. A pair of Blue Titmice have been observed to make no less than 475 journeys to the nest during a day's foraging extending over seventeen hours. Small wonder is there that the labours of both 
parents are necessary to keep the brood from starvation. Among some species these insects are "pouched," that is to say, they are carried in the mouth, forming more or less of a bolus. But commonly they are held in the beak; and how birds like starlings and wagtails, for example, contrive to gather together a huge beakful of tiny insects is a mystery : for the victims must be caught with the beak, singly; and one would have imagined that the opening of the beak after the first victim had been gripped, would have meant losing the captive.

The puffins, among fish-eating birds, are alone capable of performing a similar feat, which is even more mysterious, for they will carry half a dozen small fish, the heads all ranged in one direction, from the sea to the nest with every journey. With such a slippery prey, the feat of catching and keeping six fish in succession seems impossible of achievement-but not to the puffin.

Of late years our knowledge of the Passerine birds during the trying period of rearing a family has increased immensely, and this is largely, if not entirely, due to the amazing zeal of bird photographers like Miss E. L. Turner, Mr. R. B. Lodge, Mr. W. Bickerton, and the Keartons. During hours of patient waiting, which all must undergo if they desire success, they have seen much that in all probability would else never have been recorded. In many cases they have shown that the two sexes bring different kinds of food. With the stonechat, for example, the female apparently brings small prey, generally spiders, but sometimes butterflies and moths, while the male selects large caterpillars.

Miss Turner tells an amusing story of a scene she saw enacted on the edge of the nest of a red-backed shrike. The male had brought to the nest a young bird, and 
pulling off its head, proceeded to ram it down the throat of a very importunate youngster. But the morsel was too big, and had to be readjusted, not once, but many times; and finally it was forced home with such success that the wretched bird was in imminent danger of death from choking. At this the female, who had been sitting on the opposite side of the nest, making, apparently, very sarcastic comments on the awkwardness of her lord, and males in general, suddenly seized the offending head and dragging it forth from the throat of the choking youngster, proceeded to tear it into small pieces, giving each of the brood a piece. And during this time the male looked on in what appeared to be a very subdued fashion.

Reference has already been made to feeding by regurgitation; this presents many gradations of completeness, passing from food which has merely been held for a short space in the mouth, to food which has undergone a more or less complete process of pre-digestion. The extreme in the last direction is furnished by the case of the pigeons, which for some time feed their young on a white, semifluid, curd-like matter commonly known as "pigeon's milk." This is formed within the walls of the crop, which are richly supplied with blood-vessels; but according to some authorities this peculiar food is formed by a peculiar transformation of the mucous membrane, or inner lining of the crop. But be this as it may, the young partakes of the food thus provided by thrusting its beak within that of the parent, when by a pumping action it is transferred from one throat to the other.

Young petrels are no less remarkable in the matter of the nourishment provided for their early days, since they are fed entirely on oil distilled in the parents' crop from the fish on which they live. This oil, by the way, 
is also used as a weapon of offence, both by the nestlings and adults, being squirted out from the mouth and nostrils at any unwelcome intruder on their privacy. Unappetising as such a diet may seem, and unsuitable as one would suppose it to be for tender stomachs, it nevertheless proves to possess most wonderful sustaining powers-for young petrels. At any rate such is the case with the young of the mighty albatross, whose period of infancy furnishes one of the most extraordinary stories in the whole history of birds.

Briefly, the nestling, at any rate of the species known in common speech as the wandering albatross (Diomedia exulans), and the nearly related royal albatross (D. regia), is at first fed assiduously on this oil until it becomes a mass of fat, even exceeding the adults in weight! This is the consummation apparently desired by the parents, for they forthwith cease their attentions, and sally forth to spend the winter roaming the ocean, leaving their downclad and helpless offspring to the tender mercies of fate for the space of about four months. No wonder, after this, that not more than five per cent. survive! When at last these very indifferent parents return to the nest, if fortune has favoured them, they find the youngster standing on its edge, fully fledged, but helpless still.

From the scanty information which has with difficulty been gleaned on this subject, it would seem that the young bird soon acquires the power of flight, and then accompanies his parents to sea, there to be instructed in the art of catching squids, which seem to form the greater part of the diet of the albatrosses. The story of the long fast of the nestling wandering albatross has been doubted, and further confirmation would certainly be welcome. But there is nothing inherently improbable 


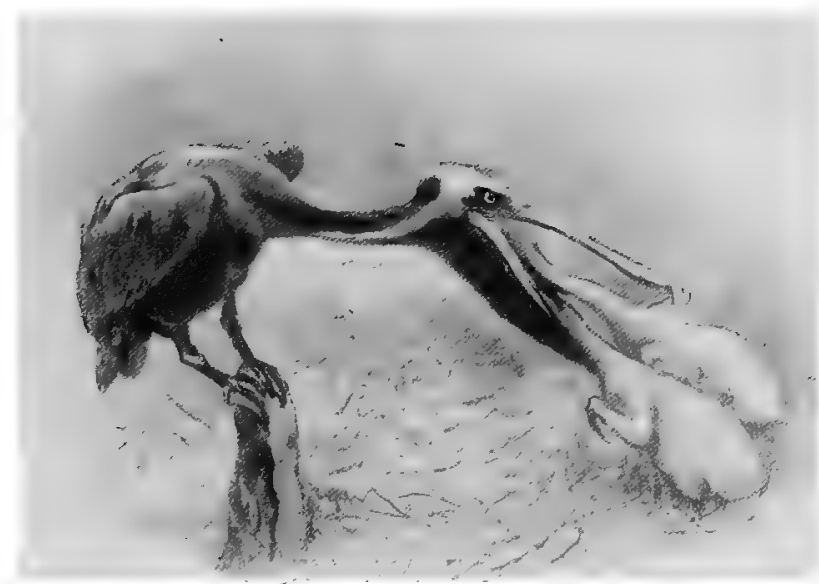

Brown Pelican feeding Young (after Chapman)

Young pelicans take their food from the pouch of the mother.

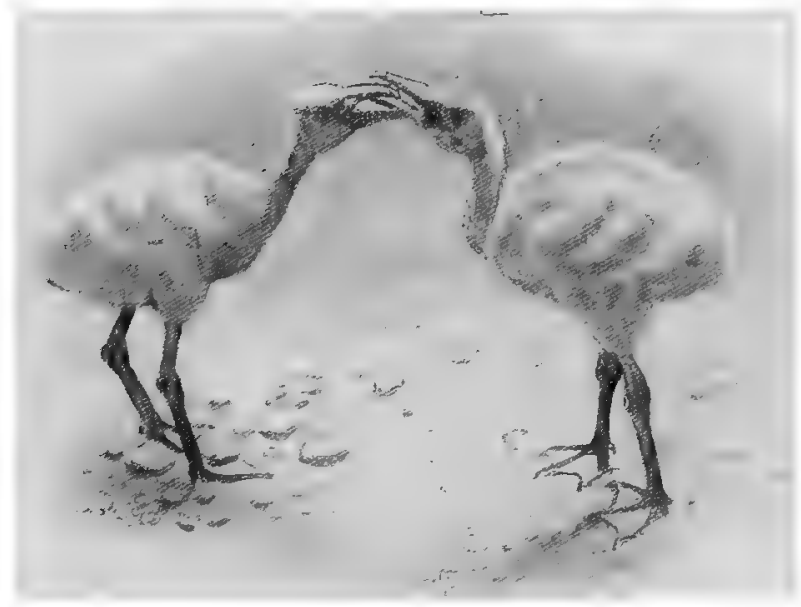

YOUNG FLAMINGOES FEEDING EACH OTHER (after Beebe).

Young Flamingoes have a curious habit of feeding one another, on occasion, or pethaps of exchanging food. 

in the account, for large numbers of animals-from fishes to mammals-make equally long fasts to avoid either extremes of heat or cold; and in every case they are sustained by accumulations of fat. The hump of the camel is a reserve of fat to be used during enforced fasts.

The nestlings of the stork tribe, and of their distant relations the gannets, cormorants, pelicans and their kin, afford some interesting illustrations of young birds , which are fed by regurgitation. Young pelicans are fed at first with partly digested fish, the meal being brought up and emptied into the front part of the pouch of the adult, and from thence it is scooped up by the youngsters. But when about three weeks old these youngsters-two or three in a brood-which have then gained their coat of woolly down, no longer need the pre-digested nourishment, and, remarks Mr. Chapman of the young of the brown pelican, they "extend their feeding excursions into the throat of the patient parent, finding there entire fish, which, in some inexplicable manner, they generally swallow before withdrawing their head. Two and even three young will thus actively pursue their search for food at the same time, and only their extended and fluttering wings seem to keep them from disappearing in the depths of the cavernous parental pouch. Not for a moment do they stop their high-voiced squealing, and the rise and fall of their partly muffled. screams indicate the nature of their success in getting food."

At times a youngster is in perilous danger of choking, having caught hold of a fish too large for his gullet: but the parent speedily comes to the rescue by removing the fish and swallowing it herself once more, to be placed later at the disposal of the disappointed 
one, when a part of its bulk shall have been reduced by the action of the digestive secretions. More often a fish will be withdrawn that is too long for the youngster's beak. In such case it is swallowed as far as it will go, the rest remaining tucked away in its growing pouch until enabled to pass on its way by the digestion of the swallowed portion.

Young cormorants in like manner thrust the head down the throat of the parent, and withdraw whatever they can grip hold of. Young herons and storks, having, like their parents, dagger-like beaks, though fed by regurgitation, could hardly thrust such formidable weapons down one another's throats. Accordingly each opens its beak to its fullest extent, and grasps the other across the cheeks; thus the mouths are brought close together and the transfer of the meal is accomplished. On one occasion Mr. Chapman saw an adult disgorge a fish at least a foot in length; and discovering this to be too big a mouthful for its offspring, it promptly re-swallowed the fish and returned to a perch near the nest to await the further digestion of the fish and its consequent reduction to the necessary size.

Ornithology is full of surprises, and this matter of the feeding of the young affords not the least of them. Thus it is curious to learn that the first meal of the young flamingo is made of the egg-shell from which it was hatched; and this is apparently for the sake of the lime it contains, just as deer eat their antlers. More curious still is the fact that when two or three broods are hatched during a season, the young of the first brood will assist in feeding that of the second-as in the case of the waterhen, for example.

But strangest of all is the fact that among young pelicans the younger broods help to feed the older, inasmuch as the 


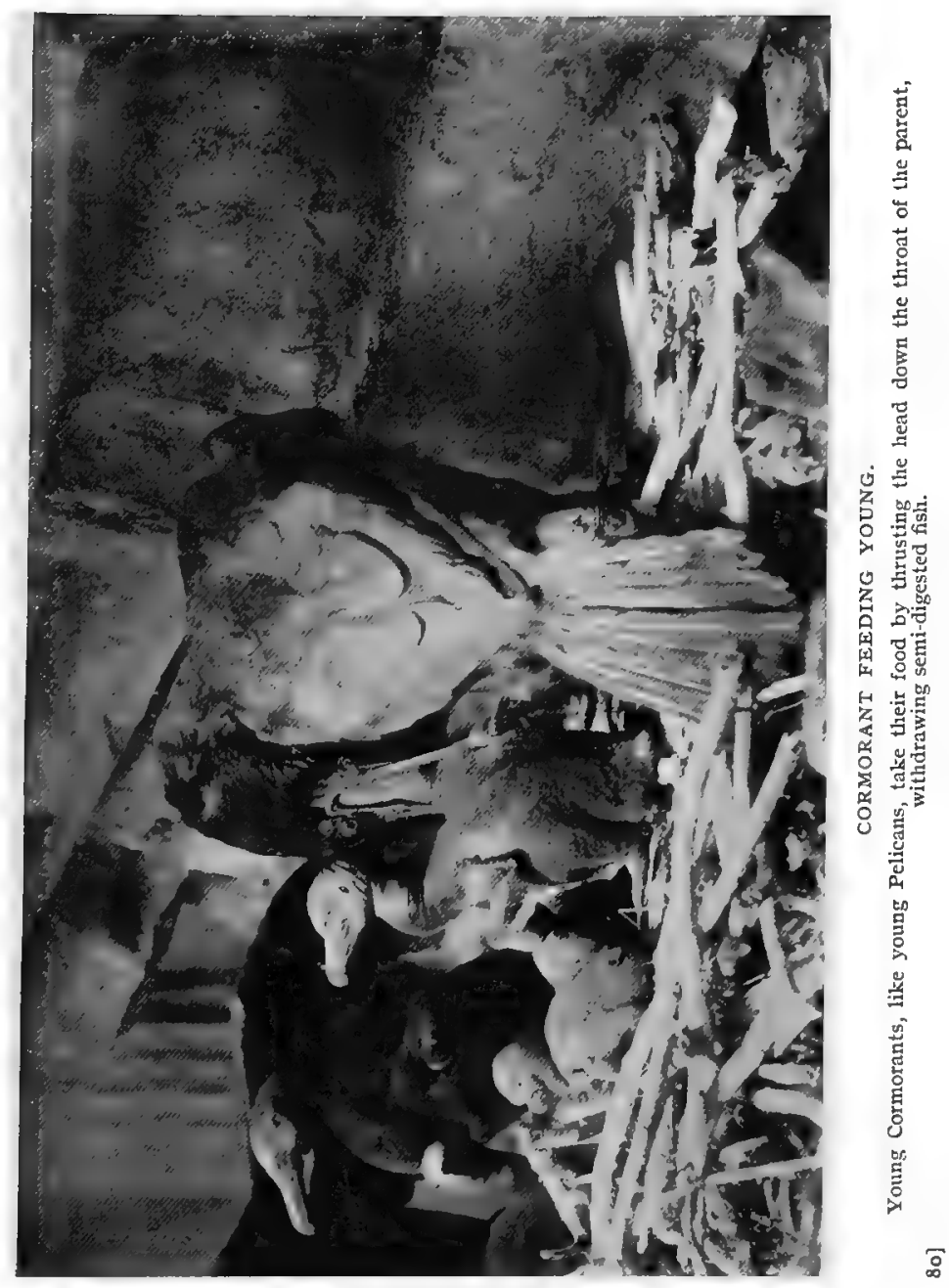



latter, whenever they get the chance, turn cannibal, and gobble up such of the younger and defenceless members of the community as have had the misfortune to come later into the world! This is the only instance known, I believe, of nestlings devouring other nestlings, and was first discovered by Mr. Frank Chapman, to whom reference has already been made in these pages.

And now we must refer to two extremely interesting facts in regard to drinking among nestlings. As a rule, so far as is known, nestling birds do not drink: but Nature is nothing if not contradictory, and accordingly she has placed those exceptions just where we should least expect to find them-in certain desert-dwelling birds, where water is conspicuous by its absence, and certain other ocean dwellers, where all the water is salt! However, these apparently insuperable difficulties are overcome in both - cases. The thirsty desert dwellers to which we have referred are the sand-grouse, and water is conveyed to them by their parents in a quite unexpected fashion. The woodcock carry their young to and fro to feed, having long legs and toes for the task of transportation. This way out of the difficulty is denied the sand-grouse, for its legs are extremely short, and its toes, at any rate in one species, are more or less completely enclosed to form a sort of foot-pad. So the sand-grouse bring the water to their young. Often this necessitates a journey of many miles. Never mind, the bird is equal to the occasion. Having slaked its own thirst at the nearest pool or stream, it proceeds to wallow therein till the whole of the feathers of the breast and abdomen are soaked. It then flies back to its chicks, which immediately run up, and drawing the still wet feathers through their beaks contrive to satisfy their thirst. 
Whether the nestlings of any sea-birds need to drink during the earlier, helpless stages of their existence is not known; but it is certain that from the fledgeling stage onwards the young, and we must suppose the adults, of the Auk tribe drink copiously, and this too of the seawater. Captive birds which have no access to salt water, at any rate when very young, soon die. But they may be reared if given enough salt water in which to swim, and of which they may drink at need.

Every now and then we get a momentary indication that the death-rate among nestlings must represent an appalling total, and herein we get an aspect of bird-life which, so far, has been entirely neglected. Here and there, however, facts have been put on record which furnish a grim picture of what Darwin called the struggle for existence. So far they seem to show that death by violence accounts for more victims than disease, to which a fairly high power of resistance seems to have been established. Internal parasites, at any rate, can be tolerated to a quite surprising extent.

I remember not long since endeavouring to save a halffledged blackbird from the clutches of a dog. I was too late, and the victim lay an instant later before me, disembowelled. From a coil of broken intestine there was plainly visible the jointed segments of the white and fearsome tapeworm, and an examination revealed two or three of these almost full grown, beside other parasites : and this before the bird had completed its first three weeks of existence!

Among species which resort to breed in large colonies this mortality is painfully obvious, but there can be no doubt that here the death-rate rises more or less in 
proportion to the size of the colony. In the first place, when helpless nestlings are being reared under these conditions rapacious birds and beasts of all kinds are attracted to the neighbourhood, finding an abundance of food at small trouble in the matter of capture. The great breeding colonies of jackass penguins and cormorants on Dassen Island afford a case in point.

Mr. J. M. Nicoll, a keen ornithologist of wide experience, visited the island in 1906, and found a "rookery" of jackass penguins (Spbeniscus demersus) estimated at nine million birds-which, be it noted, all nested in holesan enormous horde of cormorants, and thousands of gulls and sacred ibises. The gulls and ibises seem to subsist, during the breeding season, on the eggs and young of the cormorants. The gulls displayed a most extraordinary watchfulness over the sitting cormorants, seizing the eggs with a devilish dexterity if, for a moment, they were left unguarded: later they took the young. The ibises appeared to content themselves with preying on the young only, which they seized for the sustenance of their own offspring, feeding them on the entrails of their victims. The penguins escaped, owing to their choice of underground nurseries. Not so, however, the Adélie penguin of the Antarctic, which nests in the open, and whose inveterate enemy is McCormick's skua.

Dr. E. A. Wilson, one of the naturalists to the Discovery expedition, tells some lurid stories of this gull. "Hanging round the rookery," he says, "with the unmistakable look of a thief, the skua will run up to a chicken almost as big as himself, drag it by degrees away from the more crowded parts of the rookery, and then gradually worry it to death. . . . The penguin chick pipes his loudest, but the old birds standing round take very little notice. 


\section{THHE INFANCY OF ANIMAL̇S}

Occasionally one in passing will make a run at the skua and drive him off for a moment; but the chick is separated from the rest, and the old penguin has no mind to stop and shelter him, so back the skua comes to complete his work. Literally, in a rookery such as that of Cape Crozier, one cannot walk ten yards without coming on a dead penguin chick. Many of these . . are dried and flattened mummies, trodden down and flattened into the stones and guano that cover the ground. But an enormous proportion are seen to be fresh victims if one visits a rookery in January, when the skuas have not only themselves but their young to feed."

"But," he further remarks, "the skua even robs its own kind, and in a nesting colony of some twenty or thirty birds, the numbers that have apparently lost their eggs, or one at least, by robbery is always fairly large.

A further factor in keeping down the numbers of the skuas is the pugnacity of their own nestlings. Never exceeding two in number, in each nest these chicks, while yet in their downy plumage, will " fight tooth and nail with one another over some trivial bit of food, locked each to the other by every claw, and fighting with loud squalls as they use their tiny beaks." As a result of this unseemly brawling, and partly because of the tendency of the young to wander, sooner or later to get snapped up by some cannibalistic neighbour, the numbers of the skuas are still further kept in check. But for these facts probably the skuas would long since have exterminated the penguins-and incidentally themselves.

The ghoulish work of the skuas, however, only accounts for a fraction of this enormous death-rate, which seems to be due in part to the stupidity of the parents, and in part to the conditions of the environment making overcrowded 
colonies an unavoidable necessity. The sooty-grey chicks in the third week in January, Dr. Wilson tells us, were almost as big as their parents, and quite as active; they swarmed in thousands, and all were hungry, many very hungry.

"Moreover, each individual chicken acted on the assumption that every old bird, as it came from shore, was full of shrimps. On this assumption it had no choice but to run the gauntlet. Chased incontinently . . . by the unfortunate infants, the fond parent ran hither and thither with a keen eye for the chicken it had once called its own. Driven at last to bay, it could only turn to swear, and silence its persecuting followers, for the moment, with a vicious peck; but the moment its search again commenced it would be caught up and followed and worried in precisely the same way by a fresh relay of young ones, all belonging to some one else. . . . The more robust of the young thus worried an adult until, because of this importunity, he was fed. But with the less robust a much more pathetic ending was the rule.

"A chick that had fallen behind in this literal race for life, starving and weak, getting daily weaker because it could not run fast enough to insist on being fed, again and again ran off, pursuing with the rest. Again and again it stumbled and fell, persistently whining out its hunger in a shrill and melancholy pipe, till at last the race was given up. Forced thus by sheer exhaustion to stop and rest, it had no chance of getting food. Each hurrying parent, with its little following of hungry chicks, intent on one thing only, rushed quickly by, and the starveling dropped behind to gather strength for one more effort. Again it fails, a robuster bird has forced the pace, and again success is wanting to the 'runt.' Sleepily it stands 
there, with half-shut eyes, in a torpor resulting from exhaustion, cold and hunger ... a dirty, dishevelled dot, in the race for life a failure, deserted by its parents, who have hunted vainly for their own offspring round the nest in which they hatched it, but from which it may now have wandered half a mile. And so it stands, lost to everything around, till a skua on its beat drops down beside it, and with a few strong, vicious pecks, puts an end to its failing life....

"And it is not only the youngest chickens that die, but ... a very large proportion are birds which have already shed their down, and have assumed the plumage which enables them to take to the water. Why, one wonders, did these birds die on shore? The parents left them, true, but they were ready to be left; and yet apparently they never dared the water, where alone they could escape starvation. Once again the uncompromising character of Nature's laws was brought home to us, as we realised that death was the one alternative to a creature that refused to learn."

In these same desolate antarctic wilds there lives another penguin with a yet more pathetic story. This is the great emperor penguin, which never, during the whole course of its life, touches dry land; the vast icefields form its only resort when it is not braving the perils of the open water in search of food. Under conditions of such extreme severity it is marvellous, not that it contrives to maintain existence, but that it ever contrived to exist at all. One would have supposed the limit of endurance would have fallen far short of this. That the struggle for life is severe is shown by the frightful mortality which overtakes the young.

As an index of the excessive severity of the conditions of 


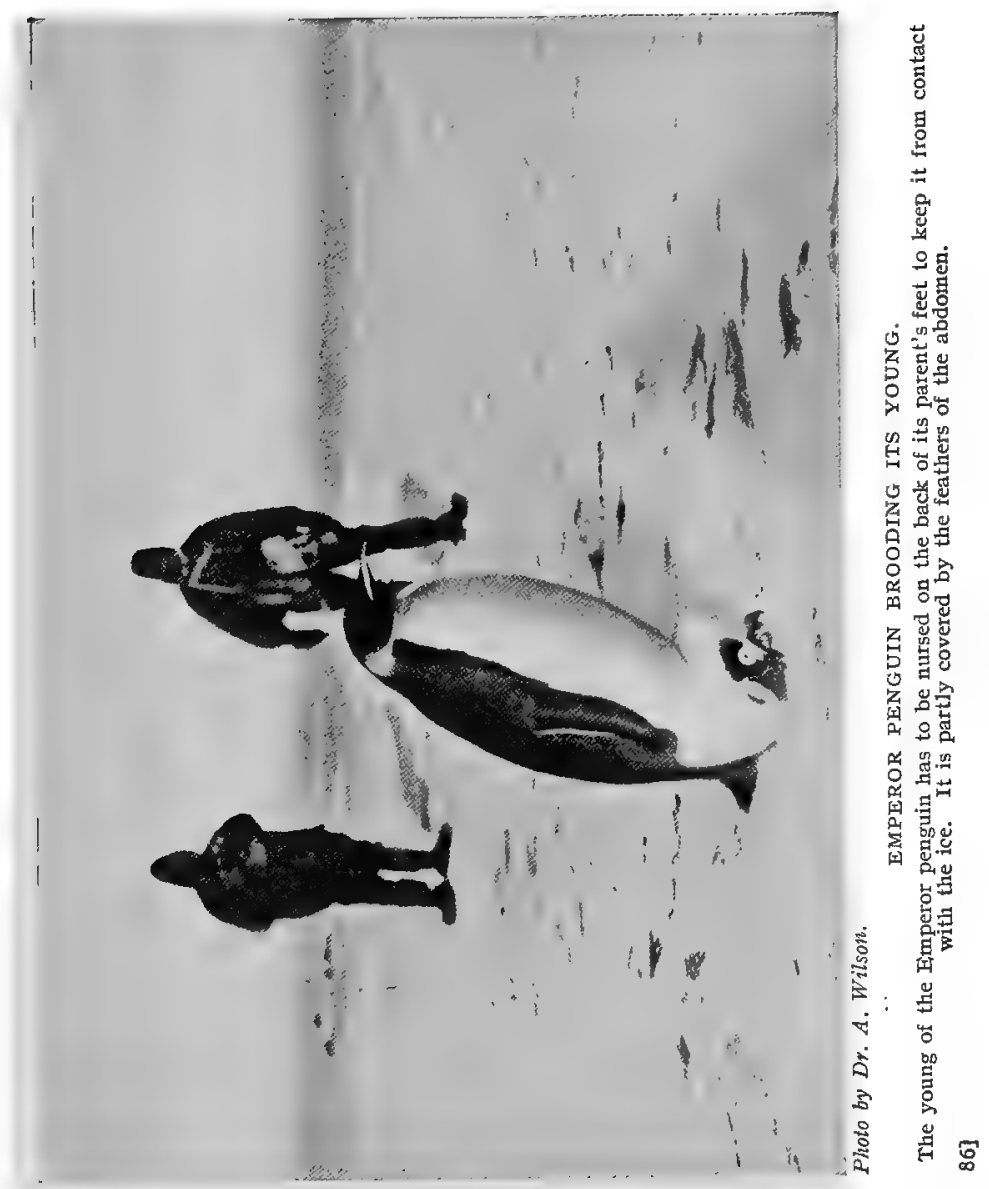




\section{,}


existence, stands the fact that incubation and brooding are impossible after the fashion prevailing among birds elsewhere. Each bird lays but a single egg. To incubate this on the ice would obviously be impossible : as a consequence, as soon as laid it is transferred to the back of the mother's feet and covered by the overlapping feathers of the abdomen, the formation of the usual "brood-spot " forming a convenient cavity for its reception. But even this singular device affords only a qualified success, for, as Dr. Wilson has shown, a large percentage of brooding birds are without eggs or young, and this loss seems to increase their desire to satisfy the cravings of the parental instinct. As a consequence, every one of these childless birds strives to adopt that of its more fortunate neighbours; leading to a competition which, of its kind and in its keenness, is without parallel.

"Incubation," Dr. Wilson tells us, "is carried out not by one bird only, or by a single pair, but by a dozen or more, which stand patiently round for a chance to seize either a chicken or an egg as the post of incubation becomes vacant." Not only do the childless females take their turn with the hens that are more fortunate, but the males also help, and so every individual has the same bare patch of skin at the lower part of the abdomen against which the egg is pressed for warmth.

"What we actually saw," writes Dr. Wilson, "again and again, was the wild dash made by a dozen adults, each weighing anything up to ninety pounds, to take possession of any chicken that happened to find itself deserted on the ice. It can be compared to nothing better than a football 'scrimmage,' in which the first bird to seize the chicken is hustled and worried on all sides by the others while it rapidly tries to push the infant between 
its legs with the help of its pointed beak, shrugging up the loose skin of the abdomen the while to cover it. . . . The chicks are fully alive to the inconvenience of being fought for by so many clumsy nurses, and I have seen them not only make the best use of their legs in avoiding so much attention, but remain to starve and freeze in preference to being nursed. Undoubtedly, I think that of the 77 per cent. that die before they shed their down, quite half are killed by kindness...."

A death-rate of 77 per cent. among the downy young alone is appallingly high : but it is a moot point whether this is not nearly approached in the case of birds which dwell within our own borders, and these are the members of the Auk tribe-the guillemot, razorbill, little auk, and puffin. These, it must be remembered, are enticed down from the cliffs to the sea before they are fully fledged, and from thence onwards till the following spring they touch no land day nor night. Through fair weather and foul at sea, far from land, they must remain, be the storms of winter never so severe. Such as fall victims, and the number must be great, rarely leave any record of their dying: they are devoured where they die by the gulls above or the fishes below them. After storms of exceptional severity, it is true, the coast may be strewn for miles with the dead bodies, not only of the immature but also of adults. The survivors, which have weathered the same storm, are survivors just because they were the "fittest," in powers of endurance, and in their ability to make the best of every opportunity, however slight, to lessen the strain of resisting the buffetings to which perhaps for days they are continually subjected.

The intensity of this struggle has been registered, so to speak, in a most convincing manner, in the skeleton, 
which in many parts has been profoundly modified in response to the demannds of this strenuous life. Some day, some inquiring student will make an effort to discover, in the bodies of the victims who have perished, some indication at any rate of the standard necessary to survival, when a new chapter on the evidences of " natural selection" will have to be written.

On the whole, young reared in nurseries on the ground suffer a higher death-rate than those reared in nests affording more shelter from adverse conditions, whether imposed by the animate or inanimate environment. Some indication of the truth of this is borne in upon us every now and then by cases of an exceptional and striking character. A few such may be cited here by way of example. Thus, Mr. Ogilvie Grant, when exploring the Salvage Islands, found innumerable nestlings of the frigate petrel (Pelagodroma marina) killed by mice, which had eaten out the victim's brain; and sucked eggs were even more numerous.

The introduction of pigs by settlers has wrought havoc among birds in many parts of the world. Thus Moseley, on his visit to Inaccessible Island, in his capacity of naturalist to the Cballenger. Expedition, found that feral pigs had nearly exterminated a penguin rookery on the south side of the island; but a few penguins remained which had saved themselves by building in holes under stones, where the pigs could not reach them.

Dr. Alcock, in his delightful book "A Naturalist in Indian Seas," relates a truly gruesome story. When landing on Pitti Island, in the Laccadive Sea, he found every foot of the ground above high-water-mark literally carpeted with young terns of two species, many living and full-fledged, many dead and rotting, and many reduced to 
clean-picked skeletons with only the quill-feathers sticking to the wing-bones. . . W We soon discovered that one great cause of the wholesale destruction of young birds was the voracity of swarms of large hermit crabs (Canobita), for again and again we found recently killed birds in all the beauty of their first speckled plumage being torn to pieces by a writhing pack of these ghostly crustaceans. There were plenty of large ocypode crabs too aiding in the carnage."

Moseley, in his "Notes of a Naturalist on the Challenger," in like manner makes mention of a grapsus crab that he saw on St. Paul's Rocks carrying off a newly-hatched tern; " but such an accident does not shock one's feelings nearly so much," he remarks, "as does the thought of full-grown young birds, nearly ready to fly out into the world and to exercise their intelligence, being overpowered by force of numbers and slowly eaten alive by animals so far inferior in the scale." But curiously enough, the nestlings of the booby (Sula leucogaster) and of the noddies (Anous stolidous and $A$. melanogaster) living in the same area as these unfortunate terns, defended themselves vigorously and successfully from similar attacks.

Nestlings of migratory species have yet another peril to face: their first attempt to convert into action the promptings of the migratory instinct. That large numbers annually fail in this is certain : many wander out of their course-from a defective instinct-as is shown by the fact that the majority of the very " rare" birds, which reach our shores are immature. Many fail in endurance and fall into the sea. But no inconsiderable proportion of late broods of young, every year, having attained the fledgeling stage, are abandoned by their parents before they are able to fend for themselves. And this because these parents find the call to migrate irresistible. 
Callous as such desertion may seem judged by human standards, it is yet justified by expediency. To go means death to the last brood, but secures the probability of more broods next year, and for many years; to stay means death to all, and thereby the safety of the species is imperilled-a point of far more importance than the wellbeing of the individual, according to Nature's rulings.

This seemingly harsh side of Nature, which might profitably be studied by many modern would-be social reformers, is well illustrated again in the case of the golden eagle. As a rule, with this species, when three eggs form the clutch the third is addled. Should three chicks be hatched, however, the third is commonly smaller than its nestfellows, and apparently less vigorous. As a consequence, the two large birds are ready to fly some days before the "runt," which is thenceforth either deserted, or fed after so perfunctory a fashion, that death from neglect and starvation soon results.

This seemingly unnatural conduct is again the best course, not for the individual, but for the race. If the parents devoted, say another week or ten days, to the nurture of the backward and constitutionally weak bird, the two strong birds would suffer materially, and might well be lost; for having now acquired the power of flight, they might, in the absence of the parents, wander away and starve, being unable as yet to capture prey. Thus two vigorous birds would be sacrificed for the sake of a weakling which in a very short space of time would inevitably perish.

Death by violence in the form of sudden cold, rain, floods, and drought add yet other factors in piling up the death-rate of nestling birds. No birds suffer more from the extremes of wet and drought than the flamingo, which 
breeds in huge colonies. Long-continued heavy rains are as bad as floods, washing away the nests and destroying the eggs of the whole community at once; droughts are no less disastrous, for then the swamp is converted into a sunbaked plain: the mud necessary for nest-building is unobtainable, and again the whole community suffers. There is no breeding that year, unless there be some favoured distant spot yet within range. If the drought comes later, after the young are hatched, matters are still worse, for every one must perish.

Than the flamingo no bird better illustrates the meaning of the word "specialisation," or demonstrates the perils arising therefrom. The curious fashion of its beak renders it incapable of any changes in the matter of food: during seasons of plenty it has no competitors but its own kind, but seasons of adversity convert this advantage into a penalty. Too much or too little, as we have just remarked, in the matter of rainfall are matters of life and death; for without a plentiful supply of mud no nests can be built, while an excess of rain may sweep away every nest in the colony and thus the continuation of the race for that season, and perhaps during a succession of seasons is rendered impossible, and thereby the very existence of the species is menaced. If by any other cause their numbers have been reduced, such adverse conditions may end in extinction.

Few realise how much birds suffer from an excess over what we may call the optimum temperature for the species. That they do so may be one of the underlying factors which have so far escaped students of the mysteries of migration. Those who have pondered this question must often have been struck by the fact that such of our native birds as winter in the tropics are driven by some mysterious factor 


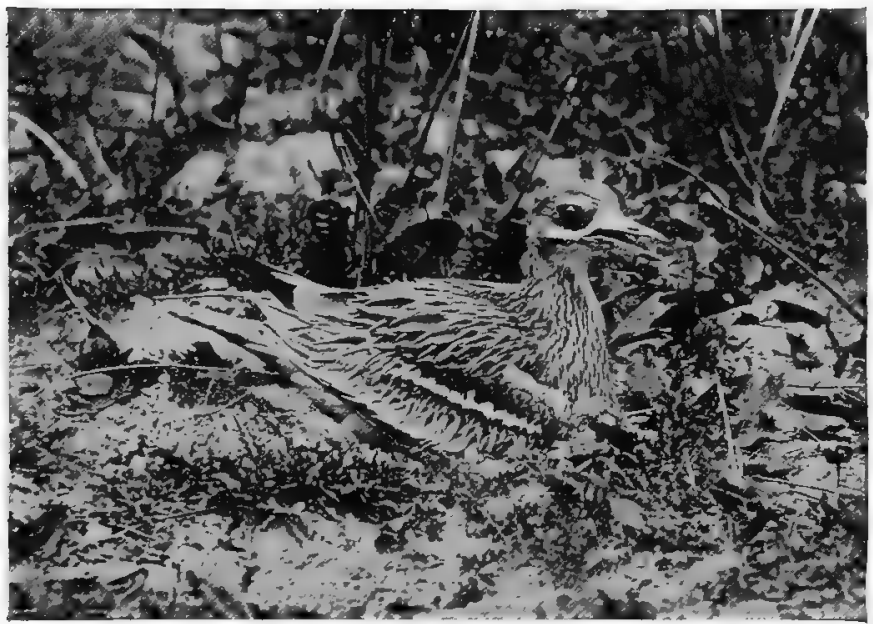

STONE CURLEW BROODING, DISTRESSED BY HEAT.

That brooding birds are greatly distressed by long exposure to the sun has only recently been discovered. The open mouth and uplif ted feathers are sure signs of this.

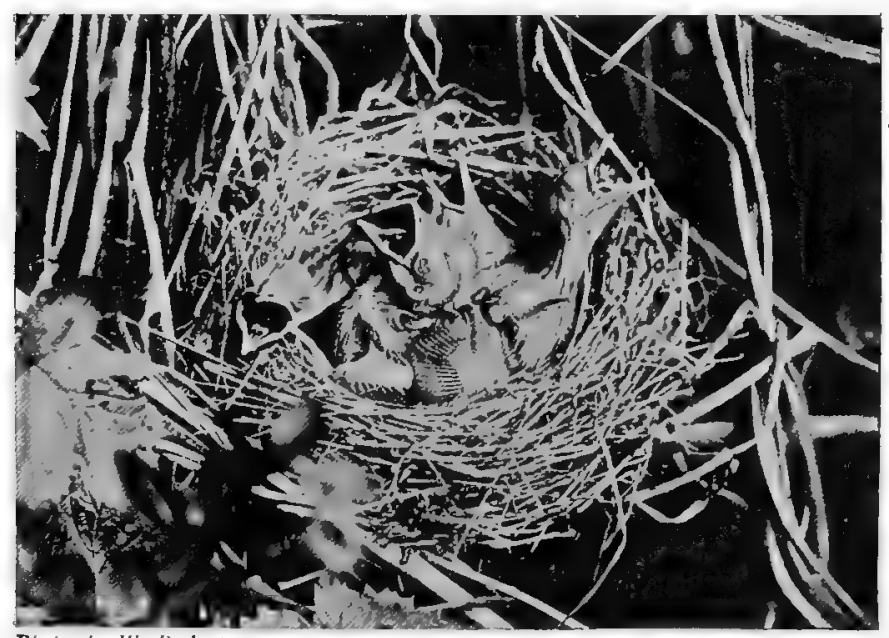

Photos by $W$. Backerton.

YOUNG BLACKCAPS DISTRESSED BY THE HEAT

Nestling birds suffer no less from too much sun. The birds in this nest are panting for breath. 92] 



\section{YOÚNG BIRDŚ IN THE NURSERY}

to leave what has proved a land of plenty to return to us in spring. It may be that they are obliged to seek areas of lower temperature for the sake of the young, though this was not the original cause of their migrations, as I have endeavoured to show in my "History of Birds." But that is another story. Here I propose only to state a few facts in regard to the effect of heat on nestling birdsfacts which we owe to the observation of two of our most expert and enthusiastic bird photographers, Miss E. L. Turner and Mr. W. Bickerton. They have shown that birds when incubating, as well as nestlings, are greatly distressed by prolonged sunshine.

Their observations show that birds of all kinds are thus affected, the snipe sitting in the sedge-grown swamp, the warblers in the reed-bed, the heath-haunting Norfolk plover, and even such birds as guillemots and razor-bills crouching on ledges of cliffs overhanging the sea, where one would suppose that a breeze, if even a light one, was always present. The signs of distress are evident enough, for the birds sit with their beaks open and all the feathers of the body raised up to admit as much air as possible to the body. Nestlings such as warblers, on these sultry days, evidently suffer much, packed close as they are, and as soon as fledged they will endeavour to find relief by climbing on to the edge of the nest.

Many of the birds of prey, like the honey buzzard, the golden eagle, and the osprey, make special efforts to protect their young from the sun's rays. The honey buzzard goes so far as to surround the nest with a bower of leafy boughs, and as these wither they are renewed. This device may well have arisen from the custom which prevails, at any rate among some of the Accipitres, of adding fresh leaves to the nest lining, as if from æsthetic 
motives, since a sprig of holly with berries on has been found in the nest of the golden eagle.

The eagle and the osprey, and their kin, afford the necessary shade for their panting offspring by standing over them with outstretched wings, and a similar plan is adopted to shield them from rain, so fatal to young birds that even ducks adopt the same device.

So far nothing has been said of disease in its relation to nestling and young birds. As a matter of fact there is little to be said, for the matter has never formed the subject of scientific inquiry. But so far as the evidence goes disease plays a very unimportant part in the deathrate of young birds. There are, however, exceptions to every rule: and records of an "enormous" mortality in colonies of the black-headed gull have been made more than once, during recent years, though no effort seems to have been made to ascertain what particular form of disease was the cause of this. Coccidiosus and "gapes" are probably the most common cause of outbreaks of this kind. Records of a mysterious disease affecting the feet of young terns, causing the toes to slough off, have been made from time to time, but the mortality from this source appears to be of a negligible quantity.

One turns with a sense of satisfaction from the contemplation of the ravages of death by violence, and death by disease, to the subject of play among nestling birds, though unhappily on this theme our ignorance at present is immense. The information that is to be gleaned from published records is of the scantiest. Such as it is, however, it is the more valuable because it affords us an insight into the play of birds of widely different kinds.

Mr. Macpherson's wonderful monograph on the golden 
eagle contains some most interesting facts in regard to the eaglet which he had the good fortune to keep under observation during so many weeks. This bird began to play, and perforce by itself, when about six weeks old. After a meal one day " the eaglet walked round the edge of the nest and began to play. He behaved exactly like a child thrown upon its own resources for amusement and compelled to fall back on any handy article as a toy. Small pieces of heather in this case served his purpose, and he appeared to enjoy lifting them from the ground and throwing them down again. $\mathrm{He}$ also picked pieces of moss from the rocks, and only desisted from this occupation after having completely stripped the walls of his eyrie. He then began to make the most comical grimaces, turning his head sideways and upwards at the same time. His manœuvres were so diverting that I had much difficulty in restraining myself from laughing, and a chuckle which escaped me involuntarily on one occasion caused him to stiffen momentarily into an attitude of attention." These games were apparently repeated daily during the next six weeks-until, indeed, he took his first flight and vanished, after the fashion we have already described.

Mr. H. Eliot Howard, in his remarkable work on the British Warblers, remarks that young sedge-warblers, just after leaving the nest, are very playful, "... their games sometimes taking the form of a tilting match. Three take part; two sit on convenient twigs facing one another, and the third, from his central position, might almost be called an umpire. Numbers one and two then lower their heads, each in anticipation of the other moving; one of them-call him number one-then springs into the air, and darts at number two; number two dodges and 
occupies the position vacated by number one; each of them then faces round ready to continue the fray, the changes of position becoming quite rapid.

Dr. C. W. Andrews has similarly recorded the play of young frigate-birds observed by him on Christmas Island. "Groups of them," he says, "could often be seen near the coast stooping to the water, one after the other, to pick up leaves and other floating objects, and then dropping them, apparently practising the method by which their parents obtain their food, which consists of surface-fish and cephalopods."

I myself have seen mallard "flappers" at play. The antics these indulged in were most interesting. Now they would race along the water, flapping their wings violently the while, and now they would suddenly take short dives; and these diversions would be varied by much bathing, sending the water all around in showers.

It is significant to note that, so far, wherever play among young birds has been observed, the parents have been absent, generally and perhaps always, on food forages. Thus, then, we may assume that play is an instinctive activity. Among the mammals, as we have already pointed out, play seems always to reproduce just those activities which later on are matters of life and death. Among the birds one cannot, so far, discover so close a relationship between the unreal foreshadowing of what is to be, and its accomplishment. The frigate bird would certainly seem to conform to this rule, but what are we to say of the play of the eaglet and that of the little sedge-warblers? Here is a field which badly needs cultivation. Perchance some reader of these pages may be tempted to take up the matter. 


\section{CHAPTER VI}

\section{COLORATION}

IN the matter of their coloration, as well as in the structural characters of their external covering, young birds differ more from their parents than is the case with the mammals, exceptions apart. As touching this matter of structural characters more will be said presently; but for the moment our conversation must be of coloration, wherein, it is curious to note, birds present what is really a singular agreement one with another: an agreement which goes far to show that among birds, in their early post-embryonic stages of development, a longitudinally striped livery has been almost universal, at any rate for an immense period of time, if not throughout practically the whole course of their evolution.

There will be no need to labour this point; it will become manifest, and that speedily, to all who care to take the trouble to examine the facts. We shall find, too, in this review, that the facts in regard to this coloration are to be divided into two groups. In the one we shall have all that pertains to the general coloration of the body as a whole, wherein the dominant note is the obliteration of ancient birthmarks; in the other will be found a series of records of the evolution of new characters in the form of head ornaments.

It is significant that among nestling birds this longi- 
tudinal striping is most completely developed, or perhaps we should say has been most completely retained in the $\mathrm{emu}$; for if we take the condition of the skull, and of the palatal bones in particular as our standard, whereby to measure which birds have departed least from their ancestral heritage, the emu must be regarded as standing nearest to the ancestral birds, or, as is more commonly expressed, is the most "primitive" of living birds.

As a reference to our illustration will show, the nestling emu is marked from one end of the body to the other by a series of alternate black and white stripes, of about equal width: though on the crown of the head these stripes have broken up to form an irregular "marbled" pattern. In the newly hatched bird irregular black stripes and spots invade even the beak and legs, but these soon vanish. In the young of the nearly related cassowary the stripes have disappeared from the head and neck, while on the trunk they have assumed the form of relatively narrow white stripes on a ground of dark brownish black. In the rhea chick the reduction of the striping has proceeded still further, but the primitive pattern is still there. The ostrich, while retaining a number of stripes on the neck, has lost those on the body, or rather they have become disintegrated by the curious transformation which the down feathers have undergone, the ends having become produced in broad, flattened, and twisted horny ribbons resembling shavings; thus the black areas of these feathers have become broken up, and present a mottled appearance of black and buff. The grebes cannot be regarded as even remotely related to the ostrich tribe, yet the nestlings of these birds display a precisely similar coloration, alternate stripes of black and white running the whole length of the body. 


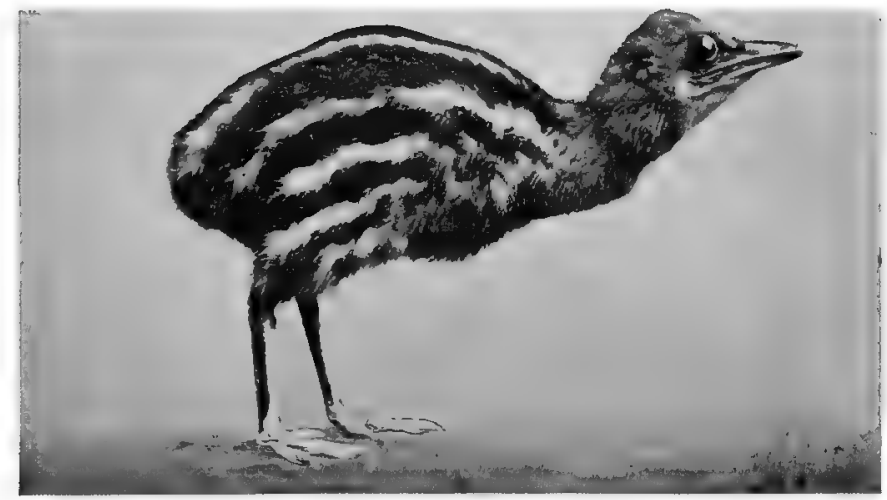

NESTLING CASSOWARY.

The Cassowary is a near relation of the emu, but in the nestling stage it is less completely striped, and in the adult more brightly coloured.

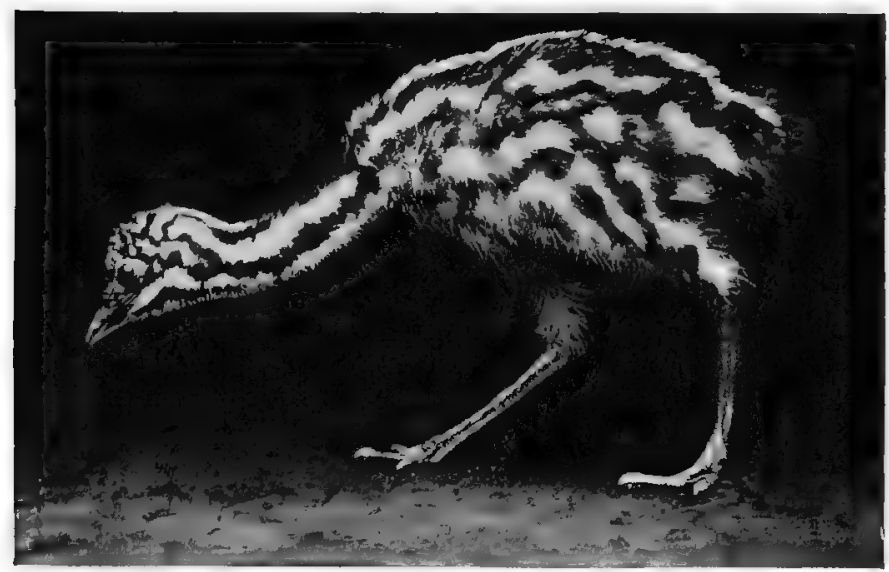

NESTLING EMU.

The Emu is one of the oldest types of living birds, and in the nestling stage it is one of the most completely striped.

98] 

The young of no other birds have retained this striped livery in such completeness as those of the ostrich tribe and the grebes: in all other cases the stripes have been reduced in number. Further, in more or fewer members of each group wherein striped nestlings occur, a gradual process of disintegration of the stripes, and the consequent evolution of a new livery, is met with: the stripes breaking up to form a mottled garb, and the mottlings disappearing to give place to a covering of uniform hue. The gallinaceous birds well illustrate this. The nestling cassowary and Argus pheasant, for example, are conspicuously striped, while the young of our native game-birds display varying degrees of the disintegration of this pattern.

The plover tribe exhibit the same phenomena, though well-defined stripes are the exception rather than the rule. They occur, however, in the young of the aberrant jacana, for example, which displays strongly defined black stripes set off by a bright chestnut, while in the Norfolk plover, or thickknee (Edicnemus), the ground colour of the body is of a pale buffish grey, which is relieved by two narrow black lines along the back, and a median line along the head. In the young common snipe three very distinct white lines stand out against a background of a rich dark chestnut. Among the gulls, which are to be regarded as near relations of the plovers, stripes are rare. But they are seen in the young of the little tern (Sterna minuta), which displays a median and two lateral black stripes on a background of sandy-buff. In the common gull (Larus canus), a median and lateral stripes are still plainly visible, and the neck, too, is spotted, as in the emu.

In most of the plovers the downy plumage is mottled: in the young Kentish plover, for example, it is of pale 
buff powdered with black; in the young knot, white, mottled with grey. And from this we see the stripes becoming more and more broken up, and the mottlings growing less and less, until at last, as in the nestling skua, the coloration is of one uniform hue.

That the nestlings of the crane tribe were originally striped seems certain; and traces of this ancient dress may be seen, for example, in the young Japanese crane, wherein a broad but nebulous median band runs down the back; while the young of the great bustard bear a close likeness to many young gulls, being pale-coloured with dark mottlings. The nestling rails are all either black or nearly so, but the young of the black-tailed waterhen (Microtribonyx ventralis) in certain lights reveal traces of a median and two lateral stripes-a fact which is of considerable significance.

The ducks, geese, and swans are a particularly instructive group in this connection. The typical livery of the downy young is now dark brown as to the upper parts, relieved by a white line above the eye, a white bar along the arm, and two short white bars on the side, behind the wing, and these, originally, obviously formed a continuous lateral stripe, indicating an earlier striped condition. The sheldrakes show a still further approximation towards the earlier coloration. But the downy young of the geese and swans, on the other hand, are of a uniform white or grey hue, having departed still further from the primitive coloration.

Such might well have remained the sum-total of our knowledge in regard to the coloration of the early stages of the Anatidx. But fortunately one or two primitive and little known types have survived which demonstrate, in a very practical manner, the soundness of the con- 


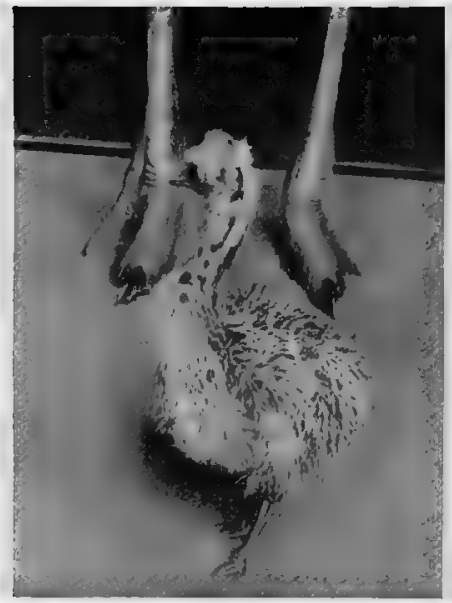

YOUNG OSTRICH.

In the nestling ostrich the stripes persist only in the neck; those on the body have been broken up by the curiously transformed down-feathers.

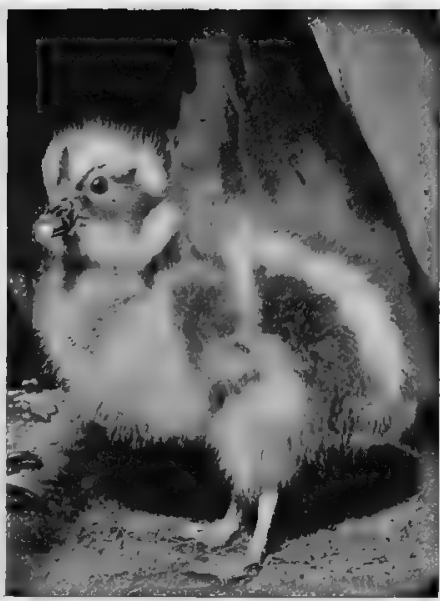

CEREOPSIS GOOSE.

The young of this goose, and its near allies, alone among the goose-tribe, display a striped livery.

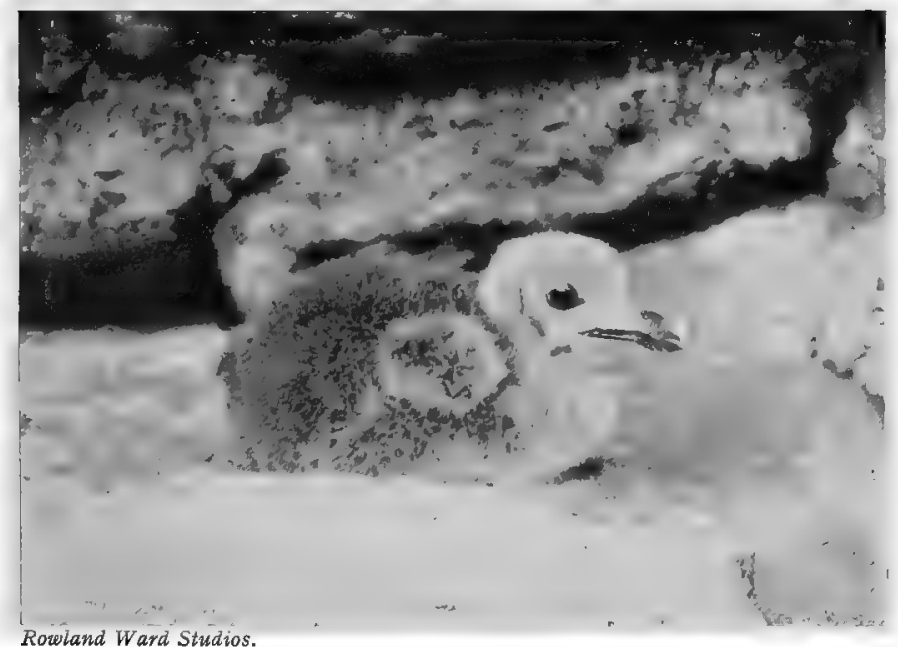

NESTLING RAZOR-BILL.

The young Razor-bill has the head buff white, the back dark brown; in its near relation, the Guillemot, the neck is striped during the nestling stage. I00] 

tention here made that the young of the Anatidx were originally more completely striped, and therein agree with what obtained apparently everywhere among the birds in more remote times. These links with the past are furnished by the geese of the genera Cereopsis and Cloephaga, and in the ducks of the genus Merganetta. Herein, as may be seen in the appended photograph of a nestling of the Cereopsis Goose, a median and two lateral stripes are present, making a close approximation to what obtains among the gallinaceous birds.

Nestling birds of the nidicolous or helpless types are all, when they have any covering at all, uniformly coloured, with the single exception of the young osprey, which is longitudinally striped. This fact is not only an extremely interesting, but also an extremely important one; for it justifies the inference that when several members of any given group afford a contrast with the remaining members of that group in possessing some character which we have reason to regard as a survival from past times, we may regard those individuals which lack this index as members which have lost that character.

The osprey, the upland goose, and the ducks of the genus Merganetta are illustrations of the truth of this. The nestlings, which exhibit striped liveries in varying degrees of perfection, are valuable indices which indicate the process of disintegration, and at the same time the evolution of new characters. The osprey is not a common bird; it might well have become exterminated by now, without leaving a record of the ancient livery worn by its young, in which case we should have assumed that the raptorial birds must be left out of the account in so far as striped liveries are concerned.

Nestling birds, then, in their coloration display three 
phases-a longitudinally striped phase, a spotted or mottled phase, due to the disintegration of the stripes, and a uniformly coloured phase representing a plumage from which these spots and mottlings have faded. This process of transformation is also met with among the mammals. But among birds, it will be noted, transverse stripes are conspicuous by their absence: this is true at any rate for nestlings, though some adults display a more or less distinctly transversely barred dress.

What relation, it may now be asked, do these phases of coloration bear to the present-day needs of their wearers ? Are they merely survivals from a remote past, displaying a more or less marked tendency to disappear; or do they fulfil any useful purpose? Do they answer to ancestral adult or to ancestral nestling liveries? All the evidence, surely, goes to show, as we have already indicated, that in discussing this matter we must consider the striped plumage as answering to an ancestral livery, whether of an adult or nestling stage, and the mottled and whole-coloured nestling plumages as derived therefrom by the gradual disintegration of the stripes. Where the stripes have preserved their integrity in existing nestlings we must hold that they still serve the purpose for which they were originally evolved. That is to say, the conditions of existence which determined the evolution of a striped livery ages ago are essentially the same to-day.

Similarly, the coloration of young birds, such as terns, gulls, and plovers, may almost certainly be regarded as having been evolved-by the disintegration of stripesto harmonise with their surroundings. They are "protected resemblance" or "procryptic" colours, investing the wearer with a veritable mantle of invisibility. How perfectly these mottlings blend with their surroundings 
is well shown in the accompanying photographs of young gulls, terns, and Norfolk plovers. It is obvious that a striped livery in the case of the gull or tern would be the reverse of protective, while the sandy hue and narrow stripes of the Norfolk plover, on the other hand, form a most effective disguise, the stripes bearing a close resemblance to the sparse blades of grass or other vegetation such as is met with on sandy wastes.

It may be objected that the persistence of stripes in the Cereopsis goose-when all other Anatidæ have lost them-and in the young osprey, when all other Accipitres are whole-coloured, and commonly white-and the black mantle of the young coot, which may be reared in a nest within a yard of that of the young grebe, which is striped, throws a strong element of suspicion on the "protective resemblance" theory. The reply of those who have studied these nestlings in the field would be that whatever may be the ultimate interpretation of these puzzling exceptions, the reality of the protective value of this coloration in the case of grebes, gulls, terns, plovers, and so on, is incontrovertible.

Before we can cite the exceptions as disproving the rule we must gather more facts as to the life-history of the birds which present them. One fact must not be lost sight of in this connection, and this is that ancestral characters may persist long after they have ceased to fulfil their original function, if by their presence they do not imperil the well-being of the animal which retains them. These persistent and apparently non-significant colours indicate, surely, either that they are useful or that the coloration in such cases is a matter of no importance, so that the ancestral livery has not been eliminated as harmful by natural selection. 


\section{IO4}

\section{THE INFANCY OF ANIMALS}

Every whit as puzzling are the phenomena presented by the birds, both of the precocious and helpless types, wherein the coloration is of one uniform hue, either white, dark grey, or brown. In the birds of prey, the owls, the swans, the storks, and some Passerine birds-that is to say, among birds not even remotely related, and which are reared in totally unlike surroundings-the downy cloak is white. In the cormorant the youngster is enveloped in a mantle of dark brown, in the gannet at the same age, and reared within a few feet of the same spot, it is pure white. Young petrels reared in holes wear a sombre cloak of brown or slate colour, where one might expect to find a mantle of white, such as is worn by the young albatross reared in the open. Similarly, young penguins, whether lying under a burning sun, as in the case of the Cape penguin (Spheniscus demersus), or crouching low on an Antarctic ice-field, as in that of the King penguin, are dark brown; but the young of the Emperor penguin, as befits him, wear an ermine robe, relieved by a black mask.

Are we to regard the loss of the pattern in such cases as due to the cessation of natural selection? But if so, why do we meet with a pigmented down in some cases and a colourless down in others? The loss of patterns in the down of such nestlings confirms the contention that such patterns are useful when they obtain. In other words, if the patterns, stripes, or mottlings are for concealment, such devices would be useless in birds confined in nests-for the latter are often conspicuous objects, and predatory animals well know the nature of their contents. That the down of nidicolous birds which are reared in exposed situations-such as the ledges of cliffs, as in the case of the auk tribe, cormorants, and gannets 


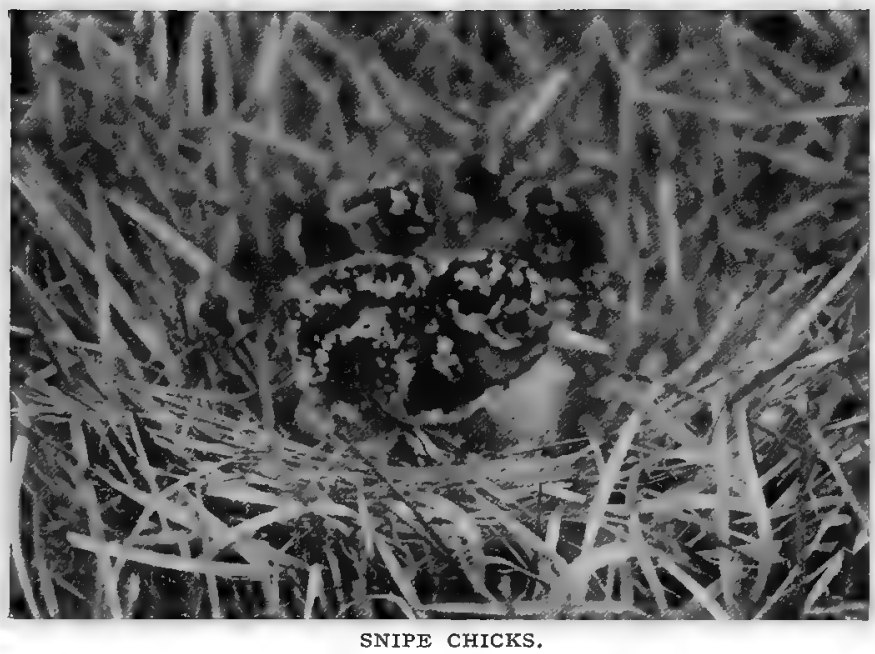

The buffish white, and black, stripes, and the rich chestnut ground colour which make up the coloration of the young snipe cause it to harmonise most perfectly with its surroundings.

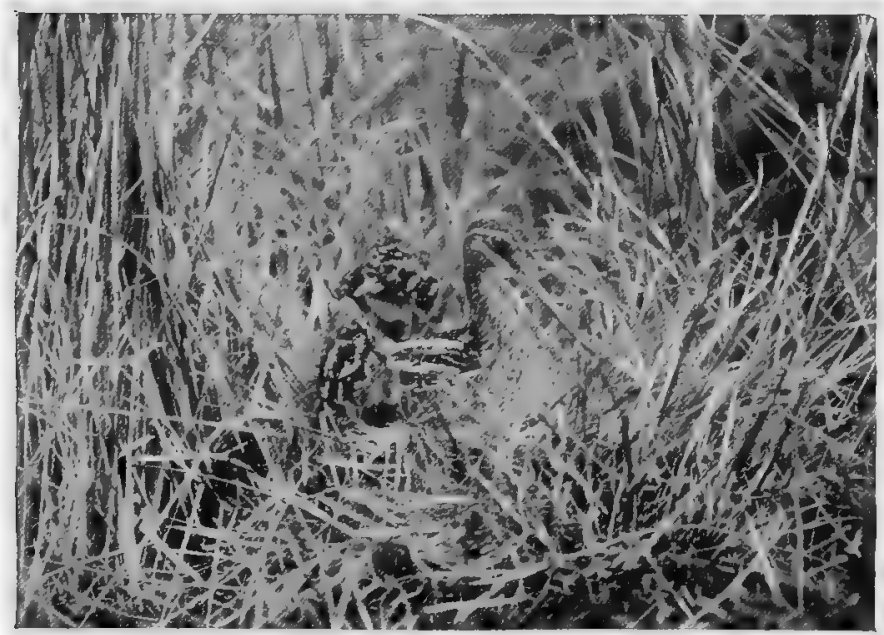

Photos by Miss E. L. Turner.

YOUNG SNIPE ON THE BACK OF THE MOTHER.

The protective value of the striped liveries of the adult and nestling snipe is well shown by the difficulty one has to find the birds in this illustration.

I04] 

-is patternless goes to show that the nature of their environment has rendered a patterned down useless. That is to say, its disappearance is due, as we have suggested, to the cessation of natural selection.

The naturalist Eimer contended, some years ago, that longitudinal stripes were developed to afford harmony with the reed-like foliage, such as formed the dominant type of vegetation in the remote past: while the development of spots marks an adaptation to the requirements of foliage which casts spotted shading, as is the case with the plant life of to-day. But if this be true, then transverse, or tiger-like, and not longitudinal stripes should traverse the bodies of the young of grass- and reed-haunting birds and beasts, and the survival of longitudinal stripes shows that the correspondence between the markings and the type of foliage need not be a close one, since longitudinal and transverse stripes must both have been developed to harmonise with foliage creating alternate shafts of light and shadow. Thus his arguments would deprive this coloration of the very virtues he seeks to claim for them! If his views as to the inter-relationship between the stripes and the environment are correct, then vertical striping must be regarded as the more primitive pattern, and this seems contrary to fact.

Sooner or later the further question is bound to arise: "Is the coloration of the nestling to be regarded as the survival of an ancestral adult livery, or of an ancestral nestling livery? And what are the factors which determined the evolution of this particular pattern?" To such questions we have as yet no answer.

Finally, it may be pointed out that, while in the mammals the coloration of the young commonly differs not at all, or only in slight degree, from that of the adults, in 
the birds this agreement between adult and early postembryonic stages is conspicuous by its absence. This discrepancy, this lack of agreement, however, is not without its significance.

When we turn to the later, but still juvenile, stages of growth we find a very close and peculiarly instructive relationship between the coloration of the juvenile and adult stages. Comment has been made already on the fact that no hard-and-fast line can be drawn between embryonic and post-embryonic characters, and the history of the development of antlers indeed shows that neither can we draw a dividing line between young and adult stages. The facts which are now to be reviewed still further demonstrate this overlapping of the juvenile and adult phases of growth.

To begin with, it is not by any means easy to distinguish between the last of the downy stages of development and that which is marked by the assumption of the first garment of typical contour feathers. But since the determining factor is in this case a structural character, we must return to this point later.

For the moment, be it noted that the plumage which answers to this first garment-as distinguished from the characteristic downy feathers of the nestling stage-bears a close resemblance to, or may be indistinguishable from that of the adult, in so far as coloration is concerned. The importance of this fact, in the present connection, turns upon the character of the adult plumage, which commonly displays a series of evolutionary phases such as leaves no room for doubt as to the reasonableness of the recapitulation theory: which has been generally discredited because allowance has not been made for disturbing factors introduced by the necessities of development. 


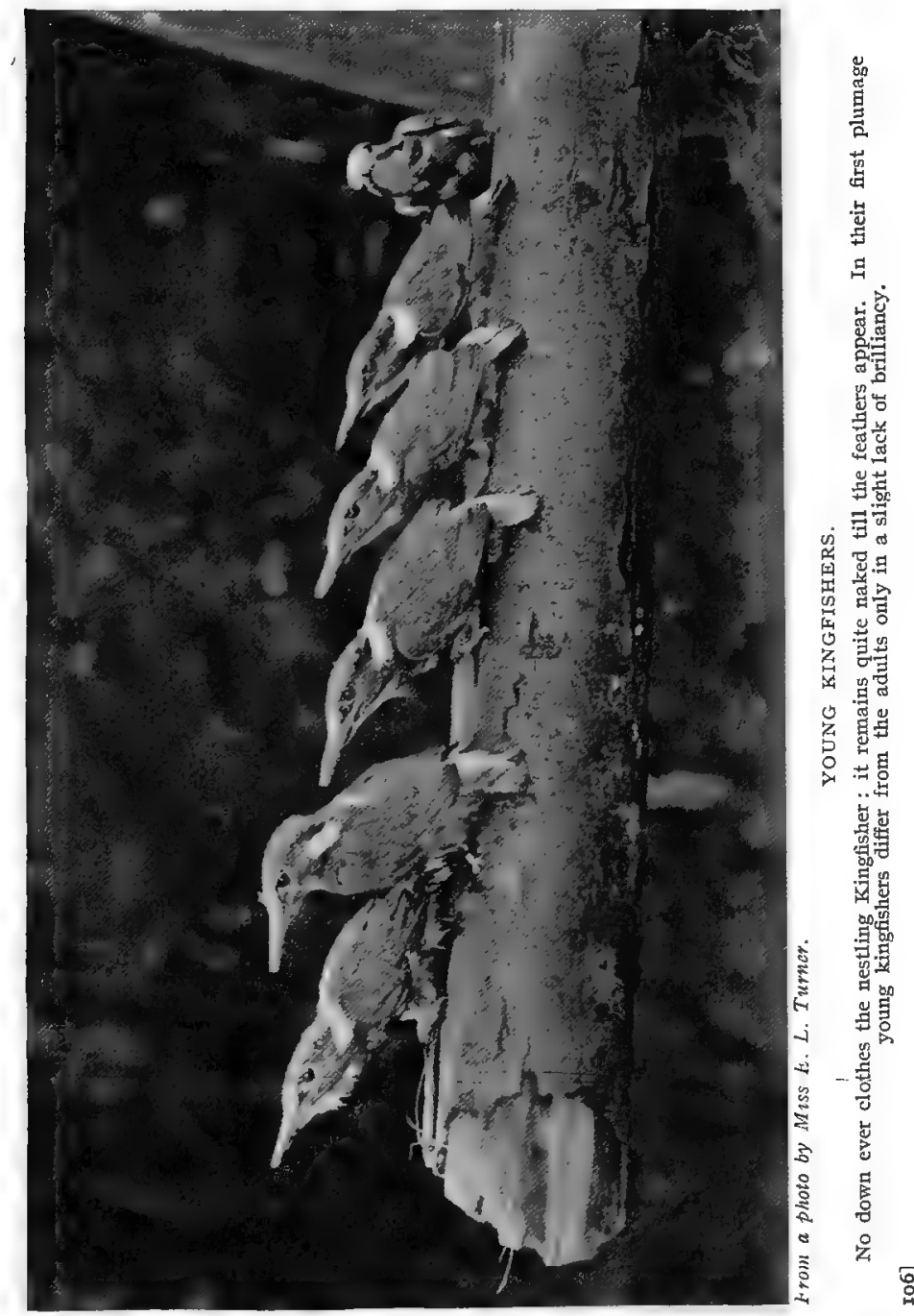



Briefly, we must regard species which have a dull brown coloration relieved by striations of a darker or lighter shade as having retained, at least approximately, the ancestral coloration. Herein male, female, and young all resemble one another. But in many species the male is distinguishable at a glance by his more ornate, more brightly-coloured dress; the measure, by the contrast, between his plumage and that of his mate, and offspring, is the measure of the distance put between himself and the ancestral coloration. And this evolution of splendour follows a very definite course, which can be traced with tolerable certainty if a careful study be made of any considerable number of species.

The evidence so far collected seems to show conclusively that the evolution of resplendent plumage begins in the form of a periodical increase of brilliancy assumed by the male at the breeding season, and is apparently due to "hormones," or certain mysterious secretions of the sexual glands. This more gaily coloured dress eventually becomes the permanent characteristic of the male. Next we find a similar change taking place in the female, until she becomes, in many cases, almost or quite indistinguishable from her mate.

In such cases, as for example in the common starling, the young wear a distinct and soberly coloured livery, answering to the earlier dress worn at first by both parents, then by the female only. In other cases, as for example in the golden oriole and crossbill, we find male, female and young each with a distinctive dress of increasing degrees of brilliancy, that of the male being brightest. Here we conclude that the young wear what was comparatively recently the dress of the adult female. Finally we have a host of instances where both adults and young 
are coloured alike-as, for example, in parrots and kingfishers, the crows, and the robin. Thus we arrive once more at a phase where offspring and parents wear a livery of the same hue, but of a higher plane of development.

Reference has been made more than once already in these pages to the fact that longitudinal stripes are, in order of sequence, followed by the development of spots, and occasionally of transverse bars. We find the same sequence of events in young birds. The goshawk and the peregrine falcon, for example, have the breast marked by dark longitudinal stripes during their immature stages, in the adult these stripes give place to narrow transverse bars. Similarly, among the Passeres, there are numerous families wherein the first plumage is distinguished both by stripes and spots, the latter being the more conspicuous, the stripes forming but narrow lines down the centre of the feathers. The thrushes, robins, and flycatchers may be cited as examples of this type of plumage : and that this is an ancestral plumage is attested by the fact that there are certain species of thrush, of the genus Geocbicla, wherein both adults and young are soberly marked; and without doubt these birds have retained the plumage once common to all those species which now, as adults, are so differently garbed.

Our common gannet furnishes us with another curious fact about the coloration of young birds. The downy nestling is white: in due time it assumes a black livery heavily spotted with white. Later this is discarded, and a white livery is once more assumed, relieved only by a delicate buff tinge on the head and neck, developed during the breeding season, and black quills. This loss of pigment during adult life is rare among animals.

The sweet reasonableness of the view that the juvenile, 

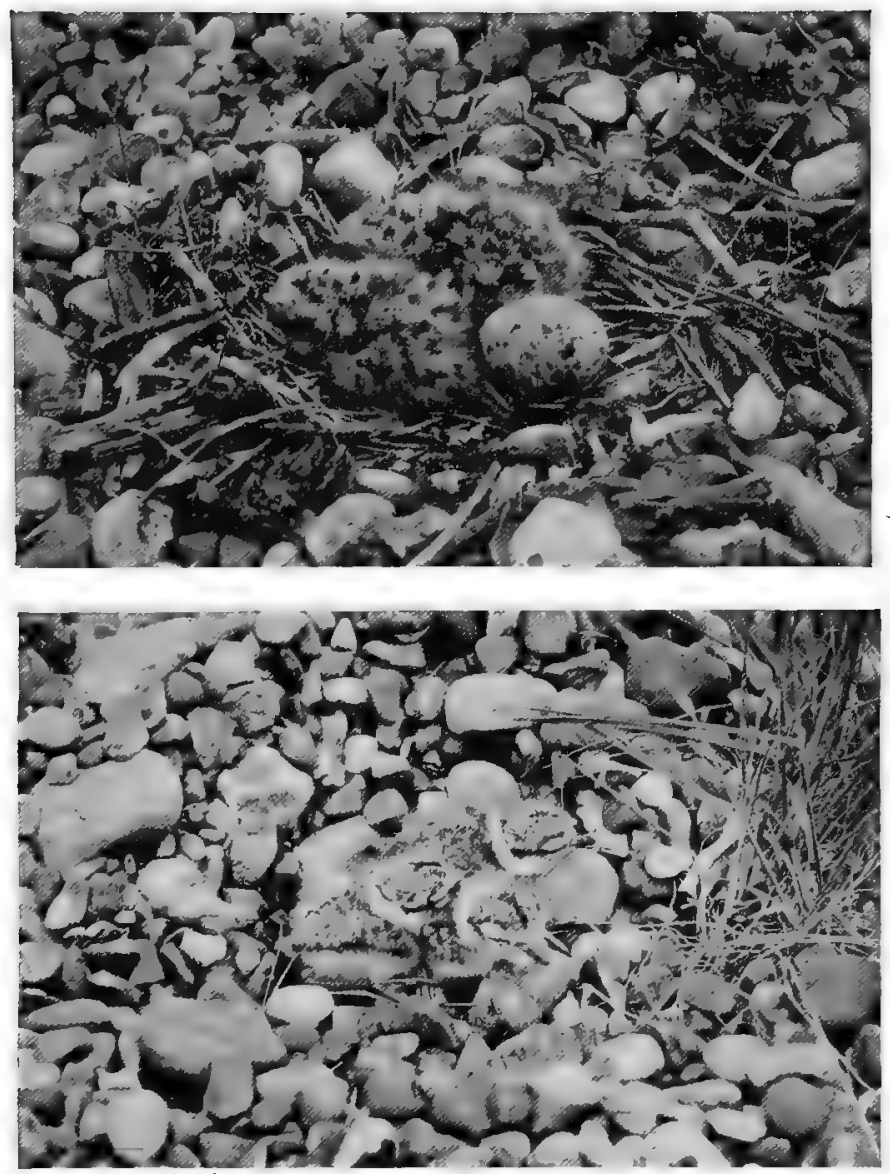

Photos by A. H. Bishop.

$$
\text { NESTIINGS OF THE COMMON TERN (UPPER FIGURE) AND OF }
$$

THE RINGED PLOVER (LOWER FIGURE).

Showing the close tesemblance which obtains between the downy young and their surroundings. The nest of the young terns contains an egg. Traces of longitudinal stripes are to be seen in the young plovers; in the terns they have become broken up to form mottlings.

108] 

or "fledgeling" plumage, commonly answers to an ancestral plumage is surely borne out by what is displayed in the case of the young of the great titmouse (Parus major) and the grey titmouse $(P$. cinereus). With the general appearance of the first named my readers must be familiar enough, for it is a common British bird. Suffice it to say that its coloration is a combination of blue, black, yellow, and white. The grey tit, on the other hand, though precisely similar in the pattern of the coloration, differs in the hue thereof, pearl grey taking the place of blue, and white of yellow. The fledgeling great tit, it is next to be noticed, differs from the adults-both sexes being coloured alike-in being duller in hue as to the blue and yellow, while the white of the face is strongly tinged with yellow, and the black lacks the metallic lustre, and is less in area, being absent on the side of the neck and breast. Now, the fledgeling grey tit is practically indistinguishable from the young great tit of the same age, from which we are surely justified in regarding the grey tit as a derivative of the great tit. The loss of the yellow colour by the adult grey tit has thereby made two species where originally there was but one. Yet other and similar cases could be cited, but this will surely suffice, while it will also serve to attest the value of a study of nestling birds as a guide to the lines of evolution which their parents have followed.

A broad, general, survey has now been given of some of the more important features which have been brought to light by a study of the coloration of nestling birds : but certain puzzling phenomena have been purposely left out of account till now. And this because they represent isolated facts, in most cases at any rate of doubtful meaning. They have to do, in short, with the development of ornaments in nestling birds, or with the development 
of coloured areas and markings not as a rule found in the adult stages.

Let us begin with the account of the ornaments. Our first case shall be that of the nestling of the common coot (Fulica atra). In this bird, it may be remembered, the downy covering is black, and this is set off, during the first few days of nestling life, by the development of vermilion and yellow hues on the head. The vermilion area is formed by numerous minute, fleshy outgrowths or villi, which have a velvety appearance, and exactly resemble the villi which form the vermilion face wattle of the pheasant. The yellow is borne by long thread-like down feathers. But there is at this stage no sign of the white shield of bare skin on the forehead so conspicuous in the adult.

In the nestling waterhen, on the other hand, the beak is of a bright red, and there is a trace of the frontal shield, also bright red in colour, as in the adult. Later, when in its first plumage of true feathers, the red gives place to a dull brownish green, and this in due course once more gives place to vermilion. In the nestling of the great crested grebe the crown of the head is ornamented by a heart-shaped shield of bare skin, vermilion red in hue: yet no such ornament is present in the adult, in which the crown is covered with feathers.

Has this curious patch any special significance? Perchance it is a recognition mark, enabling the parents to find the young after they have dispersed into hiding to avoid an enemy. If this be so it is difficult to see why a similar mark should not have been developed by other species of young grebes : yet such is not known to be the case. Nevertheless, it is significant that young grebes, coots, and waterhens all agree in this display of red at this stage of existence. 
Hitherto we have always regarded the development of conspicuously coloured areas such as these as the product of "sexual selection," and even when they may be present in the female this interpretation is still regarded as valid; for it is assumed that, though originally developed as a male sexual adornment, they have been, in such cases, transmitted to the female, as we have already seen is often the case with brilliant plumage.

The nestlings of Passerine birds, almost without exception, have the mouth parts more or less brilliantly coloured. Usually this takes the form of a more or less extensive fleshy flange, or rim surrounding the gape, of a bright yellow colour. But in some species there occur, in addition, at the angle of the gape, globular or bead-like outgrowths of bare skin, and brilliantly coloured. In the Gouldian weaver-finch these bodies are of a brilliant opalescent emerald green and blue, and the roof of the mouth is marked by five black symmetrically disposed spots, while a black bar crosses the tongue. The nestling of the crimson-eared waxbill, and of the parrot finches, are similarly marked, while the red-tailed weaver-finch of Samoa has bright red wattles.

Mention has just been made of black spots within the mouth cavity. These occur in quite a number of the nestlings of our native birds, and are made the more conspicuous by reason of the brilliant background in which they are set. As a rule this background is yellow, and the spots may be few in number, or absent altogether. In the young hedge-sparrow the background is yellow, and the tongue-spurs are each marked by a black spot. In the skylark there are three black spots, arranged in the form of a triangle on the tongue, and a fourth near the top of the lower jaw. But the high-water mark of 


\section{THE INFANCY OF ANIMALS}

ornamentation of this kind has perhaps been reached by the nestlings of the bearded tit (Panurus biarmicus). Herein the inside of the mouth bears four rows of pearly white, conical projections, suggesting the palatal teeth of reptiles, two rows on either side of the cleft of the palate. These tooth-like bodies, which are well shown in the accompanying picture, are not of uniform size, and are set against a background of black surrounded by a rich carnelian red, the whole being framed in by the lemon-yellow gape-wattles, which, however, are not very strongly developed. The tongue is black, with a white tip, and a pair of white spurs at its base.

What purpose can these strange ornaments serve? So far we can but speculate on this question, but it seems highly probable that they serve as guide-marks to the parents when feeding their young during this most helpless period of existence-for it is to be remarked these colours and patterns soon fade. In most of these cases the young are hatched in rather dimly lighted nests, so that any indication guiding the parents to the centre of the mouth would be of immense value, ensuring economy of food, reducing the labour of collecting, and, what is more important, rendering the meals of the hungry youngsters both regular and sufficient.

These spots, it may be remarked, occur just in those areas where the mouth is most sensitive to touch, so that they serve a double purpose-they form a guide to the parent, and ensure the mechanical closing of the mouth directly the right stimulus, given by the touch of solid food, is administered. It has been objected that such markings occur also in the case of nestlings hatched in open nests, on the ground, amid short grass, so that no such guide being necessary, the spots are useless. 


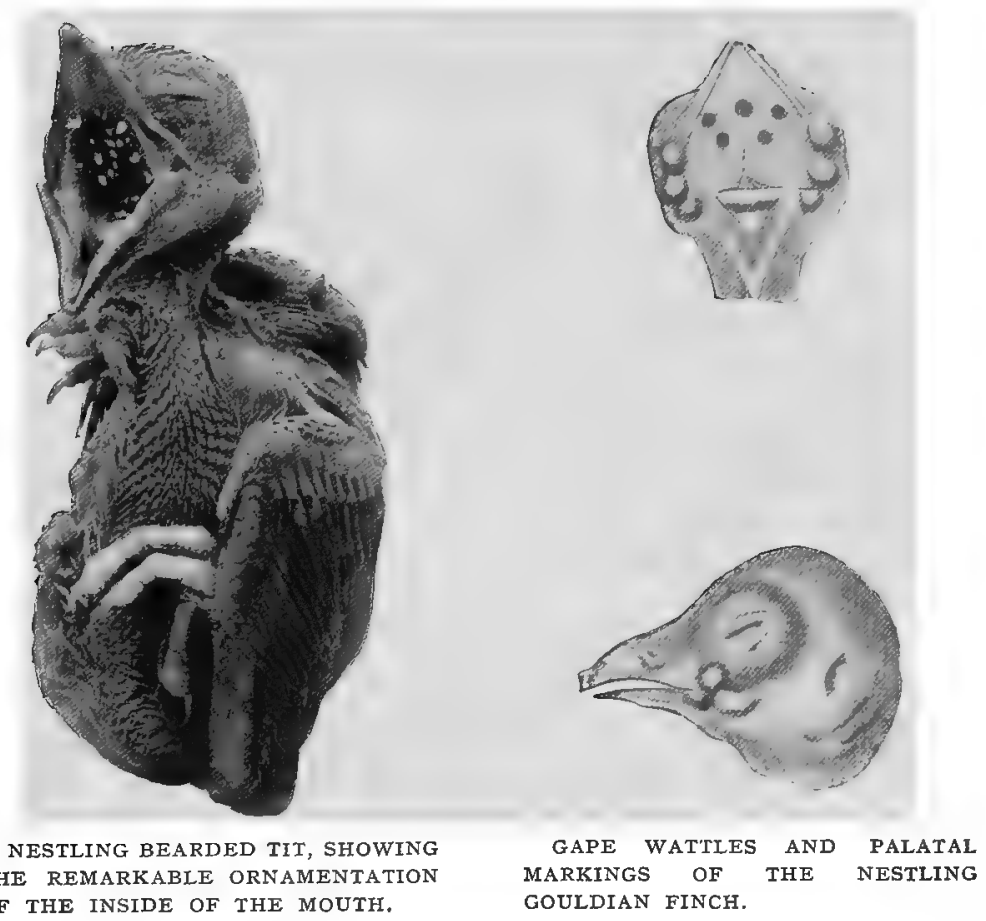

II2] 

This inference is by no means a good one. In spite of the well-lighted position, the spots may, in such species, still be necessary, for they were probably developed before the birds adopted this more open nesting site; and this being so, the birds having during these early days learned to depend on these guide-marks, they are still needed to serve as a cue, so to speak, to the right co-ordination of movements to-day necessary for the sure transference of food to its destination. The fact that in some species, as in wagtails, and the chaffinch, for example, no spots are present, does not seriously affect the question.

We may obtain a clue as to the origin of such markings through such species as the white-throat (Sylvia cinerea), black-cap ( $S$. atricapilla), garden warbler ( $S$. bortensis) and orphean warbler ( $S$. orphea), in which the tongue is marked by an indistinct, and more or less perfect triangle of a dusky hue. Surely these linear markings represent an earlier phase of this colour-pattern. The spots arose, in other words, by the concentration of the pigment to form spots instead of bars; while in certain species even these have disappeared. In support of this suggested course of evolution it may be mentioned that in certain other species of warblers, e.g. reed-warblers (Acrocepbalus streperus) and the sedge-warbler (A. pbragmitis) the tongue is marked by a pair of small black dots placed near its base.

Herein we have a parallel to those cases where, by a disintegration of longitudinal stripes, a livery of spots and mottlings has been evolved. These finally disappearing leave the down whole-coloured. 


\section{CHAPTER VII}

YOUNG BIRDS AND THE RECORDS OF THE PAST

BETWEEN young birds and young mammals there is not so wide a difference as is commonly supposed, inasmuch as the young echidna and the young platypus are both hatched out from eggs. But while these stand alone in this respect among mammals, it is the universal rule among the birds. All young mammals, however, are suckled by their parents on the peculiar secretion known as milk; the food of young birds, on the other hand, is furnished by external sources.

With the majority of mammals the true egg, or germ out of which the growing body is developed, is excessively minute, and rapidly becomes attached to the uterine wall of the parent's body, extracting nourishment from the parental tissues. With the young bird the egg or germ is no less minute, but instead of remaining within the parental body and drawing nourishment therefrom, it becomes enclosed within a hard shell together with a relatively enormous mass of yolk, which it slowly absorbs. The growth stages up to the moment of hatching are the embryonic stages, those thereafter are post-embryonic.

But, as with the mammals, we can draw no hard-andfast line between embryonic and post-embryonic: and this fact is perhaps more easily grasped in the case of the birds. As everybody knows, young sparrows and 

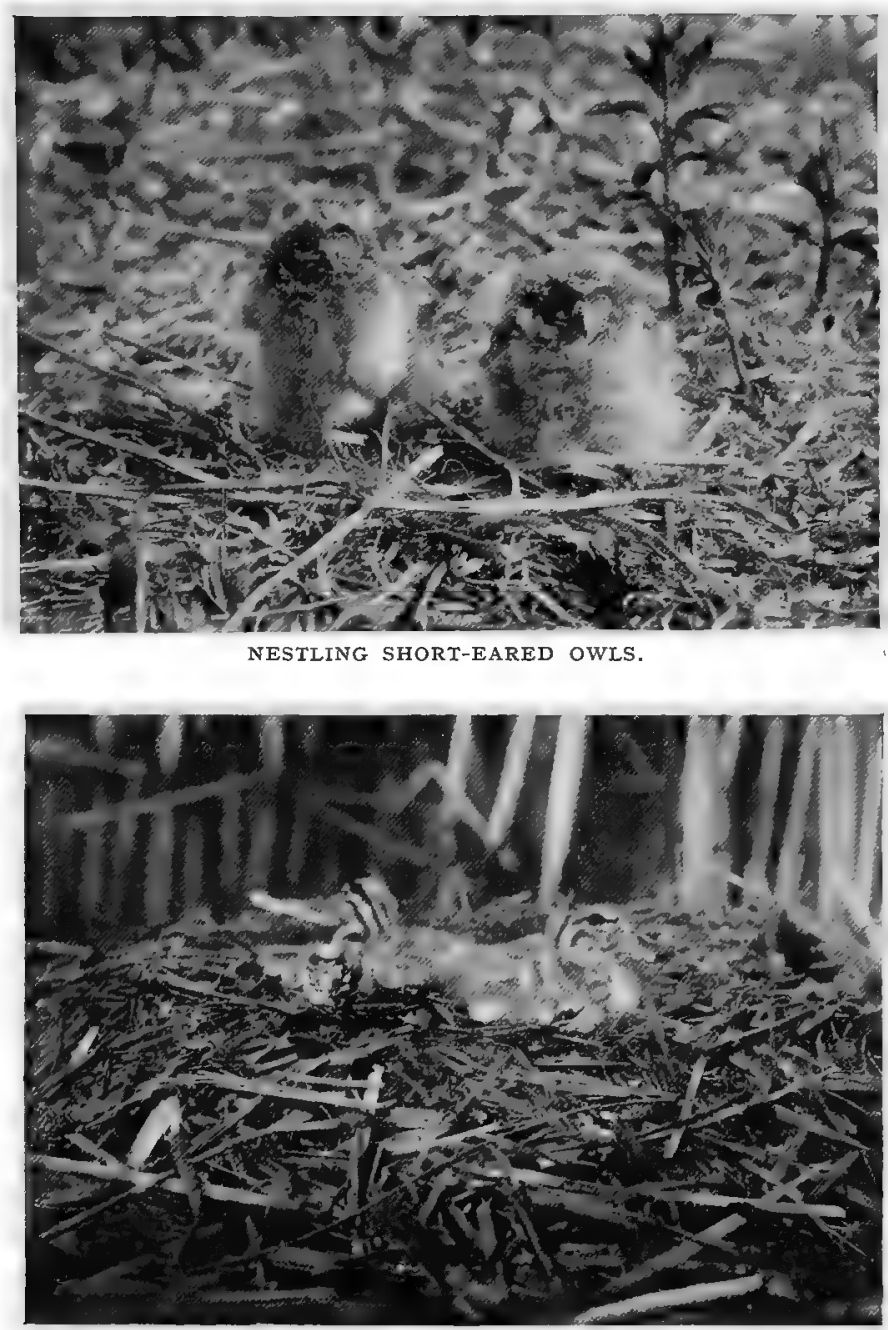

Photos by Miss E. L. Turner. NESTLING GREAT CRESTED GREBES.

The nestling owls have transversely barred down, in the grebes it is longitudinally striped. The barred type of down is met with only' among the owls.

II4] 



\section{YOUNG BÍRDŚ AND RECORDS OF THE PAST $t$ I5}

young crows are, at hatching, in a perfectly helpless condition, quite naked, and with the eyelids still sealed. They are "prematurely born," so to speak. On the other hand, young chickens and young ducks come into the world in a much more advanced condition, having the body thickly clothed in down, and being able to run about with their parents within an hour or so of their entry into life. It is plain that this advanced condition is due to the fact that, owing to the larger amount of food yolk enclosed within the shell, development has proceeded further before hatching; but the reasons for these differences in development and the relative activity of the two types of nestling are not so clear.

Ornithologists have never seriously set themselves the task of interpreting such differences, but have been content to label the helpless type a " nidicolous" or "altricial" nestling, the active a "nidifugous" or "precocious" nestling. And having duly labelled them, they have next proceeded to make use of these two types as a basis of classification.

Roughly speaking, we may regard the young of the ostrich tribe, the game-birds, gulls, plovers, sand-grouse, bustards, cranes, rails, geese, swans, ducks, grebes, and divers as nidifugous or precocious types: while those of the penguins, gannets, and cormorants, and their allies, the petrel tribe, hawks, pigeons, owls, cuckoos, hornbills, swifts, woodpeckers, and the Passeres or "perching" birds, e.g. crow and thrush, are altricial or nidicolous. But let this fact not be forgotten-no hard-and-fast line can be drawn between the precocious and helpless types, and for reasons which will appear presently.

In the matter of clothing the helpless forms present every possible gradation, from a complete investment of 
down-like feathers to absolute nakedness. Further, even in the very nature of this down there are very striking differences, the deep significance of which, until recently, has been quite overlooked. In the precocious types the downy covering has at least completed one phase of its growth at hatching time. Among the helpless types this is but rarely the case.

Young penguins, hawks and owls, for example, at hatching are but scantily clad; but in a short space an abundant crop of down makes its appearance. The young pelican and cormorant are ushered naked into the world, and never at any time develop a very thick covering. The young gannet, on the other hand, a very near relation of the pelican and cormorant, as it leaves the egg, is covered with a short, velvet-pile-like mantle of down, but speedily this gives place to an almost woolly, downy growth of considerable length. The young of the closely-related storks and herons present a striking contrast in the matter of their mantles. In the case of the stork the body is clad in a vestment of white down, short and woolly; while in the heron it is of a long, straggling, filamentous or hair-like character, and by no stretch of imagination can it be called a covering. So too with the pigeons : the down feathers have so degenerated in character that they give the rather livid and ugly-looking body the appearance of being invested with a very straggling crop of bristles.

Birds like kingfishers, hornbills, swifts and hummingbirds never develop nestling down, so that the growing feathers give the birds somewhat the appearance of hedgehogs, at any rate until the tips of the feathers begin to burst through their pointed sheaths. The young of many of the Passeres are commonly, one might almost 


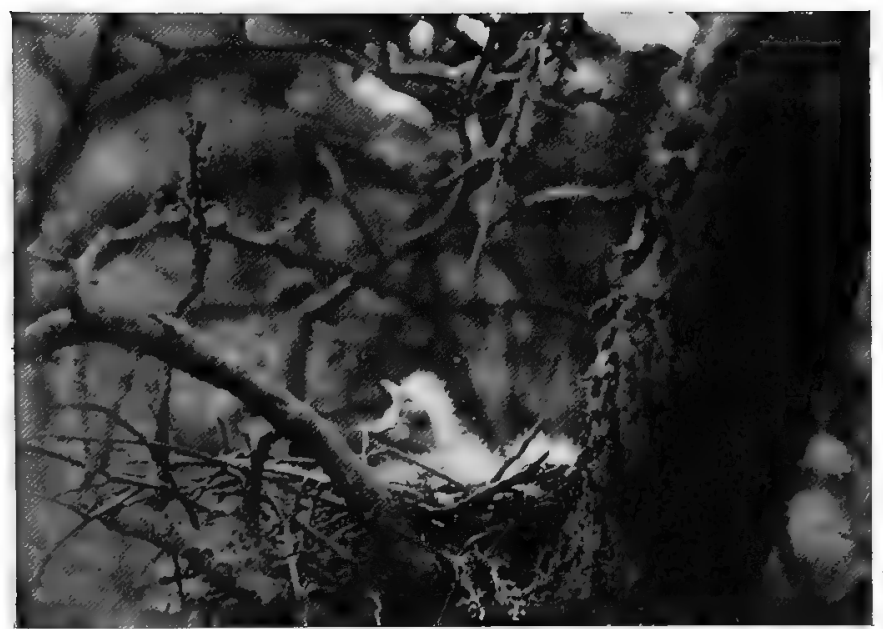

YOUNG HAWFINCHES.

The Hawfinch nestling is unusually downy. As a rule young finches are almost, or entirely, naked.

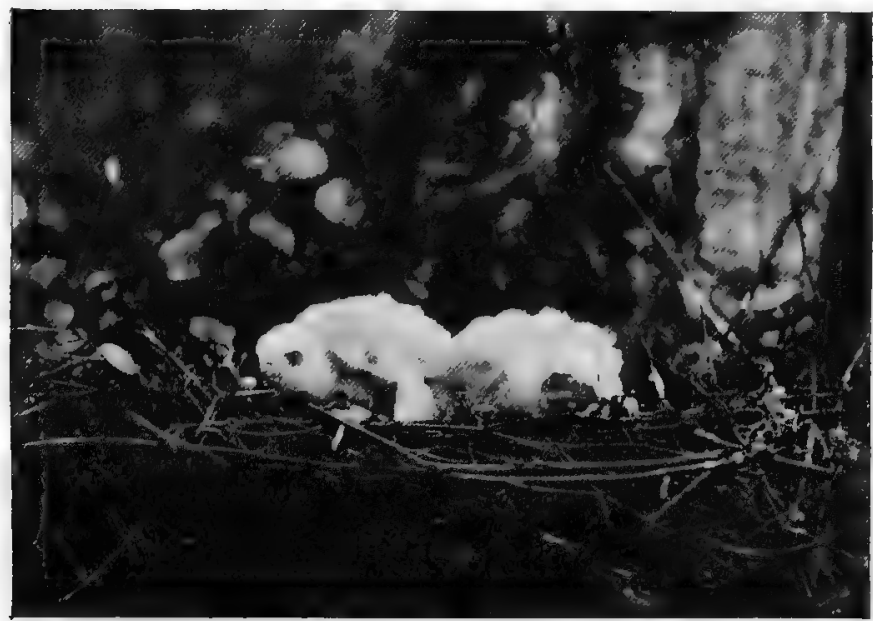

Photo by Miss E. L. Turnet.

YOUNG SPARROW-HAWKS.

Young hawks and owls, in the downy stage, bear a close likeness, but the downfeathers of the Hawks differ completely in their character from those of Owls. II 61 

say aggressively naked; others develop an apology for a covering in the shape of a few tufts of filamentous and extremely delicate down, which serve rather to exaggerate the nakedness of the body. On the other hand, some, like our hawfinch, have a comparatively thick crop of down. In the Australian Lyre-bird alone among the great host of species which make up the Passerine group, is there what we may call an ample downy covering. Herein it is of great length, and covers every part of the broad tracts which later will bear the feathers.

It is difficult to account for these differences in the clothing of the nidicolous young, but that it is intimately associated with sedentary habits there can be no doubt. The pigeons and the sand-grouse surely demonstrate this point. The former, as we have remarked, are nidicolous, and their downy vestment is reduced to a few hair-like threads; the sand-grouse are nidifugous, or precocious, and are densely clad.

The fact that the young of indubitably close allieslike the pigeons and sand-grouse-may differ one from another very conspicuously, while birds in no way related - like hawks and owls-may in their nestling stages be almost indistinguishable, shows at once the unreliability of the condition of young birds during the early postembryonic stages of development as an index of relationship, and therefore as a basis of classification. At the same time it raises the question-What is the significance of such conditions?

There can be no doubt but that the nidifugous or precocious type of nestling is the more primitive, for birds, we know, are but glorified reptiles, are divergent branches of a common stock; and among the reptiles the young are always active at birth, or, to speak more 
correctly, at hatching. Yet it is not the apparently most active types among young birds which are to be regarded as most nearly representing the ancestral condition.

The truth of this view at any rate seems to be demonstrated by what obtains in the case of the nestling of the hoatzin (Opisthocomus cristatus). This bird, which represents an extremely aberrant type of doubtful affinities, is a native of the Amazon valley. It is, perhaps, the most exclusively arboreal of living birds, and hence more nearly approaches Archæopteryx-the oldest known fossil bird-and the proto-avian types, than any other member of the class Aves known to us. This nestling, then, seems to present us with the key to the evolution of the two types of nestling of which we have already spoken-the nidifugous or precocious, and the nidicolous or helpless types; and further throws a quite unexpected light on the meaning of the vestigial claws met with in so many adult birds of diverse types.

Briefly the story is as follows. Hatched in a rough nest of sticks placed on the bough of a tree overhanging the water, the young hoatzin, soon after leaving the egg-shell, begins, with his nest-fellows, to make climbing expeditions about the tree in the neighbourhood of the nest, using not only the beak and the enormous feet, parrot-fashion, but also the wings, which at this stage of growth differ from the wings of all other birds, for they are now used as an extra pair of feet, or let us say as a pair of hands. But it is not only their use in this way which is remarkable, but also their structure.

In the first place the hand-answering to the human hand, though possessing but the thumb and first fingeris much longer than the fore-arm, while the thumb and 
finger-tip, on their under surface, recall the human thumb and finger-tip in that the under surface forms a sort of pad; and these digits terminate each in a long claw. With the fingers thus armed an additional grip is gained of the boughs, a matter of very considerable importance to the welfare of the climber. How important is the part the hand plays may be gathered from the very curious way in which the growth of the quill feathers belonging to the finger-tip is suspended.

Normally, it must be remembered, the quill or flight feathers in nidifugous, non-aquatic nestlings are pushed on fairly rapidly, though not with the same express speed which obtains among the game-birds. Now, if in the young hoatzin all the quills of the hand started and continued to grow at the same rate, a stage would speedily be reached when those at the tip of the finger would seriously interfere with the gripping action of the fingertip and claw, while these feathers at the same time would be useless for flight. Thus it happens that the growth of these outermost quills is arrested until the inner feathers, the quills nearer the wrist, are large enough to act as a sort of parachute to break the force of a fall in the event of such an accident.

So soon as this stage of development is reached, climbing is no more either necessary or possible, and a change comes over the further development of the hand, a change affecting the rate of growth of the whole wing, indeed. In the first place the claws become slowly absorbed, while the arm and fore-arm grow at a greater rate than the hand, so that in consequence the hand speedily becomes the shortest segment of the whole limb, while at first it was by far the longest. This much will be gained by a reference to the accompanying illustrations. By the 

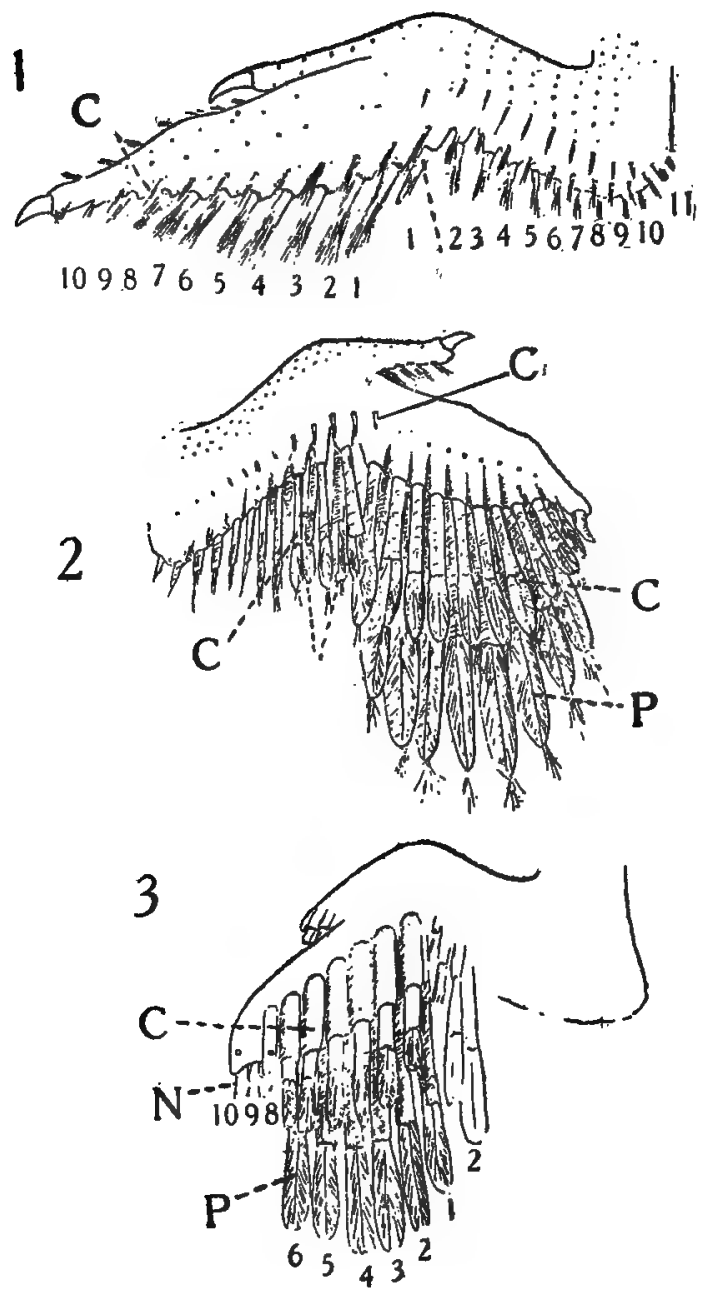

WING OF HOATZIN,

7. The wing of a newly hatched hoatzin showing the large claws and free finger-tip used in climbing.

2. The same wing at the period when the climbing stage is past, but before the claws have become absorbed.

3. The wing of a young game-bird showing the free finger-tip, but minus claws, and the accelerated growth of the wing quills. (After Pycraft). I-Io Primaries and secondaries, respectively. $\quad \mathrm{C}=$ Coverto. $\mathbf{P}=$ Primaries. $\mathrm{N}=\mathrm{Nes}$ tling down. 
end of the nestling period the quills of the hand, or primaries, and of the fore-arm, or secondaries, have attained almost their full growth.

So much for the first part of our story: now for the second, which is essential to a right understanding of the whole. It is contended that, in the first place, the sequence of events in the early life-history of the hoatzin is a sequence which carries us back to the very dawn of Avian development, and one which serves as an admirable illustration of the general truth of the recapitulation theory: the theory that animals repeat, in a general way, during the course of their life-history, what has been the history of their race during the course of ages.

Very well. First as to light thrown by the hoatzin on the events of the past. The evidence of this association is derived from a comparison of the wing of the hoatzin during its early post-embryonic stages and that of the oldest known fossil bird, archæopteryx. If such a comparison be made between the wings of these birds as is displayed on the accompanying illustration the closeness of the likeness between them should become immediately manifest.

It will be seen that in archæopteryx, as in the hoatzin, the hand is longer than the fore-arm, but whereas in archæopteryx the free finger-tip projected beyond the wing throughout adult life, in the hoatzin this relationship is soon lost. Similarly, while in archæopteryx the claws were a permanent possession, in the hoatzin they are again only temporary. Finally, in archæopteryx the primaries were fewer in number, and did not extend beyond the third digit, which also bore a claw throughout the bird's life. In all living birds the third digit is reduced 
to a mere vestige, though occasionally, in the embryo ostrich, this digit bears the vestige of a claw.

So, then, the wing of the hoatzin does repeat, as a passing phase, the characters which were a permanent feature in this ancient bird. And from this we may gather that the characters they share in common are intimately connected with the struggle for existence in both cases. Now as to the evidence conveyed by the fossil.

In the first place, from the structure of the feet we know that this ancient bird was arboreal; and we may infer therefore that its young were hatched in trees, as in the hoatzin to-day. This being so, they would need precisely similar aids to locomotion and safeguards against accident : further, on the attainment of adult life there would be the critical period of the annual moult to be faced. Now at this early stage of avian evolution it is probable that all the quills would be moulted at once, as in the ducks, geese, rails, and many other birds to-day. This would render any assistance from the wings, during the work of climbing about in the search for food, extremely valuable, and hence what is but a passing phase in the development of the wing in the hoatzin was a permanent condition in archæopteryx.

But we have not yet surveyed all the evidence that the wings of nestling birds can afford us in this connection; and the facts now to be marshalled lend no little weight to what has already been said, while they further show how features, apparently inexplicable, may become suddenly invested with a meaning and importance hitherto undreamed of.

The further evidence, then, which we are now to take, is furnished by the nestlings of the gallinaceous birds. If the wings of a young fowl, or a young pheasant, or rather 
a series of wings of such birds, be carefully studied, it will be found that, in such as have begun to develop the primary quills, there is an arrested development of the outermost quills exactly as is the case in the hoatzin. But the wings differ in this-that in the first place the finger-like tip is wanting, and in the second there is only a small claw on the thumb : to find the claw on the finger we should have to examine the embryo.

As we pass these wings in review it will be found that the development of the outermost quills remains in abeyance until the inner have acquired a length sufficient to form a moderately large fan-shaped area capable of effecting a short flight. So soon as this stage is reached the arrested quills begin to grow apace, and the secondaries similarly grow rapidly. The development of the primaries, however, is much more rapid than is the case with the hoatzin, and this acceleration, this speeding up, is evidently a direct response to the needs of the environment, for more dangers lurk on the ground than in the trees.

But what is the meaning of the temporarily free fingertip in the young of birds which pass the first few weeks of life upon the ground ? Just this : the arrested development of these feathers is a relic of earlier days, when young game-birds, like young hoatzins, were hatched in arboreal nurseries, and similarly needed a free finger-tip to the wing to serve as a climbing organ. That this change from an arboreal to a terrestrial nursery took place at a very remote period is shown by the fact that the claw of the finger has disappeared, and that the finger itself has shortened and lost its ball, or pad-like undersurface. But the hand is still, for a time, longer than the fore-arm : in the adult, as in the hoatzin, the fore-arm is longer than the hand. 


\section{THE INFANCY OF ANIMALS}

But we can carry our evidence yet further, for there seems good reason to believe that the phenomena described in the hoatzin and the gallinaceous birds were at one time common to all birds. At any rate birds so remote as the touracous on the one hand, and the rhea, or South American ostrich, and the tinamous on the other, also display an arrested development of the outermost quills, and a free finger-tip during the nestling stages; and the two last-named species have lived remote from trees for countless ages!

The fact that similar traces of an arboreal life are rarely to be met with in the precocious young of birds other than gallinaceous birds is a curious and extremely interesting point, revealing not only changes in the tactics adopted for the escape from enemies, but drawing attention to another, and what we may call a second string to the bow practised by the gallinaceous birds themselves. It is to be remembered that these latter are reared in comparatively large families, and that they in consequence afford a conspicuous and tempting bait to prowling carnivora.

Accordingly, as soon as danger is realised by the parent, the alarm-note is given and the young scatter in all directions. Halting at last, they then fall back upon this "second string"-protective coloration. That is to say, they have, in addition to the remarkably accelerated flight, also acquired a peculiar type of plumage which enables them to assimilate with their surroundings. Now it would seem that this precocious power of flight has not proved a really satisfactory method of escape, inasmuch as in fleeing from immediate danger the young either strayed too far to render recall possible, or they fled into new dangers. Consequently the young of other 


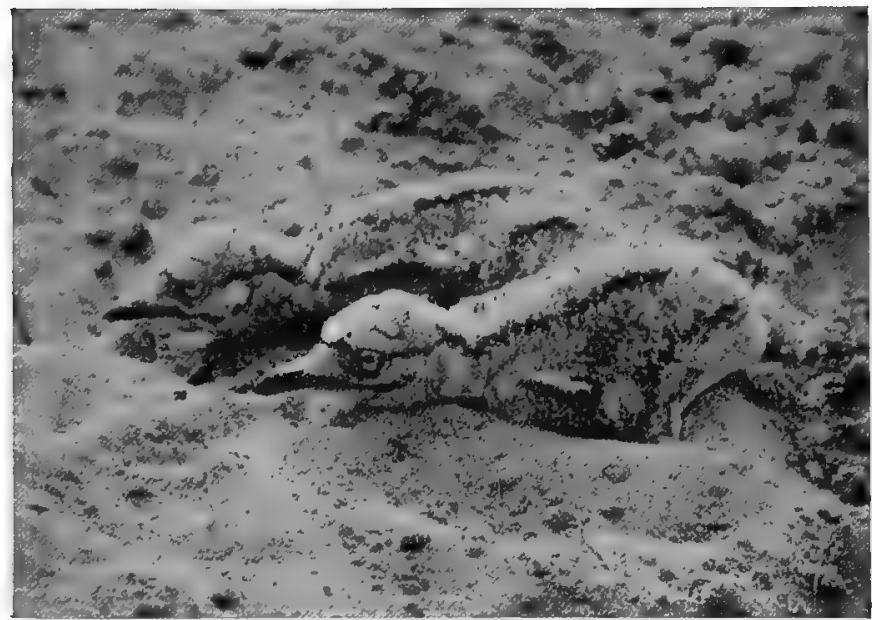

YOUNG STONE CURLEWS.

The curious attitude assumed by the young stone Curlew when alarmed, and its striped coloration, render it invisible to its enemies.

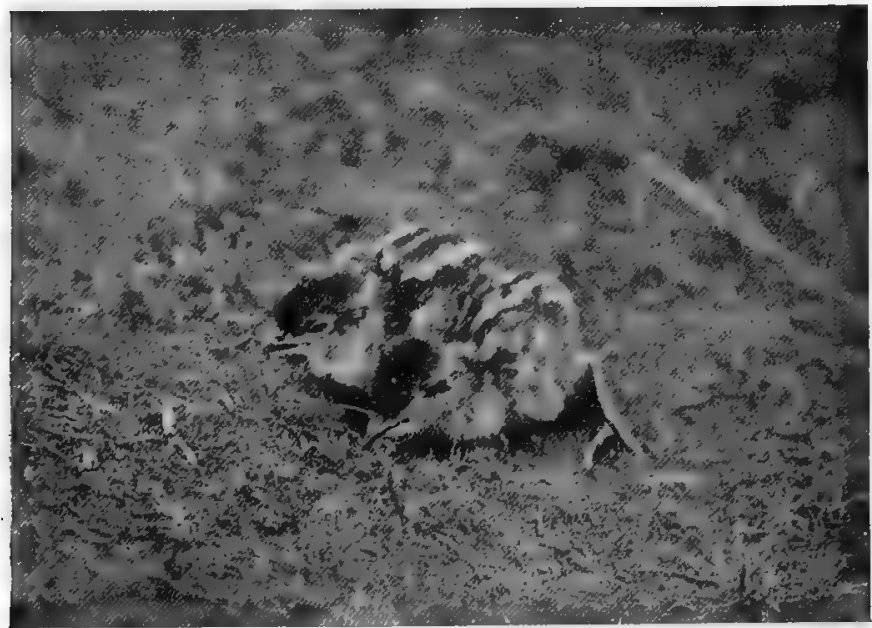

Photos by Miss E. L. Turner.

YOUNG PARTRIDGES.

These wear the livery characteristic of all young game-birds : they have assumed the position adopted when alarmed; the stripes of the body, cutting up its contour, cause it to blend with its surroundings. 


$$
\text { , }
$$


groups of birds have come to rely either on protective coloration alone, or at most they run for a few yards and then squat down, instead of trusting to the uncertain safety of precocious flight : and with this change of tactics the evidence of the earlier arboreal habits has been swept away.

The young of aquatic birds obviously do not need to seek safety in flight. Concealment amid reed-beds or other aquatic vegetation affords them ample protection. Indeed, among all these non-flying, nidifugous young we find the development of the quills has been retarded rather than accelerated, so that they appear together with the rest of the body-plumage when the downy stage is finally passed.

Among the ducks, however, the whole wing remains in its downy state until the bird is almost completely feathered as to the rest of the body: more than this, the growth of the bony skeleton is also retarded, so that for a brief period after they are feathered young ducks have the appearance of flightless birds in which the wings have been reduced to mere down-clad vestiges, recalling the condition which obtains, say, in apteryx or the emu.

Herein the conditions, as compared with the young chick, are exactly reversed, for in the latter the wings are large and fully feathered, while the rest of the body is down-clad. Here we get the extremes of development met with in the wings of nestling birds : in the one case the growth of the quills has been greatly accelerated to provide a means of escape from the numerous enemies which beset ground-dwelling birds living in areas favourable to carnivores of all types; in the other flight has been retarded, as if to compel the young to take the more secure cover afforded by the reedy growths of pools and streams.

Now let us turn to the consideration of nestlings of 


\section{I26 THE INFANĆY ŌF ÁNIMAĹ}

the nidicolous type, which, ushered into the world blind, naked, and helpless, stand in such strong contrast with those just described. According to the terms of our argument, birds were originally strictly arboreal creatures, and their young, like those of reptiles, were active from the moment they left the shell.

The evidence in support of this condition seems to admit of little doubt, but it is plain that such activity must have been attended with very considerable infant mortality through the young falling to the ground. A not inconsiderable number would perish through weakness; the habit of dispersing among the branches of the nesting tree resulting in irregular and insufficient feeding of those which had strayed too far to meet the parents returning with food. Thus would begin the initiation of the new type of nestling, the struggle for existence weeding out the more active individuals and favouring the more sedentary.

In other words we can trace the action of natural selection along two divergent paths. In the one case a certain number of species, from one cause or another, seem to have been driven to shift their nurseries from the forests to open ground. Herein the activity of the young was further increased, resulting in types such as the nestlings of the gallinaceous birds, rails, cranes, and plovers, all of which, in the course of time, have undergone considerable transformation in different directions in response to the needs of their several environments. In the other, wherein the arboreal nurseries were retained, a process of selection has taken place whereby a curtailment of the activity of the young has been brought about. And this has been accomplished by reducing the amount of food yolk enclosed in the egg. 


\section{YOUNG BIRDS AND RECORDS OF THE PAST 127}

As a consequence of this reduction the young are, so to speak, prematurely born, or rather the embryonic period of development has become relatively shortened, and the young accordingly emerge from the shell in the helpless state to which we have already referred. That the number of species which are-ushered into the world in this helpless state far outnumbers those which make their entry in a further advanced condition speaks volumes for the benefits derived from the shortening of embryonic life, even though this may lengthen the time during which the young must be cared for, and so increase the parental burdens. As examples we may cite the vast host of songbirds, their nearly related types represented by the parrots, cuckoos, kingfishers, bee-eaters and their kin, the pigeons, storks, birds of prey, and the cormorants and their near allies.

The amount of food-yolk once reduced, a return to the older fashion of active young was impossible; and this explains why the young of so many species hatched on the ground are as helpless as those reared in the topmost boughs of the highest trees. These young are descendants of birds whose young in turn had become adapted to the requirements of an arboreal nursery; and though this was later forsaken it is obviously impossible, as we haveremarked, to make a return to the earlier precocious condition.

After what has been said so far, it is somewhat surprising to find precocious young, belonging to species which are essentially birds of the marsh and beach, reared in arboreal nurseries! The green sandpiper (Totanus ocbropus), for example, will make use of deserted nests of other species -blackbirds, hawks, squirrel-dreys-at heights varying from 3 feet to 30 feet from the ground. Similarly the noddy (Anous stolidus) and the white tern (Gygis candida) 
resort to trees for a nursery. But in these cases the young are evidently on the way to become nidicolous. In appearance they are not to be distinguished from nidifugous types, but in behaviour they are nidicolous.

These instances seem the more remarkable because they stand in such striking contrast with what obtains among their immediate allies. But as a matter of fact there are a number of instances wherein nidifugous are in process of transformation into nidicolous types-such as, for example, the gannets, cormorants, pelicans and their allies, which in the early stages of development are now absolutely helpless, and some are losing their downy covering as in typical nidicolous birds. While the pelicans always nest upon the ground, some species both of gannets and cormorants nest in trees, either sporadically or constantly, as the conditions of the environment may determine. Various intermediate stages in this process of "hobbling" may be studied in the case of those species which, having precocious young, nest in colonies, often of vast size, or on the ledges of precipitous cliffs.

The reduction of the food-yolk, and the consequent earlier hatching of the young of such species, are decidedly advantageous changes. The gain of such curtailment of movement is, to species which nest in colonies on the ground, obvious. Active young, hatched in colonies affording free space wherein to roam, would soon become lost amid the general crowd of nestlings, and hence speedily starve-even if the adults had acquired the habit of indiscriminately feeding any nestling of the colony which clamoured for food. In the case of cliff-breeding species like guillemots and razor-bills, and many species of gulls, this quiescence saves an enormous mortality through falls from the cliffs. 
Whilst a large number of birds have adopted this expedient of curtailing the activity of the young, thereby increasing the burden of parental responsibility, there are certain species of gallinaceous birds known as the moundbuilders or megapodes, which have succeeded in reducing the ties of offspring to the smallest possible limits-without descending to parasitism-by enormously increasing the size of the egg so as to include a proportionately large amount of food-material for the growing embryo. As a consequence, the whole of the normal nestling period is passed within the shell, the first generation of nestling down is developed and shed, and the second generation together with the wing-quills are developed, before hatching takes place!

This is a most extraordinary fact, and once more shows how impossible it is to draw a hard-and-fast line between embryonic and post-embryonic stages of growth. But the whole history of the reproductive period of these birds is strange. The parental instinct seems, in consequence of this habit, to have become well-nigh extinguished, for there is no brooding of the eggs, and little or no care displayed for the chicks, which are hatched after the fashion of many reptiles-by warmth generated by decaying vegetable matter in which the eggs are placed, or in soil in the neighbourhood of hot springs. But of this anon.

That the megapodes were originally hatched in arboreal nurseries, like the young hoatzin, and, as we believe, all the gallinaceous birds, there can be little doubt, since they also, in the nestling stage, display the free fingertip and arrested development of the outermost quills, characters utterly inexplicable save on this hypothesis. Further, we may feel sure that the increase in the amount 
of the food-yolk did not take place until some time after the descent from the ground for nesting purposes, since the wing of the nestling megapode forms an exact counterpart of that of the young fowl or turkey. Had the increase taken place earlier, the wing would more closely have resembled that of the young hoatzin in the possession of large claws. These are now present only during embryonic life.

This increase in the amount of the food-yolk, allowing the earlier nestling stages to be passed within the egg, must be accounted for by supposing the adult megapode to have been obliged to adopt this expedient to avoid the perils attendant on normal incubation, perils which may since have passed away, leaving no record of their nature. A return to the normal method of incubation is now impossible, the instinct therefor having been replaced by that which induces the birds to bury their eggs and leave them to be hatched by heat other than that of the brooding bird.

The interpretation of the facts herein recorded is surely well supported by evidence. Yet a diametrically opposite rendering has been formulated, which certainly will not bear criticism. The great size of the egg, it has been held, takes up so much room within the body cavity, that only one can ripen at a time, and consequently long intervals must elapse between the deposition of each egg. To wait till all were laid before commencing incubation, they say, would be dangerous, and furthermore, they could not all be covered by the sitting bird. Consequently, each is deposited as it is laid, in an incubator, and left to take its chance, just as among the reptiles.

It is held, in short, that the megapodes lay their eggs in mounds because of their size. The converse is certainly the case-the large egg has been produced because of the 
need of depositing it in some natural incubator, the parent having become unable to undertake the duty.

There are few instances in the history of animals where the evidence gleaned from the present and the past can be more completely combined to yield such definite results as these phenomena in the history of nestling birds. The foundation of our deductions rests on the evidence of the fossil archropteryx. If we take this as our basis, the whole of the otherwise inexplicable facts become clear as day: forming a demonstration of the evolution theory which should convince the most sceptical.

One is often asked, what evidence is there for the oftrepeated assertion that the birds and reptiles are near akin? The two things seem so incongruous : the one all activity, the other so sluggish and "cold-blooded." Yet the fact of this relationship is incontrovertible, and great as is the distance of time since the parting of the ways, the evidences are yet so plain that he who runs may read. But he must first learn to read.

- Briefly, the most striking part of this evidence is to be gleaned from two sources-from the fossilised remains of species which lived ages ago, and from the skeletons of species yet with us; and from the insight these aspects afford us, we are enabled to link up yet other features as a part of this history, which would otherwise prove incapable of interpretation. But of this evidence we can, in these pages, examine only that which is to be found in young birds.

One of the most interesting of these links with the past has confronted most of us, all unwittingly, at our very dinner-tables! Nay, more-it may even have endangered the lives of some of our forbears, who when dining off, say, a roast fowl, enjoyed nothing so much as cleaning 
up the bones by gripping them between the fingers and gnawing off the last remaining fragments of flesh. Now when this bone happened to be the "drumstick" of a "spring" chicken, it must have been a common experience to find the end of this drumstick suddenly loose in the mouth.

In such an event, no doubt, it would have been speedily
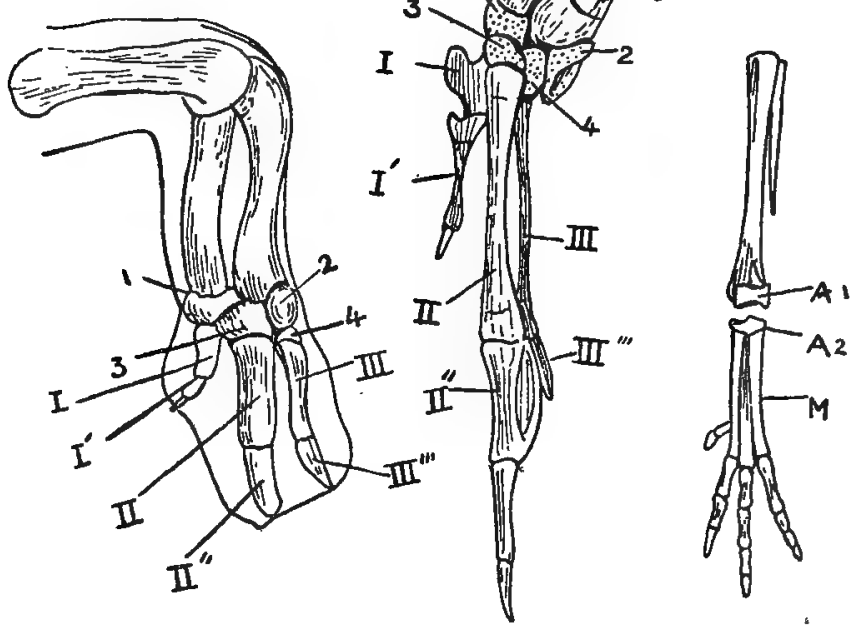

SKELETON OF THE WING AND LEG (RIGHT-HAND FIGURE) OF YOUNG BIRD.

rejected, without even a thought of "links with the past!" Having discarded some of the more barbaric customs of our forbears, we are not likely to make the acquaintance of this unexpected link in similar fashion, but a mere touch of the knife and fork at the end of this bone, the "drumstick," or shank-bone, will discover what they too found. 
Let us imagine the experiment made. We should find, then, a curious somewhat mallet-shaped bone, the handle being short and triangular. If we similarly treated the upper end of the foot-bone we should find what is necessary to complete the story-a flattened, oval plate of bone, of which more presently.

To find their like in the animal kingdom, we should have to go to the nearest museum possessing the skeleton of one of those monsters known as a Dinosaur, a giant reptile happily for our peace of mind extinct ages ago. For choice, we should seek out an iguanodon. Herein we should find the same mallet-shaped bone at the end of the shank, and the same oval plate capping the foot-bones, answering to the sole-bones, "metatarsals." But while in the bird these elements remain distinct only for a few weeks, in the fossil, it is plain, they retained their identity throughout life.

Between the bird and the fossil, however, we should find in this matter of the foot one striking difference. In the reptile this oval plate forms a cap to three separate metatarsal bones, or sole-bones as they are called in common speech ; while in the bird there is but one. This difference, however, is more apparent than real, for if this single shaft be carefully examined, there will be found running down its whole length two fine lines, one on either side of the middle of the shaft. They are the lines of contact between these separate shafts of bone, which have become blended together, leaving but a faint trace of their earlier distinctness, a trace which vanishes completely in the adult.

That this is so we shall see at once if we go to the trouble of examining the foot of an embryo, for here we shall find these three bones as distinct as in the fossil reptile, as will be seen by a comparison of our illustrations. Herein, 
then, we have another demonstration of the way ancestral characters appear, and vanish during the life-history of their descendants. But this by the way.

After such a comparison there could be no doubt about the identity of these ankle and foot bones in the two creatures-bird and reptile. But the story is not complete. If this ancient reptile helps us to interpret the bird, so the bird, on the other hand, helps us to interpret the reptile. For in all other reptiles, as in the more highly organised mammals, of whom man is the chief ornament, the anklebones are represented not by two, but a number of separate bones, arranged in two rows. In the reptile, whether the ankle-bones be few or many, and in the bird, the hinge or joint between the shank and the foot is formed between these two rows; in the mammal it is formed between the uppermost row and the shank.

But how is it that the fossil reptile and the bird agree, and differ from all living reptiles in having but two separate ankle-bones-in the adult bird indeed even these seem to have vanished? To answer this we must examine the foot of the embryo bird. Here we may find as many as six separate bones, though represented only in soft cartilage, two forming the upper and four the lower row. But speedily these separate elements blend together, and later come to form the mallet, and the oval disc with which we started. Thus, then, we may gather from this study of the leg of the young bird, that there exists an undoubted relationship with the reptiles, and more particularly with the dinosaurs : and this evidence could be further supplemented by a study of the rest of the leg.

The wing of the young bird tells us little in regard to this reptilian ancestry; but it throws a flood of light on the past history of its evolution. Some evidence of this has 
already been furnished on a previous page : this may now with profit, be supplemented by what is revealed in the skeleton.

The wing of the bird is a unique structure, and all that concerns us here is the matter and the manner of its becoming, so to speak, so far as we can glean from the evidence of the developing skeleton, displayed during the embryonic and early post-embryonic stages. But three of the originally five digits of the hand now remain, and these

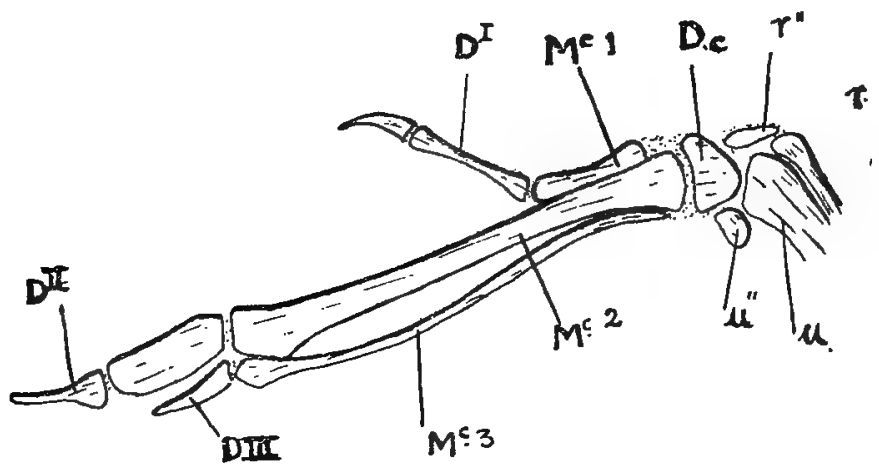

WING OF A YOUNG RHEA OR SOUTH AMERICAN OSTRICH.

have undergone profound modification to fit them to support the strong quills which bear the brunt of the strenuous movements during flight. So that in the adult we find but two separate wrist-bones, instead of several as in the reptiles, while the palm-bones have become welded together to form a brooch-shaped structure. The finger-joints have become reduced in number and changed in shape. Of the thumb, commonly only one remains: of the first finger there may be three, while the third finger is represented only by a small nodule of bone.

Some birds yet retain vestiges of a claw on the thumb, 
and one at the end of the first finger; but such cases are rare. In the very young bird, however, we find a passing stage of development which in the fossil archæopteryx was an adult stage. Herein we find the remains of the second row of wrist-bones. The remains, as is shown on p. 135, take the form of a semi-lunar mass of bone (Dc) applied to the end of the middle palm-bone (Mc2). In the fowl this mass speedily fuses therewith, and so obliterates itself, but in the fossil bird it remained distinct throughout the creature's whole life.

Here again, a reference to the embryo completes the story; for this will reveal the presence of two little nodules of cartilage answering each to a wrist-bone, one belonging to the palm-bone of the thumb, the other to that of the third finger. In archæopteryx, as in living birds, these two bones lost their identity by becoming merged with the larger central mass, which is therefore a compound of three elements, just as is the shaft of the foot or solebone of the adult bird of to-day.

There are some who hold that the daintiest morsel in a roast fowl is the "parson's nose"-there is no accounting for taste. Now, if the roast fowl happen to be that "spring chicken" to which we have several times already referred, that same "parson's nose" can be made to yield a story, as well as a bonne-boucbe.

In its very centre will be found a triangular plate of bone, which during life served as the basis of attachment for the tail-feathers, the stumps of which are arranged fanwise around it, as in the illustration. This bone is known as the pygostyle. If it be carefully examined good luck may reveal one or more transverse grooves across its surface; creating a suspicion that at an earlier stage of growth it may have been composed of several pieces now welded 

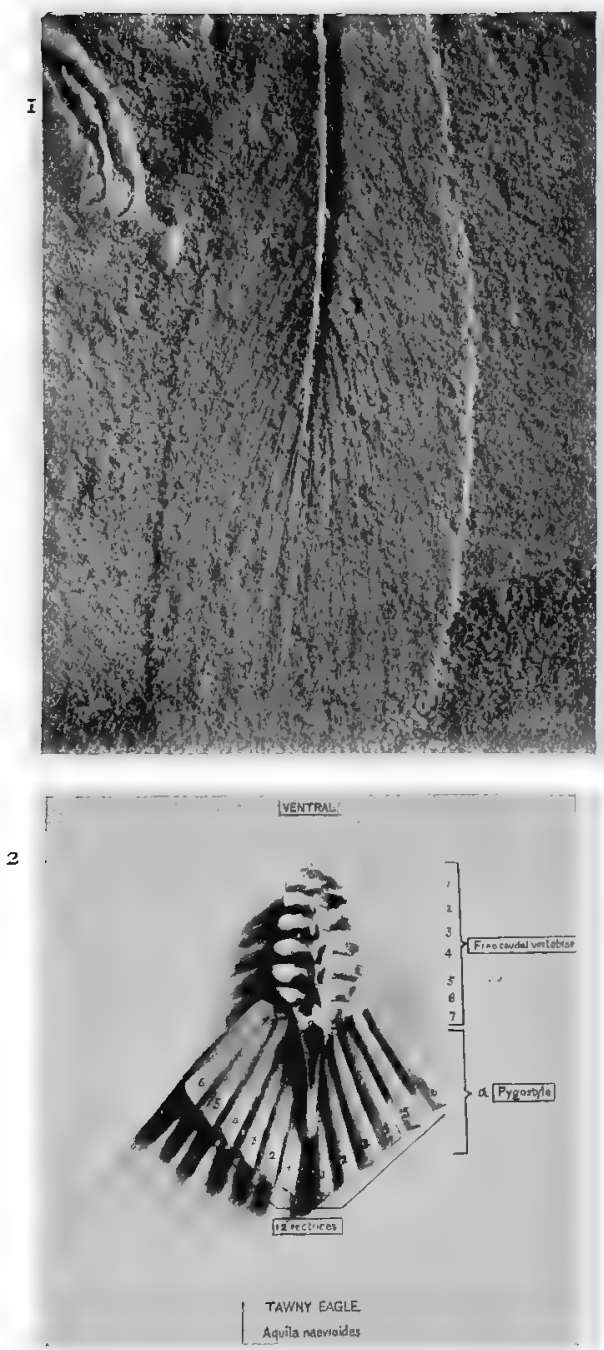

I. ARCHAOPTERYX.

2. TAWNY ,EAGLE.

The tail of Archeopteryx was made up of a number of separate bones, like a dizard's tail, and each separate bone bore a pair of tail-feathers. In all other birds, e.g. eagle, these separate bones have been shortened and fused into a single plate, cansing the tail-feathers to assume a fan-wise arrangement. 

together. And if we turn to the newly hatched chick, or better still to the nearly ripe embryo, we shall find that such is actually the case. And if we compare a number of such tails of different species-gallinaceous birds, ducks or swans, for example-we shall see that these separate elements range in number from five to ten; therefrom we conclude that this pygostyle is a new thing, relatively speaking; that time was when the end of the tail was made up of a number of separate bones, represented to-day by this pygostyle.

The fossil archæopteryx shows that this was actually the case, the tail being extremely long, like that of a lizard. But this is not its only peculiarity. The tail feathers, it will be noticed, are attached in pairs all the way down from its base to its tip, a pair of feathers to each separate vertebra, a plan differing entirely from that which obtains in modern birds, wherein, as we have seen, these feathers are arranged fan-wise about the pygostyle.

At first sight these two types of tails seem to have little in common: yet a little study of the matter will end in the conviction that they are not only closely related, but that the one has been derived from the other. The process by which the transformation has come about is not difficult to follow. If one carefully studies the tail of this ancient bird one can see how, if by some process we could "telescope" these bones, compress them by pressure at each end, till from cylinders they became little more than discs of bone, we should at once reproduce the characteristic fan-wise method of arrangement which these feathers present in modern birds. Yet but for the facts revealed by the examination of the pygostyle in the "parson's nose," and of the earlier embryonic stages, I venture to think we should never have alighted on this solution. 
Years ago, when Huxley turned that penetrating and versatile mind of his to the subject of the classification of birds, he speedily discovered that the accepted systems of the day were mere artificial, mechanical makeshifts. He replaced them with a system which, whatever its defects, was vastly superior to any other hitherto conceived of. And this because he realised, what his predecessors had not, that the superficial, external likenesses, which animals often present, are absolutely untrustworthy evidences of relationship. It was this criterion of superficial resemblances which led the older naturalists to regard the whale as a fish, and the swift and the swallow as nearly related species.

Huxley, knowing little or nothing about birds, from the ornithologist's point of view, came to his subject withoùt any preconceived notions. $\mathrm{He}$ sought to avoid the danger of prejudicing his mind by mere externals, and by turning his attention instead to a study of deep-seated, internal structures, to establish a classification which should express, more or less accurately, the inter-relationship of the various groups of birds one to another. $\mathrm{He}$ chose, and wisely, to make the skull the corner-stone of this classification. But he left out of account the evidence furnished by young birds; neither their embryonic nor early post-embryonic characters entered into his calculations. Thereby he missed some extremely important evidence such as he was seeking; evidence, too, such as his soul loved, pigeonholed as it might have been under the "comfortable word Evolution," for further use in some of those brilliant discourses delivered during his championship of the cause of Darwinism and liberty of thought.

What then, precisely, were the points which Huxley 
missed by his neglect to seek evidence of young birds ? Briefly, he founded a system of classification on the form and arrangement of the bones of the palate, whereof he recognised certain distinct and sharply defined types, without making the discovery that these were all modifications of one common plan. That is to say, he apparently regarded these several types as so many isolated units, instead of so many divergent branches of a common root. He realised, surely enough, that the palatal bones of the adult members of the ostrich tribe presented a more "generalised" condition than could be found among the adults of any other birds, and thereby he seems to have imagined a great gulf to be fixed between them. Such a view, indeed, is well justified if one compares, say, the palate of the skull of the emu with that of the common fowl, or even the gull. But the early stages in the development of these bones tell a very different story.

In the case of the emu, which we will take as our standard of comparison, it makes but little difference, it is curious to remark, whether we examine the bones of the nestling or the adult. It is curious because one would have expected to find the skull of the young emu displaying features characteristic of some distant past. But, be this as it may, the particular facts to which we desire now to draw attention concern the bones which, like rafters, form the roof of the mouth.

Turn for a moment to the figure illustrating the palate of the emu. Note down the centre a long, broad plate of bone, deeply cleft at its base to form a pair of outwardly curved bars, which are attached to a pair of short, bowed, flattened beams, pointed in front ; these are the pterygoids, and the median plate attached thereto is the vomer: a third element, which plays a very important part in this 
scheme, is the palatine. In the emu (Fig. A) this is a roughly triangular plate $(\mathrm{Pa})$, the base of which is applied in part to the foot of the vomer, and in part to the outer border of the pterygoid, as may be seen in the plate. Now compare this with the palate of the South American ostrich or rhea (Fig. C).

Here it will be noticed the vomer is reduced in size, the palatines have moved inwards toward the middle line, beneath the anterior ends of the pterygoids, and towards one another. In both, emu and rhea, it should further be noticed, for the better comprehension of our story, that the bones known as the palatine processes $(\mathrm{Mx})$, or ingrowths of the maxilla, are very large. In the skull of the tinamou, also a South American bird, and undoubtedly related to the rhea, we get a still further reduction of the vomer, while the palatines and pterygoids have become relatively longer, and more rod-shaped.

Very well. Now compare these three palates with those of the gull (Fig. E) and the common fowl (Fig. D). In the gull, it will be seen, the vomer is still further reduced, and, what is more remarkable, is now no longer in touch with the pterygoids, but is borne by the palatines $(\mathrm{Pa})$, which have greatly increased in length, and have met one another in the middle line. The pterygoids, it will be noticed, are slender rods articulating by a cup-and-ball joint with the ends of the closely apposed palatines, while the palatine processes of the maxillæ, to which attention has just been drawn, are extremely reduced.

Pass from this to the palate of the fowl. This presents the same general features as are seen in the gull, but the vomer is still further reduced, and is commonly absent altogether. If this palate be compared with that of the emu, with which we started, the differences between 


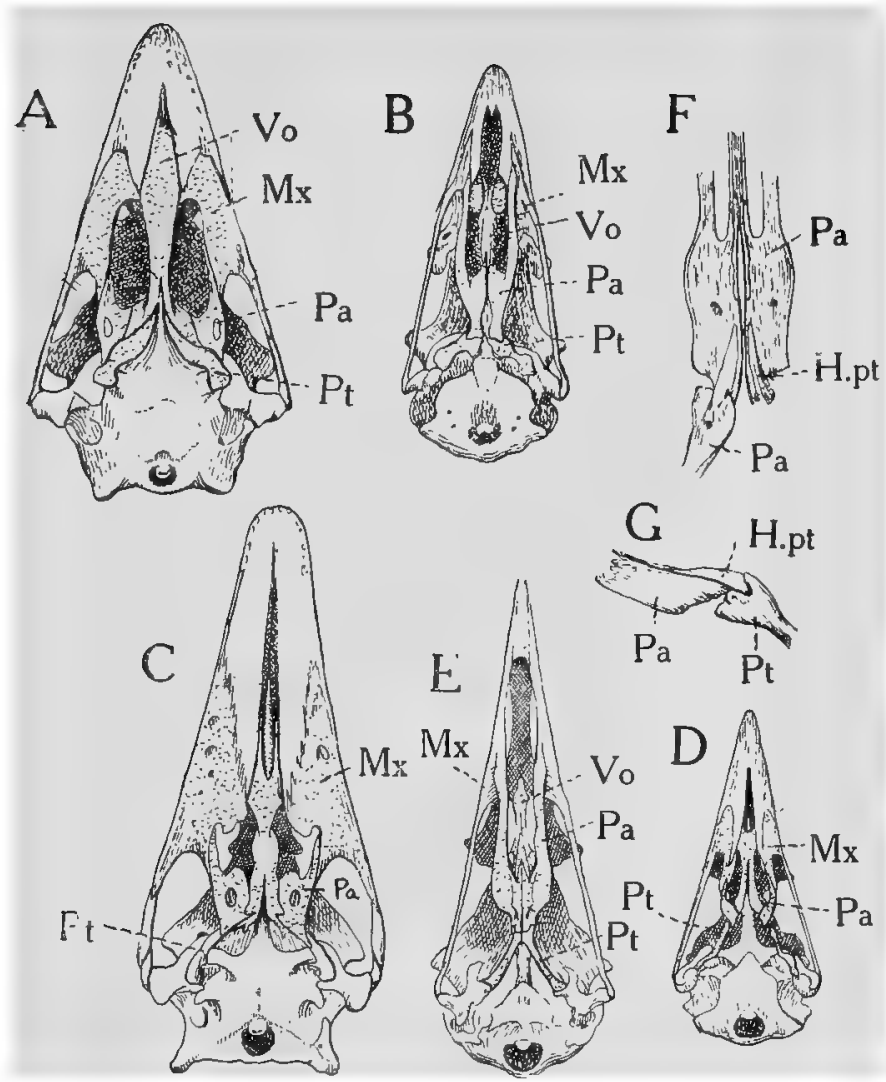

THE BONY PALATES OF MEMBERS OF THE OSTRICH TRIBE COMPARED WITH THOSE OF SOME MODERN BIRDS, TO SHOW THE DEGENERATION AND CHANGE OF POSITION OF THE VOMER (VO) AND THE TRANSFORMATION OF THE PALATINE BONE (Pa) AND PTERYGOID (Pt).
A. Ostrich.
B. Fow1.
C. Rhea.
D. Tinamon.
E. Gull. F.G. Penguin. 

the two appear to be so profound that, judging from the evidence as it stands, one would say that they represent two distinct types, bearing only a general resemblance one to another. The pterygoid and palatine in the emu articulate one with another by overlapping edges, or by "squamous suture," in the gull and fowl by a cup-andball joint. The pterygoid and vomer in the emu are in close relationship, in the gull and fowl they are widely divorced. These things Huxley saw, and they persuaded him that the two types, the one common to the ostrich tribe, the other occurring in all other birds, with various minor differences, were entirely distinct.

A study of the skulls of young birds on which I was engaged a year or two ago showed me that, as a matter of fact, the more specialised type is directly derived from the less specialised, more "primitive," or more ancestral type; and that all the specialised types of palate attain their several peculiarities only after passing through a more or less extensive series of changes, commencing with a stage which answers, more or less exactly, to the palate of the emu. The nature of the series of changes which affect the transformation from the one type to the other may be gathered sufficiently well from what obtains in the palates of the gull, the fowl, and the penguin.

In the nestling penguin the palatines have assumed the form characteristic of the "neognathine"-the type wherein the palatines meet in the middle line-but the relations between the pterygoid and vomer are as in the "Palæognathine" palate, though they show an approximation towards the more specialised type.

Briefly, the pterygoids are rod-shaped, but terminate forwards in a spike which in some individuals reaches the hinder extremity of the greatly reduced, blade-like 
vomer, while in others they just fall short of touching, as in our illustration. And now a curious thing takes place. The forwardly directed spike of the pterygoid, to which we have referred, rests upon the upper surface of the palatine, and in due course becomes separated from the main shaft, almost as if by fracture, just behind the end of the palatine. Next the fractured end fuses with the palatine, so that its identity is completely lost, and thereafter the cup-and-ball joint forms, apparently between the palatine and pterygoid, but really between the hinder end of this fused segment of pterygoid and its larger moiety. When we come to examine a large series of different types of birds, we find this spike-like anterior end of the pterygoid growing smaller and smaller; in some only a mere nodule of bone appears, in others even this is wanting. And the same is true of the vomer. In the hawk tribe, for instance, there is a more or less distinct " hemipterygoid," but this has vanished in the falcons.

Surely a more interesting illustration of the stages whereby new types of structure are evolved it would be hard to find anywhere. Huxley was, rightly enough, impressed by the profound difference which obtains between the palatal region of the ostrich tribe and those of all other birds; and he of all men would have appreciated to the full the facts revealed by a study of the skulls of nestling birds, if only chance had happened to start his curiosity in this direction. No more striking demonstration could be found of the contention that animals, in the course of their individual development, or " ontogeny," repeat the history of their race.

It is difficult for the layman, for obvious reasons, to examine such facts as the foregoing for himself, or even, perhaps, to appreciate their full significance-at any 
rate until after very careful thought. But there are other facts of a similar nature which are more easily grasped. These are illustrated by the beaks of young birds : which, as everybody knows, present a marvellous range in size and shape, and some present features which are of exceptional interest, since they represent degrees of specialisation often unique.

Take the scissor-bill tern, for example. In this bird the lower jaw is half as long again as the upper jaw, and both are flattened from side to side to the thinness of a paper-knife from tip to base. Now this bird feeds after a quite peculiar fashion, skimming along over the surface of streams with the lower jaw plunged into the water: as it ploughs its way through

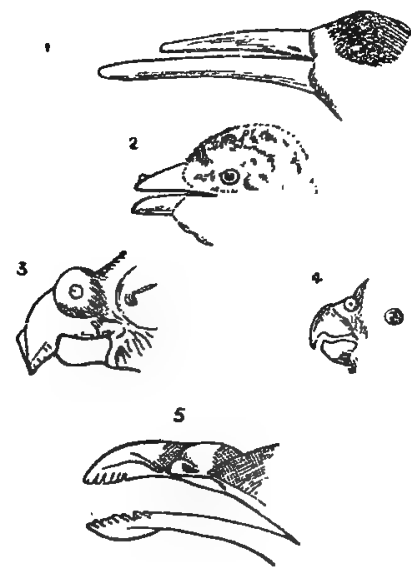

BEAKS OF NESTLING BIRDS COMPARED WITH THOSE OF THE ADULTS.

r. Adult scissor-bill.

2. Nestling scissor-bill.

3. Nestling cocatiel.

4. Adult cocatiel.

5. Nestling tinamou, showing a toothlike armature.

shoals of small fish one after another is caught, as in a cleft stick, between the upper and lower jaw, and passed back to the mouth and swallowed. But in the nestling bird no sign of this most extraordinary beak is present, the two jaws being of equal length. Similarly the long beak of the curlew, and the strange upwardly turned beak of the avocet, and the crossed mandibles of the crossbill, and the pouch of the pelican are not developed till the end of the nestling period. 


\section{44}

\section{THE INFANCY OF ANIMALS}

The parrots again display striking differences in the form of the beak when nestling and adult are compared. In the cocatiel (Calopsittacus), for example, the beak in the adult is short, and the upper jaw terminates in a sharp point : in the nestling, on the other hand, the whole beak is larger, relatively. The upper jaw, it will be noticed, differs absolutely in shape, the tumid area pierced by the nostril is larger, and if a vertical line from the point of this globular swelling be drawn it will be found to pass downwards in front of the lower jaw; in the adult such a line passes through its middle.

Further, in the nestling the upper jaw terminates in a broad, scoop-like tip instead of in a point, suggesting an earlier stage of development, when the food was different from that now eaten. The tip of this beak, it will further be noticed, bears a pointed cap : this is the " egg-tooth," a small, sharp-pointed, calcareous body used as a shellbreaker-that is to say, as a sort of "tin-opener," for therewith the bird when about to be hatched cuts away a portion of the shell the more easily to effect its escape. The egg-tooth is not peculiar to the parrots; it is found on the tip of the beak of all young birds, and soon after hatching becomes detached. It is also, be it noted, found in reptiles, and in the young echidna among the mammalia. Here is an instance of a structure which is not an "ancestral" character in the sense in which this term is used. That is to say, it does not represent a sometime adult character, but is, and always has been, an accompaniment of the final embryonic stage.

This reference to the "egg-tooth" naturally suggests the question-Are any traces to be found of teeth in the jaws of young birds? They may well be sought for, since ages ago many species, like Archæopteryx, Ichthyornis, 
and Hesperornis, long since extinct, bore teeth along the edges of the beak, which have since been replaced by the horny sheaths with which we are familiar. So far no satisfactory evidence of such structures has been met with, but some years ago I described in the beak of a nestling tinamou (Calodromas), what I believed, and still believe, may prove to be vestiges of teeth. These, along the cutting edges of the fore-part of the upper jaw, take the form of a number of tiny, white, closely crowded teeth, and a similar series is met with along the lower jaw. But from that day to this I have never been able to secure the necessary leisure to devote to the work of cutting sections of these jaws for microscopic examination.

Yet another structure peculiar to the early post-embryonic period must be mentioned. This is the curious roughened "heel-pad" which is found at the base of the shank, or rather the back of the ankle-joint in birds like the barbets, the wrynecks, and the woodpeckers. The use of this pad is not quite clear, but it will perhaps be found to be present in the young of all birds which are reared in holes on the bare ground, or in hollow trees, where no real nest is made. They may serve the same purpose as the horny pad which is found on the breast of the ostrich : and as the similar pads on the chest, wrists (" knees "), and true knees of the hind limb in the camels. There is the more reason for this view because the pad in question is so placed that it tends to throw the rest of the foot upwards. But while in the nestling birds the surface of the pad is covered with little pointed cones, in the ostrich and camels this surface is smooth.

The sheath of the beak in nestlings shows two other features which cannot be omitted here. The first of these concerns the compound character of the sheath. 


\section{THE INFANCY OF ANIMALS}

In the majority of living birds, it must be mentioned, this sheath is formed of a continuous piece of horn, but in some, as in the ostrich tribe, the gannets and cormorants and their kin, and the petrels, it is made up of several distinct plates. That this compound sheath was once a common characteristic is shown by the fact that in the embryos of many species, as for example in the common heron, these separate plates still make a fleeting appearance, and traces thereof are to be found in the beaks of many adult birds of various kinds.

The second feature to which reference has been made is one of a more striking character, since it. intimately concerns so vital a process as that of breathing. Briefly, the aperture of the nostrils which pierces this sheath in certain adult birds is closed, and the process of this closure is a gradual one which can be studied in the embryonic and nestling stages.

I had the good fortune to make this interesting discovery some years ago, while examining a recently dead cormorant. Herein, the most careful research failed to reveal any external nostrils, though a trace thereof seemed lying in a groove near the base of the beak. On forcing the plates of the compound sheath apart and raising them from the underlying skeleton I found a short plug of horny tissue lying to the inner side of the groove which I suspected originally marked the position of the external nostril, and this plug had plainly been withdrawn from a small aperture in the underlying bony skeleton. Passing a bristle down this aperture it at once emerged from the posterior nostrils in the roof of the mouth, thus revealing a most unexpected state of affairs.

Turning, when opportunity afforded, to the examination of embryos and very young nestlings, I found that external 
nostrils were still present, though extremely reduced in size. The process of closing seems to have been brought about in the first place by a gradual reduction in the bore of the tube formed by the ingrowth of the horny sheath, and this tube seems to be gradually closed by

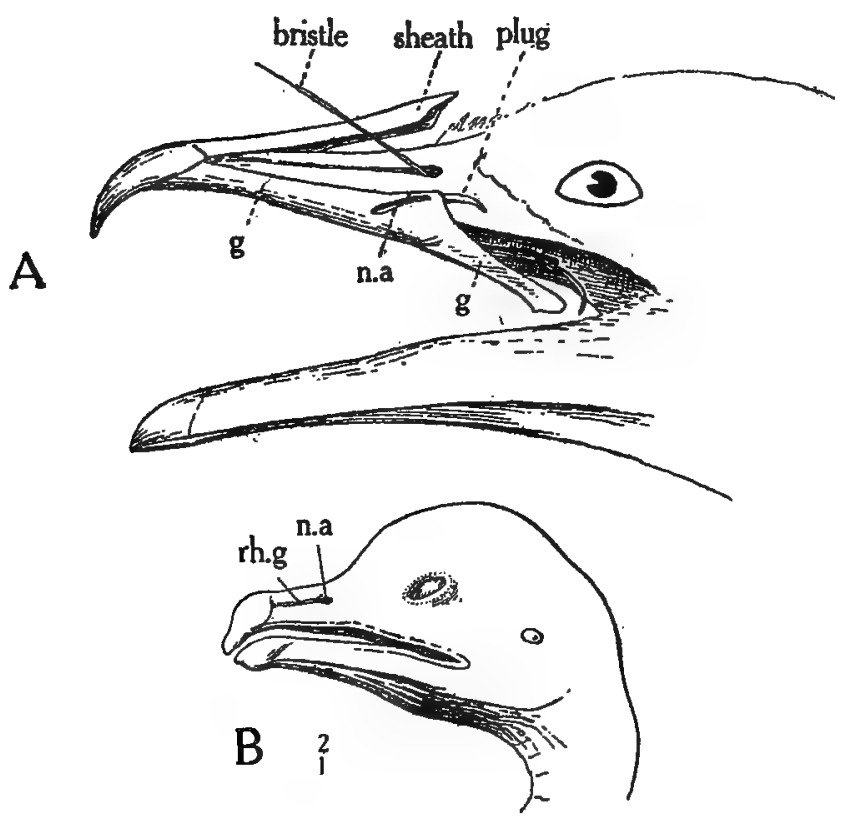

BEAK OF AN ADULT AND OF A NESTIING CORMORANT, ILLUSTRATING THE CLOSURE OF THE EXTERNAL NOSTRILS.

the shedding of the surface of its inner wall until the aperture is finally plugged. But more than this came to light. It soon became apparent that the darters, gannets, pelicans and penguins had all, in like manner, undergone this process of closing up the external nostrils, and that the underlying skeleton had also become involved in this change. 
To appreciate the nature of the latter fact it is necessary to remember that in most birds the skeleton of the beak is formed by three bony beams-an upper forming the ridge of the beak, and a right and left lateral forming its sides. Enclosed within the space thus formed, and at its hinder end, lie the cartilaginous walls of the olfactory apparatus. Now, partly by the ossification of these walls, and partly by the extension of bony matter by the thickening of the beams just described, the whole of the once spacious chamber covered by the beak sheath is filled up in all the birds mentioned in this connection save the penguins. But in the Cape penguin, this process of closing is far advanced, though even in very old birds it is never carried so far as in, say, the cormorant or the gannet. What the Cape penguin fails to do during its whole lifetime, the gannet and the cormorant accomplish before they leave the nest. In the embryo we find the typical beak skeleton of three bony beams; by hatchingtime the work of closing has begun, and by the time the nest is left it is complete.

One naturally seeks to explain these evidently related facts. It is clear, from what obtains among the penguins, that the aperture in the beak-sheath closed long before any change began in the underlying bony structure. But how the one reacts upon the other seems impossible of explanation. More difficult yet to grasp is the reason for the closing up at all. If only the cormorants and penguins displayed these phenomena we should at once be ready with an interpretation-the whole thing would have been as clear as day; for having regard to the fact that the whole of the food of these birds must be obtained by diving, we should therefore have explained the suppression of the external nostrils as an adaptation to these 


\section{YOUNG BIRDS AND RECORDS OF THE PAST I49}

diving habits, as a device for preventing the entrance of water into the nostrils during prolonged submergence.

The similar loss of external nostrils in the gannet and pelican we might have explained on the same grounds, since these birds dive for their food from a height, and might be supposed to require protection from the entrance of water into the windpipe no less. But the tropic-bird (Pbretbon), a near relation of the gannet, and the kingfisher also dive in like fashion, and have open nostrils. Similarly, the guillemot and razor-bill, the grebes and divers and many species of ducks, have to procure their food by prolonged submergence, like the cormorant and the penguin, and they have open nostrils!

Here; then, is a case which seems to defy interpretation, and one, moreover, which has no parallel among vertebrates. The process of closing revealed by a study of nestling birds reveals some interesting facts, but so far it throws light only on one aspect of the phenomena. It is surely not a little surprising that these facts should have remained so long unnoticed, for there are no other instances known among land vertebrates where the respiratory air is drawn in solely by the mouth. A careful examination of the nostrils of diving birds which remain open may show that some mechanism hitherto unsuspected may exist whereby the nostrils can be closed, as is the case with the seals, for example, during the time of submergence.

During all my life nestling birds, and their later "flapper" stages, have exercised a peculiar fascination for me : at first for reasons which I could not explain; later for the light they shed on the various evolution problems which form so piquant a sauce to the otherwise insipid meat which must form so much of the mental 
food of the comparative anatomist. Unusually favourable circumstances have provided me with exceptional opportunities for gratifying my appetite in this direction: as witness the facts already set down in regard to the coloration both of downy nestlings, and of their later, "juvenile" plumages.

I propose now to set down a few facts which have come my way in the matter of these down plumages apart from the coloration. They do not, by any means, represent the sum of our knowledge of these things, and it is to be hoped that some reader of these lines may be tempted to take up the further development of the problems raised.

In the first place, be it noted, there are two quite distinct kinds of nestling down. One of these is developed from the same germs as will later give rise to the "contour" feathers-that is to say to the outer covering of the adult bird-hence I have called such down feathers "pre-pennæ." The other precedes the down feathers which form a sort of "under-fur" in so many birds, e.g. ducks and swans, and hence are called "pre-plumulæ." Where no down-feathers are developed in the adult no pre-plumulæ occur in the nestling, as for example in the owls. Now the importance of these distinctions does not become apparent until we begin to compare one nestling with another, as for example young owls with young hawks.

Those at any rate who are not practised ornithologists would find it no easy matter to distinguish, say, a young Barn Owl from a young kestrel, for both are covered alike in a long white woolly garment of down. But a careful examination of this garment would show the difference at once; for in the owl only pre-pennx would be found, while in the hawk the downy covering would 
be of a compound character, being composed in part of pre-pennx, and in part of pre-plumulæ. In the nestling cormorant the whole of the downy coat is of pre-plumulæ, but what of the gannet? No one has yet endeavoured to discover.

By great good luck some time ago I happened one day to have sent me for the collection of nestlings which I am gathering together for the British Museum a young tawny owl, which revealed to me the surprising fact that this bird, at any rate, developed two generations of nestling down; so that it became necessary to further label these pre-pennæ. Thus the down feathers of the first generation must be known as "protoptyles" or first feathers, those of the second as "mesoptyles" or "middle feathers," since they occur between the "protoptyles" and the "teleoptyles" or the typical contour feathers. The existence of these mesoptyles forced itself on my attention the more strongly because they were so strikingly dissimilar from the typical down feathers one always associates with young birds on the one hand, and from typical "teleoptyles" on the other. For in a typical nestling down feather the barbs are long and very slender, all starting from a common base, or are, in other words, " umbelliform." The feathers of the first generation of down feathers in the tawny owl are of this character, whereas those of the second differ conspicuously, the barbs being borne in double series, on a long, tapering shaft, just as in a typical "contour" feather. But they differ from contour feathers in the loose character of the barbs, for in the typical contour feather the barbs are closely knit together by an elaborate mechanism which it is not the purpose of these pages to discuss. Moreover, in their coloration they differ entirely from either the down of 
the preceding generation or the contour feathers soon to follow, being of a pale rust-colour barred, with black.

Furnished with this clue, one naturally began to examine nestling down of all sorts of birds, and the surprising fact soon came to light that this mesoptyle plumage could be traced in quite a large proportion, though in most cases it was of a degenerate character, only to be distinguished from down feathers of the first generation (protoptyles) when found in direct association therewith. Herein we have another lesson in evolution associated with degeneration.

As a matter of fact these two phenomena are commonly associated, but not always directly. To get at the bottom - of the matter of this degenerate mesoptyle down, then, it is necessary to bear in mind the fact that, in the development of adult plumages, there are growth pauses. One generation of feathers, say that of the breeding plumage, completes its growth, and the growing or formative tissue at its base, as it were, dries up: when at the approach of the autumn moult the activities of the formative tissue begin again, the old feather is thrust out by the growth of the new one at its base. But when one generation of feathers rapidly succeeds another, it may happen, and does happen in the case of these nestling downs, that the growth of the mesoptyle begins before that of the protoptyle is finished, so that the first is organically connected with the second.

In some cases there is a hardly perceptible growth pause; such as there is can be traced only by the microscope, and then reveals itself in the absence of barbules along a part of the continuous barb common to both generations. The absence of barbules, in other words, 

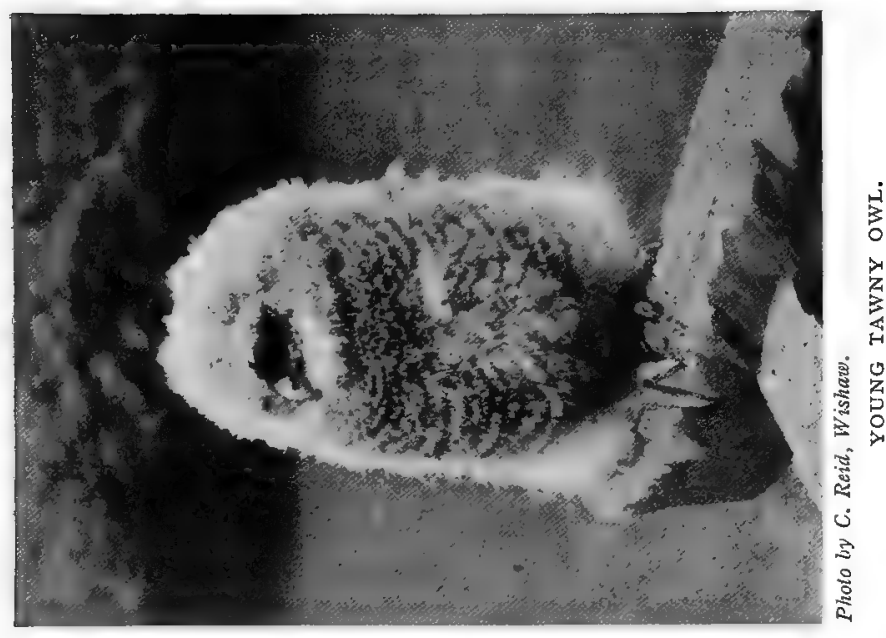

号
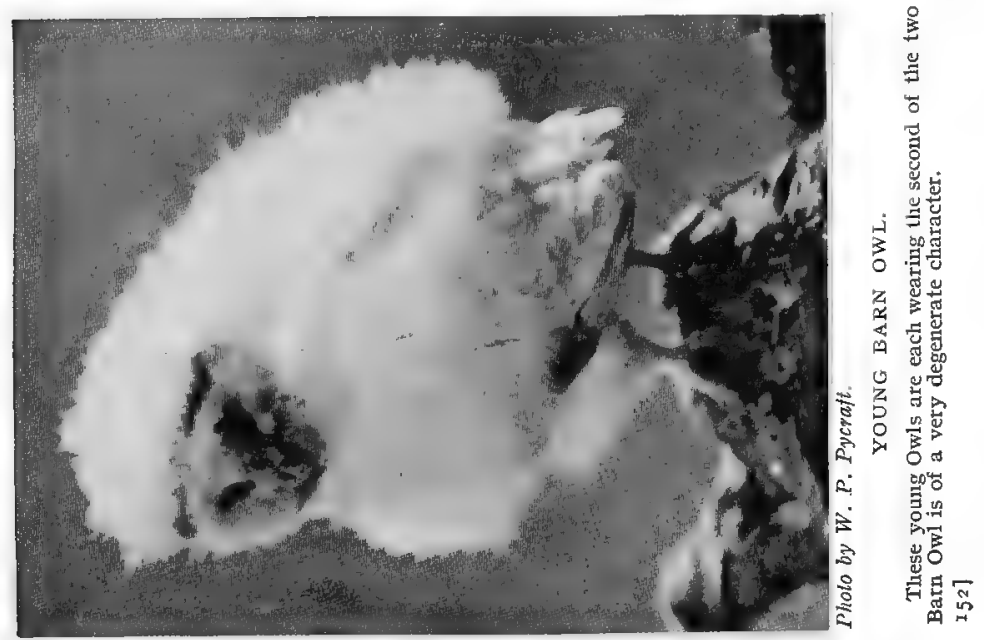

marks the pause, or rather slowing down of growth, which followed the completion of the protoptyle.

The nestling down of penguins and petrels admirably displays these phenomena; but they are no less distinct in the nestling down of the young barn owl, which, obviously, differs in a very striking manner from that of the tawny owl, for example, wherein, as we have seen, the mesoptyle down is of a complex character; and this complexity is found to far greater perfection in young megapodes and young tinamous, wherein the mesoptyle feathers have hitherto been mistaken for contour feathers. The mesoptyle nestling down feathers of many gallinaceous birds, and of the swans, geese, and ducks hold a half-way position : being more degenerate than those of the tawny owl, but far less so than in, say, the young barn owl; and this because they display a long shaft bearing a double row of barbs. But the barbs are of a degenerate character. In the gallinaceous birds every possible degree in the degradation of the mesoptyle is to be met with. In the young turkey, for instance, it is relatively well developed, presenting a long shaft and an aftershaft; in the young grouse the shaft has disappeared, and the down is umbelliform, though far less degenerate than is the young owl or hawk.

In all contour feathers save the remiges or quill-feathers and rectrices or tail-feathers, there will be found at the base of the shaft a second smaller shaft bearing a vane of its own, and rather "downy" in texture. This is known as the aftershaft. In the gallinaceous birds it is very large, in the owls it is absent; between the two every gradation in degeneration will be found. But nowhere, among adult birds, will so large an aftershaft be found as in the emus and cassowaries, in which, if 
the feather be removed from the body, it is almost impossible to distinguish between main shaft and aftershaft.

From this it has always been argued that the large aftershaft is an ancestral feature which has survived. This may be so. But if it be, it is difficult to reconcile what obtains among the tinamous, on the one hand, and the nestlings of the ostrich tribe on the other. For in the emu and cassowary the aftershaft is almost obsolete, in the nestling ostrich it is large, but absent in the adult; in the tinamou it is obsolete in the adult, very large in the nestling! So far no one has been able to interpret these contradictory facts.

In another point, however, the cassowaries do conform to the rule that the characters displayed by the nestling to-day are features which belonged to the adults of the past; and this in the matter of those extraordinary quills which stick out from each wing in the adult. These seem to be neither useful nor ornamental, and even their true nature was mistaken until it was made clear by the revelations of the nestling, or rather the bird in its later "juvenile" plumage. Examining a series of these I found that these quills were here represented by relatively normal feathers-that is to say by feathers which displayed a hollow quill, surmounted by a shaft bearing a double row of barbs.

Sooner or later, to make a long story short, the shaft bearing the vane sloughed off, leaving only the quill, which then rapidly increases in length and thickness, ultimately forming the rather crooked spike already referred to. Not the least curious thing about this transformation is that in the Apteryx the quills throughout life are of the type seen in the immature cassowary. 


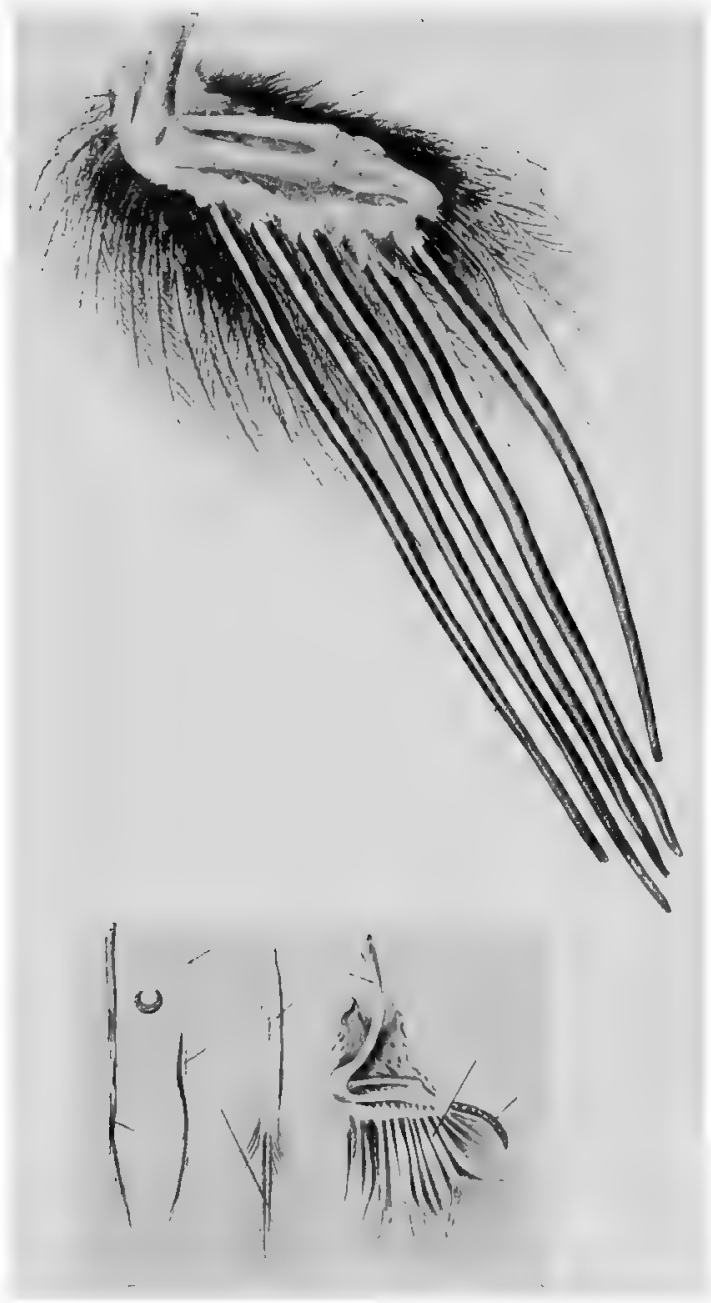

THE STORY OF THE CASSOWARIES' WING.

In the young bird the degenerate flight feathers have a typical barrel, or quill, and feebly developed shaft and "vane," as in the left-hand figures in the inset. Later, the shaft and vane sloughs off, and the hollow quill becomes scilid, as in the large upper figure. The small wing is that of the Apteryx, in which the shaft and vane are retained through tife. 



\section{YOUNG BIRDS AND RECORDS OF THE PAST 155}

Now what is the meaning of these early feather generations-the protoptyles and mesoptyles? All the evidence seems to show conclusively that they answer to ancestral plumages; and if we may judge by what obtains in some of the tinamous, the megapodes, and the tawny owl, for example, and the sequence of plumages in later stages, already discussed in our chapter on coloration, it is by their successive development and decline that new phases of plumage, that is to say of coloration, are developed. In other words, as old, ancestral phases are shed, making their last appearance in the young, new ones are developed by the adults: thus what are the acquirements of the birds of to-day will be the characteristic features of the nestlings to-morrow.

The gradual degeneration, and in many cases even the suppression, of the nestling down of the helpless or nidicolous types has possibly a special significance. In the young of the lyre bird alone have I found evidence of two generations--proto- and mesoptyle-and we may perhaps conclude that in all the other species the mesoptyle alone remains, weak and sparse in most, and suppressed altogether in many. This process of degeneration we may regard as the direct result of the nidicolous condition. Young birds crowded together in a nest keep one another warm when they are not brooded by the mother, and the fact that no down is ever developed on the under surface of the body in such nestlings goes far to confirm this view.

Surely this story of the nestling down is one of the most striking, one of the most interesting of all the things that the nestling bird has yet revealed to us. As an object-lesson in evolution it would be hard to beat. 


\section{CHAPTER VIII}

\section{REP'ILES AND THEIR PROGENY}

Young mammals and young birds differ conspicuously from young reptiles in that for a more or less extensive period they require no inconsiderable amount of care and attention from their parents; but this bond, as we have seen, is severed by the parents, sometimes in a very unceremonious fashion, so soon as this attention is no longer necessary. Young reptiles, on the contrary, are from the first independent, and as a consequence there has been no stimulus to develop the parental instinct. Between parent and offspring there are no ties of affection, save in one or two exceptional cases.

Young sea-snakes, for' example, seem to enjoy the guardianship of one or other of their parents for some time after birth, since the naturalist Semper once found a large female coiled up among the rocks, and between her folds were at least twenty young, two feet in length. The young of the common viper of our heaths seem to accompany their mother for a short time at least : and there are some who would have us believe that, so anxious is she for their welfare, that when danger threatens, she opens her mouth so that her precious offspring may take refuge within her body till the cause for alarm be past. After the existence of the sea-serpent perhaps no incident in 


\section{REPTILES AND THEIR PROGENY}

natural history has given rise to more heated, unprofitable controversy, and it must be admitted, when the facts are squarely faced, that there is absolutely no evidence in support of this fantastic belief. The story, however, is founded on no idle gossip, but on a misinterpretation of evidence, for by way of proof those who are genuinely convinced that they have really witnessed this strange disappearance adduce the fact that they have actually slain the snake and taken out the living young from within her. This they may indeed have done, for the viper is viviparous, and the young revealed by the operation of the knife are young which otherwise would not have seen the light of day for some hours later.

Young crocodiles and alligators owe more than they can ever be aware of to the guardianship of their mothers. Thus the female of the common crocodile digs a hole in the sand from eighteen inches to two feet deep, so contrived that the bottom of the nest is wider than the top, and has its centre in the form of a mound. Thus, when the eggs, some twenty to thirty in number, are laid, they roll down the slope into the circular trench. When the hole is filled up the mother selects the top for her sleeping-place, and thus betrays what she had been at such pains to conceal. In about twelve weeks the eggs are hatched. The young give warning of their readiness to rise from their burial-place by a peculiar hiccough-like noise which is heard by the mother when she returns to the nest for her nightly slumber. She then proceeds to remove the earth above them and awaits the moment of their emergence from the hard, protecting shell. They need no further aid in making their escape, for the snout of each is armed, as in the case of young birds, with a hard, tooth-like spur, which serves the purpose of a tin-opener, since it cuts away 
a circular area at the end of the shell, which can then be thrust off like a lid.

The reality of the mother's regard for her young was attested long since by the naturalist Voeltzkow, who built a fence around one of these nests near hatching time. Each night, on her return, she broke down the fence, even though each fence was made stronger than the last. Finally the nest was found to have been deserted, and then it was discovered that she had dug a hole beneath the fence and thence had led her brood away to safety.

Young alligators have a somewhat different upbringing, and would seem to receive less of the maternal attention. They are hatched like young crocodiles under a mass of earth, but in this case the nursery is formed not by excavating a hole in the ground, but by scraping up a mass of dead leaves, twigs and fine earth, till a mound some three feet high and as much as eight feet in diameter is formed. On the top of this mound, some eight inches from the surface, some twenty or thirty white, hardshelled eggs are laid, and are there left to incubate by the heat generated by the decaying vegetable matter. As soon as the young escape from the shell they readily make their way through the light soil covering them, and run to the water without any further care on the part of the mother. All this time, however, she has not been indifferent to their welfare; on the contrary, the eggs have been most jealously guarded and with less ostentation than in the case of the crocodile, for instead of lying over the spot which hides the eggs, she digs a hole in the river bank within a foot or two of the mound, and there awaits possible marauders.

Altogether about 2,600 species of reptiles are living to-day, and of this great host, only in one or two species 


\section{REPTILES AND THEIR PROGENY}

of crocodiles, and one or two species of snakes, do the young receive any parental attention after hatching, and very little before that event. The only other cases worth mention are those of the pythons and the European pond tortoise. The pythons lay from fifteen to one hundred eggs, and these the mother jealously guards by coiling her body round them. From observations made on a captive python of the Indian species (Python molurus), in the Zoological Gardens of Ceylon, this guard was kept for two and a half months, at the end of which time fortyfive young snakes emerged from the eggs, measuring from two to two and a half feet in length.

Most snakes bury their eggs, so that this custom of the python must be regarded not simply as a method of guarding them, but also as the means of incubation. And this view is supported by the fact that every now and then during her brooding period she would open her coils as though to regulate the temperature. Not until the day before the young hatched out did she relax her vigil and leave the eggs, and during the whole of this long incubation period she never once tasted food, though all kinds of delicacies were offered her.

The case of the European pond tortoise, to which reference has just been made, is one of minor interest, but it may be said to mark the beginning of wider maternal instincts, for while most reptiles simply bury their eggs in the ground, generally choosing a place affording a gentle heat, as from decaying vegetation, or a sun-bathed spot in the open, this tortoise first prepares the ground by watering it from the bladder and certain special accessory water-sacs. Then it stiffens the tail and bores a hole therewith. This is then enlarged by the hind feet, and the work of excavation is carried on until a fairly large 
cavity is made some five inches deep. Here the eggs are laid, and distributed over the bottom by the feet, when the soil is thrust back again and beaten down flat: finally, the spot is concealed by scratching the surface a little with the claws. But this done, no further interest is displayed in the welfare of the nest.

While in the majority of cases the eggs of reptiles are laid as soon as the shell has been formed around them, in some species they are retained within the body until the development of the embryo is complete. What determines which of the two courses shall prevail, is not clear, but it would seem that internal development must be regarded as a device to secure the safety of the young. In the seasnakes, which are ovo-viviparous, the advantage is obvious, since eggs deposited in the water would be liable to be carried away, or devoured by predaceous animals. But it is not so easy to understand why the slow-worm, burrowing-snakes, the viper, and the skinks, for example, should agree with the sea-snakes in this particular. A closer study of the habits of these reptiles in a wild state may clear up the mystery. It is suggestive, at any rate, to find degrees of ovo-viviparity tending to develop into true viviparity-that is to say, the condition where the young, instead of being nourished by a mass of food-yolk enclosed within a shell, are nurtured by absorption from the tissues of the parent. In some of the skinks there seems to be an approach towards this condition, the egg having no hard shell, and containing but a limited amount of foodyolk, which is replaced by the absorption of food through the thin membrane which constitutes the inner lining of the shell in normal eggs.

Whether the eggs be laid as soon as the shell is completed, or whether they be retained within the body, the 


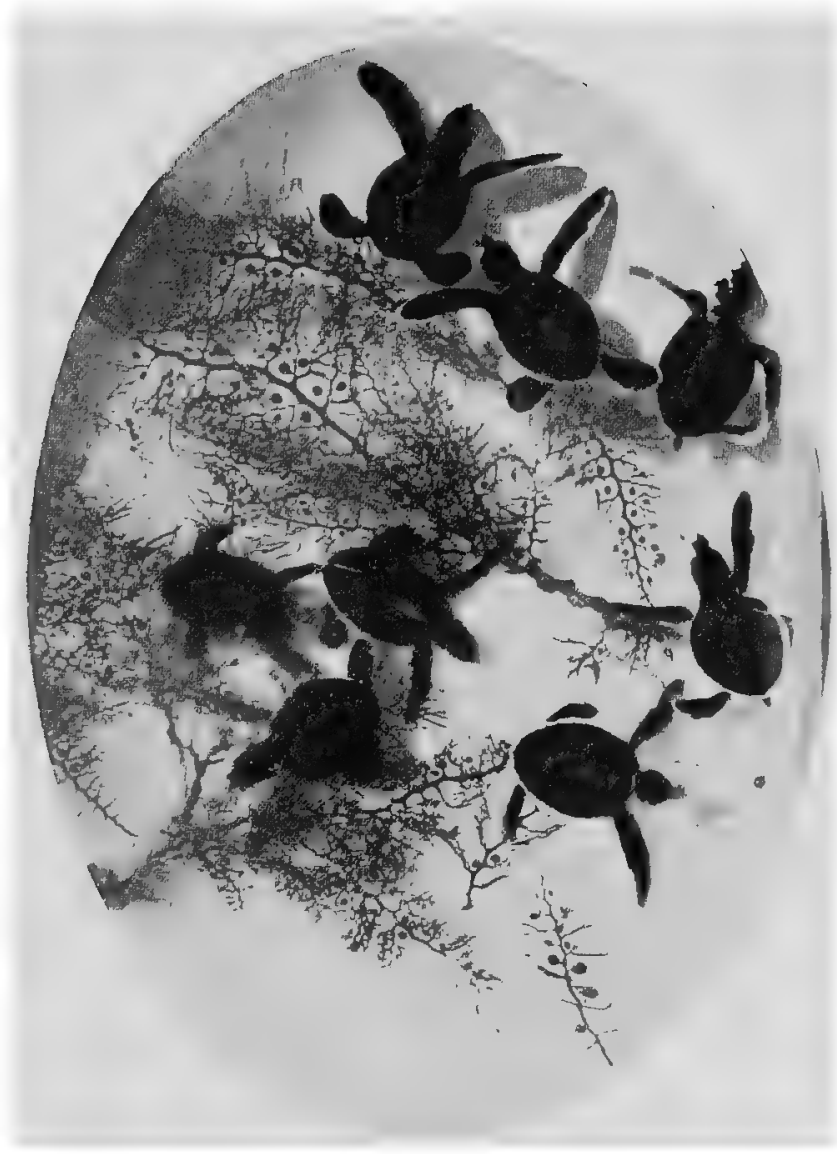

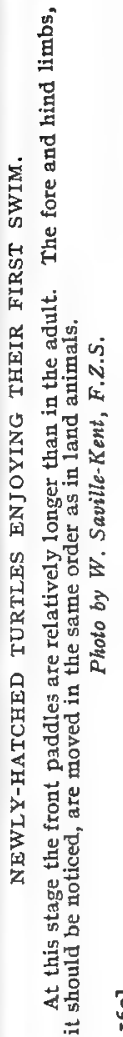





\section{REPTILES AND THEIR PROGENY}

development of the young always proceeds forthwith without interruption, save in one or two exceptional instances. In the lizard-like tuatera of New Zealand the eggs are laid during the Southern summer-between November and February-and by August, in the case of the earlier eggs, contain ripe embryos. But these do not hatch out till the following February-or until the embryos are some thirteen months old. Thus these embryos undergo a period of hibernation such as is common to many animals which have to evade starvation during the time when the food supply necessary to their sustenance is no longer attainable; migration to attain this end is the only other alternative, and this is impossible. A precisely similar instance of embryonic hibernation obtalns in the case of the European pond tortoise (Emys orbicularis). But only in the northern part of its rangein Russia, for instance-the embryonic stage extends over a period of no less than eleven months; where the winters are mild, as in southern Europe, the young hatch out the same autumn. In the common chamæleon, again, the eggs are laid in October, and do not hatch out till the following February or March.

During the last few years our knowledge of what we may call the domestic life of birds has increased enormously, affording us an insight into the deeper problems of their life-history hitherto undreamed of. This knowledge has only been gleaned at the expense of infinite patience, and occasionally some danger; but that there will ever arise an observer with sufficient patience to follow up the daily life of any of the reptiles, seems almost too much to hope for. But not till then shall we learn the significance of the singular disparity in the number of eggs laid by different species of these cold-blooded animals. 
Some of the lizards and some tortoises lay as few as five, some snakes lay one hundred, some turtles as many as two hundred. Yet the most prolific species, as with the birds, do not seem to outnumber those which lay but a few eggs. It is possible, of course, that where a large number are laid a considerable proportion are infertile. In the case of the python, referred to earlier in this chapter, out of one hundred eggs only half produced young, and some of these soon died. Nevertheless about thirty-six survived, which is a large number regarded as an annual output.

Some idea of the relation between the number of eggs and the mortality of the young is afforded in the case of the South American " arrau turtle" (Podocnemis expansa), one of the water-tortoises. This species lays its eggs, about two hundred in number, on the sand-islands of the Amazon and Orinoco and their tributaries, and as soon as the young are hatched they are greedily snapped up by crowds of jabiru storks, alligators and fishes, while the adults fall a prey to the stealthy jaguar, which turns them over on to their backs and neatly cleans out the shell with his powerful claws. But the ravages of this host of what we may call natural enemies are as nothing to the destruction wrought by man.

The naturalist Bates, in his fascinating book "The Naturalist on the River Amazon," gives us a long and most interesting account of the way in which these eggs were collected in his day. He was taken by the natives to witness the egg-harvest, and describes this in most vivid language. The "turtles" lay their eggs during the night, and when Bates climbed the look-out, erected by the natives for the purpose of observing the turtles without disturbing them, he saw the sands black with the multitudes scurrying back to the river. The collection of the 
eggs was carried out with great system, and occupied about two days. At the end of this time large mounds of eggs, some of them four or five feet high, were formed by the hut of each family of the natives encamped for the harvest.

Then began the work of smashing the eggs for the sake of their oil. The whole heap was thrown into an empty canoe and mashed with wooden prongs; but sometimes naked Indians and children jump into the mass and tread it down, besmearing themselves with yolk, and making about as filthy a scene as can well be imagined. This being finished, water is poured into the canoe, and the fatty mass is then left for a few hours to be heated by the sun, on which the oil separates and rises to the surface, when it is skimmed off with long spoons made by tying large mussel-shells to the ends of rods, and purified over the fire in copper kettles.

At least 6,000 jars holding each three gallons of oil were annually exported to Pará, to be used for lighting, frying fish, and so on : and another 2,000 jarfuls were consumed by the natives along the river. Bates estimated that at least 6,000 eggs would be required to make one gallon of oil, and that the total number of eggs annually destroyed amounted to about $48,000,000$. The yearly offspring of some 400,000 turtles was thus annihilated. Small wonder, then, can there be that over enormous areas these turtles are now reduced almost to the verge of extinction; only in some of the less accessible parts of their old haunts are these creatures still numerous.

We are often reminded that where we meet with great prolificness, there we also find a corresponding mortality, and that therefore the prolificness is Nature's endowment to enable a much persecuted species to maintain existence. 


\section{THE INFANCY OF ANIMALS}

Darwin himself showed the fallacy of this view. The mortality is not a stimulus to prolificness, but, on the contrary, the prolificness begets mortality; for from the vast numbers of young to be met with at hatching time, a lure is offered to predatory animals of all kinds, the last to join the marauders being always man himself, and he outdoes them all in his power of destructiveness. We must regard prolificness as a specific character answering to extravagance of ornament or gorgeousness of colour in other species. 


\section{CHAPTER IX}

\section{REPTILIAN LIVERIES}

IF the records in regard to the coloration of young reptiles be few in number, they lack nothing in point of interest; and when surveyed as a whole, and measured by the standard of interpretation adopted in the case of the mammals and birds, they will be found to present some very puzzling and contradictory features. But in making such comparisons it must not be forgotten that the reptiles are a far older group than either, and in consequence we should expect to find a greater elimination of such superficial ancestral characters as coloration, especially when one remembers the important place this often plays in the struggle for existence.

We have already pointed out the fact that longitudinal stripes are most commonly met with in the young of the more primitive types, that is to say, in those types which have retained the greatest number of ancestral features; and this rule is again illustrated in the case of the reptiles, for we find that the young tuatara "lizard," the most archaic member of the living Reptilia, is marked with longitudinal bands of grey and white, and more or fewer indistinct transverse bars of the same hues. These are soon lost, however, the adult being of a uniform greenish colour, or occasionally spotted, the spots representing the last traces of the earlier stripes. Such spotted adults, then, are probably not quite mature. 
The European wall-lizard (Lacerta muralis) is an extremely variable species in the matter of its coloration; but if a series of individuals of varying ages be studied, every stage in the evolution of colour and pattern will be found, and moreover these changes follow one another in the regular sequence which has been seen to obtain already in this matter. Thus we find in the history of this single species all the phases represented elsewhere-say among the plover tribe, for example-in a whole group of species. Thus, while apparently all individuals of this particular species of lizard are at first longitudinally striped, in some these stripes break up into spots, in others cross-bars are formed, and finally these disappear and leave, in the adult, a uniform brown or sandy coloration.

Certain individuals of this species undergo all these changes of coloration from youth to old age, others stop short at the second, or even the first stage, and a few skip the first or second stage and begin life in the third or fourth. In all cases, it is curious to note, these changes of coloration begin near the tail and advance forwards in a kind of wave-like manner, so that the shoulders may be in one of the intermediate stages while the tail has attained the permanent sandy condition. It is curious because the moulting of birds presents a similar rhythm. In the red grouse, for instance, the eclipse plumage begins on the head and neck and works backwards, while at the autumn moult the reverse order obtains.

In certain tropical American lizards, as in the ameivas, we meet, in the young, with longitudinal white stripes, showing a tendency to break up into spots. These eventually disappear in the adults, though, be it noted, they commonly persist in the females. In this connection it may be remarked, that white or pale stripes are sometimes developed 
by the interposition of white pigment along the centre of a dark median band, so that a white stripe and two black stripes result : or the process may be reversed. A primitive white stripe running down the centre of the back may broaden, and at the same time develop dark pigment down its centre, thus forming a single dorsal black stripe flanked by a pair of white stripes.

That the colour, number, and distribution of these stripes are largely determined by the needs of the environment, that is to say by the need that the body of each particular individual shall harmonise as much as possible with its background, seems evident enough. Thus, if we start with a species like the wall-lizard, wherein the young are normally marked by many stripes, it will be found that in individuals frequenting sandy districts dotted with sparse tufts of grass there is a tendency to an increase in the number of stripes, which may increase from six to eight, or eleven. On the other hand, in neighbouring areas, where the vegetation is more abundant, the number of stripes is usually from seven to nine, and these show a tendency to break up into spots on the hind part of the back. As we pass into open forest with much undergrowth, the lateral stripes fade, while the others dissolve into spots which have a tendency to disappear in the loins of old individuals.

Again, in races inhabiting open tableland with scattered spiny shrubs and hedges, the young form with six stripes and pale spots on the dark bands passes into a crossbarred type. Finally, in similar localities, but with more mixed vegetation, all the lines become broken up into spots in addition to those which existed in the intermediate dark intervals.

There seems little doubt but that these stripes cannot 
survive unless their wearers live in situations where such a type of coloration tends to render them in harmony with their surroundings; nor can the creatures keep their pale spots amid desert surroundings. For it is a wellascertained fact that when spots occur in desert-dwelling animals, they are dark on a light ground, as is exemplified among reptiles by some of the sand skinks (Chalcides) and among mammals by leopards and servals; while among forest-dwellers, light spots on a dark ground are the fashion, as in the fallow-deer and the Indian spotted deer.

In the young of the "painted terrapin" (Cbrysemmys picta), there is a conspicuous stripe of bright orange running down the middle of the carapace, or back shield, while the naked neck, limbs and tail bear numerous narrow longitudinal lines of yellow on a blackish-brown ground colour. Gradually a line of orange or red appears down the middle of each of these yellow bands, and the yellow band down the back disappears, to be replaced by transverse bars of yellow.

In the soft-shelled fresh-water turtles of the genus Trionyx the young are profusely spotted, indicating an earlier striped condition. But in the Indian Trionyx burum and the Burmese Trionyx formosa these spots are augmented by two pairs of large black and yellow, eye-like spots on the back of the shield, whose purpose is difficult to imagine. Difficult because, according to current theories, such spots are generally borne on areas which may be damaged with impunity, and serve as Iures to draw off the attention of predatory animals from the vital parts of the body. In butterflies, for example, the spots commonly occur on the edge of the wing, so that birds, in chasing them, snap at the fragile wing membrane and leave the vital organs uninjured. But the "eyes" in these 
soft-shelled "turtles" are placed over the very centre of the body. True, this is protected by a shell, but this is easily pierced when the animal is young. We know so little, however, of the life-history of these creatures, that it may well prove, after all, that these spots, so conspicuous in museum specimens, or when the animal is newly dragged out of the water, are highly protective in character, harmonising, perhaps, with the stones or vegetation of the under-world in which these creatures live.

While there can be no doubt as to the facts in regard to the phases of coloration just discussed, the interpretation placed thereon is obviously theoretical, and therefore liable to be set aside at any time. Indeed, there are not wanting those at the present day who venture to call this interpretation in question. These objectors, however, have so far given us nothing better than sceptical criticism, and much of it not of a very convincing kind. In any speculations on this theme certain underlying aspects of the subject are commonly ignored, which, nevertheless, must always be borne in mind when seeking to piece together the evidence which we have just reviewed.

In all endeavours to explain the origin of this striped coloration, and the further evolution therefrom of spots, mottlings, transverse bars, ocelli, and so on, stress has been laid, and rightly, on the tendency of all animals to vary in all directions, and in colour perhaps especially. But one must go deeper: one must begin with the question, Whence the origin of the pigments which display these variations? There can be little doubt but that these are waste products of the blood deposited in the skin or its covering, and retained there because their presence confers a benefit.' But the further elaboration of the different kinds of pigment, and of structural colours, which are not 
due to pigment, and the distribution and deposition of this pigment in the form of patterns of a definite and orderly and constantly recurring type is a much more mysterious matter. Yet. if we take a broad survey of the facts we seem to find justification for the view that there is what we may call a natural, inherent tendency for more or less of such pigment to be deposited in the form of stripes. But the primary physiological reason for this longitudinal deposition of the pigment remains quite obscure.

But however constant the recurrence of this longitudinal pattern may be, in any large number of individuals constituting what we call a "species"- - a collection of individuals all possessing the same features-it is never absolutely alike in any two individuals. It shows a tendency to vary. This "tendency" in each individual again tends to be exaggerated in successive descendants of that individual : just as a stone thrown into a stream creates a series of ever-widening ripples. Commonly this "accident" of pattern confers a benefit on the wearer by causing it to blend or harmonise, more or less perfectly, with its surroundings. As a consequence, those individuals which most completely harmonise have the best chance of escaping predatory enemies, and leave the greatest number of descendants which will possess the same fortunate "accident" of coloration.

But since the pattern is never, as we have remarked, faithfully reproduced, and since each variation or deviation from the type tends to increase in successive generations, such deviations sooner or later assume a critical, vital importance. They may no longer conceal, but advertise the wearer; and thenceforward all individuals so marked will suffer an ever-increasing toll on their numbers from predatory creatures, and finally that particular pattern 


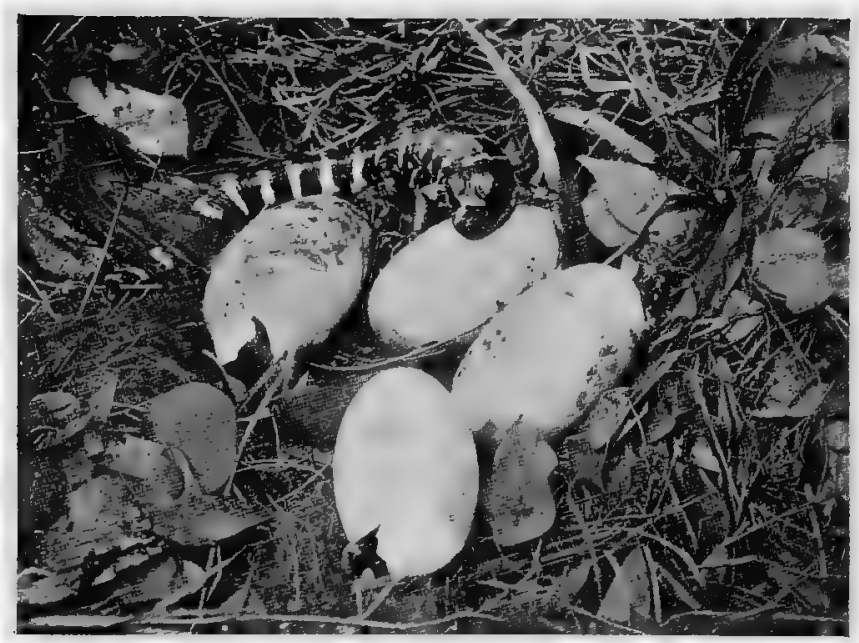

YOUNG CAIMANS EMERGING FROM THE EGG.

The sharply contrasted bands of colour disappear with age.

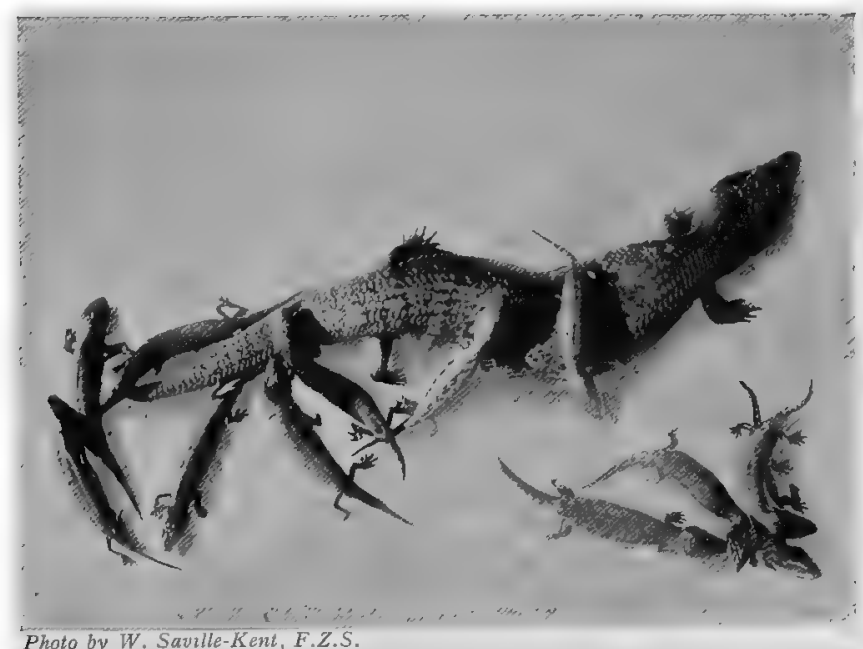

BLUE-TONGUED LIZARD AND YOUNG.

Female with her family of twelve young oncs. In the young the body is relatively shorter, the limbs longer, than in the adult. I 70$]$ 

will become extinct. Where the original striped livery shows a tendency to break up into spots, or bars, irregular marblings, or, by a clustering and blending of groups of spots into large eye-like patterns, or "ocelli," that tendency will become more and more manifest in this or that particular area if such patterns form a more efficient mark than the original stripes : on the contrary, if they prove less effective, variations in this direction will be eliminated.

The precise degree of importance of this coloration varies indefinitely : it varies with the age of the individual, and with the locality, that is to say with the relative abundance of its enemies if it be a vegetarian, or, on the other hand, with the relative abundance of its prey if it be a predatory animal, for it must not be forgotten that concealing coloration is just as important to the hunter as to the hunted. It is never an absolute protection in either case. Movement will betray the most cunningly devised mantle of invisibility: scent will effect the same end. Concealing coloration only reduces the chance of being eaten, or the chance of death by starvation.

Finally, the precise coloration of an animal is never caused by its environment. The coloration is the outward and visible sign of the inward invisible physiological processes going on within the body. All that the environment does is to determine which of an indefinite number of combinations of colour and pattern which make up the potential "coloration" in any given case shall persist.

As with young mammals and young birds, so with reptiles, where the young are striped the adults are often of one uniform hue, and it is not easy to see why, in the case of the reptiles, the stripes, if they serve any purpose, should cease to be useful in the case of the adult. The converse is equally puzzling: yet there are many cases 
where the young are sombrely coloured, while the adult is more or less handsomely marked. Thus the young of the common lizard (Lacerta vivipara) are nearly black, the adults are brown or reddish and spotted. No less mysterious, at first sight, are those cases where the stripes of the young are retained in the adult female, but lost in the male, as in the case of the green lizard (Lacerta viridis), for example. But this also obtains in the case of many birds, as we have already shown.

A remarkable case of colour change, wherein the pattern is reversed during the transition from youth to age, is found in an African snake known as Grayia ornata. In the young stage, which was originally regarded as an adult subspecies of Grayia ornata, the body is black, with broad whitish or greyish transverse bars, which split on each side so as to form a series of reversed $Y$ 's, each $Y$ being slightly speckled with black about the middle line. With advancing age the black ground changes to grey or brown; whereas the Y's show more and more black until they have only white margins, and even these eventually vanish. Consequently the fully adult snake has black markings on a grey ground in place of the light markings on a black ground characteristic of the young; in other words the colour pattern of the adult is exactly the reverse of that of the young.

The snakes of the genus Coluber are remarkable for the fact that the coloration of the young differs entirely from that of the adult, and both stages are strongly coloured. This transformation is well illustrated in the case of the chicken snake (Coluber quadrivittatus). At the time of hatching it is greyish, decorated with a regular series of oblong blackish saddles. As it approaches maturity the body colour changes to yellow, a dark stripe appears on 
each side of the saddle-shaped markings, and another on each side of the body. These stripes rapidly become very distinct, and at the same time the saddles begin to fade, so that in the adult form, which is assumed during the fourth year, the coloration is of a uniform yellow or brown, traversed by four longitudinal stripes.

In an earlier chapter, when discussing the coloration of young birds, mention was made of one or two cases wherein the young developed bright colours which were wanting in the adult stage; but among birds it is rare to find the young brighter than the adults, as is the case, for example, with several species of warblers in their immature condition. Among the lizards, on the contrary, there are many such instances, from which we select one or two of the more striking. Thus, in the American blue-tailed skink (Eumeces quinquelineatus) the young have the tail of a bright blue and the body blackish with five yellow stripes. As it matures the tail fades to a sombre grey, the body changes from black to brown, the stripes (in the males at any rate) entirely disappear, and the head, in the males, assumes a bright red hue. So strikingly different are the two types of coloration that the adult was at one time regarded as a distinct species.

Among snakes there are several such instances. In Wagler's viper, for example, a Malay species, the young is of a bright grass-green, later on the scales develop black edges. Gradually these increase their width, till in the adult animal they have suffused over the whole scale, transforming the sometime green livery into a black, or nearly black one. In this particular case we seem to be able to interpret the reason for the change. And this because the creature is arboreal and feeds on birds. This extremely agile prey it is able to capture with ease, 
because it has developed a prehensile tail whereby it is able to take a secure grip of a bough, leaving the rest of the body free to be instantly uncoiled as the fatal dart on the victim is made. The green colour of the young snake is a protective garment, enabling it to lie concealed among the smaller green boughs. Later, with increased bulk, older and therefore black boughs have to bear the weight of the body, against which a green body would be somewhat conspicuous, or would at any rate excite suspicion.

Among the deadly pit-vipers (Crotalinæ) the young, at any rate of three species-to wit, of the copper-head, Ancistrodon contortrix, the water moccasin (A. piscivorus) and the fer-de-lance (Lachesis lanceolata)-present a very remarkable colour device not present in the adults. When newly hatched, and for some little time after, the tip of the tail, for about an inch, is of a brilliant sulphur yellow; and it has been found that when food is introduced into the cage of captive specimens, these young vipers set up writhing, twisting movements in this yellow-coloured tailtip, producing a likeness to a crawling worm or maggot. Thereby, no doubt, small lizards and frogs are lured to their doom, for the rest of the body lies cunningly concealed amid dead leaves and grass.

The existence of this strange lure is a feature of quite exceptional interest, for it seems to be a device enabling its possessor during its days of inexperience and feebleness to decoy its victims so close up to the head that they may be seized at once and securely. For at this time, when the body is still growing, the long fasts, broken by enormous meals, which punctuate the life of the adult, are impossible meals must be small and often, and. less energy is used when the prey can be brought almost to the very mouth than when it has to be tracked down and stalked. Further, 
these large meals so characteristic of the snake dietary mean large prey, which can only be overmastered by the deadly poison fangs. These, in the young snake, are only in process of development, and not until the fangs and their poison are ready is the lure dropped.

The pit-vipers are among the most deadly and most dreaded of venomous snakes, and hence where these abound even bites from harmless snakes arouse terror in the person bitten. A good story illustrating this fact is told by Colonel Ingersoll, of "Mrs. Tom Murphy," who lived in a log cabin in the woods about a mile up Black Creek. "Wan day," as she told the listener, "I stepped out o' my door and there, on the top of a rock ferninst the well lay a pilot [the copper-head or red-adder], all curled up, and the childers all playing close by without a wan of 'em noticin' the baste. I let a yell out o' me, and I picked up the first thing handy, a shovel, 'n whacked the shnake over the head, 'n he sthruck me hand, an' I knew thin I was gone. I threw the baste into the brush, and then called the childers ' $n$ run into the cabin. I was wantin' to die as daysint as may be, and I wint and lay down on the bed, biddin' the childers all good-bye and lavin' word for 'em for the ould man at his wurrk in the ice-house. Thin I sint 'em all out again so they shouldn't see me in me agonies. I lay there all straight out, as if I was a corpse at a foine wake wid me hands folded proper, awaitin' to die, and wanst in a while the young wans 'd come and say: 'Are ye dead yit, Mamma ?' 'nd I'd say 'Not yit.' And-wad ye belave it ?-I lay there more'n two hours, composin' meself and praying to the Virgin, and I niver died wanst! Thin I said to meself : 'It's an ould fool Teare, Mrs. Muxphy,' and I got up." 


\section{CHAPTER X}

\section{REPTILES IN THE MAKING}

Young reptiles as they step out from the shell are, so to speak, adults in miniature; whereby they differ conspicuously from the mammals and birds, which pass through a more or less extended infantile period. But there are exceptions to every rule, and the tortoise-tribe are among these. If it were not for the fact that the tortoise is numbered among our "familiar beasts," we should regard it as one of the most remarkable, if not the most remarkable, of backboned animals, since it alone among its peers lives inside its skeleton, so to speak, just like the beetle and the butterfly, wherein, as everybody knows, the hard parts which afford attachment and leverage for the muscles which are responsible for movement, are outside, and often tinctured with all the hues of the rainbow. But in the case of the tortoises and turtles this anomalous condition is confined to the trunk alone, which is encased within a bony, horn-ensheathed shell. How this extraordinary condition came about is revealed in part by a study of young tortoises and in part by what is revealed in the case of that strange creature the Leathery Turtle or Huth.

In this last-named species the great back-shield is formed of a number of small more or less circular bony plates, interlocking by means of jagged edges : the whole 


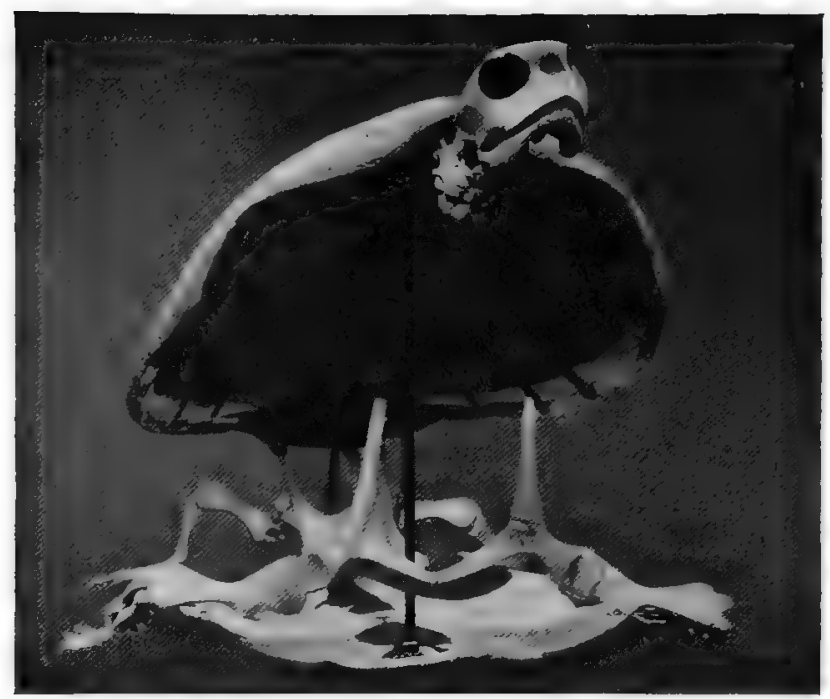

SKELETON OF THE GREEN TURTLE,

Wherein the bony shell, originally developed in the skin, has become fused with the skeleton.

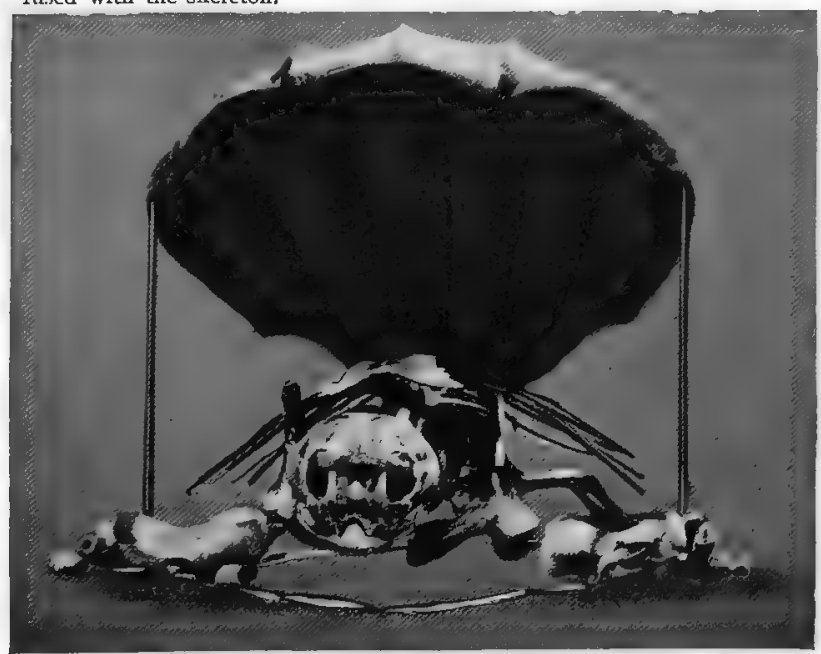

SKELETON OF THE LEATHERY TURTLE,

Here the bony shell formed in the skin remains distinct from the skeleton. I76] 



\section{REPTILES IN THE MAKINǴ}

being covered by a thin leathery skin. These bony discs were undoubtedly represented in the ancestors of the Huth by small nodules of bone embedded in skin. In course of time, by the increase of the nodules, a complete shield was formed. Very well. If this shield be raised there will be found underneath a thin, degenerate layer of muscles covering the ribs and backbone. Save that there is no degeneracy, this is just what we find beneath the skin of all the vertebrates, from fishes up to man himself.

In all other tortoises and turtles, whether fossil or recent, the course of this development has been pushed to what we may call its logical conclusion. Briefly, the shell, owing to its unyielding character, has rendered the muscles of the back useless, so that they gradually degenerated, the shell descending at last on to the tops of the spines of the backbone, and then on to the ribs themselves, between which and the shell a fusion or blending finally took place so complete that in many species the only evidence of ribs is that afforded by their tips, and the upper ends where they join the backbone.

The truth of this those who will may test for themselves by examining the growing skeleton of a very young tortoise, where the complete ribs will be found. Soon, however, they blend, as we have described, with the shield. The backbone itself, it should be mentioned, has not escaped these profound changes. Originally composed of a number of separate vertebra, all that now remains is a shrunken tube of bone; the separate elements having lost their power of movement during the growth of the great back shield, have gradually dwindled and finally blended to form a sheath just large enough for the passage of the spinal cord. 
The history of the breastplate is no less strange. Like the shell of the back, this is covered externally by symmetrically arranged plates of horn, answering to the skin of other animals, and these plates cover a series of symmetrically arranged bones, which answer in part to the bones of the shoulder-girdle, and in part to what are known as "abdominal ribs"-bony rods developed in the fleshy walls of the abdomen, as, for instance, in the tuatera "lizard," and the extinct ichthyosaurs or sea-dragons.

But this is not all; for the position of the limb-girdles, as the bony supporting frameworks for the limbs are called, furnishes another remarkable feature. In all other vertebrates, above the fishes, the shoulder-blades lie on the outside of the foremost ribs, but in the tortoise tribe these lie under the ribs, and therefore inside instead of outside the body-that is to say within the shell. Similarly, the haunch-bones which support the hind-limbs in other animals lie behind the last rib, and near the surface of the body. In the tortoise tribe they lie, like the shoulderblades, within the shell. But these curious conditions again obtain only in the adult. In very young tortoises, where the development of the shell has only just begun, the shoulder-blades lie a little in front of the first rib, whilst the hip-bones are to be found just behind the last rib. But the broadening of the ribs caused by the excessive development of the external bony shields gradually creeps over the shoulder-blades in front and the hip-bones behind, so that at last they come to lie, as we have seen, within the shell.

That this shell was developed to afford a protective armour against predatory animals seems certain, since, when tortoises have no further need of such armature, the shell tends to degenerate, and to enlarge the openings for 
the head and neck, which, like the limbs and tail, can no longer be drawn within the shelter of the bony fortress. In some of the giant tortoises which live on islands where there are no large carnivores, the shell has thus lost its protective character and has grown exceedingly thin.

Certain aquatic tortoises display interesting phases of degeneracy in this connection. Thus in the "Mud-turtle," or "Stink-pot Terrapin," the degeneracy has begun apparently with the horny outer sheath of the breastplate. This covering is composed, as in other tortoises, of several symmetrically arranged plates, and in the newly-hatched terrapin these have a normal arrangement. But as the growth of the body proceeds, that of the horny plates ceases. As a consequence they are gradually forced apart. In the water tortoises or "soft-shelled turtles" of the genus Trionyx, the upper part of the bony shell or back shield has degenerated so far that it forms but little more than a large island of bone in the midst of a great expanse of leathery skin, the horny shields which form so characteristic a feature on the back of the typical tortoise having vanished completely.

The belly shield, curiously enough, seems to have degenerated in like manner, and then to have undergone a process of renewed vitality; for in very young specimens of such tortoises the several bony pieces which make up the typical breastplate are represented by mere splints embedded in skin. Later these bony bars thicken, broaden out, and come almost to the surface, as if once more they would assume the form of a bony, horn-ensheathed breastplate. 


\section{CHAPTER XI}

\section{CONCERNING TADPOLES \\ W. The toad, ugly and venomous, \\ Wears yet a precious jewel in his head.}

Concentrated into these few words, Shakespeare has expressed the indefinable and unreasonable dislike and repugnance with which the human race, from earliest times till now, has regarded both the frogs and toads and their kin and their more advanced relatives the reptiles; for even now all these are, in common speech, described as "reptiles." But they have been condemned without trial : a few, like the poisonous snakes, are to be looked at askance, but even these strike only in self-defence, or legitimately to secure their daily bread.

A very brief suspension of prejudice, a very little unbiassed observation, would have shown that these despised and rejected ones were among the most interesting and fascinating of living creatures. And this is more especially true of the frogs and toads and their kin, which collectively form what are known as the "Amphibia." Psychologically, these creatures are most puzzling; for many, to secure the well-being of their offspring, seem to display both intelligence and affection, attributes which nowadays we accord only to the human race. But of this anon.

The young of the frogs and toads and their kin differ conspicuously from the young of reptiles, in that they do not enter the world as miniatures of their parents, as do young reptiles, but in a guise far otherwise. In the course r8o 
of the life-history of the frog, for instance, we may recognise four stages-the embryonic, the larval, the tadpole, and the adult-and this transformation of the larvæ into the tadpole, and finally into the adult stage forms what is technically called a "metamorphosis."

Let us follow these changes as they are unfolded in the common frog, for example. The eggs, as everybody knows, are deposited in large masses in ponds and ditches. Such masses are commonly referred to as "spawn." When first set free into the water these eggs look like little black beads, surrounded by a thin transparent layer of jelly : but speedily the jelly absorbs a large amount of water and swells up so that the black central portion, which contains the germ of the frog that is to be, and the food yolk on which it is to live, lies in the centre of a crystal globe. This outer envelope serves to protect the young embryo from pressure, and also from predatory insects, while the black layer of pigment surrounding the egg itself serves to attract the warmth of the sun's rays necessary for development. If a number of hen's eggs were broken into a basin, care being taken not to rupture the yôlks, a mass would be produced similar to frog's spawn: the yellow yolks answering to the frog's eggs, and the transparent "whites" to the gelatinous envelopes of the spawn. And just as the chicken is formed neither from the yolk nor the white of the hen's egg, but from a minute germ, so also is the frog developed from a similar tiny germ. The black ensheathed yolk and the swollen, gelatinous outer covering of the frog's egg, and the yellow yolk and transparent white of the hen's egg, form the food with which these germs, indistinguishable so far as chemical analysis and microscopic examination go, slowly build up in the one case a bird in the other a frog. The formation of creatures so 
unlike out of matter which, by all human tests, is identical is one of the greatest of all mysteries.

In about a week this black sphere has become ovoid, and by the tenth day slight constriction foreshadows the development of a head, body and tail. Presently this growing body assumes the form of a young fish, branching tufts growing out on each side of the head to serve as gills or breathing organs. In about a fortnight from the time the egg was laid, the tiny body wriggles its way out of its jelly-like envelope and swims freely in the water. It has now ceased to be an embryo, and has become a "larval" frog.

But its swimming excursions soon cease, for almost at once it proceeds to attach itself to some piece of weed in the water by means of a pair of sucker-like organs on the under surface of the head. Here for a few days it hangs motionless, waiting for its.mouth to grow, for as yet this very important orifice is conspicuous by its absence, and the body is nourished by what remains of the food yolk originally stored within the egg.

The mouth makes its appearance a few days after hatching; and a wonderful mouth it is, bearing not the remotest likeness to the mouth which will presently succeed it. In the first place it is fringed by two large fleshy lips, which, seen under the microscope, are found to bear rows of horny, claw-like teeth, with serrated edges under the curve of the claw. Altogether there are some 640 of such teeth, and what is more, these are constantly being shed and replaced, the new teeth lying one inside the other, so that as the uppermost is shed the one hitherto lying within it comes into use. Thus, during this brief period of larval life it uses up a thousand or so of these teeth. They are used chiefly for hooking on to the food, which is demolished by the jaws. These are similarly armed with hundreds of tiny teeth, so closely packed as to form a kind of beak, recalling 


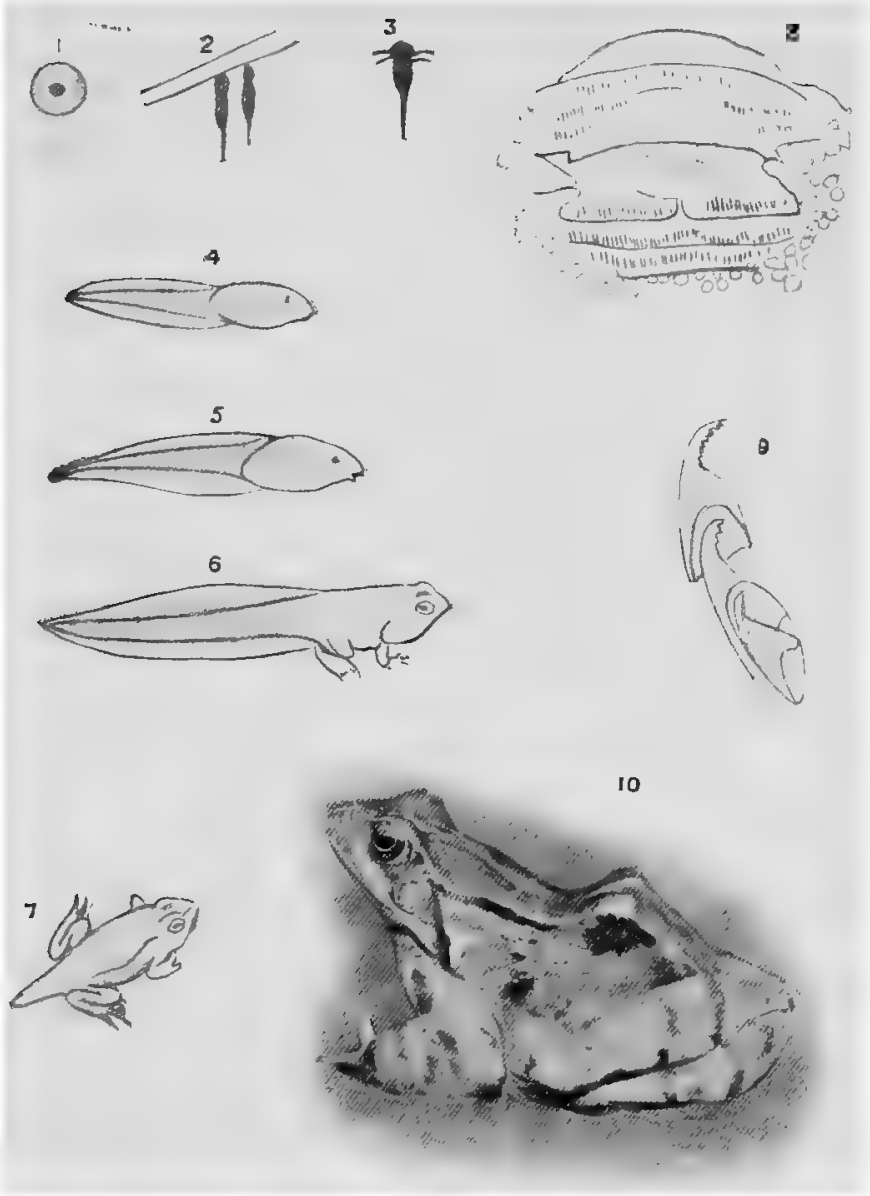

STAGES IN THE DEVELOPMENT OF THE FROG.

I shows the egg, 2 and 3 the larval, and $4-7$ the tadpole stages. Io is the adult stage. (Photo by W. B. Johnson.) Fig. 8 shows the morth of the I82] 

that of a parrot, but blunter. They break up tiny particles of food by a rasping action like that of snails. This formidable armature is used to demolish convervæ and other vegetable matter, or, when obtainable, the dead bodies of their comrades or other creatures which have fallen by the way.

The eye now shows its first signs of being, making its appearance as a ring of pigment just under the skin. Soon after this, four slit-like apertures pierce the walls of the upper end of the gullet, and their margins speedily become folded to form internal gills, and in proportion as they develop, so the external gills, always a source of danger, decline.

A stage is now reached in the development of this larva answering to the condition of the adult fish; that is to say, it breathes by internal instead of external gills. The growth of the internal gills is accompanied by the development of a backward growth of the skin of the head so as to enclose these gills within a chamber. Towards the end of the fourth week the hinder edges of these folds of skin merge, or fuse, with the body wall, leaving a spout-shaped opening on the left side of the body, and through this the water taken in at the mouth, after having bathed the gills, is passed. Thus is breathing carried on.

Thelarvalstage has now ended, and the "tadpole" stagehas begun. By much feeding the body, inky black and spangled with gold, has become large and round, and the tail has greatly increased in length and thickness, forming, as in the fish, a powerful swimming organ. Meanwhile the suckers bordering the mouth have decreased in size and arelittle used. At the base of the tail two little buds have made their appearance. These are the rudiments of the hind-legs : by about the seventh week they have become divided into segments or " joints," and a week later the toes make their appearance. The fore-limbs have reached a similar stage of growth, but as yet they lie hidden, folded up within the gill chamber. 


\section{I84 THE INFANCY OF ANIMALS}

Profound changes now take place. The walls of the back of the throat grow inwardly, and soon meet one another in the middle line to form two tubes-an upper, or gullet for the passage of food for the stomach, and a lower, or windpipe, from the lower end of which the lungs are formed. The young tadpole now comes frequently to the top of the water for air. For the gills are fast decreasing in size, and are accordingly unable to suffice for the fish-like fashion of breathing, while the lungs are as yet not large enough to serve as efficient respiratory organs for the absorption of atmospheric air.

A fortnight or three weeks later a critical stage is reached. The normal processes of life are suspended pending extensive and profound structural alterations. The tadpole ceases to feed, the outer layer of the skin is cast, and with this go the gills; the horny jaws are shed, the large frilled lips shrivel up, the mouth loses its round shape and assumes the broad cleft characteristic of the frog; the tongue becomes enormously increased; the eyes, so far concealed beneath the skin, are now exposed. The abdomen shrinks, the stomach enlarges; the gut, till now a long tube coiled like a watch-spring and visible through the skin, is reduced to a relatively short irregularly coiled tube, and from a vegetable and carrion feeder the animal now becomes a carnivore, preying only upon living animals such as worms and insects.

While these internal changes are going on the fore-limbs appear : the left foot being thrust through the hole which served as the exit for the water used for breathing, while the right bursts through the now degenerate skin. During this enforced fast the nourishment necessary to sustain not only life, but these remarkable changes, has been furnished by the tail, now no longer necessary. All that now remains is a small stump, the last evidence of the 
tadpole phase. Nothing now remains for the youngster but to swim ashore and emerge a frog.

But its days of fasting are not over. Its first, it will be remembered, was enforced during the time when it hung itself up by means of its suckers to await the appearance of its mouth : till this appeared it lived upon the remains of the food-yolk which formed part of the egg from which it was hatched. During its second it fed upon its tail. Again, with an abundance of food around it eating was impossible, because a new mouth was being fashioned. Henceforth, with a capacious mouth, it is annually reduced to a long period of fasting because there is no food to put into it! As the chill of autumn passes into winter the frog retreats to the nearest pond or ditch, perhaps the scene of its birth, and there buries itself deep down in the muddy bottom out of the way of frost to await the return of spring in a state of suspended animation. During these long months of fasting the body becomes considerably emaciated. Nevertheless, emerging into the upper world again, the most strenuous period of life-the reproductive period-has to be immediately faced, and this fasting. But, to change an old adage, "God tempers the fast to the starving frog." The sustenance necessary for the due ripening of the products of the reproductive glands-the sperm and ova-is provided by a pair of "fat-bodies." But for these the wretched frog would be reduced to a state of utter exhaustion, such as would prove fatal to most of the individuals called on to face the ordeal, before the eggs and sperms could be shed, and thereby the speedy extinction of the species would follow : for while a few might survive this, the remnant would not be large enough, to withstand the toll levied during the rest of the year by predatory animals and other chances of death.

The life-history of the toad follows a precisely similar 
A
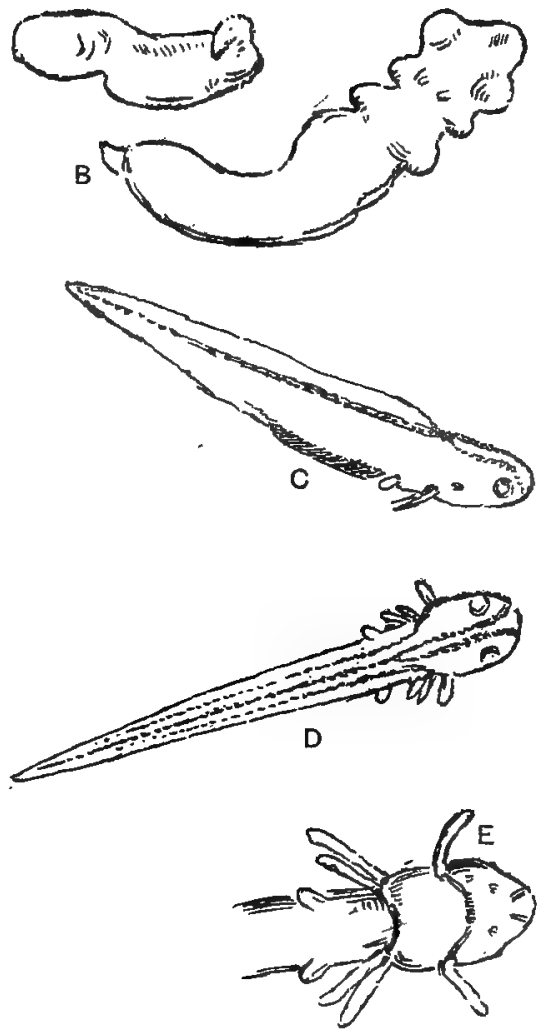

STAGES IN THE DEVELOPMENT OF A NEWT.

$A$ and $B$ show two very early phases before the body has begun to assume its final shape, and C D E show the "balancer," the beginning of the external gills, and the little buds which answer to the undeveloped fore-limbs. course; but there is one curious point of difference in the distribution of the eggs, which seems to have no meaning, but may be fraught with much. In the frog it will be remembered these are laid in great shapeless masses; in the toad they are shed in a long glassy rope which is twisted about the stems of waterplants. There must be a meaning, some advantage to the species, behind this, but so far no one seems to have had the curiosity to search out the meaning of the riddle.

For the sake of what is to follow a brief outline must now be given of the early stages in the life-history of the newt, which may be taken to represent the normal sequence of events in the development of those more lowly relatives 
-of the frogs and toads known as the "Urodela" or "tailed Batrachians," and in common speech as the "efts" or "newts," and the "salamanders." These creatures retain their tails throughout life, and display only a "larval "stage : the tadpole phase of the frogs and toads being more or less retained throughout life.

Why is it
that the early
history of the
young newt,
or salaman-
der, is so
much more
simple and
direct than is the case with the frog and its kind ? We ask at present in vain, but such is the case. The young newt develops no-specia 1 mouth, like the young
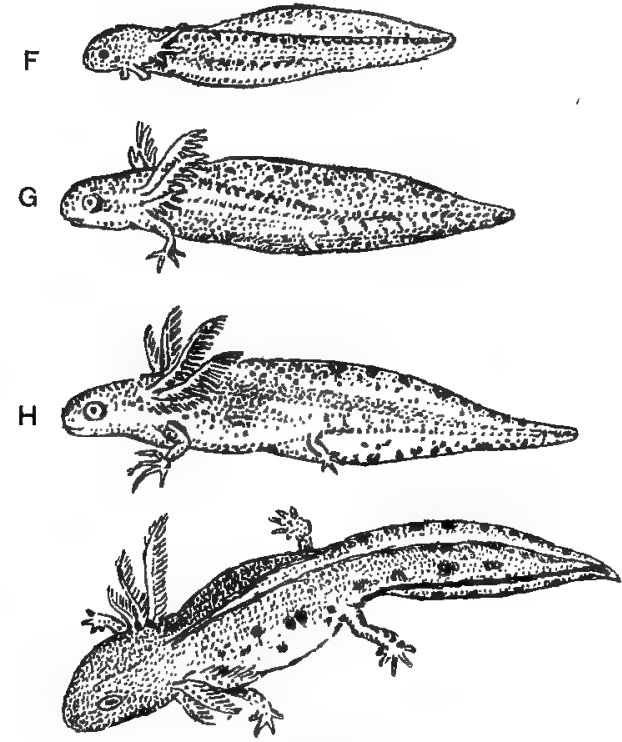

STAGES IN THE DEVELOPMENT OF A NEWT (continued).

The stage shown at I answers to the perfmanent stage of the curious S. American Axolot1, wherein the external gills are retained throughout life.

frog, and fasts only for a brief period while the mouth that is to last its lifetime undergoes its finishing touches : the larval frog and the later tadpole are inky black, the young newt is transparent. 'The larval newt breathes at first by external gills, like many young fishes and larval rogs; but later these are exchanged, as in the case of 
the frog, for internal gills, and these in turn are replaced by lungs. But during the time that the external gills are worn the young newt displays a curious rod-like outgrowth from the side of the head which is supposed to serve as a "balancer," but of its precise functions we have probably still much to learn. Another curious point of difference lies in the fact that in the young newt the fore-legs make their appearance first: here again we ask, Why? and we have no answer to give.

More puzzling still is the strange case of the Mexican salamander commonly known as the "Axolotl," which commonly never "grows up," but remains in the larval stage throughout its lifetime, yet becomes sexually mature and reproduces its kind! It is an ugly creature, large, heavy-looking, and black as ink. But every now and then, once in a dozen years or so, one out of ten thousand of such erratic larvæ loses its gills, decreases in size, and crawls out on to the dry land a yellow-spotted salamander known as the Amblystoma. This is the adult form of the axolotl. And, in due course, it lays eggs, and produces a swarm of axolotls, and not for dozens of generations will the phœnixlike amblystoma appear again!

Certain other salamanders present features of a no less startling character. Thus in the newts of the genus Desmognatbus and Sperlerpes, of which we may cite as examples the Red Desmognathus (Desmognatbus fuscus) and the Double-lined Sperlerpes (Sperlerpes bilineatus), the larvæ display vestigial lungs, but the adults are quite lungless and breathe, according to some authorities, entirely through the skin, which is always moist. According to others respiration is performed by taking repeated gulps of air into the throat and then expelling them, the blood-vessels in this region absorbing the oxygen from the air thus introduced. 
Breathing by means of the skin is practised by many of the Amphibia : in the frog and toad, for instance, the skin performs a certain amount of respiratory work, and during the period of hibernation it is the sole means of breathing.

The foregoing cases are further interesting as affording yet other illustrations of the fact we have already insisted upon-the difficulty of drawing any hard-and-fast line between embryonic and post-embryonic characters; they show that, similarly, there is no hard-and-fast line to be drawn between larval and adult characters; and we shall find further and yet more striking instances of these facts.

Our survey of what we may term the normal sequence of events in the life-history of the frog tribe, or to give the more technical term, the Amphibia, is ended. We are now to pass in review some of the more remarkable phases of

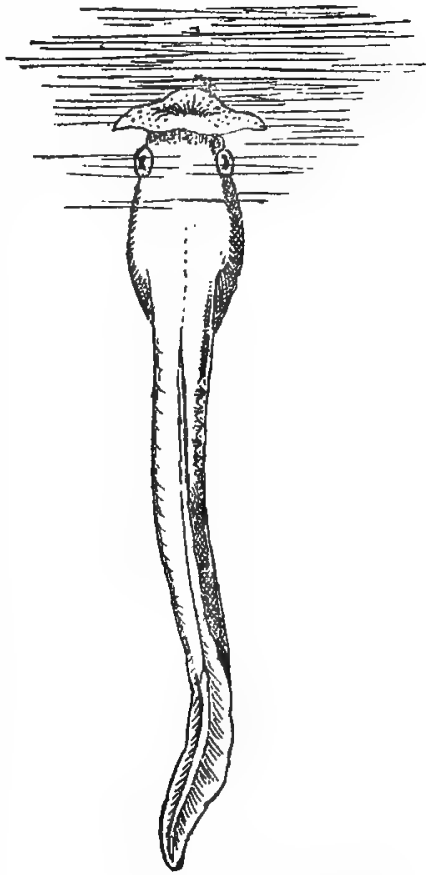

MEGALOPHRYS MONTANA. development which have, so to speak, been forced on other members of this group by circumstances which we can only roughly measure. These are all, as might be surmised, exceptional cases, and confined to individual species, and but for this ability to surmount the abnormal conditions of existence imposed by their environment, that particular 
environment would have been tenañtless so far as the Amphibia are concerned.

A good illustration of this is furnished by a larval frog found in sandy streams and pools of water from 2,000 to 3,000 feet above the level of the sea. Unlike all other tadpoles, they float vertically, and have the fleshy lips of the mouth answering to the lips of the tadpole of the common frog produced into a large trumpet-shaped funnel which acts as a surface float. The inside of this funnel is beset with a radiating series of little horny teeth, and the whole apparatus is apparently used for scraping the under-surface of the leaves of water-plants in search of food. Obviously in such out-of-the-way situations vegetation is scarce and food is not plentiful, but one wonders what started the modification of the fleshy lips in the.new direction, enabling this particular species alone to obtain a living. Needless to say, it is little known save in museums, and hence has no name in everyday speech, but it is known in scientific works as Megalopbrys montana.

More mysterious, and much more extraordinary, is the case of the South American Paradoxical Frog (Pseudis paradoxa). The adult is entirely aquatic in habits, and most beautifully coloured, displaying wonderful tints of bronze, bright green and black above, while underneath it is a bright yellow spotted and barred with brown. Finally, be it noted, it does not exceed two and a half inches in length. Yet, in the tadpole stage it not only presents a peculiar shape, but attains a monstrous size. This at any rate is no exaggeration of speech for a tadpole which attains nearly a foot in length at its maximum of growth ! Of this bulk the head and trunk represent only a fraction over three inches, the rest is made up of an enormous tail, 


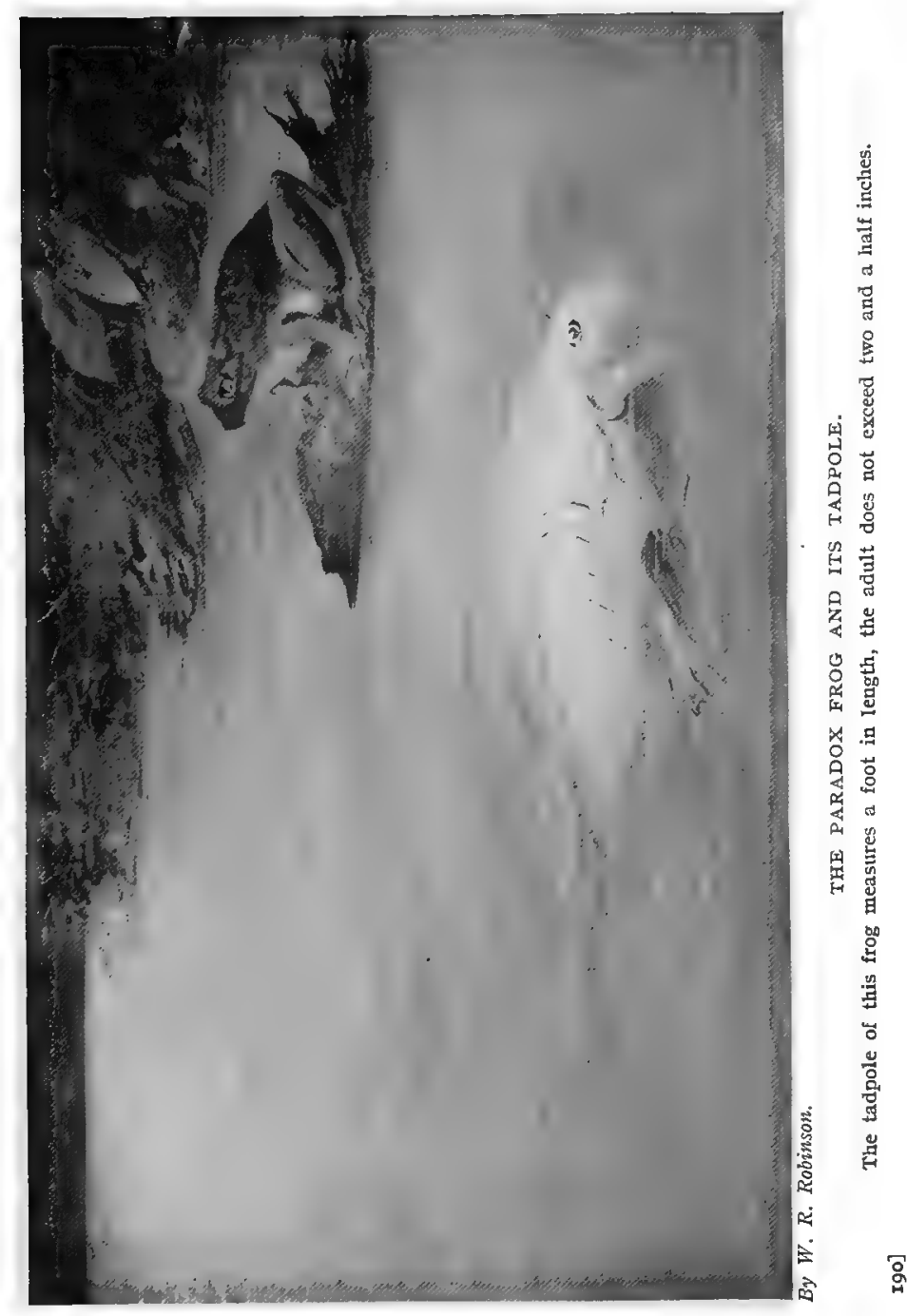



as is shown in our illustration. With the fin which surrounds it this tail is just four inches deep.

Having attained its maximum, it begins slowly to decrease in size. A tadpole in the British Museum in which the hind legs measure three inches in length has a total length of seven inches. By the time that it is ready to leave the water, the body has shrunk to an inch and a half long, and the tail to two inches-a mere shadow of its former self. What interpretation is to be placed on this marvellous history? So far no one seems to have attempted the task of answering this question. But it seems to indicate either some special provision to meet peculiar external conditions, or a provision to enable the animal to tide over an unusually prolonged fast pending the remodelling of the jaws and intestines, such as we have already described in the common frog, wherein it will be remembered the tail serves as a source of food-supply during the fast.

That the Amphibia display a very remarkable ability to maintain existence under adverse conditions, the foregoing instances surely amply demonstrate. And the following cases further illustrate the versatility of this group of animals, whereby they have been enabled to occupy odd corners in Nature's garden which otherwise would have been closed to them.

This departure from what we may call the normal train of events can be traced through many gradations, some of the more striking of which are now to be considered. One of the simplest cases is that furnished by a large tree-frog (Hyla faber) known in Brazil as the "Ferreiro"- " the smith "-from its extraordinary voice, which sounds like a mallet slowly and regularly struck upon a metal plate. This frog actually builds a nursery in the shallow water 
bordering ponds. A basin-shaped hollow of mud is scraped by the female to a depth of three or four inches, the material removed being used to form a circular wall or parapet which is carried up until it emerges above the surface. The work of construction is performed with its fore-feet, which may be likened to webbed hands, being used for smoothing the inside of the wall as a mason would use a trowel, while the floor is levelled by the action of the belly and hands together. In this crater-like cavity, which measures a foot in diameter, the eggs are deposited, and here they remain protected against the attacks of aquatic insects and fishes.

A Japanese tree-frog (Rhacophorus scblegelii) forms a chamber a few inches above the water-level in the damp earth on the edge of a ditch or flooded rice-field. After smoothing the walls of the nursery the female produces from the vent a secretion which, by rapid movements of the feet, is rapidly worked up into a froth; and in the midst of this mass of foam the eggs are laid. The male, who has all this time been clinging to her back, at once fertilises them, and this done, the pair separate and make their way out of the chamber by driving a tunnel which slopes down to the water, the tunnel by which they entered having closed up. The eggs remain protected and aerated by the surrounding mass of foam for some days, till the larvæ have developed and are capable of independent movement.

By this time the walls of the nursery have collapsed, forming a liquid stream which pours out through the tunnel bored by the escaping builders, and in the stream the larvæ make their escape into the water, there to undergo the tadpole stage. The eggs, it should be noted, differ from those of the common frog in that the yolk is 
not surrounded by a layer of black pigment; and this because they are excluded from the sun's rays and hence the pigment, which serves at once as a screen from excessive light, and to attract heat, is useless.

The "Wollunnkukk" (Phyllomedusa bypocbondrialis) of Paraguay furnishes an even more extraordinary instance of nursery building, discovered during the exploration of the Paraguayan Chaco by Dr. Budgett. While sitting near the water's edge he saw a female carrying a male upon her back. At last she climbed up the stem of a plant, reached out and caught hold of the tip of an overhanging leaf, and climbed on to it. Both then caught hold of its edges and held them together; and into the funnel thus formed the female poured her eggs, the male fertilising them as they passed. The jelly surrounding the eggs served as a cement to hold the edges of the leaf together. Then, moving up a little further, the process was repeated until the leaf was full, and about a hundred eggs had been enclosed.

The eggs are peculiar in that they contain much foodyolk surrounded by a quantity of jelly which soon becomes fluid, so that the embryo is seen floating within a glassy capsule. Herein the larval life is also passed, and from the absence of pigment from the skin the external gills assume a crimson colour, imparting to the egg at this stage a singularly beautiful appearance. In due course the tadpole stage is reached. And a most wonderful tadpole it is. At first, transparent as glass, the only conspicuous feature is the eye, which is of a bright metallic green, so that when swimming these jewel-like discs and a bright metallic green spot between the nostrils are all that can be seen. Soon, however, the hind-legs appear. This is the signal for a further astonishing change. The glassy 


\section{İ́4}

\section{THE INFANCY OF ANIMALS}

body now becomes gaily tinctured, the upper surface glossy green, the under iridescent rose and silver!

A nearly related Brazilian species, Ihering's frog ( $P$. Iberingi), makes similar provision for its young. But they lack the gorgeous colour displayed by their relatives, and

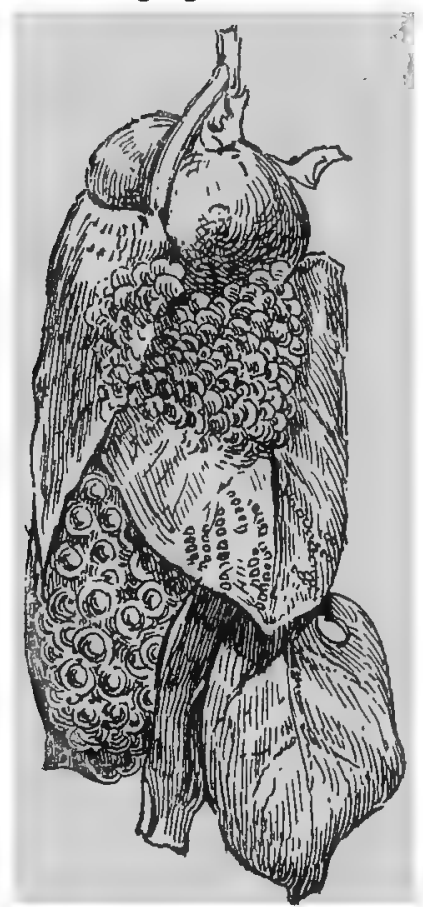

NEST OF PHYLIOMEDUSA SAUVAGII. further, the walls of the egg soon burst, releasing the tadpoles, which lie wriggling within the fluid contents set free in part by the bursting, and in part by the liquefaction of thousands of addled eggs. Soon the end of the funnel formed by the edges of the leaf gives way, and the tadpoles drop out into the pool below. Savages leaf-frog, $P$. sauvagii, of which a nest is shown here, builds a similar nursery.

In all the cases so far examined, the spawn, even when elaborate care is displayed for its welfare, is eventually abandoned. But there are many species which seem to leave nothing to chance, one or other of the parents guarding their offspring with the most jealous care. In a Papuan frog, for instance, the eggs, about seventeen in number, are held together by threads, and the whole are then pressed together to form a bunch, over which the male sits 
holding it with both hands. This vigil he keeps while the young are undergoing development, the whole of the larval and tadpolelife being passed within the egg, so. that on hatching they escapeas young frogs.

More remarkable is the case of the celebrated Midwife

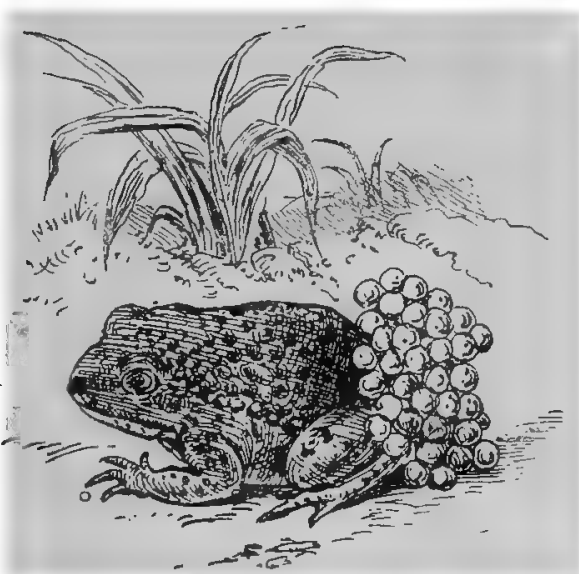

MIDWIFE TOAD. Toad (Alytes obstetricans). The eggs are attached one to another by threads, as if on a string; and as soon as laid, and fertilised, the male proceeds to wind these strings of eggs around his hind-legs. Thus laden, he retreats to a hole in the ground, stealing forth at night to feed, and to bathe the eggs in dew or, when possible, in water. Owing

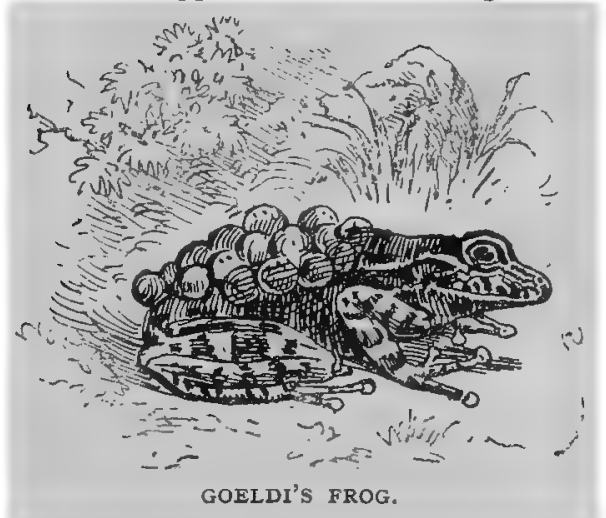

to the large amount of foodyolk stored up within the eggs, the greater part of the larval stage is passed before hatching, which takes place in about three weeks, the young being liberated 


\section{I96 THE INFANCY OF ANIMALS}

into the water, where they are then left to fend for themselves.

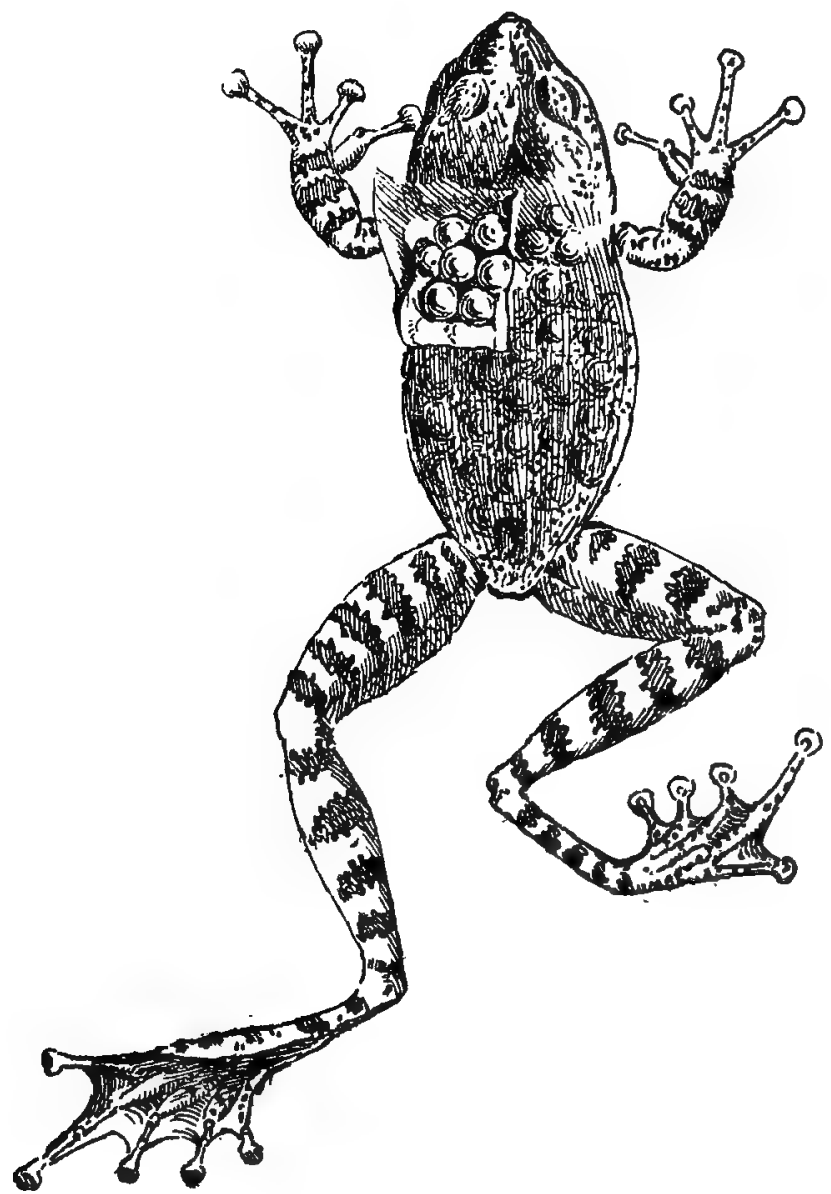

POUCHED FROG: A PORTION OF THE SKIN OF THE BACK HAS BEEN REMOVED TO SHOW THE FGGS IN THE POUCH, WHICH OPENS BEHIND, 
In several species of frogs the eggs are carried by the female upon her back. In Goeldi's tree-frog these eggs, few in number and large, are kept in position partly by their own adhesive nature, and partly by a fold of skin which runs round the lower region of the back, forming a low parapet to support the precious burden. Now mark what follows. From this we pass to a nearly related Venezuelan species (Nototrema pygmeum), in which the walls of this parapet rise up on either side and arch over the back till they nearly meet, leaving but a mere slit between them. Thus the eggs are enclosed in what is practically a pouch. By an easy transition the formation of a complete pouch could be accomplished by the actual closing of the slit and the fusion of the edges thus brought together. This completion of what was foreshadowed in Goeldi's frog is found in the pouched frog (Nototrema marsupiatum), shown in the adjoining illustration.

There are several species which thus bear the eggs, which may range in number from seven to one hundred. Where the eggs are few in number, be it noted, they are large, containing a considerable amount of food-yolk, and in such cases the larval stage is passed within the egg. In some of the cases, at any rate, these larva have been carefully studied, and it has been found that the mechanism for ensuring an adequate aeration of the blood, that is to say, for breathing, is somewhat remarkable, inasmuch as the external gills, instead of assuming the characteristic feathery shape, take the form of long stalks surmounted by a convolvulus-like cup, which is richly supplied with bloodvessels.

The celebrated Surinam toad (Pipa americana), one of the ugliest members of its tribe, presents another, and if possible, still more extraordinary variation in the method 
of carrying the eggs upon the back. In the species just reviewed it will be remembered we started with Goeldi's frog, wherein, for the further safety of the eggs, a low parapet of skin encircles the mass: from this we found the walls of the parapet growing upwards and inwards, to arch over and enclose the eggs, finally ending in the evolution of a pouch.

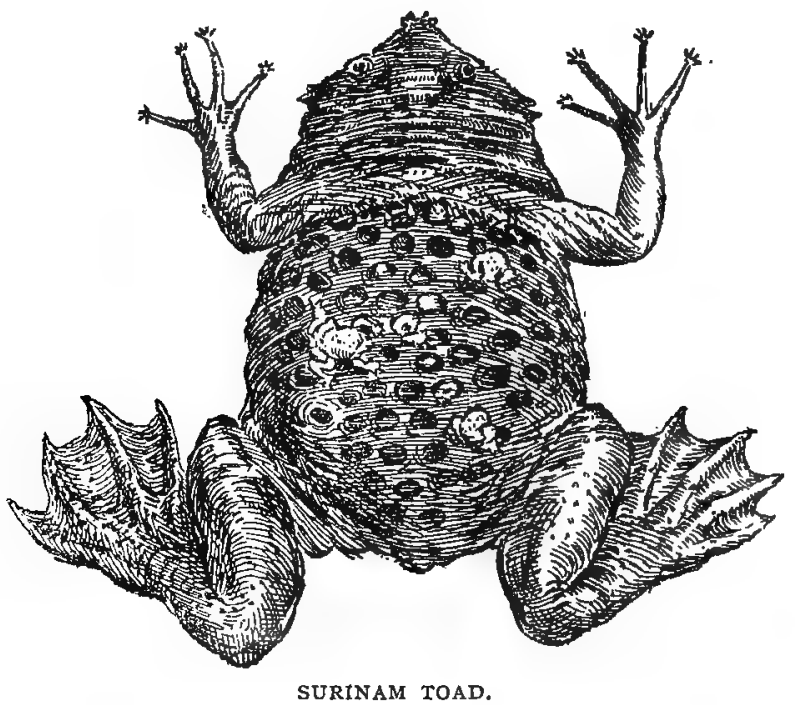

In the Surinam toad the skin responds in a different manner, since it swells up around each egg, so that each, to the number of a hundred or more, is enclosed in a separate cell, or pit, and covered with a lid! In due course the larvæ develop, and passing through the longtailed tadpole stage while still within the egg, finally emerge as perfectly developed toads in miniature, not even the stump of a tail being left. 
Some frogs take up the burden of their young only after they have assumed the tadpole stage-as, for example, in certain S. American and African species. But of their life-history little is known. A small frog found in the Seychelles (Artbroleptis Seychellensis) undertakes a similar guardianship. This fact was discovered by the German naturalist Brauer, who found during August, at about I,500 feet above the sea-level, an adult of the species

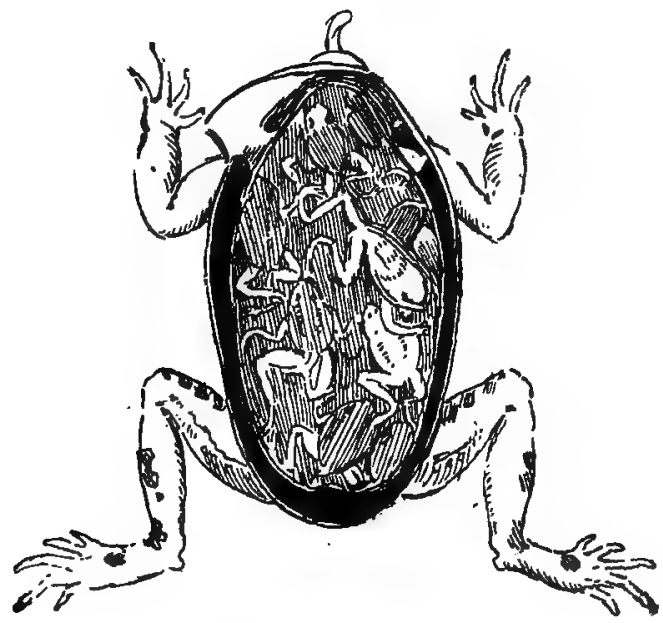

DARWIN'S FROG,

bearing nine tadpoles on its back, to which they adhered by a sucker on the belly. In such cases it is believed that the eggs are laid in some shallow pool, and that later, one or other of the parents returns to take up the young. Unhappily nothing else is known of their history.

Two further remarkable cases yet remain to be considered. The first of these is that of the West African Short-handed Tree-frog (Hylambates breviceps), wherein the 
female carries the eggs in her mouth; and the second is that of Darwin's Frog (Rbinoderma darwinz), the only frog discovered by Darwin in Chili during his memorable trip as naturalist on the voyage of the Beagle. The male has a great pouch under the throat, opening by two slits into the mouth; and this pouch, during courtship, is used as a voice organ, producing sounds like a little bell. But the sounds cease as soon as the eggs appear, for he thrusts them into his pouch, through the apertures just referred to; and here they hatch. To provide for their accommodation, and they range from twelve to fifteen in number, the pouch is now enormously enlarged, extending backwards under the belly to the groin, and upwards on each side almost to the backbone! In the chamber thus formed the tadpoles lie, and here they seem to remain, fasting, until they emerge as young frogs. At any rate, in tadpoles which have so far been examined, no horny jaws and no gills have been found : but the intestine was filled with the remains of the yolk of the egg from which they were hatched.

A contrast has already been drawn between the young of the frog tribe and those of what we call the "tailed Batrachia"-the newts and salamanders. Now we propose to refer to one or two of the more remarkable features which these present in regard to their early history. And with them we shall also consider the infantile and early developmental stages of certain other amphibia known as the "Cœcilians," of whose very existence most of us have never heard. These creatures form a race apart, differing structurally in many important particulars from all their kin. Their most conspicuous feature, externally, is the total absence of limbs. They are burrowers, and found only in tropical and sub-tropical countries. 
The young of the newts and salamanders are never so completely abandoned to fate as are so many of the frogtribe; and it is significant to notice that the number of eggs produced at a time is rarely very large. Even where least care is bestowed the eggs are either attached singly or in small groups to stones or weeds; generally, as in the case of the common newt, the female folds one or two leaves over the eggs as they are laid, thus recalling the curious practice of the tree-frogs of the genus Phyllomedusa. Keyserling's Salamander, a Siberian species, deposits its eggs, to the number of fifty or sixty, in a sausage-shaped bag, attaching it to the water-weeds near the surface of the water. The larvæ in due course hatch and escape from the nursery into the water in a limbless condition, and breathing by external gills.

The Giant Salamander of China and Japan, a huge creature measuring over five feet in length, lays its eggs, to the number of five hundred, in clumps, each egg being attached to its neighbour by a short thread. A male in the Zoological Gardens of Amsterdam kept guard over such a mass of eggs for no less than ten weeks, every now and then crawling among the eggs and lifting them up, apparently for the purpose of aerating them.

Many young of the salamander tribe, like many species of young frogs, have their nurseries ashore, in which case they undergo more or less of the larval stages of growth within the egg-that is to say hatching does not take place till the larval gills have been absorbed. As a case in point we may cite the grey plethodon of North America, which lays her eggs in small packages of about five in number, beneath stones, then curls her body round them till they hatch : an event which does not take place until after the larval stage has been passed-that is to say the external 
gills are developed and absorbed while still within the eggs. How jealously they are cared for is shown by an instance of a captive specimen of a nearly related species-the Oregon plethodon-which was placed with its eggs in a jar. She at once took possession of them, forming a loop around them with her tail. Dissatisfied with her surroundings, she moved them repeatedly from place to place till a suitable spot was found, the work of transportation always being performed by the tail.

Certain American salamanders, e.g. the spotted autodax, deposit their eggs, from ten to twenty in number, in a dry hole in the ground, or in a hollow tree; one or both of the parents then take up their place beside them, apparently in order that the exudations of their bodies may provide the eggs with the moisture necessary for their development, and also to provide for their protection against predatory foes, for they bite fiercely at all intruders. The eggs are remarkable for the fact that they are firmly anchored in the ground by a narrow stalk formed of the gelatinous substance which constitutes their outer coat. The stalks all converge to a point, so that the eggs are held together in a bunch. The embryos develop curious flap-like gills, which absorb the necessary oxygen through the surface of the egg, but by the time of hatching these gills have disappeared, and the young emerge in the likeness of their parents.

The curious eel-like or three-toed salamander (Ampbiuma), a native of the south-eastern United States, lays its eggs in rosary-like strings; and these the female guards most jealously, winding the precious chain several times around her body, and then retiring to some sheltered and comparatively dry spot, where she remains till hatching time relieves her guard. 
And now as touching the Cæcilians. The young of the strange and little-known ichthyophis of S.E. Asia and Ceylon are guarded much after the fashion just described in the case of the three-toed salamander. The möther, though as limbless as a snake, somehow contrives to dig a hole close to the surface, in damp ground and near water. Here she produces about a score of large yellow eggs, which are strung together by strong stalks containing a twisted central thread. These stalks answer to the chalaza of a hen's egg. By their means the eggs are held together in a bunch, and round this the mother coils her body, as shown in our

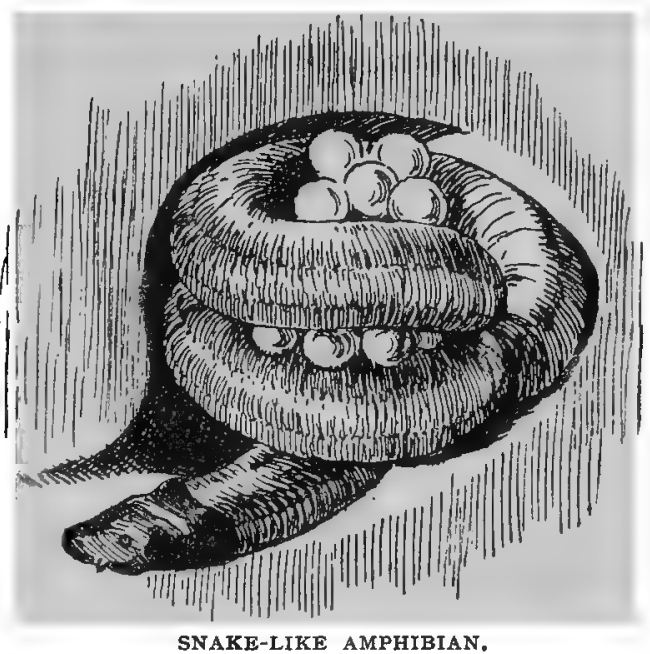

illustration. During incubation the eggs actually enlarge to allow room for the growing larva, which absorbs air, or "breathes," through the delicate envelope which answers to the sheil of the egg, by means of large external gills. These, it is to be noted, disappear just before hatching, being replaced by lungs, a hole in the neck marking the spot where the gills were seated. On hatching, the young leave their mother and betake themselves to the water, where for some time they lead an eel-like existence; and 
as an aid to locomotion, are provided with a fin down the back. In due course, however, the fin vanishes, and the fish-like stage is thrown off, the young emerging on to dry land, where for the rest of their existence they remain.

Some of the salamanders are viviparous, and they present some curious facts in this connection. Thus in the yellow-spotted, or fire salamander, the female retires to the water to give birth to her young, which range from ten to fifty, of small size, and bearing gills, like larval newts, but having all four limbs developed. In the other, the black salamander, which lives in the Alps, at an altitude of between 2,000 and 9,000 feet, the young are not born till the larval stage is passed. Not more than four, be it noted, are produced at a birth, and they have a remarkable history, one indeed unique of its kind. In the first place, a large number of eggs are formed in the ovaries and escape into the uterus-that portion of the oviduct wherein the development of the eggs into embryos takes place; but, as a rule, not more than one egg, and never more than two, are destined to produce a salamander. And this because the rest are broken up to serve as embryonic food. Briefly, the embryo passes through three stages. During the first it lies within the egg and feeds upon the yolk stored therein, after the fashion common to the race. The second is entered upon when it escapes from this egg and feeds upon a mass of yolk formed by the disintegration of hundreds of other eggs, and this yolk is directly swallowed by the mouth, not absorbed - by the intestine as in the first stage. Whether these eggs represent its potential brothers and sisters, or are merely infertile eggs, produced for the sake of the yolk, seems not to be known. The third stage is reached 
when the whole of this mass of food yolk has been eaten. The embryo is now provided with external gills; but these, instead of serving as breathing organs, as in all the cases we have so far examined, take on the work of feeding, absorbing a nutritive fluid formed by the maternal uterus, a method of feeding met with elsewhere"only among

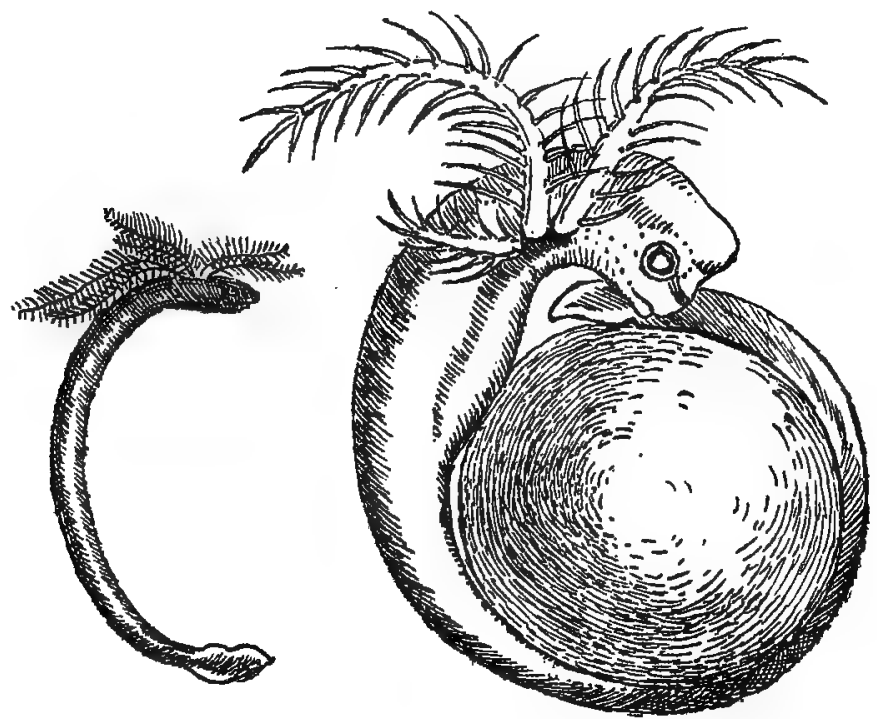

LARVA OF THE SNAKE-LIKE ICHTHYOPHIS.

One of these has been much enlarged. Note the great development of the external gills, and the huge size of the yolk-sac.

certain fishes, and furnishing a wonderful instance of the manner in which organs developed for one purpose may in course of time take on another and totally distinct office.

But even now we have not reached the end of this remarkable history. For if embryos in the second stage of their growth be artificially released from the uterus and placed in a tank of water, they will thrive as well as the 
larvæ of the spotted salamander, which are normally gillbreathing and living a free life at this stage. But where this experiment is tried it is always found that the uterine gills speedily degenerate and are replaced by a new set adapted for breathing in the water, which the replaced gills, whose function is for the absorption of food, are not. 


\section{CHAPTER XII}

THE INFANCY OF FISHES

THE early stages in the life-history, even of our commonest fishes, are enshrouded in mystery, baffling the penetration even of the most persistent and most curious among us. Nevertheless, during recent years, a host of facts have been gleaned which throw a flood of light not only on the theme of the evolution of fishes, but also of the higher groups of animals.

Like the frogs and their kind, fishes are born into the world in that premature, incomplete condition which we know as "larvæ," wherein they commonly bear not the slightest likeness to their parents. Larvæ, as we have already remarked, result when the germ which forms the essential part of the egg is provided with but a limited amount of yolk for its support and development : hence the growing body to which the germ has given rise, be it frog or fish or what not, so soon as it has exhausted its portion of yolk, must at once set out to secure food from its environment or die.

Young fish, in short, are like young people-their early life depends upon the resources of their parents. The children of the well-to-do are provided with food, schooling and pocket-money, so that they grow at ease, and are not driven to the premature exercise of their limbs and 
wits. The children of the impecunious, on the other hand, are launched upon the world at the earliest possible moment to hawk matches or newspapers in the streets. There is one material difference, however, between the offspring of the impecunious members of the human race and the offspring of animals of limited resources: and this lies in the fact that in the latter cases the young, though driven to fend for themselves while still exceedingly frail, are always sent out into the world with a sufficiency of food to last them till they can feed themselves.

Among fishes, as with all the groups of animals so far discussed, this matter of food during the early stages of development varies enormously in its amount : as a consequence we find, as usual, that there is no hard-and-fast line to be drawn between embryonic and post-embryonic stages, between larval and post-larval life. The members of the shark tribe well illustrate this.

As with the reptiles, some are viviparous, some undergo development within eggs bountifully supplied with yolk, while others are less well provided for. Since the viviparous condition has almost certainly been evolved from the oviparous, we propose to survey the latter first.

As with the reptiles, some undergo a more or less prolonged period of development within the body of the parent-of which more must be said presently: some are hatched from eggs of curious shape. As a rule, both with ovo-viviparous and oviparous types the growing body draws its sustenance from a generous store of yolk. The basking shark (Lamargus) affords an interesting exception to the rule, since the young of this species are hatched from exceedingly small eggs deposited, without any protecting case or shell, on the sea-bottom. And 
$\mathbf{I}$

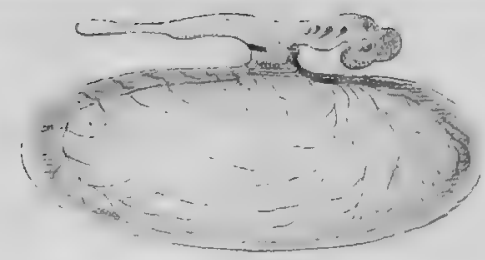

2

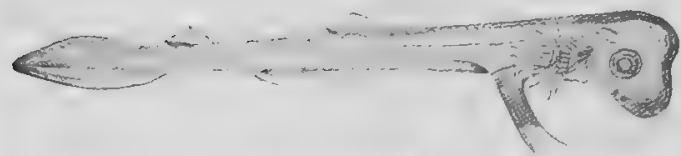

3

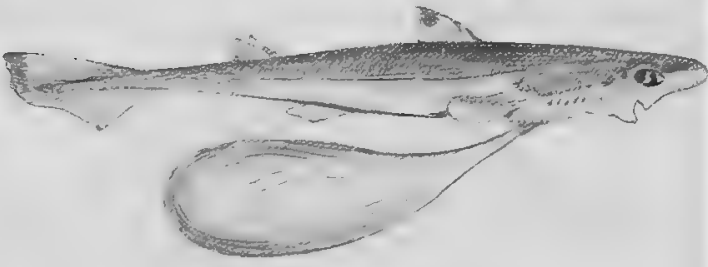

4

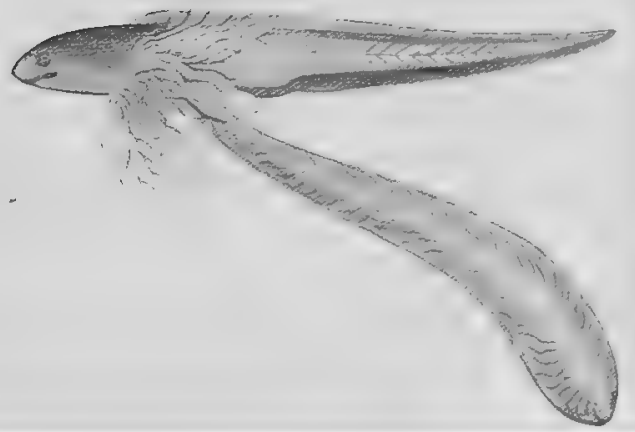

FIGS. I-3. STAGES IN THE DEVELOPMENT OF A DOG-FISH (after Bashford Dean). FIG. 4. THE YOUNG GYMNARCHUS (after Budgett).

In all these the young and growing fish derives its nourishment from an enormous store of yolk attached to the under surface of the body, and serving as an anchor. No food is taken in by the mouth till all the yolk has been absorbed.

208] 

what is true of the shark tribe is true also, as we shall presently show, of other groups of fishes.

As we have already pointed out, when the food store is large the embryonic period is prolonged, and in the case of the fishes now under consideration the larval stage is further commonly passed before emergence from the sheltering egg-shell. The hatching, indeed, of the young of the shark and dog-fish tribe is commonly long deferred. In some of the dog-fish, as for example in Pristiurus, it does not take place till the end of the ninth month of incubation: in the common dog-fish at the end of the seventh month.

It will be remembered that the larvæ of the common frog are hatched in a very premature condition, being mouthless, limbless, and blind; but that in a few days external gills make their appearance. In the young sharks and dog-fish these external gills are developed and absorbed before emergence from the shell, as may be seen in the accompanying illustration, showing the larva of the picked dog-fish. But it is remarkable to find that the food store is so enormous that at the time of hatching a large amount has still to be absorbed. The little fish, as is shown in our illustration, has attained the fully developed adult form, but suspended from its abdomen is a large sac of still unabsorbed yolk. This performs the dual and remarkable function of larder and anchor, for by its weight the young is held down to the bottom of the sea, a prisoner until the process of digestion is completed!

And a precisely similar state of affairs obtains in the case of the curious eel-like gymnarchus, of the Nile, wherein the yolk sac is drawn out into an enormous sausage-shaped body. Here, it will be noticed, hatching 
has taken place earlier than in the young dog-fish, wherein the external gills are absorbed before emergence from the egg. One cannot suppress a feeling of surprise at this most extraordinary exposure of the young, anchored for weeks by the enormous weight of the provender they must consume before they can contrive to move. It seems impossible that so hampered they could avoid the hosts of predatory animals by which. they must be surrounded: and that the shelter of the egg-shell would be absolutely essential till this gargantuan feast had been completed.

This matter of the food yolk has here been brought prominently to the front because of its bearing on what has gone before and what is to follow, for no other animals afford quite so striking a demonstration, perhaps, as to the part played by this important source of nourishing animals before they are able to feed themselves. We may now turn with the more profit to the consideration of the care which the eggs and young receive among fishes.

Commonly, as among the Amphibia, the eggs are small, and are extruded, often in enormous numbers, to form masses of "spawn." The shark tribe afford an interesting exception to this rule, since they lay but few, very large eggs, and these are encased within a horny shell which takes diverse shapes. In the dog-fish, for instance, the egg-case is oblong and furnished at each corner with a long tendril, which serves as an anchor. As the egg is being extruded the fish swim round and round some piece of upright seaweed, and the curling tendrils become entwined therewith after the fashion shown in our illustration. The egg-case of the Port Jackson Shark (Cestracion) is pear-shaped, and surrounded by a broad spiral 
band; while the pointed end of the case terminates in a pair of anchoring tendons.

In the curious chimæra or callorhynchus the egg assumes a striking likeness to a piece of seaweed, and this is the only known instance of such protective resemblance. But stranger still is the fact that the egg, when laid, has imperforate walls. Soon, however, certain areas of the walls decay, forming a series of small holes which allow of a current of water being drawn in by the growing embryo in the fore part of the egg-sheath, and expelled by the holes at the hinder end, thereby enabling the work of respiration to be carried on effectually.

Those near relations of the sharks and dog-fish, by the way, the skates, lay eggs recalling those of the dog-fish, but that the tendrils are short; projecting from the case like four short handles, one at each corner of the oblong case. In all the instances of egg-cases among the shark tribe the walls of the egg are formed by two separate plates, just as a walnut-shell is composed of two separate valves. And these, in the case of the fish now under discussion, just at hatching-time undergo a kind of degeneration, so that the right and left halves of the upper end split open and thus afford egress for the young.

The eggs of all other fishes stand in strong contrast with those of the shark tribe and chimæras, in that they have no shell. But some have remarkable modifications of the outer sheath, as for instance in the case of the egg of the smelt. As soon as this is laid the outer sheath splits along the equator of the egg, and rapidly peels off, and turns inside out, remaining attached only at one small circular area. The separated membrane now forms a sort of adhesive swab, attaching itself to the piles of bridges, posts, and other upright objects in the water, 
so that the eggs hang suspended. In other cases the outer sheath produces threads, or cords, which are attached to the egg at opposite poles and fasten themselves either with the other eggs laid at the same time, or with foreign objects, as in the case of the gar-fish (Belone), the saury pike (Scombresox), and the flying-fishes (Exocetus). In some of the gobies the egg develops at the lower pole a bunch of fibres, which serve to anchor it to some stone or lump of rock on the sea-floor. Only a few eggs are laid at a time, and these are deposited, one by one, to form a little cluster of small spindle-shaped bodies.

In a number of species the eggs are deposited in masses held together in a gelatinous matrix. In the perch such masses take the form of a long tube, recalling the eggchain of the common toad, and this, in like manner, is attached to weeds at the bottom of the stream. In the case of the marine angler or fishing-frog (Lopbius piscatorius) the eggs are laid in masses of from 25 to 30 feet long, even longer, and about to inches broad, forming a sort of floating raft which drifts about at the surface of the sea, at the mercy of wind and waves. This being so, it is not surprising to find that such rafts contain an enormous number of eggs. In a raft 36 feet long and 1o inches broad the number of eggs was computed to amount to $1,345,000$ !

More commonly the eggs are laid separately on the floor of the sea or stream, though thousands may be deposited at a time, as in the case of the salmon. Sometimes, as in the case of the herring, they are adhesive, sticking to shingle and rock on the sea-floor.

In a large number of species the ova are shed in enormous. numbers and float, each by itself, at the surface of the sea. Such eggs are always remarkable for their extra- 

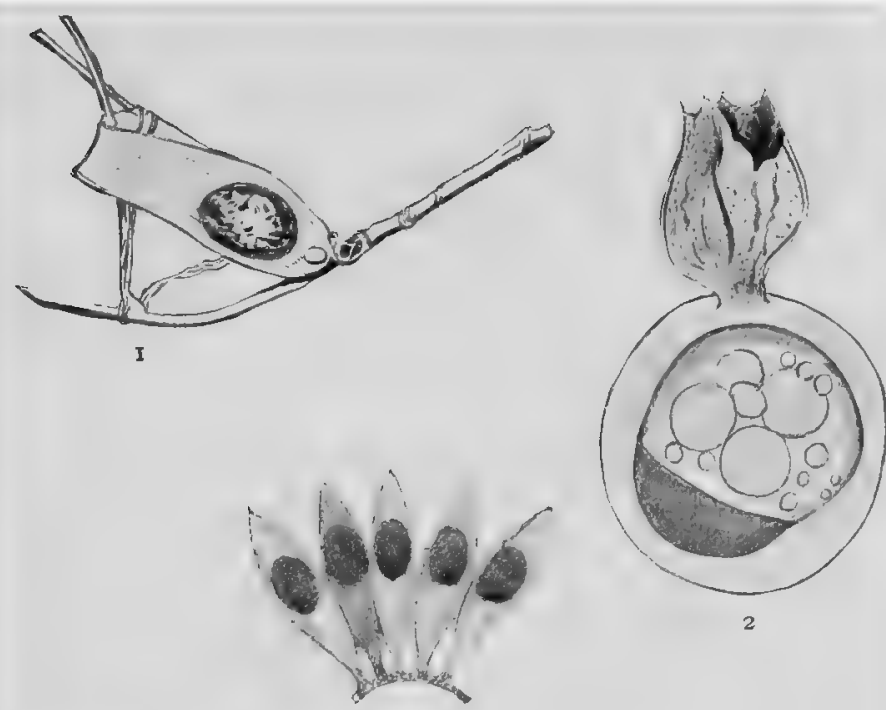

2
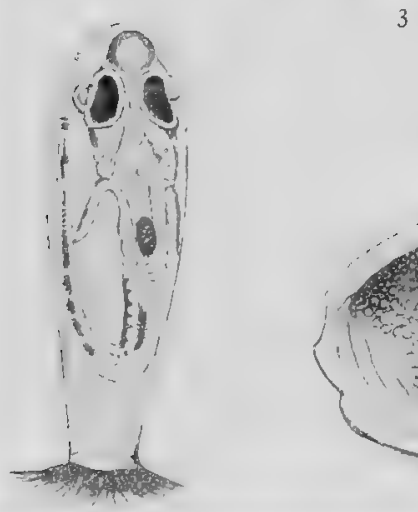

3

4

I. EGG OF DOG-FISH.

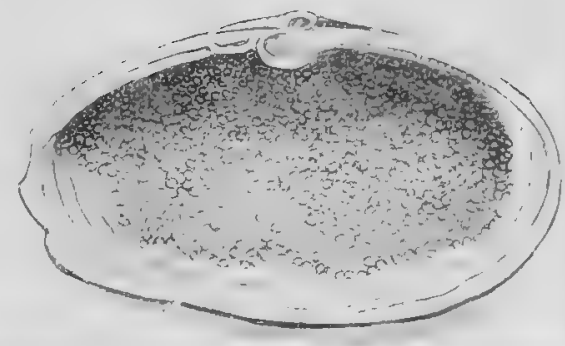

5

2. EGG OF SMELT (after Cunningham). 3-5. EGGS OF GOBY.

The egg of the dog-fish is protected by a horny case, held to seaweed by tendrils. The egg of the smelt is attached to seaweed by the turning back of the outer layer, which is adhesive. The eggs of the Goby are attached in masses to the underside of rocks, or shells. They are seen in situ in 5, magnified in 3 and 4 . 2I 2] 

ordinary transparency. So great is this that if a few be placed in a bottle of sea-water they are practically invisible; thereby, no doubt, enormous numbers are saved from the maws of predatory fishes. The cod, haddock, whiting, bib, poor-cod, pollack, coal-fish, plaice, flounder, dab, and lemon-sole, lay eggs of this kind. In the case of other floating eggs each is provided with a small globule of oil serving as a buoy-as for example in the rockling, hake, ling, turbot and brill : the mackerel, grey mullet, gurnard and bass. Why in some this oil-globule should occur and not in others is as yet unexplainable.

It goes without saying that eggs which are turned adrift to float at, or near, the surface of the sea, are extremely small: and this means that they are but ill provided with yolk. Further than this, they are excessively numerous : not so much because of the loss by predatory animals which must be provided for, as because they are fertilised after extrusion, and this means that a considerable percentage do not get fertilised at all.

A notion of the enormous numbers laid by fishes which disperse their eggs after this fashion may be gathered from the estimates which have been made in the case of many of our food fishes: the number increasing, be it noted, with the size and weight-that is to say with the age of the fish. Thus, in a ling of $54 \mathrm{lb}$. the ovaries contained 28,36r,000 eggs, a $2 \mathrm{I}$-lb. cod, 6,652,000, a haddock of $\mathrm{I}_{2} \frac{1}{\mathrm{lb}} \mathrm{b}$., I56,000, another of $4 \mathrm{lb}$., 806,000, a whiting of $10 \frac{1}{2}$ Oz., I09,000; a flounder of I lb. $9 \frac{1}{2}$ oz., I,638,000; a sole I lb. Io oz., 409,000; a turbot I7 lb. 5 oz., 9, 16r,000. The "vigour" of the fish is evidently another factor, for in two mackerel of the same length, and differing in weight only by a quarter of an ounce-the heavier fish weighing $18 \frac{3}{4}$ oz.-the lighter 
yielded 639,000, the heavier 689,000; and again, of two grey gurnards, one weighed I $2 \frac{3}{4}$ oz., and yielded 244,000, the other weighed I4 Oz. and yielded 269,000 eggs. Again, take the case of two herrings. One measured $11 \frac{1}{2}$ in. and yielded 47,000 , the other II in. and gave only $21,000$.

From this list, as $\mathrm{Mr}$. J. T. Cunningham has pointed out, it is clear that the ling is the most prolific and the herring the least,' though the herring is a more abundant fish than the ling. This is not so contradictory as at first appears, for the ling is a predaceous fish, and much larger than the herring, and a predaceous fish must necessarily be much larger than the fish on which it preys. Since, then, it is quite clear that fishes producing but a few thousand eggs are often more abundant, in spite of hosts of enemies, than those which produce millions, we learn that the production of a very large number of eggs usually implies an enormous destruction of eggs and young, either by the action of enemies or by surrounding conditions, or from scarcity of food.- Thus in the case of the herring, which feeds, both during the young and adult stages, on the swarms of minute crustacea, and other equally small animais, an abundance of food is usually everywhere obtainable; while only such young ling can survive as succeed in finding smaller fishes than themselves to prey upon, and these are not found everywhere, hence hosts must starve to death. A careful survey of the facts shows us that the production of large numbers of eggs and young attains the same result as obtains where but few eggs are laid, and are either carefully guarded by the parents or are specially protected by some other means. The spiny dog-fish, for example, is ovo-viviparous, producing but six or seven young at 
a time, yet this fish is certainly as abundant as the ling: and both are predaceous species.

How great are the dangers to which floating eggs are exposed has been shown, among others, by Professor G. O. Sars, who has recorded cases where cods' eggs have been blown ashore and thrown up on to the beach, a glistening line at high-water mark. But the "demersal" eggs, that is to say those deposited at the bottom of the sea, when laid in numbers large enough to attract attention, suffer a no less heavy toll. Thus spawning herrings, whose eggs adhere to stones and rocks at the sea-bottom, are followed by shoals of haddocks all greedily contending for the newly shed spawn. And to these natural enemies must now be added man himself, who, with the deadly trawl-net, sweeps away tons of eggs yearly.

Let us now briefly survey some of the more striking cases of parental guardianship, either of the eggs or young, among fishes.

The common stickleback of our ponds and streams affords an admirable illustration of this phase of fish life. In this species the eggs are deposited in a nest, and the whole task of guarding them is undertaken by the male, his labours being with the construction of a nest. This is formed of bits of weed collected with much discrimination and held together by a cement formed by his kidneys. Having prepared the nursery, he sets out to find a female heavy with eggs, and by dint of much persuasion induces her to deposit her burden in his nest. Having laid, she forces her way out of the nest by wriggling through the wall opposite the entrance, and thereby furnishes a channel through which a continuous supply of fresh, cool water can be driven, thus keeping the eggs bathed. Next day he persuades her to add still further to the deposit, and 
these he promptly fertilises. When the nest is at last full he mounts guard over the entrance, and stays at his self-imposed sentry-duty for nearly a month, defending his precious charge with great spirit against all comers. Curiously enough, the most dangerous of such assailants are his own wives, for commonly more than one female seems to be induced to spawn in the nest. They would, if they could, devour every single egg. But his work is not confined to keeping out marauders; since to ensure the successful hatching of the eggs he seems to be obliged from time to time to change their position in the nest, and to keep them constantly bathed in fresh water. This last he contrives to do by driving a stream through the nest by means of a fanning motion of the breast fins and the tail,

When the fry at length appear, his vigilance is still further taxed. For in addition to defending his offspring from predaceous fishes, including his own kind, he has to guard and restrict the activities of his brood. If they stray too far from the nest he seizes them in his mouth and gently expels them into the zone of safety again. Soon, however, his task lightens, and his vigilance relaxes: indeed, it seems probable that death puts an end to his labours, for it is believed that the adults die at the end of their first breeding season.

The spotted goby, or pole-wing, which occurs in the Thames, for instance, is a nest-builder. Here, however, an old cockle-shell is made to do duty for a nest. The shell is placed with its concavity downwards, beneath which the soil is removed and cemented together, it is said, by a special secretion of the skin. Access to the nest is gained by a cylindrical tunnel, and the whole nursery is covered by loose sand. Here again, the male 


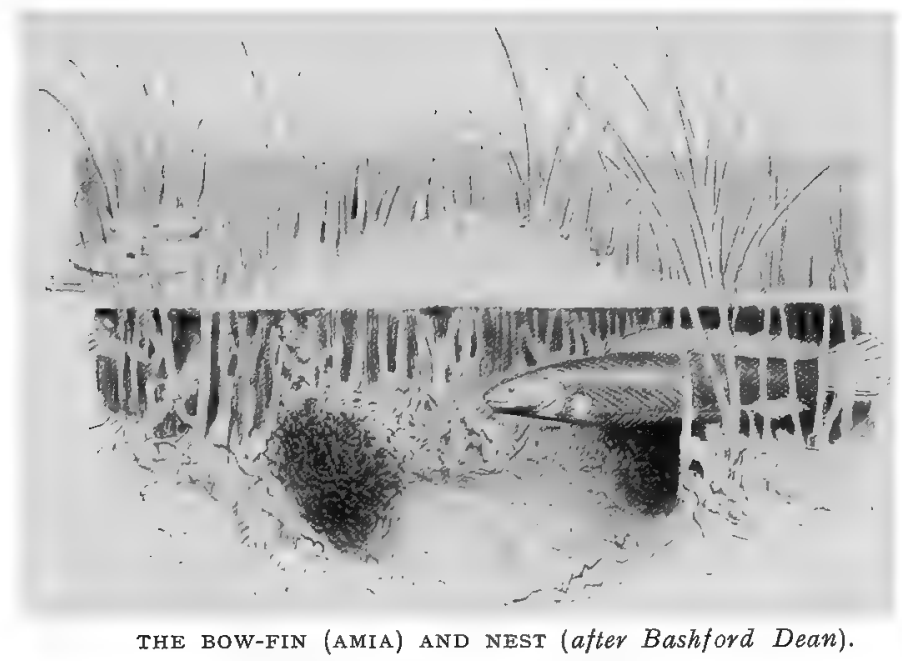

Tinis remarkable nest is formed by clearing away the weeds from the hottom of a pool. The young, on hitching, are jealously guarded by the mile.

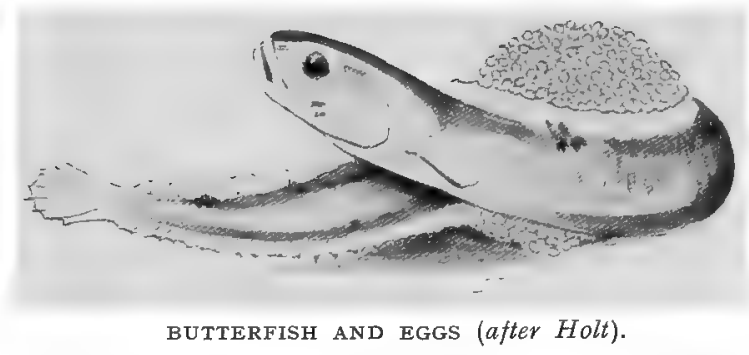

The male and female butterfish keep a jealous guatd over their eggs, taking turns in coiling their bodies round the mass till hatching takes place.

216) 

mounts guard aver the eggs, but his vigil lasts only about nine days.

A very remarkable nest is built by the American " bowfin" (Amia calva), in the Eastern States of North America. The female, it is to be noticed, may attain a length of four feet and a weight of $30 \mathrm{lb}$., while the male is only about two-thirds as large. In April and May the male and female come up from the deep water to the reedy shallows to spawn. Both sexes participate in the construction of the nursery, which is formed by clearing away the reeds over a large circular area-the fish actually biting through the stems of all plants that cannot be broken and pressed aside. Then a shallow depression is formed at the bottom of the pool thus created, in which the eggs are deposited. These develop with remarkable rapidity, not more than eight days dividing the interval of laying and hatching. This does not mean that the early stages of development are passed within the body of the parent, for the eggs are not fertilised till after extrusion. The young are jealously guarded by the male, who keeps the swarm together-often numbering as many as a thousand individuals-by circling around and above them continually.

The eel-like gymnarchus of the Nile builds a huge floating nest of grasses, measuring some two feet long and a foot broad. A part of the nest, curiously enough, projects above the water. Within this about one thousand eggs are laid, and as soon as they are safely deposited the male mounts guard, defending them, and later the young, with great ferocity. They certainly need protection, for, as we have already shown, they are for some time anchored by an enormous weight of food yolk.

Some of the frogs, it may be remembered, make nests of foam: some species of fishes also construct cradles 
of this kind. One of these is the gourami (Ospbromenus), and another the paradise fish (Macropodus viridi-auratus), the foam being thrown from the mouth, and in this the eggs are laid. In yet another, an African fish (Sarcodaces odoe), the young, when the foam subsides, hang suspended from the surface of the water by means of a large sucker-like apparatus on the front of the head.

Even where no nest is made the eggs are often most jealously cared for by one or other or both of the parents, but generally by the male. In the common lump-sucker, for example, the eggs are deposited in the form of clumps of spawn, sometimes of great size, measuring as much as a foot in length, eight inches in breadth, and three or four inches in thickness. To allow the water to penetrate to the centre of the mass, and so secure the oxygenation of the eggs, the male presses his head into the centre of the clump when it is first deposited, and before the adhesive secretion which holds the eggs together has hardened. Thereby he presses the spawn firmly into the crevices of the rock on which it is always laid, and prevents the eggs from being too closely crowded, thereby suffocating the embryos in the centre.

From the moment he mounts guard all would-be robbers are promptly driven off. Star-fish and crabs make ceaseless attempts to get at the mass, and other fish are no less persistent; but their efforts avail nothing. From time to time he pushes his head into the depressions which he formed, and sends a powerful stream of water into the mass of eggs-an artificial method of purveying oxygen apparently absolutely necessary for the wellbeing of the embryos. When the young appear new duties await him, for they promptly attach themselves to his body and are borne about by him, as in the case of some frogs. 
The butter-fish (Pbolis) of our coasts lays a mass of eggs, and around this the male coils his body just as do the python, and the ichthyophis which we have already described.

Mention has been made already, in discussing the frogs, it may be remembered, of certain species which carry the eggs, and sometimes the young, attached to their bodies. We meet, strangely enough, with similar instances among the fishes. Thus the Aspredo, of the Guianas, bears her eggs attached to the lower surface of the body, which, for their reception, assumes a spongy condition in which the eggs are embedded, and for further security are attached by a short stalk richly supplied with blood-vessels.

Similarly, just as certain frogs display a singular habit of carrying the eggs in the mouth, so also, strangely enough, do some fishes. These belong, on the one hand, to the Cat-fishes (siluridx), and on the other to certain wrasse-like species known as Cichlidx. Generally this duty is undertaken by the male. In Arivs, an Indian species of cat-fish, the eggs have been found filling the cavity of the mouth as far back as the gills, so that during the process of incubation he is quite unable to feed. Among the freshwater wrasses, or Cichlidx, the eggs are apparently more commonly carried by the female. This seems invariably to be the case with the African species of this group.

In some cases, at any rate, the parent not only incubates the egg in its mouth, but also shelters the young therein when danger threatens. Dr. Reinhold Hensel, writing of a species known as Geophagus scymnopbilus-a Brazilian species which unhappily has no name in common speechstates that one of the parents, he does not say which, 
keeps careful guard over the family, which may number twenty or thirty individuals, at a short distance from them. When alarmed for their safety a swift move is taken towards them : they then collect around their parent's mouth as though at the word of command. Suddenly, if the cause of alarm be not removed, the mouth is opened and the whole swarm is engulfed. In an adult captured while thus laden the young were found crowded together with their heads towards the gills. When the cause for alarm is past the youngsters are probably suddenly expelled from their living cavern.

Among the frogs again, it will be remembered, there are several species which carry either the eggs or young, and sometimes both, in pouches. It is therefore the more interesting to note that the fishes furnish us with similar cases. Thus the eggs of the pipe-fish and its kind are carried in a pouch at the base of the under surface of the tail. Here they hatch, and for some time after the young have left this queer nursery they are said to seek its shelter on occasions of danger.

We must pass now to speak of certain cases where the young are sheltered during the earlier phases of this development within the body of the parent-a device, so to speak, which has been adopted by species in no way related one to another. The number of species in which the young are thus provided for is so large, and they display so close a likeness, that for our present purpose it were profitless to do more than cite one or two of the more interesting cases.

In Cymatogaster aggregatus, one of the surf perches (Embiotocida), a fish too little known to have earned a popular name, the young, which range from three to twenty, according to the size and age of the mother, lie 
packed within the walls of the ovaries, which are provided with several folds of membrane, richly furnished with bloodvessels and extending among the developing embryos, supplying them at once with oxygen for respiration and with nourishment. At first this nourishment is absorbed by the general surface of the embryo. Later, when the intestine is developed, the nourishing fluid is taken up by it and digested, finding its way thither, not by the mouth, which has not yet come into being, but through the gill-slits, into which it is drawn by the vibratile motions of certain delicate thread-like growths clothing the walls of the gullet, which is pierced by these slits. But the most surprising thing of all takes place when, to ensure more efficient oxygenation of the blood, or in other words more effective breathing, the fins become pressed into service, and take up the work which later will be performed by the gills! For this purpose the delicate skin which lies between the bony fin supports, or rays, is produced beyond the edge of the fin, and supports a delicate network of blood-vessels which absorb the lifesustaining oxygen from the walls of the ovary. This is really a most remarkable fact, and one without parallel among fishes.

Quite as extraordinary is the case of some of the skates of tropical seas. The most famous is that of the Bat Ray (Pteroplatea micrura). During the early stages of its growth it is sharklike in form, and provided with a yolksac, like a young shark. The contents of this bag of provender pass, in some way not understood, up the hollow stalk by which it depends from the body, into the intestine; but a certain amount of yolk is also absorbed by a veritable cloud of thread-like external gills, which turn downwards and backwards to envelop the yolk-sac. 
Later these external gills disappear, and the young is nourished on a milky fluid formed within curious fingerlike outgrowths of the wall of its mother's womb, these conveying the precious fluid to the gullet by thrusting their free ends into a pair of large holes behind the head known as spiracles-apertures which play an important part in breathing during later life.

That distinguished naturalist Colonel Alcock, to whom we owe the discovery of the singular embryonic conditions just described in the case of Pteroplatea, tells us further, in his most delightful book "A Naturalist in Indian Seas," that on one occasion when on board the Investigator they caught a female of Dussumier's shark measuring $7 \frac{1}{2}$ feet long. She contained ten young ones when opened, and these, when turned into a tub of sea-water, "swam about.with perfect unconcern."

As a rule the number of young produced by viviparous is far smaller than is the case with oviparous species. Among fishes, however, this rule is subject to many exceptions. Thus the Blenny (Zoarces viviparus) produce from twenty to three hundred or more at a birth, according to the age and condition of the fernale; while in the socalled Norway haddock (Sebastes norvegicus) more than a thousand are produced at a birth.

That some fishes should be viviparous seems natural enough, having regard to what obtains among the frog tribe; but one cannot suppress feelings of astonishment at finding even one instance where hatching takes place within the body of another animal! This is actually so in the case of a little fish known as the bitterling (Rhodeus amarus), a small member of the carp family common in parts of Europe, which enforces the hatching of its eggs 


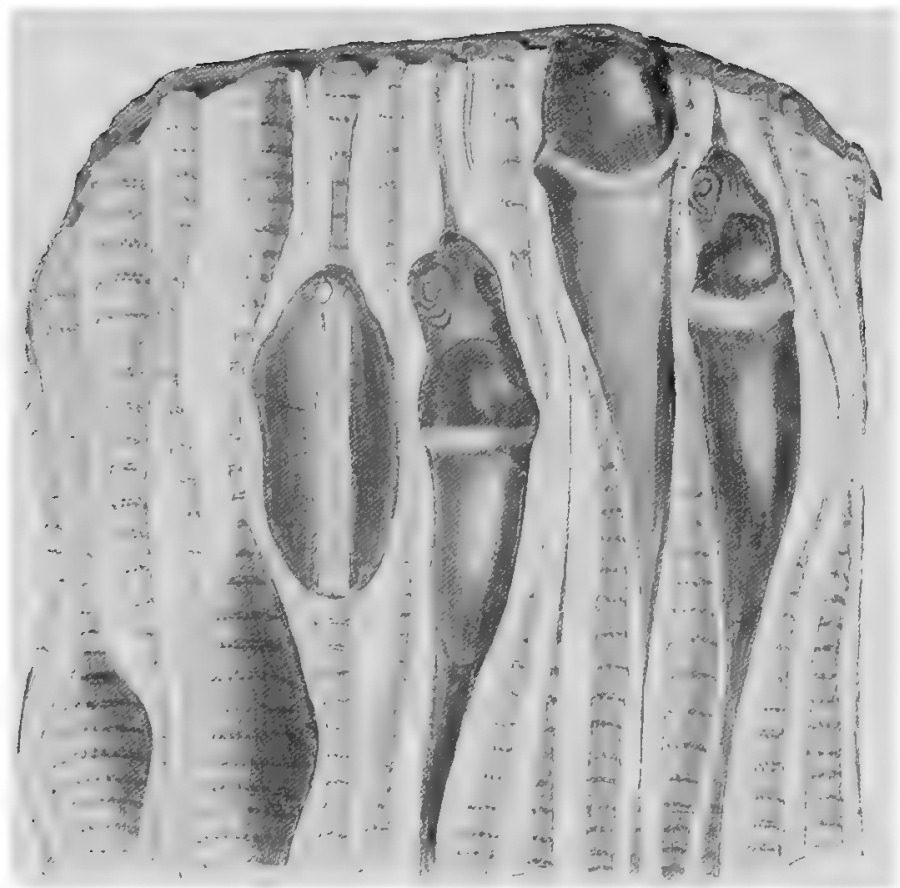

YOUNG BITTERLING IYING IN THE GILLS OF A FRESH-WATER MUSSEL.

In this strange nursery a plentiful supply of fresh water is assured, and they are shielded from enemies. (After olt.)

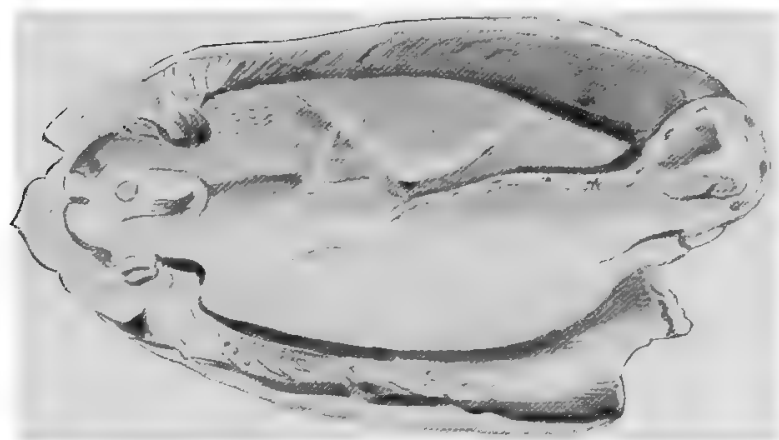

YOUNG PTEROPLATEA SKATE LYING IN THE OVIDUCT.

The walls of this grow into the hinder gill-openings and pour into them a milky fluid, which is swallowed. 

and the housing of its young, at any rate for a brief period, on the common pond mussel!

The female, at the breeding season, develops a long tube or ovipositor, which forms a sort of funnel enabling her to deposit her eggs between the opening of the shell valves of the mussel. Having reached the interior, these eggs settle down between the folds of the "mantle" or gills of the mussel, and here they remain till they hatch. The young, for about a month, continue to occupy this strange nursery, being closely packed away as shown in our illustration. In due course, however, they escape to complete their growth in normal fashion. The gain to the eggs and larvæ from this temporary lodgment is clear, for both protection and a constant supply of fresh water are assured.

But the mussel exacts a quid pro quo from the bitterling; for at the time the fish is seeking to secure safe harbourage for her offspring the mussel, having a prodigious number of young of her own just ready to launch forth into the world, and neéding temporary assistance, discharges her fry upon the mother-fish. Being armed with a curiously toothed shell, more or fewer of the young mussels succeed in hooking themselves on to the skin of the fish. Herein they become speedily embedded by the swelling of the skin caused by the wound of the tiny shell. Thus ensconced they undergo further transformation, and finally from their increased size burst the walls of their temporary prison and fall to the bottom of the stream, to grow into mussels and found new colonies in due season.

In the course of these pages a number of really extraordinary forms of nursing have been cited, and some striking instances of what we may call infant precocity have 
been given. As regards the latter surely the most remarkable of all is that furnished by the young of the Horsemackerel (Caranax tracburus). These, as if by some mysterious process of divination, seek shelter from predatory foes beneath the umbrella of jelly-fish, where they are effectually shielded from attack by the powerful batteries of stinging cells with which the pendant tentacles of jelly-fish are armed. How do they know, these tiny atoms, that under such guardianship they are secure? We cannot suppose that they do know. But this makes the association the more mysterious. We meet with one other similar case in the "Man-of-war fishes" (Nomeus gronowiz), which shelter in like manner among the tentacles of the Portuguese Man-of-war (Physalia). But these are adult, not larval fishes; and their guardian seems to levy toll on their ranks, at least occasionally, by eating one or more of those who have sought sanctuary. At any rate dead Man-of-war fishes have been found within the stomachs of the jelly-fishes.

Notwithstanding the numerous and varied instances of parental care among fishes, the majority of species, as we have already remarked, make no provision for their young, but lay an enormous number of eggs. These, of necessity, contain little or no food-yolk; and in consequence the young fish hatches long before it has acquired its adult shape, or rather the form of its parents. They enter the world, in other words, as larvæ. In many cases these larvæ present quite extraordinary forms, displaying structural peculiarities the meaning of which we can only guess at, and often we cannot do even this.

The young of the Ribbon fish afford an illustration of one of these enigmas. In the form of the body it is totally unlike the adult, for in the first place it is very 


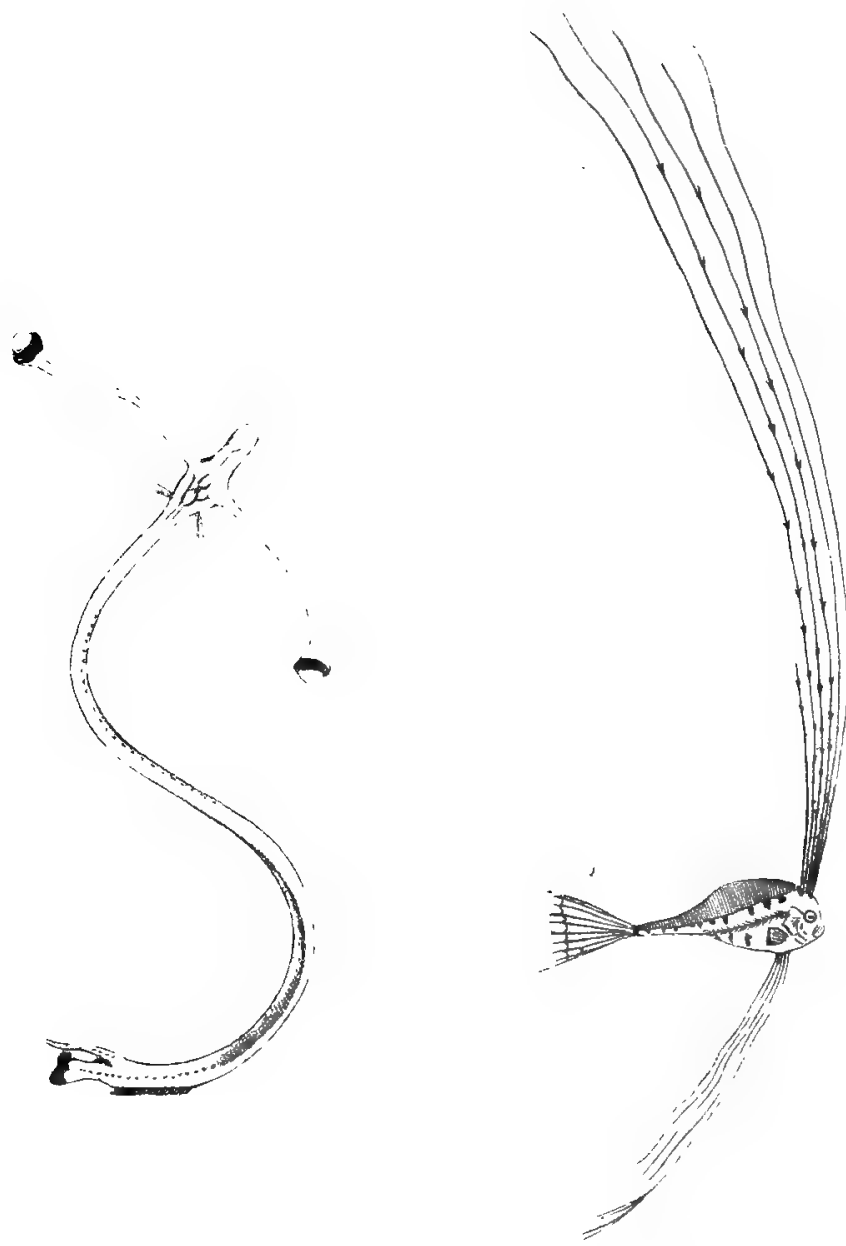

\section{YOUNG "STALK-EYE" (Stylophthal- mus) (after Chun).}

This extraordinary larval fish is very rare, and is to be obtained only from the abysses of the ocean. The adult is unknown.
YOUNG RIBBON-FISH (Trachypterus). These excessively long fin-rays serve as "feelers" in the ocean abysses, where the larval stage of the Ribbon-fish is passed. The adult, which has no such " tentacles," is about ro feet long, and ribbon-shaped, lence the populat name. 

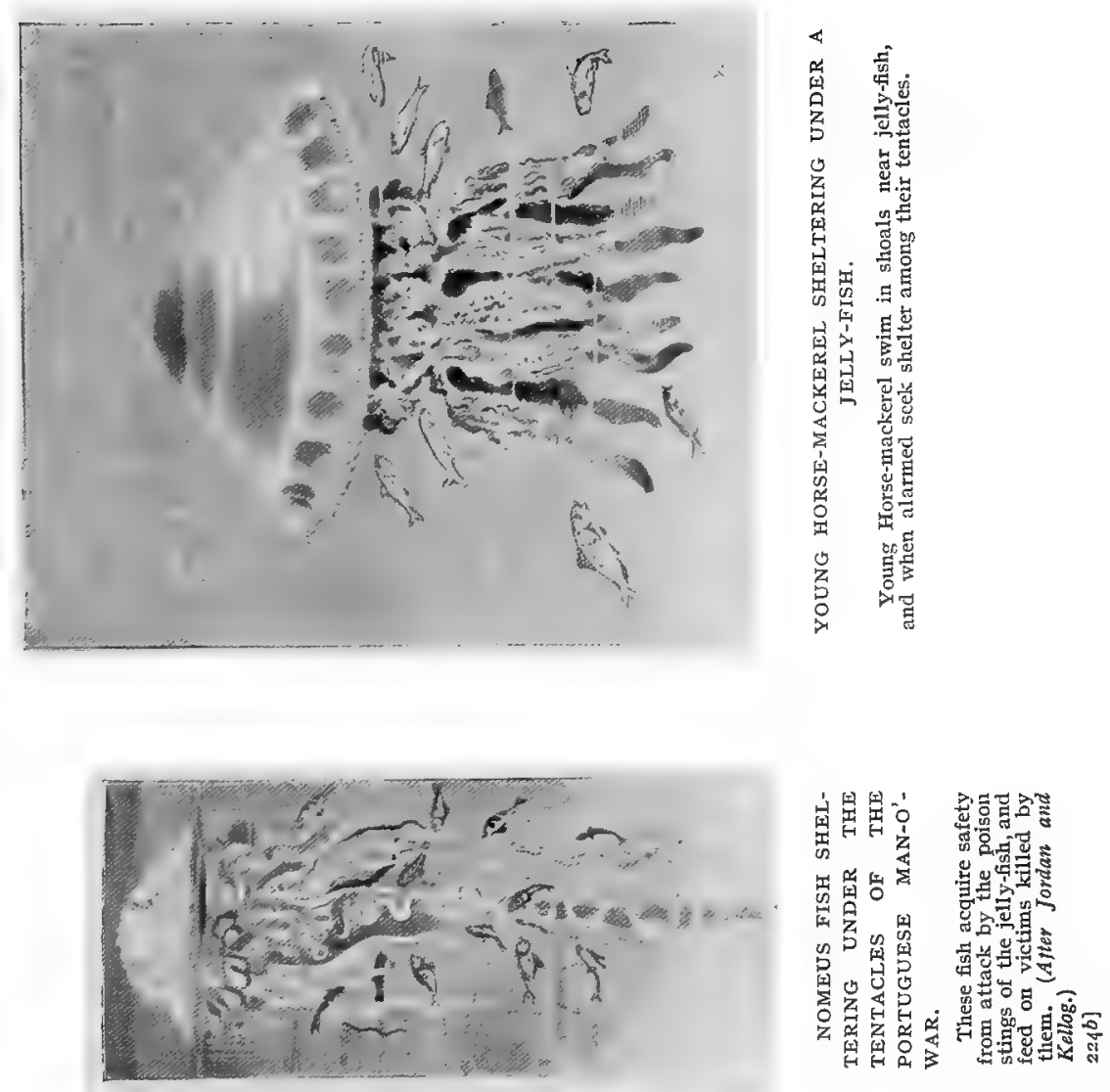

short, the adult being excessively elongated, and flattened from side to side. In the form of its fins, again, it is totally different. And this is especially true of the back fin and the breast fin. In the first named the foremost of the fin rays, or supports of the fin, are prodigiously elongated, attaining a length far exceeding that of the body, and each ray is further provided with small flaps of skin. The fin-rays of the breast fin are in like manner elongated, and to the same excessive degree. What purpose such fragile filaments serve we can only guess at. Briefly it is believed that, like the adults, the larvæ are dwellers in the great deeps of the ocean, and that these long rods and their flag-like appendages are highly sensitive organs of touch.

Equally puzzling is the stalk-eyed fish shown in our illustration. This has been obtained once or twice in deep-sea dredging, and is believed to be a larval fish. Its most conspicuous feature, undoubtedly, is its eye, which, it will be noticed, is mounted at the end of a long stalk-a peculiarity shared by no other member of the vertebrates. This stalk is apparently retractile, so that, warned perchance by vibrations in the water of an oncoming foe, the stalk can be suddenly shortened, the eyes drawn down to the head, where it will be comparatively safe. But of what advantage can it be to the larvæ to have its eyes exposed to such constant peril ? The only light they can ever perceive is the dim phosphorescent glow of the creatures around it; for in the abysses in which it lives the light of day can never penetrate. Only among insects and crustacea and the snail do we meet elsewhere with eyes mounted on stalks, and here, save in the case of the snail, the stalks are inflexible. Among fishes, it is true, we have an approach to this 
stalk-eyedness in the case of the hammer-headed shark, but the likeness here is not very close.

The Sword-fish in the course of its development from the egg onwards presents some curious changes. Just compare, for a moment, the three figures on the adjoining page, and note, first of all, the differences in the fins. The long, low back fin of the youngest, the semicircular fin of the middle stage, and the high, deep fin of the later growth, which even now has not assumed its fully adult form. The pair of fins answering to the hind limbs of higher vertebrates in the youngest specimen have as yet only begun to sprout; in the second they have enormously lengthened, forming two long, slender rods, while in the third stage they have decreased in length. Next, it should be noted that in the youngest specimen the gill-cover bears a long, backwardly directed spine; in the next stage the spine is longer and more slender, and the gill-cover is larger. At the top of the gill-cover, in both these stages, is another large spine. In the later stage the upper spine has almost vanished and the lower has become extremely reduced. Then it should be noticed, that in the younger stages the jaws are of equal length-the "sword" does not make its appearance till the third stage is reached. Finally, note the great difference in the size of the eye, that of the third stage having decreased considerably-possibly because the earlier days are spent in deeper water than the later stages. The young of the Angler (Lopbius piscatorius) affords a no less striking series of changes in the course of its growth from the egg to the adult. Look first at the newly hatched fish. Translucent and finless, and bearing a great burden of food in the shape of a yolk-sac, it gives but little forecast of the hideous thing it is going to be. 



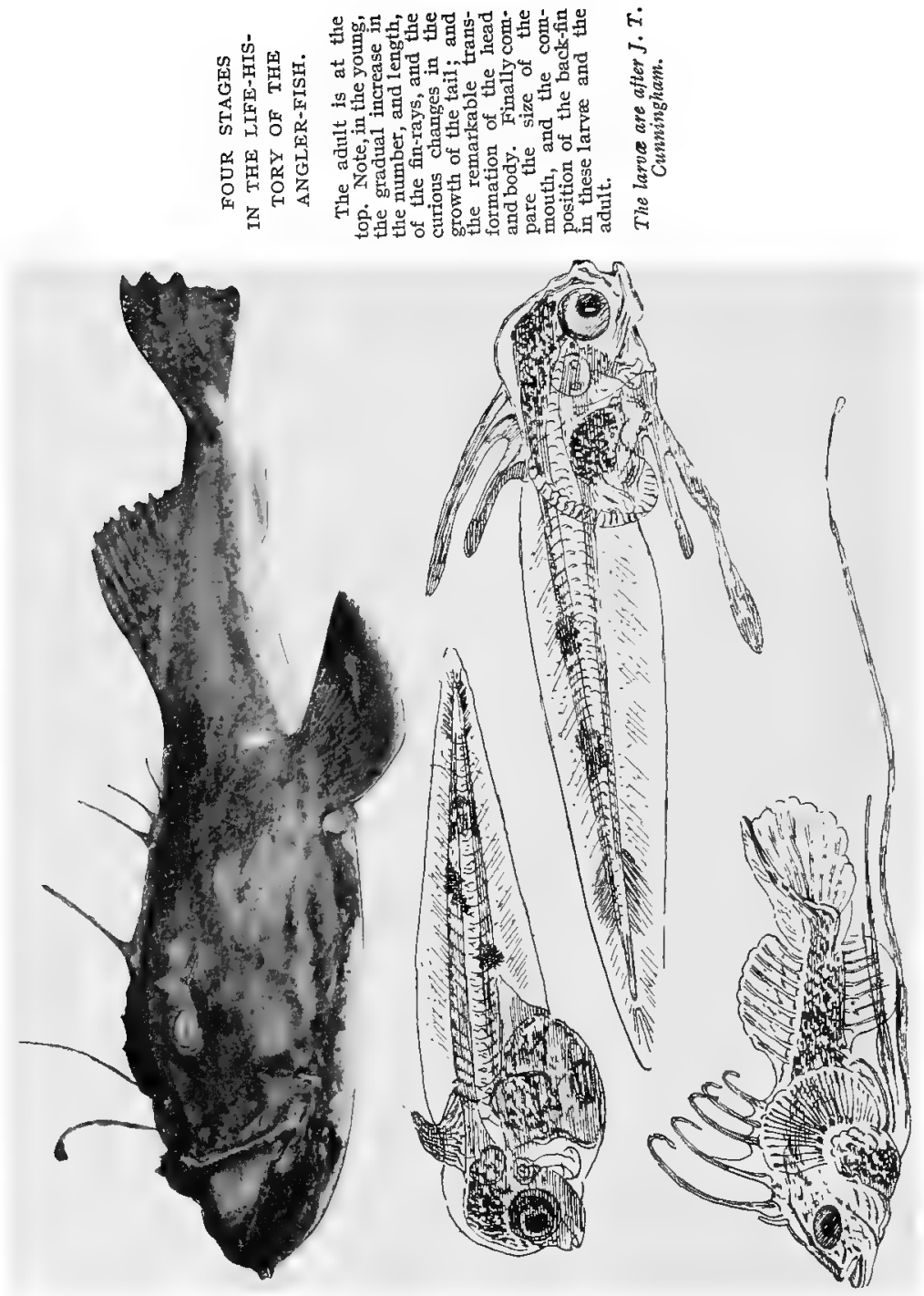



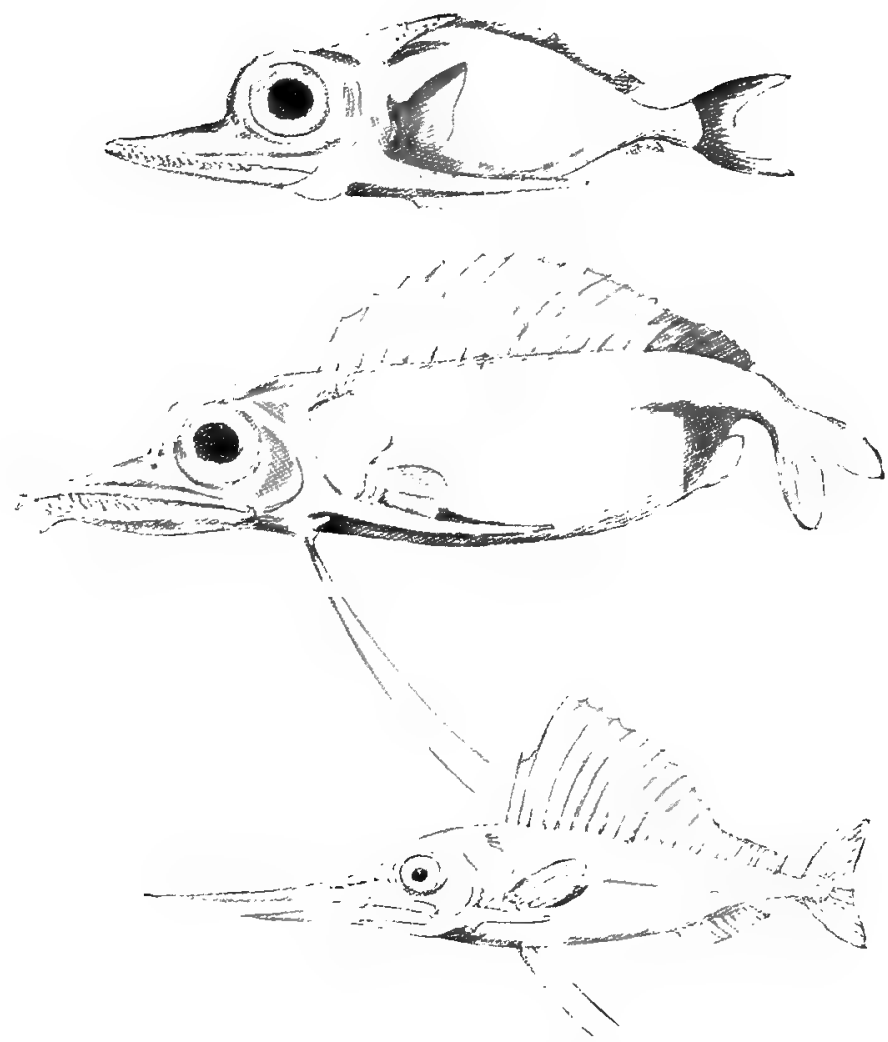

YOUNG SWORD-FISH (after Günther).

In the size of the eye, the spines which project backwards from the head, and in the development of the fins these three stages present striking contrasts. The youngest fish (at the top) did not exceed It of an inch in length, the oldest (at the bottom) about $2 \frac{1}{2}$ inches. The adult measures about I $_{5}$ feet long.

$226 b]$ 

One little stump projecting from the back of its head foreshadows the fin-rays that are soon to sprout, and a few blotches of black pigment give emphasis to the general transparency of its body. In a few days more two finrays have made their appearance on the back, and a pair on each side depend from the belly, these last answer the hind-limbs. The fore-limbs or breast fins have now appeared, and the free edge of the right fin may be seen as a broad semicircle across the body. Now compare these with the still later stage. All the fins which it. will ever have are now present, but they have still further changes of shape to undergo.

In the oldest of these larval stages, it will be noticed, the foremost fin is composed of a number of hookshaped rods united at the base by a thin sheet of transparent skin, which is continued backwards to embrace the second back fin. The breast fin is now large, but the most striking change of all has occurred in the form of the fins which answer to the hind-limbs. These, it will be seen, form two enormously elongated streamers, much longer than the whole body. We can only surmise that they serve as organs of touch and are highly sensitive. But why are such intelligences needed at this particular stage of life? And what, it may be asked, is the meaning of the striking difference in the form of the tail as compared with the younger stages? To the first question Science has, as yet, no answer; to the second we must return presently.

Remarkable as are the differences displayed between these three stages, they become still more accentuated when we come to compare them with that of the adult. The young fish has a cylindrical body, and is apparently free-swimming. It is certainly comely in appearance. 
The adult well deserves the epithet "hideous." One can almost imagine its ugliness, and its hateful mode of life, to have been the infliction of some jealous and infuriated sorcerer! Glance for a moment at the huge flattened head and enormous mouth, and note the curious disposition of the rays or supporting rods of the back fin. These have now become reduced to three in number and widely separated. They no longer support a fin-membrane, as in the larval stage. Their function has changed, for they now serve as lures, the free end of the foremost supporting a little tab of skin, forming a sort of flag, while small tags or flaps of skin run down along the sides of the head and trunk, which by their movement in the water decoy fishes on the look-out for scraps. The body of this vile-looking monster being partly covered in mud, the dupes approach unsuspectingly, and so soon as they get near the cavernous mouth it suddenly opens, and with the inrush of water they are engulfed!

To return for a moment to the great length of the pelvic fins in the larval stages of the sword-fish and angler, be it noted that a similar elongation obtains also in the case of the ling, and here also, as the types just referred to, in the adult stage these fins are quite short. What part do they play in the young?

The young of the Senegal polypterus, or snake-fish, afford another striking illustration of the differences between larval and adult stages. As will be seen from the adjoining pictures, in the young of this remarkable fish, a native of the rivers of Western Africa, the back and tail fins form a continuous series of bony rods, the latter of considerable length. Later, it will be noticed, these closely set rods open out, so to speak, each becoming widely separated from its neighbour, and each bearing a thin flap of skin, 


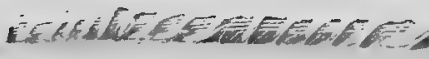

1

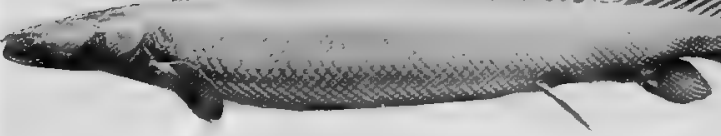

2

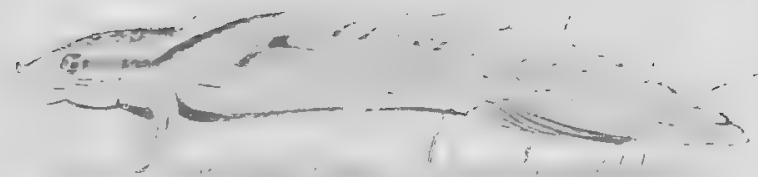

3

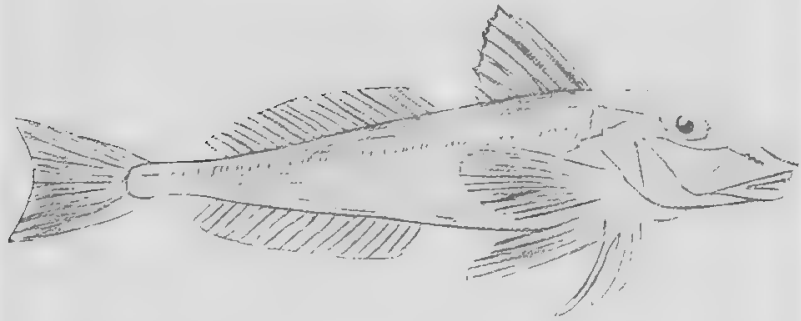

4

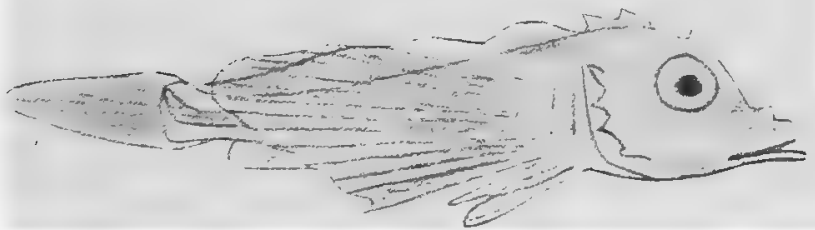

I. THE ADUlt sNAKe-Fish (Polypterus). Photo by A. Rudland. 2. ADULT GREY GURNARD. 3, 4. YOUNG OF THE SAME.

The Shake-fish breathes by internal gills, and has the back fin made up of many finlets, and a short tail-fin. The breast-fins are used simply as balancers. In the larval stage the fins have a very different form, breathing is performed by external gills, and the breast-fins are used as supports. Note the very different form of the back-fin and tail, and the enormons breast-fin of the young Grey Gurnand.

$228]$ 

while the tail fin shortens. Further, both in coloration and in the shape of the breast fins the larva differs conspicuously from the adult, in the young stage these fins are used after the fashion of fore-legs, to support the body. Finally, attention must be drawn to the external gills, which recall those of amphibia. These are, as we have already seen, confined to larval life, carrying on the task of breathing till the adult gills are sufficiently advanced to take up their work: though in many cases they also serve to absorb nourishment from the yolk, and thus combine the duties of feeding and digestion!

While some of the most striking of the peculiarities of young fishes are those which belong solely to larval life, and have been developed to meet its needs, others, unquestionably, answer to phases of earlier, ancestral, adult phases of growth. To enlarge upon this aspect of young fishes would involve us in technicalities, but the nature of the evidence can readily be grasped from an examination of the tails of one or two of the larvæ which we have already surveyed.

Take the young Angler, for example. In the earliest stage it will be noticed in the figure that the tail forms a continuous line with the rest of the body, and has no fin; in the second stage rudiments of the fin have appeared; while in the third stage, it will be noted, the end of the tail turns suddenly upwards, bearing a narrow marginal fin along its upper border and a much larger fin on its hinder border. Here we have what is known as a diphycercal tail, characteristic of adult sharks. Now in all the more specialised or so-called "bony" fishes, such as the angler, and the herring, salmon, cod, and so on, the tail fin, as any one can see for himself who will take the trouble to look, is fan-shaped, the bony 
supporting rays springing from a rounded base, and hence the tail is called "homocercal." As a matter of fact this symmetry is deceptive. Sooner or later, the upwardly directed portion degenerates and finally vanishes, leaving the fin-rays originally belonging to the undersurface of the upturned portion to arrange themselves in the fan-wise fashion just referred to.

Thus we see that the peculiar arrangement of the tail-fin of the most highly developed species passes through the ancestral stage before arriving at the form with which most of us are familiar. And it is quite possible that the whole appearance of the angler at this third stage is that which characterised the adult stage of some remote ancestor. A more striking illustration of the general truth of the contention that every animal climbs its own ancestral tree it would not be easy to find.

In some cases, on the other hand, we are confronted with the evolution of new characters, and these often of a very remarkable kind. The young of the "flat-fish" plaice, sole, turbot, and their kin-illustrate this in a very striking manner. In the adults of these fishes the dark-coloured upper surface answers, apparently, to the back, and is generally so regarded, more especially since the eyes are also uppermost. But, as a matter of fact, this surface answers to the right or left side, as the case may be: in some species the right, and in others the left being uppermost. The back is only to be distinguished after an examination of the mouth, and a search for the pair of fins answering to the hind-legs of terrestrial animals. How has this singular condition come to be? The answer again can only be found after an examination of the larval stages. These show us that the young of all the flat fish enter the world as "round" 


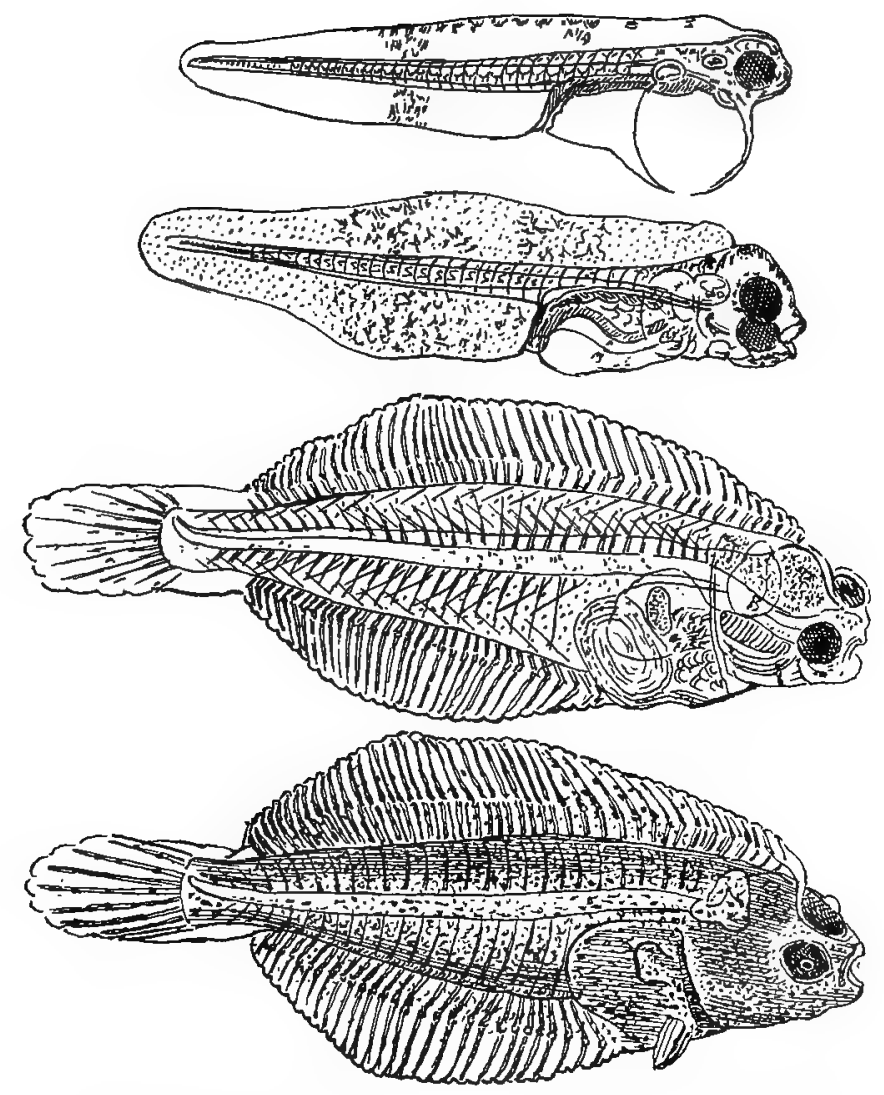

EARLY STAGES IN THE LIFE-HISTORY OF THE PLAICE (after Cunningham).

In the earliest, uppermost, stage the body is still " round," the eyes have their normal place-one on each side of the head; and there is a large yolksac. In the figure next below the eyes are seen to be changing their position. Note- the growth of the fins and the transformation of the tail.

230] 

fishes, closely resembling, say, the young of cod-fish, and showing no trace whatever of the strange transformation which they are presently to undergo.

There is one curious point, however, which is to be noted in regard to a yet earlier stage, a point which in itself seems insignificant, yet, as the sequel proves, is fraught with deep meaning. Briefly, the eggs of most of the right-sided species - that is to say the species in which the uppermost is the right side, as in the plaice, dab, flounder, lemon-dab, witch, halibut, and long-rough dabhave no oil-globule; while this is present in the leftsided species like the turbot and Norwegian top-knot. The eggs of the sole differ again in having a number of such globules. Herein lies hid a mystery so far insoluble. Very well. The larvæ of flat fishes, as we have already remarked, are very much like those of equal-sided fish, and at first swim near the surface and feed on the minute floating creatures in the same way.

Sooner or later, however, comes the groat change that is to anchor them, so to speak, to the sea-floor till they die. They grow deeper and deeper from back to belly, and at last are unable to rest save on one side-the right or left, as the case may be. The eye on the under side, in any case, is in a very dangerous place, and it is clear must either perish from constant contact with the ground or migrate to the upper side. The latter alternative, we know, has been adopted, if we may be allowed this expression, for it is certain that the fish can neither choose nor determine the position of its eyes. What is the stimulus which starts this uncanny migration of the eye, and why the form of the body should compel the creature to pass the whole of its adult life with one of its sides instead of its back uppermost, the wisest of us cannot even guess at. 
But the migration is a fact, and gave rise, years ago, to a heated controversy as to the method of travel. The Swedish naturalist Malm was the first to study this problem, and from the species which he examined he decided that the eye moves outwards and upwards across the roof of the head till it takes up a position by the side of its fellow. But at about the same time-between 1860 and 1870-a Danish naturalist was also tackling the problem, and he came to the conclusion that the eye passed through the head; and for a long time controversy waxed furious as to which was right. As a matter of fact, both were! This was proved when, in 1878 , an American naturalist actually kept living specimens of young flat fish, in some of which the eye passed round, and in others through the head. And when this apparent diversity came to be further explored it was found that the passage through the head was apparent, not real, and was due to the fact that in such species the dorsal, or back fin, extended far forwards beyond the level of the uppermost eye, and that the eye of the under surface simply tunnelled under the fin, and over the head. In the sole and the turbot the forward growth of the fin to the snout does not take place until after the undermost eye has taken up its position on the upper surface of the body.

We bring this chapter to an end with a brief account of the early history of the common fresh-water eel, which for long remained an apparently insoluble mystery. We now know that the eels of our rivers and ponds migrate to the sea to spawn, and that having done this they die. No eel, whether of fresh water or of the sea, like the conger, ever lives to see its offspring. Our river eel, then, when the supreme period of its life is at hand, makes all speed for the sea, putting on, during the journey, nuptial 


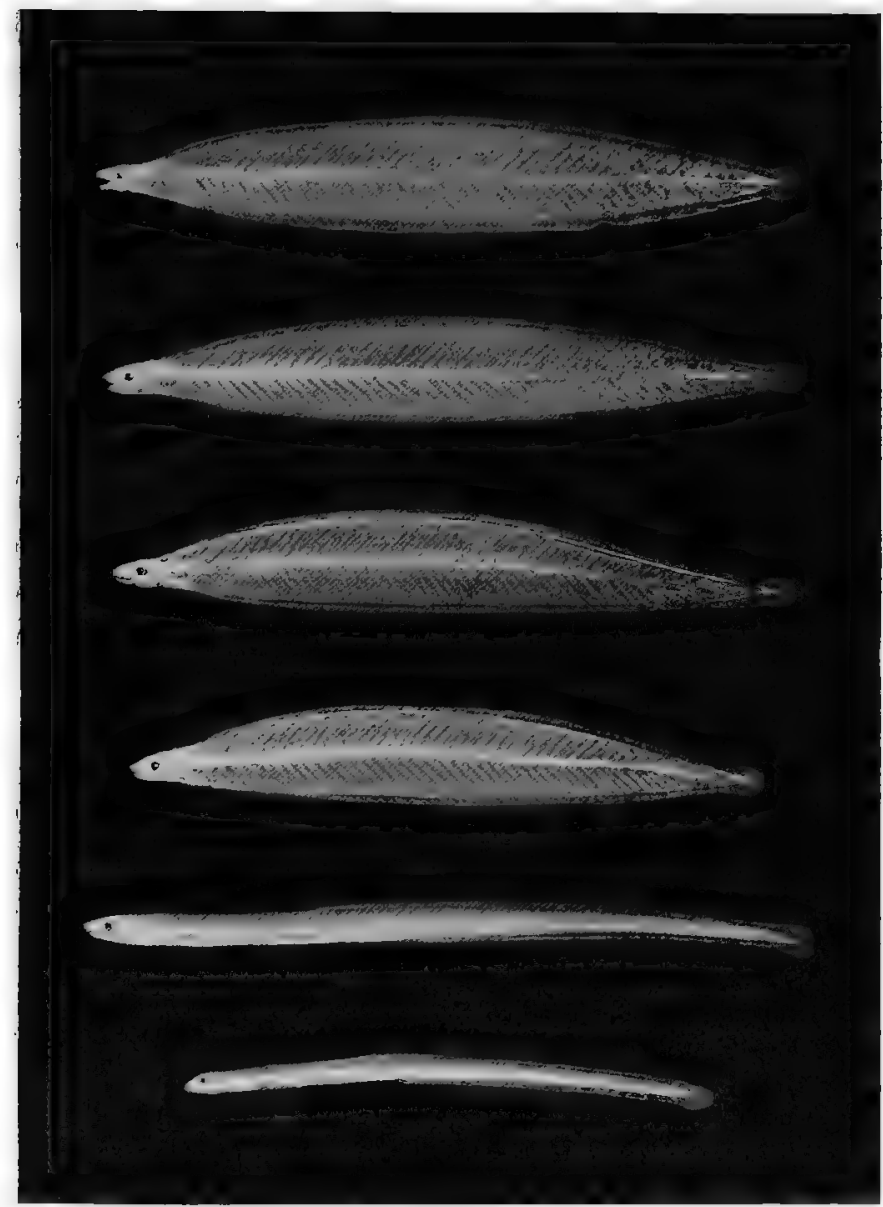

TRANSFORMATIONS OF THE EEL.

Young eels display the extraordinary phenomenon of decreasing in size as they increase in age, up to a certain point ; then they begin to assume the adult shape and continuous growth. The two lower figures should be transposed.

232] 

hues, which are especially conspicuous in the male, who is always smaller than the female. The skin becomes silvery, the breast fin black; and, what is really very significant, the eyes become considerably larger. And this because they are to spend the short space of life remaining to them under new and remarkably different conditions. For years they have lived in the mud of some shallow ditch or slow-moving stream, now they are not only to sojourn in the great and wide sea, but they are to descend its awful and mysterious depths, and there, some two hundred fathoms deep, and in a darkness that might be felt (for the light of day never touches these abysses) they fulfil the purpose of their lives and-die.

How long the eggs of the eel take to hatch is unknown, nor can we say anything of the earliest stages of larval life. But we may safely assume that they do not differ in any essential respect from those which are known to obtain in the life-history of the conger-eel. Sooner or later, however, the young eel becomes transformed into a diaphanous ribbon-shaped creature, with a ridiculously small head and no fins, and with white instead of red blood. Its backbone and the muscles of its body are plainly visible through the skin. What it feeds on during the early days of life we do not know, but it has no large reserve of yolk to draw upon. For a time, anyhow, it feeds, and increases in size in consequence.

Then a strange thing happens. The mouth has to be closed for alterations : a new set of teeth has to be developed, and other changes made, hence a prolonged fast becomes enforced, and daily the little eel dwindles in size. At the same time it is moving, with millions of its own kind, nearer and nearer to the light, nearer to the sun, and nearer and nearer to the land. What guides 
this strange exodus from the pit of the sea? how do they find their way landwards? Perchance they are provided with some subtle, supersensitive power of detecting the presence of fresh water poured out from the rivers, which promotes a species of "river-hunger." Be this as it may, the invading hosts sooner or later strike the mouth of a river, and ascend its stream in myriads. By this time the adult eel-shape has been assumed, the blood has become red, and pigment tinges the body, though it is still transparent. The little eel is now a "glass-eel" or "elver," about a year old, and of the length of a darning needle.

It is difficult to estimate the numbers which annually ascend our rivers during the spring and early summer months. The advance guard may make its appearance as early as February, but the main body pass during May and June, when the remarkable phenomenon known as the "eel-fare" takes place-the time when the young eels, or elvers, "fare" up from the sea. Sir Herbert Maxwell tells us he has "seen a Scottish trout-stream slate-coloured from bank to bank, with the throng, for a distance of twenty or thirty yards," and, he continues, "It is a display of the prodigality of Nature, as well as of her heartlessness to the individual fate of her creatures; for it must be only a very small percentage of elvers which escape the voracity of birds and fish at this tender age. Even man deigns to consider elvers a delicacy. Couch, the ichthyologist, was told by a Cornish fisherman that he had seen at Easter four carts loaded with elvers for sale." They are fried in a form called elver-cakes, made by pressing the tiny soft bodies into a shape, which presents a somewhat curious appearance from the number of tiny black eyes which bespangle the mass. In the 
Severn, a generation ago at any rate, prodigious numbers were thus wastefully disposed of.

These little creatures make their ascent with a pertinacity that is amazing. Not even locks bar their progress, for they wriggle their way up out of the water and travel round to the river on the other side in the wet grass; and by a similar overland route they will make their way even to distant, isolated ponds, there to remain till the call of the sea drags them forth again to return no more. 


\section{CHAPTER XIII}

THE INFANCY OF CRABS AND CATERPILLARS

THE childhood of animals is a theme about which we shall be able to say more a generation hence, when more attention has been paid to the early phases in the lifehistory of such animals as the collector and the advance of "civilisation" have left to us. So far, our survey in these pages has been confined to that great group of animals which are technically known as the "Vertebrates," wherein, from Man downwards, we remark a gradual shortening of the infantile period, and a lessening of the intelligence.

Among the higher groups-from Man to the Reptileswe find the young, exceptions apart, as in the case of the kangaroo, enter the world as more or less complete miniatures of their parents. From the Amphibia-the frogs and their kind-downwards, we find, on the other hand, that the young enter the world in a form quite unlike that of the adult, and frequently lead a totally different kind of life. Among the Invertebrates, which we are now to consider, the differences between adult and offspring are generally still more marked, not only in outward appearance but also psychologically.

Young mammals and young birds commonly betray, with more or less frequency, a joy in living, an exuberance 236 


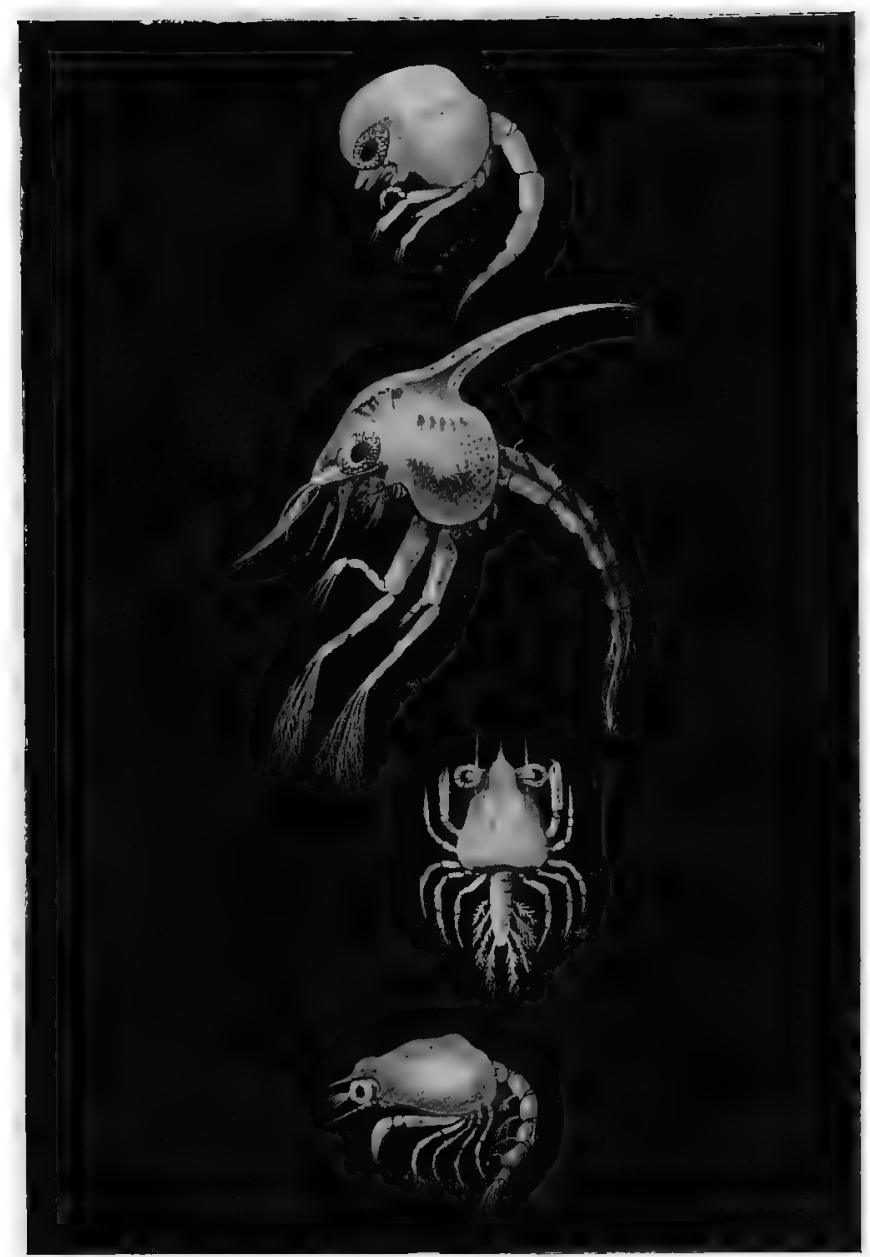

EARLY STAGES IN THE LIFE-HISTORY OF THE CRAB.

The newly-hatched crab, and for some time after, lives at the surface of the sea : the adult dwells on the sea-bottom. 236] 

of spirits, in the form of gambols. No record of such vitality has been recorded of young reptiles, or of the frog tribe, but I have seen young fishes in the Norfolk Broads absolutely revelling in the summer sun; turning and twisting till their silvery bodies glistened, now shooting along the surface, and now diving into the cool depths as if to avoid some imaginary foe. But with the Invertebrates there is no such demonstrativeness: on the contrary, some of these reveal an almost criminal depravity; while for the most part they give no sign of the consciousness of life, no indication that they are either glad to be alive, or find life a bore! It is then for the strange contrasts of shape and the curious history of these early phases that we must study them. Among the lowest groups of all there is no childhood, no period of infancy.

In these pages it will be impossible to do more than select a few of the more striking illustrations of the infantile period among the invertebrates, for the number of species they embrace represents a colossal total. The insects alone far outnumber all the land animals of the world, while the vertebrates compared therewith form but an insignificant band.

But, if only by way of affording a contrast with what has gone before, it is worth while to take a survey of some of the more striking cases of infancy among these lowly creatures. And no better introduction to this theme could be found than that furnished by some of the aquatic types-as for example the Crustacea.

If a fine muslin net be towed at the surface of the sea on a calm day, and the contents turned out into a jar of sea-water, it will be found to have captured, among other things, clouds of animated specks, which dance in the 
water, hither and thither, with wonderful rapidity. Many of these specks, under a microscope, will be found to be crustacea. Some are adults, belonging to that group of minute species known as Copepoda, which pass the whole of their life swimming at, or near, the surface of the sea; others will be the larvæ of larger species which in their adult stages crawl about on the sea floor.

Take the case of the larval history of the Common Shore Crab (Carcinus manas). The youngest stage is that known as the "Zoea," wherein the head and fore-part of the body are covered by a shield, or carapace, with a long spine thrust up from the middle of the back, and another, like a beak, in front. Behind is the long abdomen, which can be freely bent backwards and forwards, and ends in a forked "fin." The eyes are large, and set close to the head, not on stalks, as in the adult. Behind the "beak" are short antennules and antenni, and behind these two pairs of swimming feet, which really answer to a part of the jaw armature in the adult. True feet have not yet made their appearance.

This zoea stage, as a matter of fact, is preceded by a yet earlier stage; for when first hatched this youngster lacked the spines on the carapace and some other details. But the zoea stage is assumed a few hours after hatching, by a "moult." It now swims rapidly about in the sea, undergoing several moults. Soon, however, it assumes a new form, such as that shown in the accompanying figure. This is the "Megalopa" stage. Herein the spines of the carapace have vanished, and the legs have appeared -crawling legs under the carapace, and "swimmerets" under the abdomen. Note that this abdomen is stretched out behind the carapace, lobster-fashion.

Next follows the stage wherein the general shape of the 


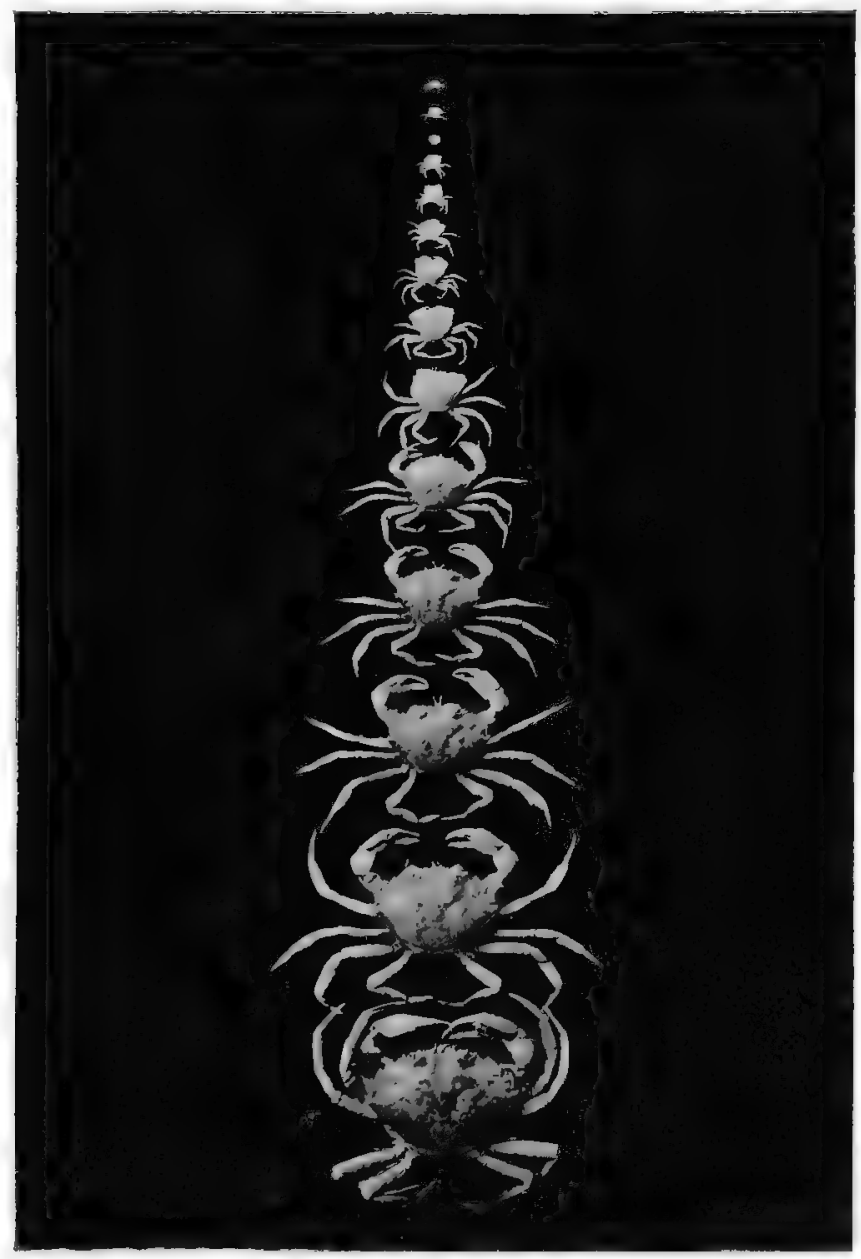

THE CAST-OFF CLOTHING OF A CRAB.

The shell of the crab, having once hardened, cannot grow. The above series represents the successively moulted shells of a single individual, each larger than the last. 238] 



\section{INFANCY OF CRABS AND CATERPILLARS 239}

adult is assumed, and from thence onward, by a series of moults, the characteristic shape of the shore crab is put on. But this only after a long and numerous series of moults, as seen in our illustration, which shows all the cast-off shells worn by a young crab during a period extending from June 13, I901, to July 20, 1904, when the captive died, still, so to speak, in infancy. On the average it will be seen, from the first appearance of the crab stage till death, there were sixteen moults; and no one has yet discovered how many moults take place from the hatching of the egg onwards to the end of the megalopa stage.

But more remarkable is the history of the prawns of the genus Penaus. So long ago as 1863 Fritz Müller found that the young of Penceus left the egg in what is known as the Nauplius stage-a form of larva hitherto unknown save among those minute crustacea the Copepoda, and the cirripedes or barnacles. Herein the body is pear-shaped, and there are only three pairs of limbs. These limbs, however, do not answer to legs, but to the antennules, antennæ and jaws of later stages of development! These organs, in the adult, are about as unlike as can be, yet in the larva they are hardly distinguishable one from another!

The antennæ of the nauplius in fact serve as jaws till they are eventually replaced, in the adult, by the mandibles. Finally, at this stage of development there is only a single eye, which is placed in the middle of the head. From the nauplius stage this larva passes through a "metanauplius" to the "zoea" stage, thus undergoing a series of most striking changes of form. Then follows the "schizopod" stage, which is the last step towards the adult Penceus - a near relation of the highly esteemed pink shrimp; but the swimmerets, it will be noted, have not 



\section{INFANCY OF CRABS AND CATERPILLARS 239}

adult is assumed, and from thence onward, by a series of moults, the characteristic shape of the shore crab is put on. But this only after a long and numerous series of moults, as seen in our illustration, which shows all the cast-off shells worn by a young crab during a period extending from June I3, I90I, to July 20, 1904, when the captive died, still, so to speak, in infancy. On the average it will be seen, from the first appearance of the crab stage till death, there were sixteen moults; and no one has yet discovered how many moults take place from the hatching of the egg onwards to the end of the megalopa stage.

But more remarkable is the history of the prawns of the genus Penaus. So long ago as 1863 Fritz Müller found that the young of Penceus left the egg in what is known as the Nauplius stage-a form of larva hitherto unknown save among those minute crustacea the Copepoda, and the cirripedes or barnacles. Herein the body is pear-shaped, and there are only three pairs of limbs. These limbs, however, do not answer to legs, but to the antennules, antennæ and jaws of later stages of development! These organs, in the adult, are about as unlike as can be, yet in the larva they are hardly distinguishable one from another!

The antennæ of the nauplius in fact serve as jaws till they are eventually replaced, in the adult, by the mandibles. Finally, at this stage of development there is only a single eye, which is placed in the middle of the head. From the nauplius stage this larva passes through a "metanauplius" to the "zoea" stage, thus undergoing a series of most striking changes of form. Then follows the "schizopod" stage, which is the last step towards the adult Pencus-a near relation of the highly esteemed pink shrimp; but the swimmerets, it will be noted, have not 


\section{$24^{\circ}$ THE INFANCY OF ANIMALS}

yet appeared-they are not developed till the final, adult form is assumed.

How strange and varied are the zoea stages of the Crustacea will be brought home still more forcibly, after a glance at the zoea of a near relation of Pencus-the sergestes. This, as our illustration shows, presents a most extraordinary appearance, owing to the excessive development of spines. This formidable armature probably affords protection against enemies, but it seems more particularly to serve to increase the surface of the body and so retard sinking, as the sergestes larvæ, like other very spiny larvæ, live at the surface of the sea. The nauplius larva of one of the barnacles, and the zoea of the common porcelain crab (Porcellana longicornis), afford other illustrations of this excessive development of spines, to serve the same end.

But as if to show her resourcefulness, her love of successful experiments, Nature is always displaying contrary means of attaining the same end. Hence, having as it were demonstrated the need of spines as aids to delicate creatures of limited muscular power, but which can only keep afloat by constant effort, she proceeds to display zoeæ of a totally different type, such as that of the spiny lobster (Palinurus vulgaris). In its adult state this creature, which spends its days crawling at the bottom of the sea, is as spiny as a hedgehog. Yet in its early, surfaceswimming days, spines have no place. Instead, the body is excessively flattened, till it is no thicker than a sheet of paper, and as translucent as glass-hence these little creatures are also known as "Glass Crabs."

To those who would ask the question, "Are crabs good mothers?" we would answer-using the term crab in a wide sense-Some are. The majority leave their eggs to 


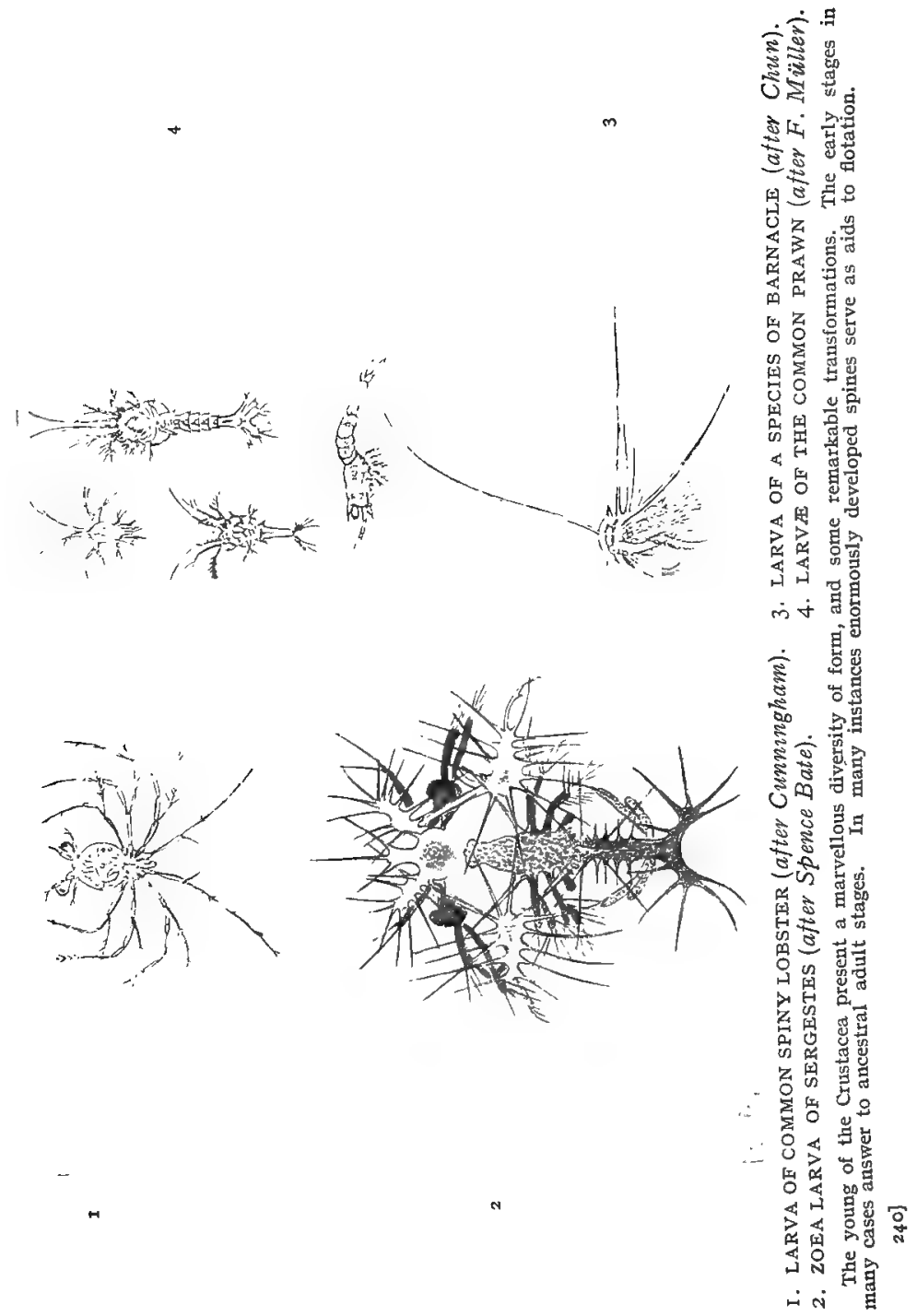



the uncertain care of fate; but some, like the fresh-water crayfish, carry the eggs about with them attached to their swimmerets, and to these the young cling on hatching. In such cases it is to be noted the "zoea" stage is passed within the egg, so the young emerge in a form not greatly unlike that of the adult. As a rule, when the eggs are thus carried the young hatch in the zoea form and betake themselves off as soon as they leave the egg-shell.

The motherliness of the crayfish is a matter of expediency. If her young were cast adrift as helpless zoeæ, they would be carried down by the stream to the sea and speedily killed. Nature has provided against this catastrophe by saddling the mother with the care of her young till they can safely fend for themselves. In a marine isopod-a near relation of the familiar woodlice of our gardens-Arcturus bafini-the young are always carried, but they are borne on the antennx, which are of huge size; while in the "opossum-shrimps" the young are carried by the female in a "brood-pouch." In some of the minute and more primitive fresh-water and marine crustacea a brood-pouch, borne beneath the carapace or shell, instead of by the legs, is commonly met with. In the marine genus Evadne, one of the Cladocera, the young remain in the brood-pouch until they themselves are mature, so that by the time they escape they already bear parthenogenetic embryos in their own brood-pouches!

From crabs to caterpillars seems a far cry. Yet both are members of the same great family of " jointed animals," or, as the text-books have it, of the "Arthropoda." Caterpillars, as everybody knows, are the larval stages of growth of butterflies and moths, and thus, in their transformation from one to the other, they display an even greater con16 


\section{THE INFANCY OF ANIMALS}

trast than is the case between, say, the zoea and the adult crab. For what could be more unlike than the sluggish, almost worm-like caterpillar, all day long slicing up leaves with its horny, pincer-like jaws, and the aerial, nectarsipping butterfly, flitting from flower to flower in the sunlight of a summer day, on wings which reflect all the hues of the rainbow, and some to spare! Almost the only feature which the caterpillar and the butterfly share in common is the method of breathing. But we are not here concerned so much with the anatomical differences between these two sharply contrasted periods of life as with the incidents of these periods; and many of these are of a truly remarkable character.

The ordinary course of the caterpillar's life, whether of moth or butterfly, is too well known to need description here: the principal phases thereof are admirably summarised in our illustration representing the life-history of the puss-moth, from the caterpillar to the perfect insect. What is depicted here is true of all. But there are striking differences in the form, coloration and behaviour of the caterpillars of the different species of butterflies and moths, and no less so in the events which mark the close of larval life.

As a rule the eggs are attached to the food-plant by some adhesive covering, as in the case of the privet hawkmoth for example, which, as is the rule, distributes its eggs over a wide area-a few in each place. But the Ghostmoth scatters its eggs broadcast as it flies, and this is the only case of the kind known to me. The young, on hatching, commonly make their first meal of the shell from which they emerged. Growth from the period of hatching onwards takes place in a series of stages broken by short fasts followed by a moult-for, as in the case of all the 


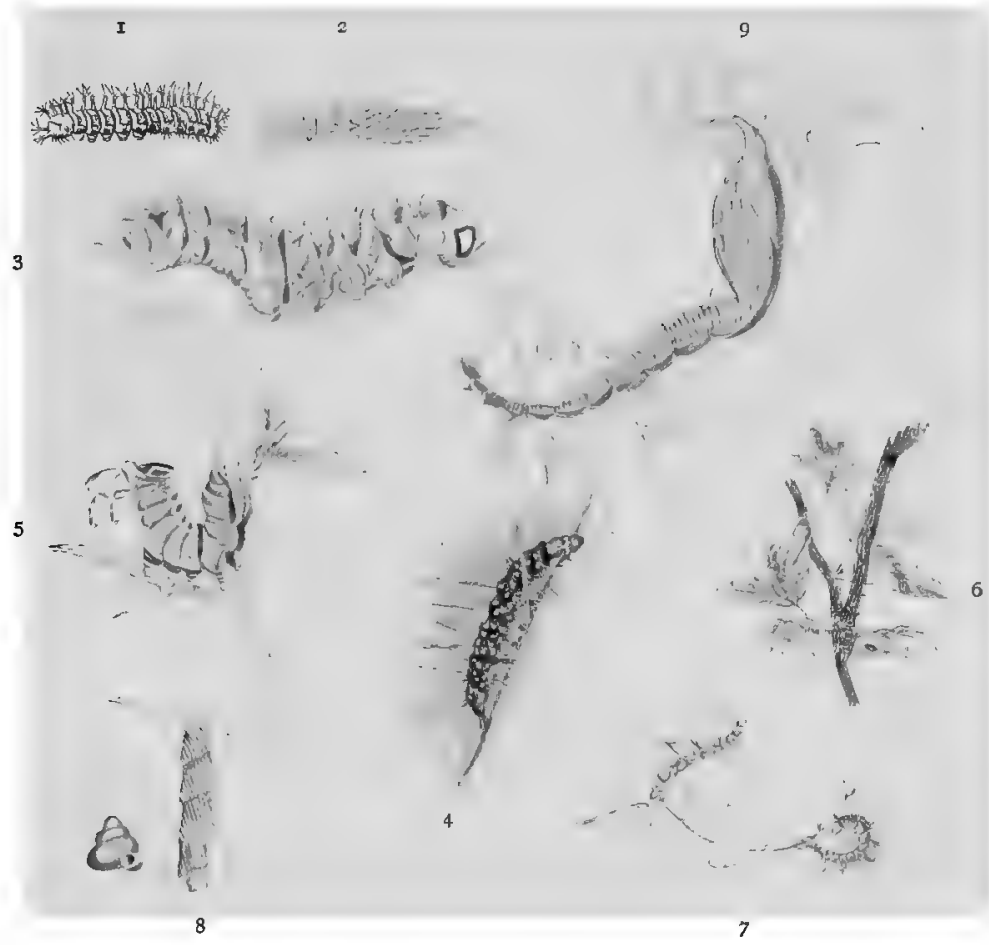

I.-3. STAGES IN THE LIFE-HISTORY OF THE ATLAS MOTH CATERPILLAR, SHOWING CHANGES IN THE FORM OF THE SPINY ARMATURE (after Poujade).

4. CATERPILLAR OF TIGER MOTH, SHOWING ARMATURE OF BRISTLES.

5. CATERPILLAR OF LOBSTER MOTH IN A THREATENING ATTITUDE.

6. CATERPILLAR OF FEATHERED THORN MOTH (Himeria), SHOWING STICKLIKE ATTITUDE.

7. CATERPILLAR OF ESSEX EMERAID MOTH WITH LEAVES ATTACHED TO BODY FOR DISGUISE.

8. DWELling-CASES OF CASE-WEAVER MOTHS (Psychida).

9. CATERPILLAR OF HAMMOCK-MOTH IN CASE MADE OF ITS OWN EXCREMENT.

242] 


$$
\text { , }
$$


"Arthropoda," the outer skin of the body cannot increase, and hence every now and then the growing youngster has to wriggle out of its skin and form a new one. More correctly, the new skin forms under the old, so that when the latter is shed all that remains is to harden the new integument and begin to feed again.

So far so good. Now let us survey these caterpillars a little more closely. To begin with, they are infant butterflies or moths, as the case may be. But for them there are no parental ties; and we may be certain that the parents cannot recognise their own offspring. Commonly, indeed, they die long before their young launch themselves upon the world. The two phases of life are absolutely different and distinct. And here, more easily perhaps than anywhere else in the animal kingdom, we can see how the environment acts upon the individual-how the larval stage is moulded and modified by its present environmentand thereby we shall the more readily understand how it is that the larvæ of other animals may not only represent lowlier, ancestral conditions of bodily structure, but also how large is the element of probability that we may not seldom fail to distinguish between ancestral phases in larval life and phases which are demanded by the immediate, present environment, as the minimum standard of response to the demands necessary for the survival of the race to-day.

Let us make this clear. In an earlier chapter it was shown that the tail of young fishes passes through the ancestral stages before arriving at the form characteristic of the adult stage, which is of a quite different form-e.g. the young Angler. The larva of many fishes, and most frogs, for some time breathe by external gills : these may be ancestral adult, or ancestral larval conditions; but that 


\section{THE INFANCY OF ANIMALS}

they are not essential to present-day conditions, are not responses to present-day needs, is shown by the fact that they have become eliminated in most of the "bony" fishes of to-day.

In other words, owing to the prolonged period of larval life, caterpillars have been subjected to the action of Natural Selection no less rigorously than in the case of the adults. Hence it is that caterpillars display an amazing variety of shape and coloration, and methods of defence; so great is the range of differences in these particulars that it is impossible in these pages to do more than select one or two of the more striking instances.

Caterpillars being succulent morsels, and incapable of offering active resistance to their enemies, have had to resort to passive measures-coloration, unpalatability, defensive armour, and the simulation of foreign objects. One has only to turn over the pages of entomological volumes which are furnished with coloured plates, to discover at a glance how extraordinarily varied are the hues of caterpillars.

Many are "protectively" coloured : obviously agreeing so closely with the prevailing hues of their surroundings as to make detection a matter of extreme difficulty. Such are the green-coloured individuals, or those in which the ground colour is green, relieved by horizontal or oblique stripes of white or pink, as in so many of the caterpillars of the hawk-moths. Herein the green merges with that of the leaves of the food-plant, while the stripes more or less closely imitate the mid-ribs and narrow stems of such leaves. This type of coloration renders detection difficult even to keen-eyed birds. And it is found that caterpillars so coloured are always greedily eaten when, by chance, they are discovered. 


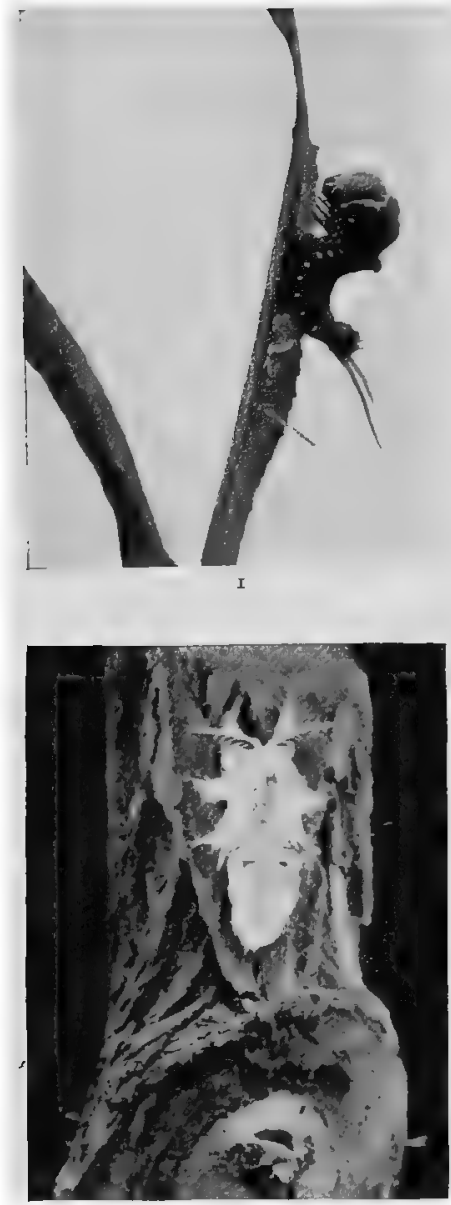

3
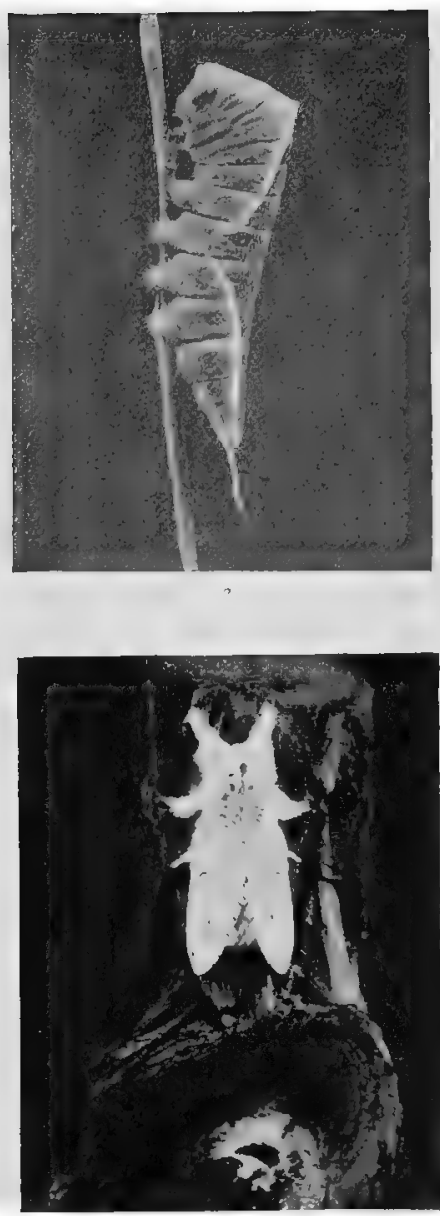

$\dot{4}$

From Photos by Fred. Enock, F.L.S.

FOUR STAGES IN THE LIFE-HISTORY OF THE PUSS MOTH.

r. Young caterpillar. 2. Full-grown caterpiliar. 3. Puss moth five seconds after emergence from cocoon before the wings have expanded. 4. Development complete. 244] 



\section{INFANCY OF CRABS AND CATERPILLARS 245}

But in some cases, advertisement, not concealment, seems to be sought, as when the body is marked by alternate rings of black and yellow-as in the caterpillar of the cinnabar moth, for example-or when the body is cut up into alternating bands of black and red, as in the case of the wood-tiger moth. In all such cases it is found that such larvæ are unpalatable, and will be refused by birds and other insect-eating creatures. The garish colouring seems to warn the prospective eater that the attempt will be followed by disagreeable results ! The one device is as effective as the other. Spines and long hairs, as in the case of the "woolly bear," the larva of the tiger-moth, form an equally effective protection; though nevertheless not an absolute defence, since the cuckoo preys greedily thereon, and its stomach, in consequence, is matted with the hairs. But this is the only bird which will touch them.

But yet other devices are to be found calculated to save the exhibitor from being eaten. Take, for instance, the case of the larva of the puss-moth. Herein the body is green enlivened by bars of red on each side of the head, and a broad black band, bordered by a narrow white line down the back. But this is not all. The tail ends in a pair of short rods formed by transformation of the last pair of legs; and from these, when the creature is alarmed, a pair of long red filaments are thrust, and waved rapidly about, the whole body at the same time being thrown into a most wooden and "unnatural" attitude. Evidently this combination of colour and jugglery serves as a useful deterrent where too curious birds or other insecteating creatures are about. But this device is used only by the young larvæ.

By the time they have reached what we may call middle age in larval life they lose the power of thrusting out the 


\section{THE INFANCY OF ANIMALS}

red whips. At the same time, however, they develop a new and more effective weapon of offence, which assumes the diabolical character of vitriol-throwing! At the lower part of the red margin below the head is a slit-like opening leading into a gland wherein is distilled a highly irritant mixture of formic acid and water, analysis showing the presence of no less than forty per cent. of acid. While this fluid is used on all occasions of alarm, it is more especially employed to ward off the attacks of an ichneumon fly.

This insect lays its eggs on the skin of the caterpillar, and these speedily hatch out and bore into the body of their victim, slowly devouring its internal organs, yet avoiding any vital part till their growth is complete. Within the body they then become chrysalides, and hatching there, emerge in due course as adult ichneumon flies, to start another brood of children trained to murder. To repel such attacks the puss-moth has developed the, under the circumstances, quite legitimate device of "vitriolthrowing," for should the spray of this touch the invading fly, death is the result.

More singular, however, is the case of the caterpillar of the Lobster-moth, wherein the body has been still further transformed, till it has assumed a shape which, to our eyes at any rate, borders on the grotesque. As will be seen in our illustration, the fore-part of the body bears a series of large spines, while the hinder end is curiously swollen and turned forwards over the back. In this strange position it bears a strong likeness to one of the withered leaves of the beech, on which it feeds. The stalk is formed by a pair of long filaments which are kept close together so as to appear single, while the second and third pairs of legs are extraordinarily long, but the length is halved by 


\section{INFANCY OF CRABS AND CATERPILLARS 247}

doubling in the middle, and all four doubled-up legs hang down in a bunch. They thus bear a remarkable likeness to the bunches of brown scales (the stipules of the foliage leaves), which enclose the buds of the beech and hang down after the latter are unfolded, so that the legs then suggest the appearance of scales, and thus the whole body, from its likeness to the inanimate leaf, escapes the notice of insect-eating animals.

But so soon as the creature is alarmed, it rears up the fore-part of its body, which gives it a curious likeness to a spider. And the deception is further perfected by the four long legs, which are now made to quiver in the most terrific manner, as if preparation was being made for a bound forward; and to heighten the effect the hind part of the body is turned forward towards the head, and the two appendages, made to appear as one in the resting position, are now forced apart, giving the effect of a pair of antennæ. Thus a monstrous being, unlike anything else on earth, is suddenly brought into existence, and this has commonly so terrifying an effect on predatory birds as to effectually protect the performer from the threatened attack!

But these caterpillars are singular even from their birth. For from the moment of hatching they keep a most careful guard over the egg-shell from which they have just escaped. This is, to them, a most important item, providing them, as it does, with the first and only food for seven days : indeed, not until their first moult do they eat anything else! As soon as they leave the shell they have a good stretch, then begin to nibble portions of its walls. They never leave it for more than an inch or two, and then rapidly scuttle back. If perchance another caterpillar should approach within touch of it a vigorous 
attack is made to drive off the intruder. If by any mishap a young caterpillar is driven from its shell, death is certain to result, for it cannot be induced to eat the shell of one of its neighbours! Beech, birch, oak and hazel are the favourite food-plants of this interesting insect, and my readers would do well to keep a look-out for specimens, when they can verify these strange statements for themselves.

But the Lobster-caterpillar has a rival in the posturing business in the caterpillar of the American red-spotted purple butterfly (Basilarcbia astyanax). This creature is curiously marked with varying shades of brown, olivegreen, and rosy cream-colour, and covered with strange warts and prominences; and in this motley garb he performs the strangest of acrobatic feats. His common attitude of rest is that shown in our illustration, where he stands with his head bent under his body and tail raised. Thus posed he will stand for hours, motionless-till, indeed, the stimulus of hunger sets him moving. But there is method in his madness, for so long as he remains still he looks so unlike a live and luscious caterpillar that the hungriest of birds, and the most assiduous of ichneumon flies-the most formidable enemy that the caterpillar has to face-will pass him by.

$\mathrm{Be}$ it remembered that these instances of bizarre shapes and colours are but samples, selected almost at random, from a range that is bewildering in its number, and a like extensive series of instances is to be found where the body is transformed so as to simulate a likeness to the creature's inanimate surroundings. The commonest form of this prorective resemblance, as it is called, is furnished by caterpillairs such as those of the thorn-moths and carpetmoths, and the Brindled Beauty for example. Here, as 


\section{INFANCY OF CRABS AND CATERPILLARS}

may be seen in our illustrations, the body bears an extraordinary likeness to one of the twigs of its food-plant, and the deception is still further completed by the ability of the insect to support itself by its hinder clasping legs alone, while the body is held out stiffly at a sharp angle with the supporting stem; and is maintained in an absolutely rigid and motionless position for hours at a time. Some support the pull of the body by means of a silken thread, almost invisible, from the mouth to the twig, but more commonly no such aid is used. Thus, when not feeding, they become a part and parcel of their surroundings, absolutely invisible.

Even more remarkable are the caterpillars of the blotched emerald (Eucbloris pustulata) and the Essex emerald ( $E$. smaragdana), which attach portions of the food-plant to their bodies, so that, unless they move, they are absolutely indistinguishable from their surroundings. These fragments are attached by means of threads of silk to hooked bristles, running down the body. When these deceptive trappings are removed, a reddish-coloured, longitudinallystriped skin is revealed, a coloration in itself protective.

What strange and subtle influences have been at work to bring about this extraordinary conduct ? The question is the more difficult to answer since the young caterpillars, the moment they leave the egg, begin to disguise themselves, so that parental instruction and imitation are out of the question. More singular still is the fact that some crabs adopt a precisely similar device, attaching pieces of seaweed to a spine-covered shell by means of the big claws!

But these disguises are assumed to enable their defenceless wearers to escape the prying eyes of their enemies. Disguise, however, has often a more sinister purpose; and 
this is the case with the strange carnivorous caterpillar, Erastria scitula of Southern Europe. This is the larval form of a Noctuid moth which lays its eggs singly, and far apart, on trees infested with scale insects. When hatched the young caterpillar selects a large female coccid, and, eating its way through the scale, devours the insect beneath, passing on to find a fresh victim. As it proceeds it fashions a coat for itself of the scaly jackets of its victims and its own excrement, binding the whole together with silken threads. Covered by this extraordinary garment, it resembles the bark of the tree, enabling it to roam about from place to place without fear of detection!

Wonderful as these cases and coverings undoubtedly are, none of those so far surveyed have any claim to be regarded as beautiful. But this is not so with the strange silken and basket-work houses fashioned by the caterpillars of the moths of the family Psychidæ. Those of the genus Apterona weave a silken case indistinguishable, save to the touch, from a small snail-shell. So faithful is the model that the first specimens received by the British Museum were sent as shells! Others build similar shells of earth, and all these, it should be noted, live among grass where real snails of this shape abound. Some build exquisite spirally shaped baskets with pieces of wood all cut to the same length, as in our illustration. When at rest they suspend the basket by silken threads, and these are cut away when the tiny householder desires to move about in search of food. A similar device, as everybody knows, is practised by the caddis-worm; but it is more than remarkable to find such widely different creatures adopting the same device in their larval stages.

Mention was made just now of a caterpillar which built itself a covering made of the skins of its victim, and 

its own excrement, woven together with silk. This is a sufficiently remarkable fact, but it is even more remarkable to find that there are other caterpillars which construct these excremental habitations. Such, for example, are those of the hammock-moth (Perophora sanguinolenta) of South America. Exactly how these unsavoury cradles are made we do not know, but of their nature there is no doubt. In form, as may be seen from our illustration, they have certainly some pretensions to beauty.

Certain other caterpillars form large communities living together, either under a tent-like web of silk, or in a more solid, oval case. The larvæ of the Small Ermine moth are such tent-dwellers, while the case-forming species are illustrated by the African moth, Anaphe panda, whose dwellings form so conspicuous a feature on trees in parts of Africa. The young of the American Bull's-eye moth (Saturnia io) live in communities of a different kind. They construct no house, but live in crowds, all on the underside of the leaf of the food-plant, with tails in and heads out, and bodies curved to fit nicely together. They eat the edges of the leaf. When disturbed, all draw back together into a compact mass, and heads drawn in so as to be protected by the branched poisonous hairs which cover their bodies. When they wish to remove to a fresh feedingground, they move in procession, marching in single line, head to tail. The leader's head is constantly moved from side to side as he spins, from his mouth, a carpet of silk for himself and his followers to walk on. If the leader stops to nibble a leaf, the rest wait patiently till he moves on again, till finally the new camp is decided on.

That caterpillars display considerable powers of adaptation there can be no question, after the instances cited in these pages. But there are some which have gone to the 
length of living under water. These are the caterpillars of certain moths of the family Eripterotidee, and of these those of the South American genus Palustra are the most remarkable. They, like their other aquatic relations, are very hairy, and swim by rapidly coiling and uncoiling their bodies. When the end of this life in the underworld comes, one of them proceeds to form a cocoon, and so soon as this is finished its fellows come successively and add theirs to it, forming a compact mass.

But why? What prompts this singular behaviour? And how comes it that they pass their caterpillar life under water, a mode of existence one would have supposed not only utterly foreign, but utterly impossible to a caterpillar-for to this day no one has succeeded in discovering how they have solved the difficult problem of breathing under water ?

And now let us take a rapid survey of the final stages of larval life through which all must pass before they can enter upon that short, but glorious period, when they can range from flower to flower, borne on wings of gorgeous colours, in order that they may drink deep draughts of nectar drawn up through that quill of marvellous mechanism known as the proboscis.

The caterpillars of butterflies, when they feel the end is near, generally crawl up the stem of their food-plant, or seek some cranny in the neighbourhood, and then suspend themselves head downwards. This done, they close their eyes, so to speak, and go to sleep. Then a strange thing happens. Beneath the worm-like caterpillar skin a shell of horny consistency and angular shape is formed; and as soon as this is complete, the wrappings of its childhood fall away and reveal-a chrysalis. This certainly bears no likeness to any living thing, but its surface, if carefully 

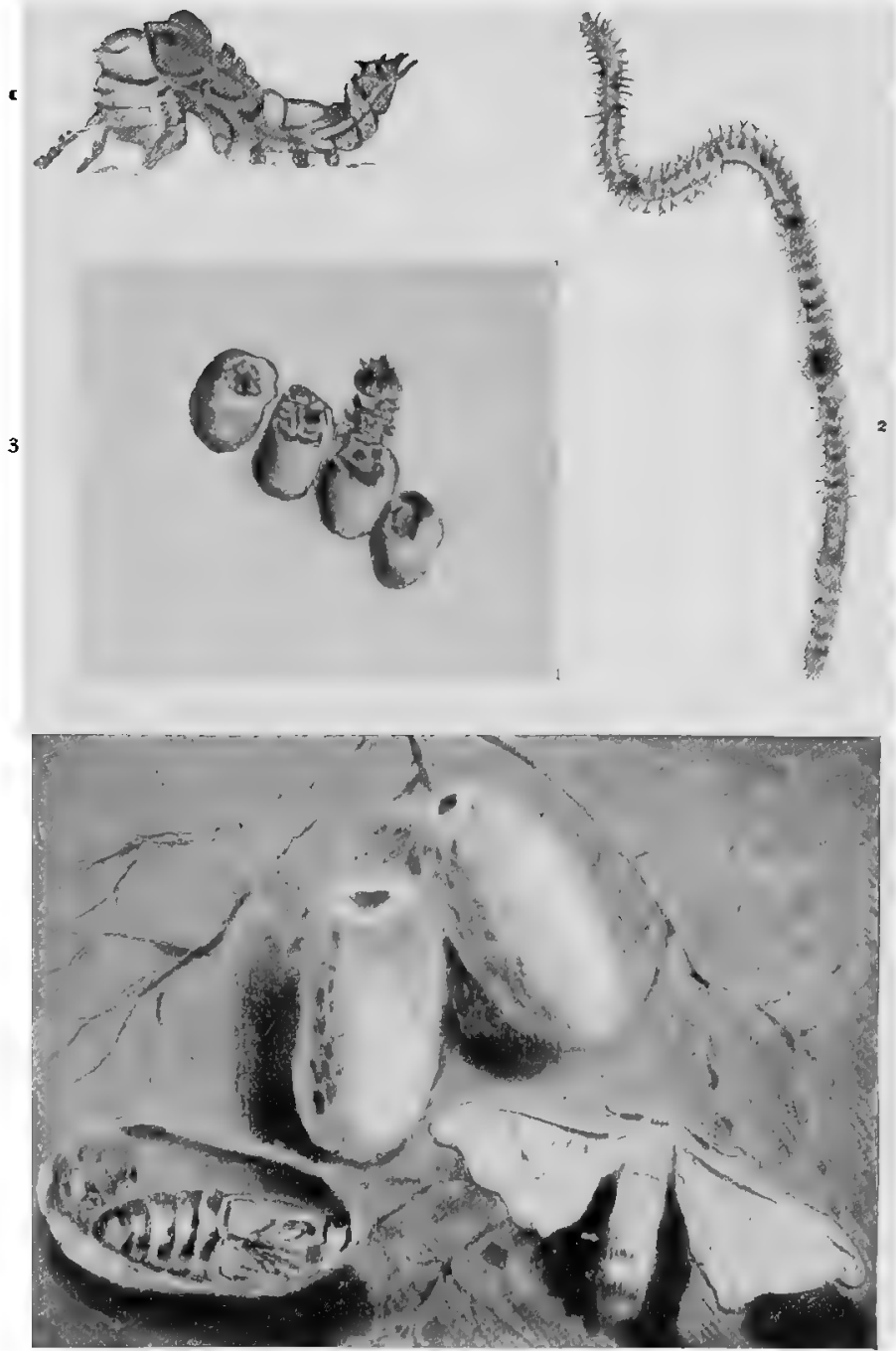

INCIDENTS IN THE LIFE-HISTORIES OF SOME BUTTERFLIES AND MOTHS.

I. Caterpillar of the red-spotted purple butterfly when resting

2. Young Io caterpillars walking in procession to new feeding-place.

3. Cecropia Moth caterpillars emerging from the egg.

4. Cocoons and chrysalis of the Chinese silkworm. 

examined, shows the form of the gorgeous wings that are to be, the long, honey-sucking proboscis that is to replace the horny jaws, the long legs folded neatly together, and the rings of the body.

Many of these caterpillars, for their greater security, take the precaution to fasten a silken cord around their bodies to hold them in safety during their long sleep through the storms of winter-a precaution which seems to display a quite uncanny foreknowledge. But the custom which obtains among some of the moth tribe at this time is still more singular, for while most simply bury themselves and become transformed into "pupæ," as the chrysalises of the moths are called, among a large number of species the caterpillar, as if realising that the end of its life is near, proceeds to weave for itself a silken shroud, or "cocoon," within which the form of the pupa is assumed. The silk is formed in a fluid state by glands within the mouth, and is drawn thence as a sticky thread, which hardens at once on exposure to the air. How it contrives to weave this wondrous winding-sheet is a matter which passes one's comprehension.

These silken fabrics, as a rule, enclose the body as a nutshell encloses the kernel; and as the moth which is to emerge has no jaws, special means have had to be devised to save the resurrected body from the horrors of a living grave. The puss-moth escapes by soaking one end of the cocoon with a corrosive fluid containing potassium hydroxide, and protects itself from injury therefrom, while passing through the moistened gateway to life, by a shield formed of a portion of the pupa skin. Some cut their way out by means of a spine at the base of the front wing. Yet more remarkable is the case of the emperor moth, which, in spinning its cocoon, fashions 


\section{4}

\section{THE INFANCY OF ANIMALS}

a doorway guarded against invasion from without by an ingenious chevaux-de-frise! The cocoon of the "slugcaterpillar" is hardly less remarkable, since it is furnished with a movable lid.

The extraordinary instincts of the caterpillars of the American hog-moth deserve particular notice here. These larvæ, while they spin their cocoons in the full light of day, yet contrive so artfully to blend them with their surroundings as to make them practically invisible. To attain their ends they are often obliged to resort to a device which exhibits the high-water mark of instinctive sagacity. If the caterpillar cannot find at hand a suitable place in which to weave its cocoon, it frequently makes for itself more satisfactory surroundings by killing the leaves, upon which, after they have become dry and brown in colour, it places its cocoon,

To secure the desired dry leaves, when these are not already to hand, several caterpillars unite together, and, selecting a long and vigorous immature shoot or leader of the orange tree, they kill it by cutting into its base until it wilts and bends over. The leaves of a young shoot in drying turn a light tan colour, which harmonises most perfectly with the hairy locks of the caterpillar spinning the cocoon. The latter is, consequently, not easily distinguished even when placed upon the exposed and upturned surface of the leaf.

The life of a caterpillar, from the human standpoint at any rate, is dull and uneventful enough. And this being so, the closing scenes therein are the more remarkable. Among the higher animals we are accustomed to find complicated actions acquired only after much practice and some parental instruction. But the caterpillar which climbs the stem of its food-plant for the last time, 


\section{INFANCY OF CRABS AND CATERPILLARS 255}

hangs itself up by its hind-legs, and puts a silken cord around its body to sustain its weight during the long months it must pass absolutely incapable of movement, performs these acts but once, and perfectly. And the same is true in the case of the more marvellous silkspinning feats. The cocoon of the silkworm moth, or of the emperor moth, with its marvellous exit, is the work, so to speak, of an untried, unpractised amateur, but it is performed without hesitation, and without mistake. Even when we ascribe these acts, performed but once in a lifetime, by isolated individuals which have never known their parents, and can therefore never have received instruction, to "Natural Selection" acting during thousands of years on millions of individuals, and weeding out the bunglers, we are still far from understanding how, and why, these varied means to attain the same end came to be. And we shall probably fail to penetrate these mysteries to the end of time.

Alfred Russel Wallace, years ago, strove to show that birds built their nests by imitation: that when the time came for a bird to build its first nest it was guided, in its choice of materials and in the application thereof, by the memory of the nursery in which it was reared. And failing this, then the untried youngster mated with a bird of riper experience! But what need for such an explanation? Those who have reared young birds from the nest know that, even when an individual has been brought up in an environment where contact with its own, or any other species, is impossible, yet that youngster will in dūe course perform all the acts common to its tribe perfectly -its note, its song, its mode of bathing, its peculiarities of flight, and finally, its particular mode 


\section{THE INFANCY OF ANIMALS}

of nest-building. These are "instinctive" acts. But what is instinct ?

Mention has already been made in this chapter of the caterpillar's most formidable foe, the ichneumon fly; and it would be well therefore, in conclusion, to give a brief survey of the fearsome rôle this insect plays.

The adult ichneumon is a four-winged fly-one of the Hymenoptera-and goes about seeking diligently for caterpillars. The success or failure of the quest is allimportant both to the seeker and the sought. Should success attend its search, it alights gently on its victim, and, with an instrument which is at once stiletto and ovipositor, it proceeds to thrust down into the body. Once the skin is pierced an egg is passed down the stiletto, which is hollowed on purpose, into the body of the caterpillar. The process may be repeated many times; the caterpillar, writhe though it may, is powerless.

But this is only the beginning of the trouble. Speedily the egg, or eggs, according to the species of ichneumon, hatch out, and the larvæ begin their diabolical work of feeding in the interior of the caterpillar, yet contriving to touch no vital part. Were the daughters of the horseleech ever so bloodthirsty? In some cases these tiny fiends complete their course of development before the caterpillar has run its allotted course, and eat their way through the body of their host and spin for themselves cocoons of golden silk outside. In others the caterpillar completes its growth, and assumes the chrysalis, or pupa stage, as the case may be. But it goes no further. The ravening wolves within complete their work and leave but the empty shell of the chrysalis, which forms their shelter for the winter. With the warm days of spring the chrysalis case yields up, not the body that was to 


\section{INFANCY OF CRABS AND CATERPILLARS 257}

be, with resplendent wings, but a horde of murderous ichneumons which speedily enter upon their hideous work.

In order that an idea may be gained of the part these ichneumons play in preventing the undue increase of caterpillars, the reader should collect, say, fifty caterpillars of the common cabbage-white butterfly; and he will find that of these only a small fraction will ever become butterflies. The majority of these butterfly children are destined to nourish the offspring of their relentless enemy!

It will be clear that we cannot enlarge upon the lifehistory of these remarkable insects when we mention that over 1,200 species of ichneumon flies are to be met with in Great Britain alone! 


\section{CHAPTER XIV}

\section{PUZZLES AND PARADOXES}

THE study of animals in infancy is full of surprises and contradictions, and insoluble riddles. Why, for example, should the caterpillar have to pass through a practically inanimate stage sealed up in an unyielding horny case, before it can attain to the full glory of its winged state ? The answer which first presents itself seems adequate enough-to wit, that the caterpillar stage being of necessity somewhat lengthy, a period of suspended animation is necessary to tide over the winter months, and the chrysalis case forms an exceptionally effective protection for the development of the delicate mechanism such as the wings and honey-sucking proboscis. And this line of argument gains support by a comparison with the history of the dragon-fly.

The larval dragon-fly, as everybody knows, is a waterdweller, and spends at least a year, and some even three years, in this state; but when at last the end of its larval life arrives it just climbs a reed-stem, waits a bit, and in a little while, lo! its skin bursts and out steps the gauzywinged creature we all so admire. Here the environment of the larva is less affected by seasonal changes, and hence, it would seem, there is no need for a break. But this cannot be the whole truth, for the larval water-beetle has 


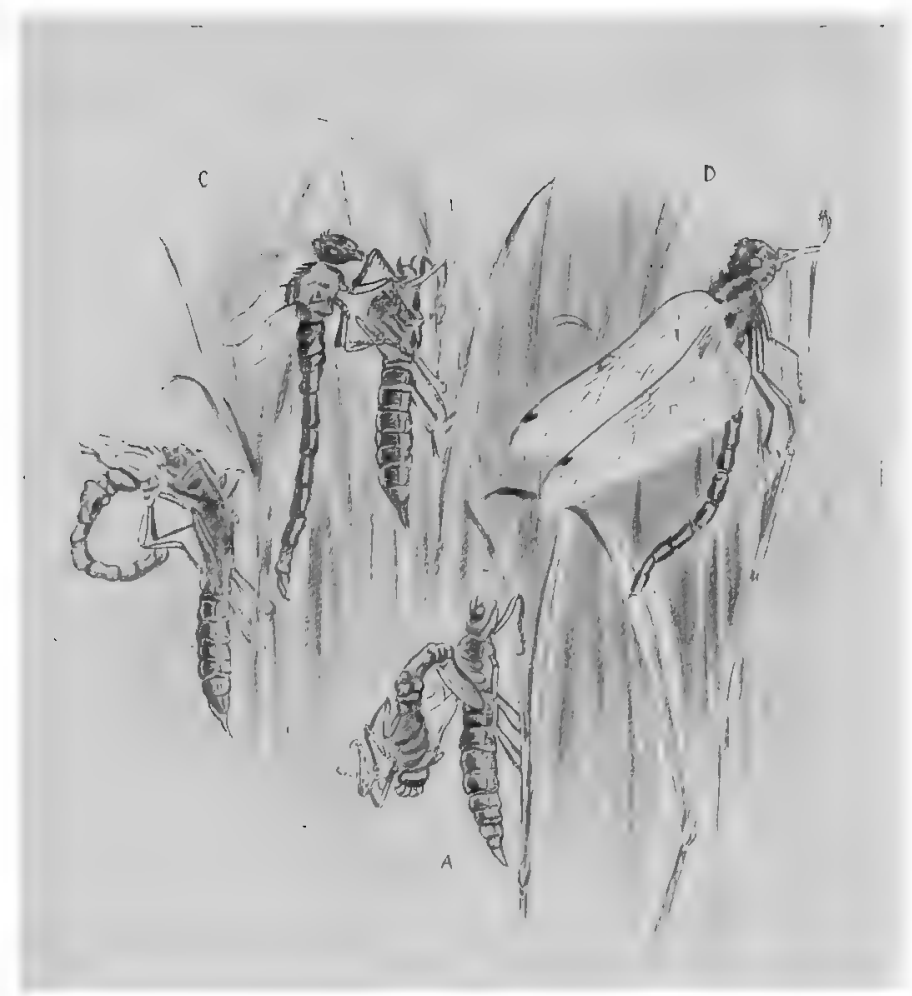

THE BIRTH OF THE DRAGON-FLY.

There is no chrysalis stage in the life-history of the Dragon-fly. When the larva has completed its growth it climbs out of the water. Speedily its skin bursts and the Dragon-fly wriggles out, dull in colour, and with undeveloped wings. But the final stages are completed with amazing rapidity.

258] 

to undergo a resting stage precisely similar to that of the caterpillar.

That the contrasts and paradoxes of larval life are many, these pages have already shown. Thus the salamander known as the Amblystoma rarely attains to its adult form; as a larva-the axolotl-it lives and dies, though year after year producing offspring. Not one axolotl in a hundred generations ever assumes the adult form and mode of life as a land-dweller : it remains to the end of its days a gill-breather, and withal a breather by external gills.

In all the other members of the salamander and newt family these external gills are the outward and visible sign of extreme infancy, as in the tadpoles among the frogs. On the other hand, many lowly creatures, like the protozoa, are, so to speak, born adults. Having attained the maximum size of their race, they are suddenly, as it were, cleft asunder by an invisible sword, and the two halves become two individuals. There is neither birth nor death, and offspring are denied them. In certain rare cases, as in that of the Pseudis frog, the larva attains a size many times larger than it will ever have when full grown!

Sweet liberty is known to many animals only during larval life: in others the reverse obtains. The caterpillar is tied, so to speak, to its food-plant throughout the whole of its childhood. The longest journey made during this stage is that in search of a place suitable for the dread change which is, after all, to end in such a glorious transfiguration. On the other hand, creatures like the mussel and the oyster have their $W$ anderjabr very early in life, and settling down, remain fixed for ever after to the same spot, helplessly anchored. 
Compare the larvæ, for instance, of such sedentary animals as the oyster, that extraordinarily interesting shell-fish known as Yoldia-a near relation of the Razor-
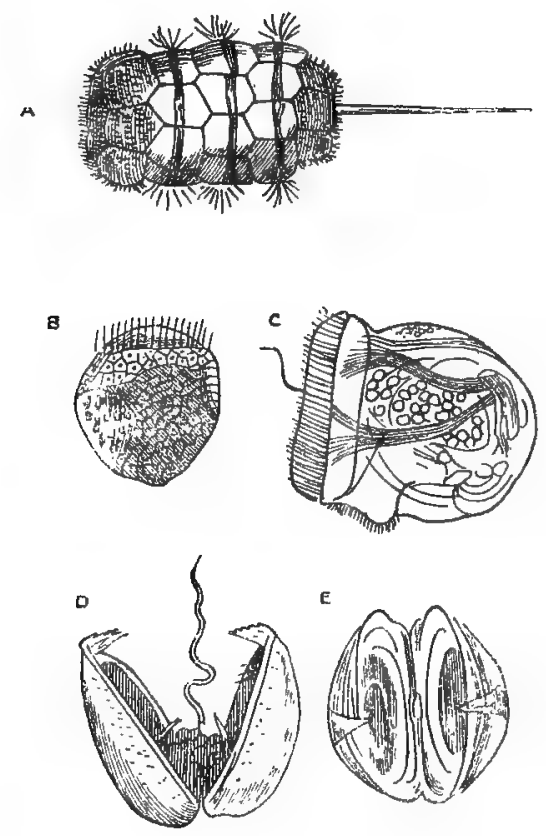

YOUNG MOLLUSCA.

A shows the larval state of Yoldia, a near relation of the Razor-shell.

$B$ and $C$ show the free-swimming, larval stage of the Oyster.

$D$ and $E_{\text {, }}$ are Glochidia-the larve of the freshwater mussels Anodonta. Note the teeth on the shell, and the long, vibratile "byssus." shell, and one of the most ancient types of mollusca now living, its forbears being traceable into the remote geological pastand the infant stages of the two fresh-water mussels Driessensia and Anodonta. These are all different, as their parents are different, but all are for a time freeswimming. Sooner or later, however, they have to settle down in life, grow a pair of shells, and become respectable.

But of these the little anodonta has by far the most adventurous existence.

For a time it shelters within its parent's gills, but on the first favourable opportunity it is suddenly expelled, with a swarm of its brothers and sisters, to the number of half a million or more at once! This is freedom, 
but with qualifications. The young glochidia, as they are now called, thrs suddenly sent forth slowly sink to the bottom of the stream. At this time each is possessed of a bivalve shell of curious design, the front edges bearing each a triangular tooth beset with smaller teeth, and with a long sticky thread or byssus, which floats loosely in the water.

Patiently and anxiously they await the arrival of a shoal of fishes. The disturbance in the water caused by their approach throws them all into a state of intense agitation, the valves are suddenly opened and closed with extreme rapidity, and these movements force the thread upwards. If-and this is a tremendous "if," for it means life or death-if the thread touches any part of the body of one of the passing fish, it sticks, and the youngsters, a dozen or more to each fish, are thereupon for a time trailed through the water. Chance movements of the tail or fins are certain to bring some of the glochidia into actual contact with the skin of the fish. Directly this happens the valves are snapped together, and the teeth grip, dragging the skin well into the shell cavity. Speedily a cyst is formed entirely covering the glochidium, and rendering any danger of falling off impossible.

For the next three months the snugly ensconced glochidium lives a parasite upon its host, drawing nourishment from its lymph. Meanwhile a new shell is growing within the glochidium shell, and extensive alterations are made in the structure of the body. But sooner or later the cyst bursts and the youngster falls to the bottom of the stream, this time a mussel differing from its parent only in size. It has not, however, succeeded in casting off the glochidial shell, which for some three or four weeks forms a sort of overcoat to the new, and as yet trans- 
parent shell that is to protect the soft body of the mussel for the rest of its life.

The comparison of the glochidium stage with the freeswimming stage of the fresh-water mussel Dreissensia, or of the oyster, it should be remarked, is

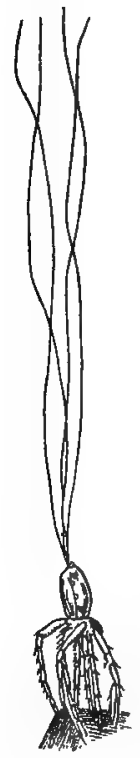

A YOUNG SPIDER SPINNING GOSSAMER THREADS PREPARATORY TO TAKING FLIGHT. not exact, for the glochidium has already passed through the shell-less stage of the oyster within the egg while enclosed within its parent's gills : thus furnishing another illustration of the different periods of development at which post-embryonic life begins. The little yoldia, and the oyster and the young dreissensia all agree in having excessively frail, transparent bodies, microscopic in size, and furnished with rows of vibratile threads, the movements of which drive the body through the water, till a suitable place for settling down is found, when all further roaming is at an end.

Life with the glochidium hangs indeed by a thread, and the same is true for a season with the young of spiders. Not the dreadful things which make the blood of the householder run cold, but of spiders which live a healthy outdoor life. My readers must often have seen the fields in the sunlight of an early October morning glistening with the sheen of gossamer threads: all but invisible, and with no apparent source of origin. And to many it may be news to learn that these threads are spun by hundreds of thousands of tiny spiders who are seeking to explore the world. The device they adopt 
to attain this end with the least possible expenditure of energy is to rear up the hinder end of the body and to squeeze out therefrom a sticky juice, akin to that of the silk-forming caterpillars. This juice exudes from four separate apertures, and forms, on exposure to the air, as many threads. These are soon caught by the breeze, and speedily, delicate life-lines of several yards in length are being wafted about. At last so much has been paid out, that the body of the tiny spinner is lifted up from the ground and borne aloft, to be transported, perhaps, for miles. When the breeze drops the little aeronauts descend, and finding congenial country, settle down to grow into big spiders, and wander no more.

It is obviously of vital importance to species which in their adult state are almost or quite sedentary, that some means of emigration should be devised for the young: it is of importance to the individual since it averts famine, and of importance to the species since thereby it escapes extermination.

Dr. Watts long since assured us that " birds in their little nests agree," and this is, as a rule, perfectly true: indeed, cases are on record where the young of the first brood assist their parents in feeding those of the second. The waterhen affords a case in point.

But a ferocious contrast to this picture is the case of nestling buzzards. With the buzzards, as with all the birds of prey, the eggs are incubated as soon as laid. As a consequence the bird first hatched is several days older than the youngest. Being thus stronger and hungrier than its nest-fellows, it contrives to get the lion's share of the provender. Now, when the nursery is built among the hills, where food is relatively scarce, there are often long breaks between meals, and not seldom, during one of 


\section{THE INFANCY OF ANIMALS}

these enforced fasts, the hungry senior turns upon his youngest brother and eats him: sometimes the second follows suit, leaving the survivor in the position of the Mate of the Nancy Brig! This must be a common occurrence, for a nest of three youngsters is rare in the hills; but in the more productive valleys such broods are the rule.

Crime in the nursery is happily rare in the animal kingdom, but there are nevertheless numerous well-authenticated instances of the kind just quoted. Young whelks invariably derive a part of their nourishment after this fashion. The large globular bunches of the egg-capsules of the whelk must be familiar to most of my readers, for they are strewn along the beaches all around our coast. Each bunch contains five or six hundred capsules, and each capsule contains several hurrdred eggs, which must be rather a crowd when embryos begin to develop. But the numbers are soon reduced, for the embryonic life is apparently passed in an endless cannibal feast, only thirty or forty young whelks eventually emerging from each of these tiny chambers.

No less gruesome is the case furnished by the larva of some of the gall-fies (Cecidomyiida). Herein an adult fly lays a few very large eggs, out of which come larvæ that while still larvæ become mothers, producing larvæ within their own bodies. These feed upon the tissues of their larval mother, and when they have quite consumed her they bite a hole through the empty skin and creep out, becoming themselves adult!

Parents, we know, under stress of circumstances, as of famine or terror, will eat their offspring. Even among the human race, as we learn from Biblical and other sources, these unnatural and horrid meals are partaken of: 
Mice and rabbits, and even bears, if they are much disturbed, will eat their young when newly born.

Parental solicitude, however, is the rule. Even among the lowliest creatures we seem to find convincing proofs of this. We say "seem" advisedly. For while there can be no doubt about the reality of the anxiety displayed by beasts and birds for the welfare of their young, it is not so easy to estimate the degree of consciousness which creatures like bees, wasps, ants, spiders and scorpions, beetles, sea-urchins and sea-slugs appear to exhibit. The two last, at any rate, can surely hardly be credited with the conscious care of their offspring; yet at least one species of sea-urchin carries its eggs in a pouch on its back, while the sea-slug carries its young on its back. Many spiders, and the book-scorpion, carry their eggs in a silken bag, attached to the under surface of the body. Of the true scorpions some carry their young on their backs, while on the subject of the bee and the ants whole volumes might be, and indeed have been, written on their domestic economy.

Though all sorts and conditions of Infants have now been surveyed in these pages, one inference certainly seems to be justified, and this is that the course of development from the egg to the adult is one of more or less continuous betterment. But this, apart from the facts furnished by a study of parasites, is by no means universally true, for we meet with cases of physical degeneracy of a most extraordinary kind. The most striking of all, without doubt, is that furnished by the young of certain curious animals which, in their adult stage, may be described as animated jelly-bags. Many of my readers will recognise them under the name of sea-squirts, for they are common ęnough on rocks and seaweed, at low tide, at most places 
on our coasts, where they form encrusting masses of leathery consistency, and no particular shape, though commonly gaily coloured. When touched they will

a
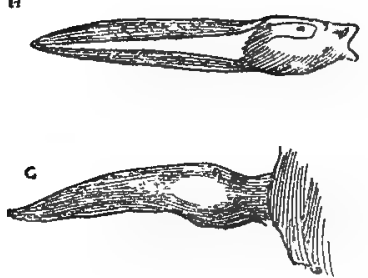

D

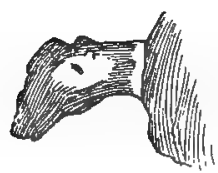

E

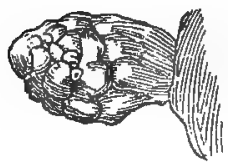

A LESSON IN DEGENERATION.

B, C, D, E show the several stages of physical degeneration displayed by many of the sea-squirts. A $=$ the tadpole of a frog for comparison with $B$, which shows the larval stage of a seasquirt at its maximum development. $C, D, E$ are successive stages in degeneracy.

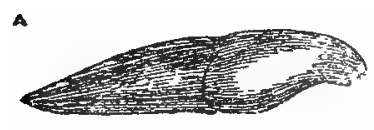
generally expel a jet of water -hence the name sea-squirt. There are also free-swimming species, and species which grow in colonies, some in pear-shaped lumps of a blood-red colour, others of a beautiful rose-pink spotted with white, and resembling a strawberry. It is not of the adults, however, but of their offspring that we are to speak. These are hatched within the body of the parent, and for a time are packed within the breathing chamber. Eventually, however, they escape from what we may call the maternal apronstrings, and emerge-in the guise of tadpoles! Could anything more surprising be conceived, having regard to their origin ?

This is no fanciful resemblance, as a reference to our illustration will show. The brain, eye, gills, tail, and the rudiments of a backbone are all plainly visible. But it resembles the unfinished, newly-hatched tadpole in that the mouth is not yet open, and in that we eye has not yet 


\section{PUZZLES AND PARADOXES}

become separated from the brain, of which, as in all vertebrates, it is an outgrowth: and further only one eye, in the middle of the head, is present, recalling the third eye in the middle of the head, of the ancient fish-lizards and other reptiles.

It is manifest, then, that the leathery, bag-like adults are degenerate vertebrates; kin to the fishes and the frogs-nay, to man himself. How and why this change has come about the wisest of us cannot tell, nor ever will. The fact remains that for a day these youngsters endure: then, as if cloyed with the sweets of liberty, or appalled at the heritage that is theirs, they choose rather to vegetate than to lead the life of a healthy animal. The die once cast, they settle down by the head to the nearest rock or broad blade of fucus and speedily cast off all semblance of their fleeting greatness. The tail, and rudiments of the backbone are absorbed, the eye and brain vanish, and they become leather bottles or mere shapeless masses, glorified by a tincture of red, or blue, or black and white, as the case may be. But for the evidence of these larvæ the most skilled anatomist would never have wrung this extraordinary story from the adult: so that here again we have convincing evidence of the importance of the study of young animals. 


\section{N D E X}

Adélie penguin, mortality among nestlings, 83

Albatross, remarkable story of nestling of, 78

Alcock, Dr., mortality among terns, 89

Alligator, care of for young, I 57

Andrews, Dr., play of frigatebirds, 96

Angler-fish, huge egg-masses of, 232

- transformation of, 226, 229

Ant-eater, transverse stripes of, $3 I$

Antelope, harnessed, stripes of, 3 I

Antelopes, young, number of, 20

Antennæ, as cradles, $24 \mathrm{I}$

Antlers, nature of, 47

- growth of, 48

- shedding of, 49

- of fossil deer, 49

Apes, carriage of young in, 20

Archaopteryx, tail of, 3

- wing of, I 21

Arius, curious nursing habits of, 2 I, 49

Aspredo, carrying eggs, 219

Auks, nestlings of, 64

Axolotl, remarkable history of, I 88,259

Bat, Horse-shoe, disposal of young, I7

- Noctule, young of, how carried, 16

- Naked, young of, how carried, I 8

Bat-ray, embryo of, 22 I

Bats, young of, how carried, I4 Beaks, of nestling birds, remarkable, 143
Beak-sheath in nestling birds, 146 Bearded tit, mouth ornaments in nestling, 112

Birds, kinship with reptiles, I 3 I

Birth-rate, modifying factors of, 22,23

Bitterling, curious nursery of, 223

Bow-fin, nursing habits of, 2 I 7

Brood-pouch, remarkable contents of, 24I

Butler, A. L., a nestling Egyptian plover, 60

Buzzard, cannibalism of nestlings, $26_{3}$

Cæcilians, 203, 205

Californian quail, curious habits of, 62

Calman, Dr., on netting larval crabs, 238

Caterpillars, 242, 244

- and instinctive actions, 253

- carnivorous, 250

- devices of, 244 et seq.

- eating egg-shells, 247

- mistaken for snails, 250

- moulting of, 243

- remarkable postures of, 240 , $245,248-9$

- working in concert, 254

Cat - fish, remarkable nursing habits of, 219

Chamaleon, hibernation of embryo in, $16 \mathrm{I}$

Chapman, F., on young flamingoes, 70

- - on young pelicans, 79

Chimæra, strange egg of, 2 I I

Chrysalis, how formed, 252

Cobego, carriage of young, I9

Cocoon, how formed, 253

- remarkable types of, 254 
Coloration, secant, $3 \mathrm{I}$

- spotted, 32

- evolution of in mammals, 37

- of nestlings, meaning of, 102 et seq.

- " self," 37

- survival of ancestral, 38

Coot, nestling, coloration of, 1 Io

Cormorant, feeding young of, 80

- nostrils of nestling, 146

Crab, larva of, 238

- moulting of, 239

- device of, 249

Crabs, eating nestlings, 89

- glass, 240

Cranes, nestling, coloration of, 100

Crayfish, care of young in, 24I

Crocodile, care of for young, I 57

Cunningham, J. T., on eggs of ling, 214

Cuscuses, pouch of, 12

Dabchick, care of young in, 63

Death-rate, among lions, 2 I

- - among auks, 88

- - among nestlings, 82,83

- among penguinș, 88

- - among petrels, 89

- - and weather among nestlings, 91

Deer, evolution of antlers in, 49

- spotted coloration of, 33

Degenerates, remarkable history of, 265

Dog-fish, young of, 209

Down, nestling, kinds of, 106, I 50

Dragon-fly, larvæ of, 258

Drinking, among nestlings, $8 \mathrm{I}$, 82

Ducks, coloration of nestlings of, Ioo

Eagle, Golden, play of nestling, 95

- - life-history of nestling, 65 , 71,74

Echidna, eggs of, 67

-method of suckling, 7

Eel-transformation, 232

Egg-tooth of birds, I44
Elephant, hairiness of young, $5 \mathrm{I}$

- reproductive period of, 23

Embryonic v. post-embryonic characters, 14 I

Emerald moth, strange caterpillar of, 249

Falcon, coloration of young, 108

Fawn, condition at birth, II

Fish, carrying eggs in mouth, 219

- - in pouch, 220

- eggs of, 210 et seq.

- embryo, breathing by fins, 221

- - fed on milk, 22 I

- - reared in mussel, 223

- larvæ, yolk sac of, 209

- nest-building of, $216 \mathrm{et} \mathrm{seq}$.

- transformations of young, 226

- viviparous, 22 I

Fishes, enormous numbers of eggs, 2 I 3

- viviparous, 222

Flamingoes, nestlings of, 70

Flat-fish, floating eggs of, 2 I 3

- transformation of, 230

Flight, how acquired in nestlings, 65

Foal, condition at birth, I I

Frigate-birds, play of nestlings, 96

Frog, froth-nests of, I92

- Goeldi's, method of carrying eggs, 197

- Japanese tree-, remarkable nest of, 192

- leaf-nests of, 193-4

- mud-nests of, 192

- paradoxical, remarkable tadpole of, 190

- pouched method of carrying eggs, 197

- tadpole, history of, 181

Frogs, carrying eggs in mouth, 200

- carrying eggs on back, 197

Froth-nests, of fish, 218

- of frogs, 192, 217

Gall-flies, young devour mother, 264

Geophagus, curious nursing habits of, 219 
Ghost-moth, egg-laying of, 242

"Glochidium," strange history of, $223,26 I$

Gobies, curious eggs of, 2 I 2

Goby, spotted, nest of, 216

- Godman, F. D., on young woodcock, 64

"Gossamer," nature of, 262

Gourami, foam nest of, 2 I 8

Grant, Ogilvie, mortality among petrels, 89 .

Grebe, nestling, coloration of, IO3

— - ornament in, I I o

Guillemot, transporting young, 64

-Gulls, eating nestlings, 83

Günther, A. L., on young guillemots, 64

Gymnarchus, nursing habits of, 217

Hare, condition at birth of, 79

Heat, distressing to birds, 93

- effect of on nestlings, 93

Heel-pads in nestling birds, 145

Hoatzin, nestling of, I 8

Horns of young mammals, 46

Horse-mackerel, larvæ of, 224

Horse, number of young of, 2 I

Howard, H. E., on nestling warblers, 74

[bises, eating nestlings, 83

Ichneumon fly, 240, 256

- - gruesome larvæ of, 256

Infant, ape-like characters in, 53

- loss of hair in, 52

- mortality, 83

- strength of arms in, 53

Instinct, 253, 255

Jacana, coloration of nestling, 99

Kangaroo, young of, 7

Kangaroos, carrying young, I I

- forsaking young, 12

- number of young of, $I I$

Koala, young of, I3, I4

Larval stages, permanent, 2
Leg, development of in birds, I 32

Lion, mortality among young, 2 I

- number of young of, 2 I

- spots of young, 34

Lobster-moth, strange caterpillar of, 246

Lobster, spiny, remarkable larva of, 240

Lumpsucker, care of eggs of, 218

Macpherson, H. B., on young eagle, $65,7 \mathrm{I}$

Mammals, condition at birth of, 8 et seq.

- young, coloration of, 27

- - education of, 24

Man, loss of hair in, 52

Marsupials, young of, 7

Maturity, periods of attainment, 23

Megapodes, precocious nestlings of, 129

Mesoptyles, meaning of, I 5 I

Mice, pouched, young of, 13

Migration, perils of, 90

- probable cause of, 92

Millais, J. G., ptarmigan, remarks on, 57

Mouth, changes in form of, I82, I 84

- ornamentation in nestlings, I I I

- receptacle for young, 20 219

Mussel, early stage of, 259

- fresh-water stage of, 260

Nestling birds, death-rate among, 82

- - disintegration of stripes in, 99

- - eaten by crabs, 89

- - eaten by mice, 89

- - excrement of, 73

- - feeding nestlings, 80

- - feeding of helpless, 75

- - feigning death, 59

- - helpless types of, 73 
Nestling birds, obedience to alarm notes, $59-60$

- - parasites of, 82

- - parental care of, 57

- - play of, 94

- - protection from weather, 93

- pugnacity of, 84, 263

- - striped coloration of, 98

Nestlings, condition determined by food-yolk, 120

- down of, II 6

- in unusual nurseries, 127

- of megapodes, strange history of, I 29

-. ornament in, I Io

- types of, II 5

Newt, larvæ, history of, 186

Nicoll, J. M., and penguin rookery, 83

Nidicolous nestlings, 73,75

Nostrils, absence of in birds, 146

Opossum shrimp, care of young in, 24I

Opossum, young of, I 3

Ornament in nestlings, I 10, I I 2

Ornithorhynchus, eggs of, 6

Osprey, nestling, distressed by heat, 93

- striped young of, 10o

Ostrich, nestling, coloration of, 98

Owl, Tawny, nestling of, I I I

- Barn, nestling down of, I 53

$O x$, number of young of, 2 I

Parrots, nestling beaks of, 143

Partridge, care of young in, 58

Peacock-pheasant, curious shield for young of, 62

Pelicans, young eating fellows, $8 \mathrm{I}$

Penguins, nestling, colonies of, 83

Petrels, method of feeding young, 77

Phalangers, flying, young of, 13

Pig, number of young, 2 I

- reproductive of, 23

"Pigeon's milk," 77

Pipe-fishes, care of young in, 220

Pit-vipers, remarkable coloration of young, 174
Platypus, eggs of, 6

Play of fishes, 237

Plethodon salamander, carriage of eggs in, 201-2

Plover, Egyptian, young, burying in sand, $6 \circ$

Plovers, coloration of nestlings, 99

Plumage changes, evolution of, Io 7 et seq.

Polyandry, disadvantages of, 57

Polygamy, disadvantages of, 57

Pond-tortoise, hibernation of embryo in, I6I

Ponies, stripes of, 32

Prawn, transformations of a, 239

Precocious types of nestlings, 56,63

"Primitive" animals, meaning of, 55

Privet-hawk moth, eggs of, 242

"Protoptyles," definition of, I06

Ptarmigan, care of young in, 57 Puffins, feeding young among, 76

Puss-moth, remarkable larva of, 245

Python, brooding eggs, I 59

Quail, care of young by male, 62

Rabbit, condition of birth at, 9 Regurgitation in feeding young birds, $70,77,79$

Reptiles, ovo-viviparity in, 160

- stripes of young in, 165

Ribbon-fish, remarkable larva of, 224

Salamanders, lungless, 188

- giant eggs of, $20 \mathrm{I}$

- loss of lungs by. $c$;

- nursing habits of, 202

- strange food of embryo, 204

- viviparous, 204

Sand-grouse, bringing water to nestlings, $8 \mathrm{I}$

Sanitation among birds, 73,74

Sars, Prof., on cods' eggs, 2 I 5

Scorpions, care of young, 265

Seal, young coloration of, 35 
Seals, "eared," evolution of under-fur in, 52

Sea-snake, young, care of, I 56

Sea-squirts, strange history of, 265

Shark, basking, eggs of, 208, 2 10

Skinks, rengrkable colour changes in young, 173

Skuas, devastations of, 83

- pugnacity of nestlings of, 84

Skull, evolutionary evidence of in nestling birds, I 38

Smelt, remarkable egg of, 2 I I

Snake, remarkable colour-change in young, 172,173

'Snake-fish, development of, 228

Specialisation, perils of, 92

"Specialised" animals, meaning of, 55

Spider, flight of young, 262

Spiders, care of young, 265

Spiny ant-eater, eggs of, 7

- pouch of, II

- - suckling of, 7

Squirrel, flying, carrying young, I9

Stalk-eye, curious larval fish, 225

Stickleback, nursing habits of, 2 I 5

Striped coloration of mammals, 28,30

Surf-perches, embryos of, 220

Swine, coloration of young of, 29

Sword-fish, transformations of, 226

Tadpole, curious nurseries of, I 98 et seq.

- funnel-mouthed, 189

- glass-like, I93

Tadpoles, extraordinary, 189 , Igo

- spawn of, I $8 \mathrm{I}$

Tail, evolution of in birds, 3 , I 36

- evolution of in fish, 229

- of archæopteryx, 3

- of modern bird, 3

Tapir, coloration of young in, 29

Teeth, of embryo whales, 3,43
Teeth, " milk," 4 I

- of young platypus, 44

- remarkable changes in, 42

Teleoptyles, meaning of, I 5 I

Temperature, effect on nestlings, 92

Tenrecs, spines of young, 5 I

Terrapin, painted, coloration of young, I 68

Thylacine, transverse stripes of, 3 I

Tinamou, vestiges of teeth in nestling, I 43,145

Titmouse, evolution of, Iog

Toad, midwife, method of carrying eggs, 195

- Surinam, method of carrying eggs, 197

Tortoise, care of young in, I 59

- evolution of shell in, 176

- degeneration of shell in, 179

Trionyx, eye-spots in, 168

Tuatera, embryos of, $16 I$

Turner, Miss E. L., on young water - rails, 58 ; on young shrikes, 76

Turtle, arrau, prolificness of, 162

Warblers, sanitation of nest in, 74

- play of nestlings among, 94

Waterhen, coloration of nestling in, Ioo

Weaver-finch, nestling ornament in, II I

Whales, teeth of young, 3

Whelk, young, preying on fellows, 264

Wing, development of in birds, I 34, I 37

- of nestling aquatic birds, 125

- of nestling archæopteryx, I 2 I, I 36

- of nestling game-birds, 122

- of nestling hoatzin, I I 8

Woodcock, carrying young, 63

Young devoured by parents, 264

- devouring one another, 264

- driven off by parents, 72

Zebra, stripes of, 3 I 





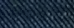

